Prepared in cooperation with the U.S. Environmental Protection Agency and Teck American, Inc.

Acute and Chronic Sensitivity of White Sturgeon (Acipenser transmontanus) and Rainbow Trout (Oncorhynchus mykiss) to Cadmium, Copper, Lead, or Zinc in Laboratory Water-Only

\title{
Exposures
}

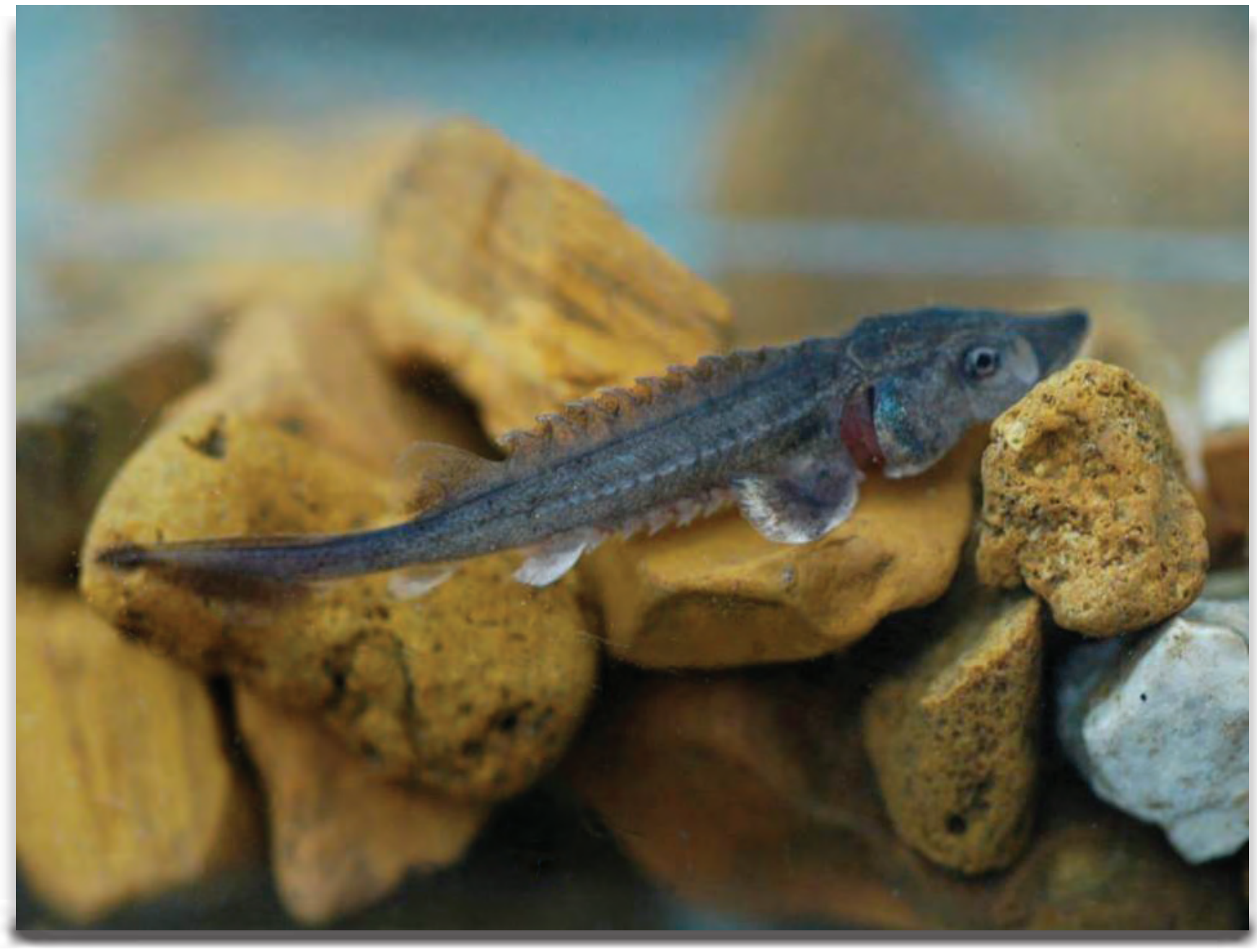

Scientific Investigations Report 2013-5204 
Cover photograph. A 30 days-post-hatch white sturgeon (Acipenser transmontanus). Photograph by Doug Hardesty, U.S. Geological Survey. 


\section{Acute and Chronic Sensitivity of White Sturgeon (Acipenser transmontanus) and Rainbow Trout (Oncorhynchus mykiss) to Cadmium, Copper, Lead, or Zinc in Laboratory Water-Only Exposures}

Edited by Christopher G. Ingersoll and Christopher A. Mebane

Contributions by Ning Wang, Robin D. Calfee, Erinn Beahan, William G. Brumbaugh, Rebecca A. Dorman, Doug K. Hardesty, Christopher G. Ingersoll, James L. Kunz, Edward E. Little, Christopher A. Mebane, and Holly J. Puglis

Prepared in cooperation with the U.S. Environmental Protection Agency and Teck American, Inc.

Scientific Investigations Report 2013-5204 


\title{
U.S. Department of the Interior SALLY JEWELL, Secretary
}

\section{U.S. Geological Survey \\ Suzette M. Kimball, Acting Director}

\author{
U.S. Geological Survey, Reston, Virginia: 2014
}

For more information on the USGS - the Federal source for science about the Earth, its natural and living resources, natural hazards, and the environment, visit http://www.usgs.gov or call 1-888-ASK-USGS.

For an overview of USGS information products, including maps, imagery, and publications, visit http://www.usgs.gov/ pubprod

To order this and other USGS information products, visit http://store.usgs.gov

Any use of trade, firm, or product names is for descriptive purposes only and does not imply endorsement by the U.S. Government.

Although this information product, for the most part, is in the public domain, it also may contain copyrighted materials as noted in the text. Permission to reproduce copyrighted items must be secured from the copyright owner.

Suggested citation:

Ingersoll, C.G., and Mebane, C.A., eds., 2014, Acute and chronic sensitivity of white sturgeon (Acipenser transmontanus) and rainbow trout (Oncorhynchus mykiss) to cadmium, copper, lead, or zinc in laboratory water-only exposures: U.S. Geological Survey Scientific Investigations Report 2013-5204, 70 p., plus appendixes, http://dx.doi.org/10.3133/ sir20135204.

ISSN 2328-0328 (online) 


\section{Preface}

White sturgeon (Acipenser transmontanus) are experiencing poor recruitment in the trans boundary reach of the upper Columbia River in eastern Washington State. Limited toxicity data indicated that early life stages of white sturgeon are sensitive to metals. In acute 4-day (d) exposures with larval white sturgeon, previous studies have reported that the 4-day median lethal concentrations (LC50) based on biotic ligand model (BLM) normalization for copper were below the U.S. Environmental Protection Agency national recommended acute water-quality criterion. In previously published chronic 66-d exposures starting with newly fertilized eggs of white sturgeon, 20-percent lethal effect concentrations (LC2Os) for copper, cadmium, or zinc generally were within a factor of two of the chronic values of the most sensitive fish species in the databases of the U.S. Environmental Protection Agency water-quality criteria (WOC) for the three metals. However, there were some uncertainties in the chronic exposures previously performed with white sturgeon, including (1) low control survival (37 percent), (2) more control fish tested in each replicate compared to other treatments, (3) limited replication of treatments ( $n=2)$, (4) lack of reported growth data (such as dry weight), and (5) wide dilution factors for exposure concentrations (6- to 8-fold dilutions). The U.S. Environmental Protection Agency concluded that additional studies are needed to generate more toxicity data to better define lethal and sublethal toxicity thresholds for metals for white sturgeon.

The objective of the study was to further evaluate the acute and chronic toxicity of cadmium, copper, lead, or zinc to early life stages of white sturgeon in water-only exposures. Toxicity tests also were performed with commonly tested rainbow trout (Oncorhynchus mykiss) under similar test conditions to determine the relative sensitivity between white sturgeon and rainbow trout to these metals. Toxicity data generated from this study were used to evaluate the sensitivity of early life stages of white sturgeon and rainbow trout relative to data published for other test organisms. Toxicity data generated from this study also were used to evaluate the level of protection of U.S. Environmental Protection Agency WQC or Washington State water-quality standards (WOS) for copper, zinc, cadmium, or lead to white sturgeon inhabiting the upper Columbia River.

Chapter $A$ of this report summarizes the results of acute toxicity tests performed for $4 \mathrm{~d}$ with white sturgeon and rainbow trout exposed to copper, cadmium, or zinc. Chapter B of this report summarizes the results of chronic toxicity tests performed for as many as 53 days with white sturgeon or rainbow trout exposed to copper, cadmium, zinc, or lead. Appendixes to the report are available at $h t t p: / / p u b s . u s g s . g o v / s i r / 2013 / 5204$. Supporting documentation for chapter A toxicity testing is provided in appendix 1. Supporting documentation for chapter B toxicity testing is provided in Appendix 2. Supporting documentation on analysis of water chemistry for chapter $A$ and chapter $B$ is provided in appendix 3 and 4 . The rationale for applying corrections to measured copper and zinc values in water samples from some of the toxicity tests performed in chapter $A$ is provided in appendix 5 . A summary of dissolved organic carbon measurement variability and implications for biotic ligand model normalization for toxicity data summarized in chapter $A$ and chapter $B$ are provided in appendix 6 . An evaluation of an interlaboratory comparison of analyses for dissolved organic carbon in water from the U.S. Geological Survey Columbia Environmental Research Center and University of Saskatchewan is provided in appendix 7. Finally, appendix 8 provides a summary of retesting of white sturgeon in 2012 to determine if improved survival of sturgeon would affect copper effect concentrations in 24-d 
copper exposures started with newly hatched larvae, and to evaluate the effect of light intensity or temperature on the response of newly hatched larvae during a 25-d study.

\section{Acknowledgments}

Funding for this study was provided in part by Teck American Incorporated through an agreement with the U.S. Environmental Protection Agency (USEPA) Region 10 with funds provided by USEPA to U.S. Geological Survey (USGS) through the Department of Interior Central Hazmat Fund.

We thank Eric Van Genderen of the International Zinc Association, Durham, North Carolina, for providing the biotic ligand model-based zinc data, and thank Jasim Chowdhury of International Lead Zinc Research Organization, Durham, North Carolina, for providing the biotic ligand modelbased lead data.

We thank the staff in Toxicology Branch, Ecology Branch, and Environmental Chemistry Branch of the USGS, Columbia Environmental Research Center, for technical assistance. 


\section{Volume Contents}

Chapter A. Acute Sensitivity of White Sturgeon (Acipenser transmontanus) and Rainbow Trout (Oncorhynchus mykiss) to Copper, Cadmium, or Zinc in Laboratory Water-Only Exposures

by Robin D. Calfee, Edward E. Little, Holly J. Puglis, Erinn Beahan,

William G. Brumbaugh, and Christopher A. Mebane

Chapter B. Chronic Sensitivity of White Sturgeon (Acipenser transmontanus) and Rainbow Trout (Oncorhynchus mykiss) to Cadmium, Copper, Lead, or Zinc in Laboratory Water-Only Exposures

by Ning Wang, Christopher G. Ingersoll, Rebecca A. Dorman, James L. Kunz, Doug K. Hardesty, William G. Brumbaugh, and Christopher A. Mebane

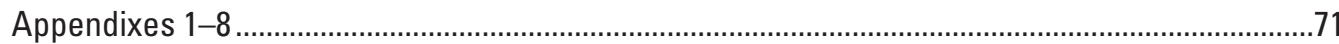




\section{Conversion Factors}

Inch/Pound to SI

\begin{tabular}{lll}
\hline \multicolumn{1}{c}{ Multiply } & By & \multicolumn{1}{c}{ To obtain } \\
\hline centimeter $(\mathrm{cm})$ & Length & inch (in.) \\
millimeter $(\mathrm{mm})$ & 0.3937 & inch (in.) \\
meter $(\mathrm{m})$ & 0.03937 & foot (ft) \\
kilometer $(\mathrm{km})$ & 3.281 & mile (mi) \\
mile, nautical $(\mathrm{nmi})$ & 0.6214 & kilometer (km) \\
meter $(\mathrm{m})$ & 1.852 & yard (yd) \\
\hline & 1.094 & \\
\hline liter $(\mathrm{L})$ & Volume & ounce, fluid (fl. oz) \\
liter $(\mathrm{L})$ & 33.82 & gallon (gal) \\
\hline & 0.2642 & \\
\hline gram $(\mathrm{g})$ & Mass & ounce, avoirdupois (oz) \\
kilogram $(\mathrm{kg})$ & 0.03527 & pound, avoirdupois (lb) \\
\hline
\end{tabular}

Temperature in degrees Celsius $\left({ }^{\circ} \mathrm{C}\right)$ may be converted to degrees Fahrenheit $\left({ }^{\circ} \mathrm{F}\right)$ as follows:

$$
{ }^{\circ} \mathrm{F}=\left(1.8 x^{\circ} \mathrm{C}\right)+32
$$

Temperature in degrees Fahrenheit $\left({ }^{\circ} \mathrm{F}\right)$ may be converted to degrees Celsius $\left({ }^{\circ} \mathrm{C}\right)$ as follows:

$$
{ }^{\circ} \mathrm{C}=\left({ }^{\circ} \mathrm{F}-32\right) / 1.8
$$

Concentrations of chemical constituents in water are given either in milligrams per liter (mg/L) or micrograms per liter $(\mu \mathrm{g} / \mathrm{L})$.

Concentrations of chemical constituents in sediment are given either in milligrams per liter $(\mathrm{mg} / \mathrm{L})$ or micrograms per liter ( $\mu \mathrm{g} / \mathrm{L})$. Sediment concentrations are expressed on a dry weight basis, on an organic-carbon normalized basis, or on a molar basis.

Concentrations of chemical constituents in tissue are given in micrograms per kilogram ( $\mu \mathrm{g} / \mathrm{kg}$ ). Tissue concentrations are expressed on a wet weight basis or on a lipid-normalized basis. 


\section{Abbreviations}

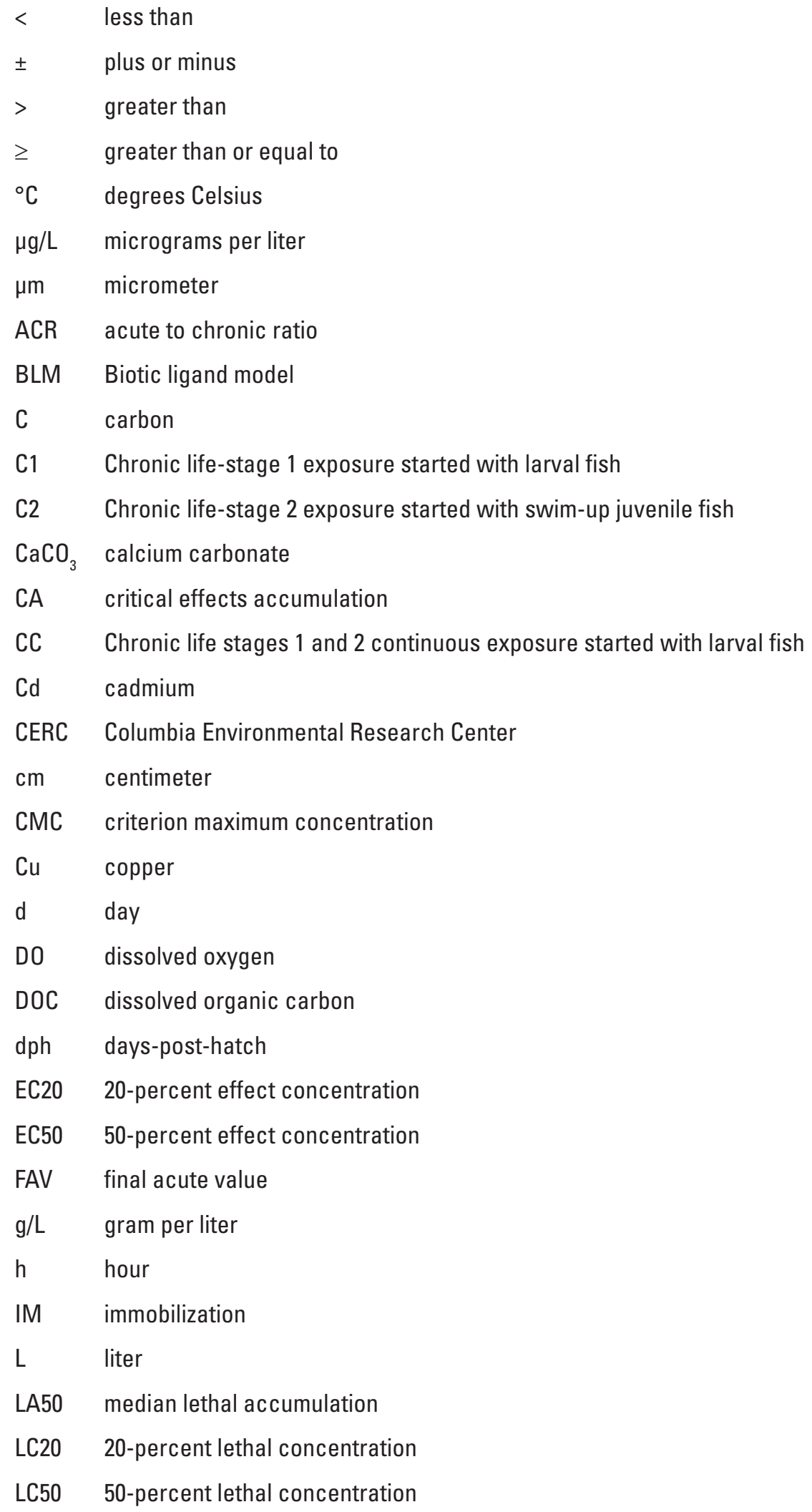




$\begin{array}{ll}\text { LOE } & \text { loss of equilibrium } \\ \text { LOEC } & \text { lowest-observed-effect concentration } \\ \mathrm{mg} \mathrm{C/L} & \text { milligram carbon per liter } \\ \mathrm{mg} / \mathrm{L} & \text { milligrams per liter } \\ \mathrm{mL} & \text { milliliter } \\ \mathrm{mm} & \text { millimeter } \\ \text { NOEC } & \text { no-observed-effect concentration } \\ \text { POC } & \text { particulate organic carbon } \\ \text { OA/OC } & \text { quality assurance quality control } \\ \text { RPD } & \text { relative percent difference } \\ \text { SSD } & \text { species sensitivity distribution } \\ \text { TOC } & \text { total organic carbon } \\ \text { UCR } & \text { Upper Columbia River } \\ \text { USEPA } & \text { U.S. Environmental Protection Agency } \\ \text { USGS } & \text { U.S. Geological Survey } \\ \text { WOC } & \text { water-quality criteria } \\ \text { WOS } & \text { water-quality standard } \\ \text { Zn } & \text { zinc }\end{array}$




\section{Acute Sensitivity of White Sturgeon (Acipenser transmontanus) and Rainbow Trout (Oncorhynchus mykiss) to Cadmium, Copper, or Zinc in Laboratory Water-Only Exposures}

By Robin D. Calfee, Edward E. Little, Holly J. Puglis, Erinn Beahan, William G. Brumbaugh, and Christopher A. Mebane

Chapter A of

Acute and Chronic Sensitivity of White Sturgeon (Acipenser transmontanus) and Rainbow Trout (Oncorhynchus mykiss) to Cadmium, Copper, Lead, or Zinc in Laboratory Water-Only Exposures

Edited by Christopher G. Ingersoll and Christopher A. Mebane

Prepared in cooperation with the U.S. Environmental Protection Agency and Teck American, Inc.

Scientific Investigations Report 2013-5204 


\title{
U.S. Department of the Interior SALLY JEWELL, Secretary
}

\author{
U.S. Geological Survey \\ Suzette M. Kimball, Acting Director
}

\author{
U.S. Geological Survey, Reston, Virginia: 2014
}

For more information on the USGS - the Federal source for science about the Earth, its natural and living resources, natural hazards, and the environment, visit http://www.usgs.gov or call 1-888-ASK-USGS.

For an overview of USGS information products, including maps, imagery, and publications, visit http://www.usgs.gov/ pubprod

To order this and other USGS information products, visit http://store.usgs.gov

Any use of trade, firm, or product names is for descriptive purposes only and does not imply endorsement by the U.S. Government.

Although this information product, for the most part, is in the public domain, it also may contain copyrighted materials as noted in the text. Permission to reproduce copyrighted items must be secured from the copyright owner.

Suggested citation for the volume:

Ingersoll, C.G., and Mebane, C.A., eds., 2014, Acute and chronic sensitivity of white sturgeon (Acipenser transmontanus) and rainbow trout (Oncorhynchus mykiss) to cadmium, copper, lead, or zinc in laboratory water-only exposures:

U.S. Geological Survey Scientific Investigations Report 2013-5204, 70 p., plus appendixes, http://dx.doi.org/10.3133/ sir20135204.

Suggested citation for this chapter:

Calfee, R.D, Little, E.E., Puglis, H.J., Beahan, Erinn, Brumbaugh, W.G., and Mebane, C.A., 2014, Acute sensitivity of white sturgeon (Acipenser transmontanus) and rainbow trout (Oncorhynchus mykiss) to cadmium, copper, or zinc in laboratory water-only exposures, chap. A of Ingersoll, C.G., and Mebane, C.A., eds., 2014, Acute and chronic sensitivity of white sturgeon (Acipenser transmontanus) and rainbow trout (Oncorhynchus mykiss) to cadmium, copper, lead, or zinc in laboratory water-only exposures: U.S. Geological Survey Scientific Investigations Report 2013-5204, p. 1-34.

ISSN 2328-0328 (online) 


\section{Contents}

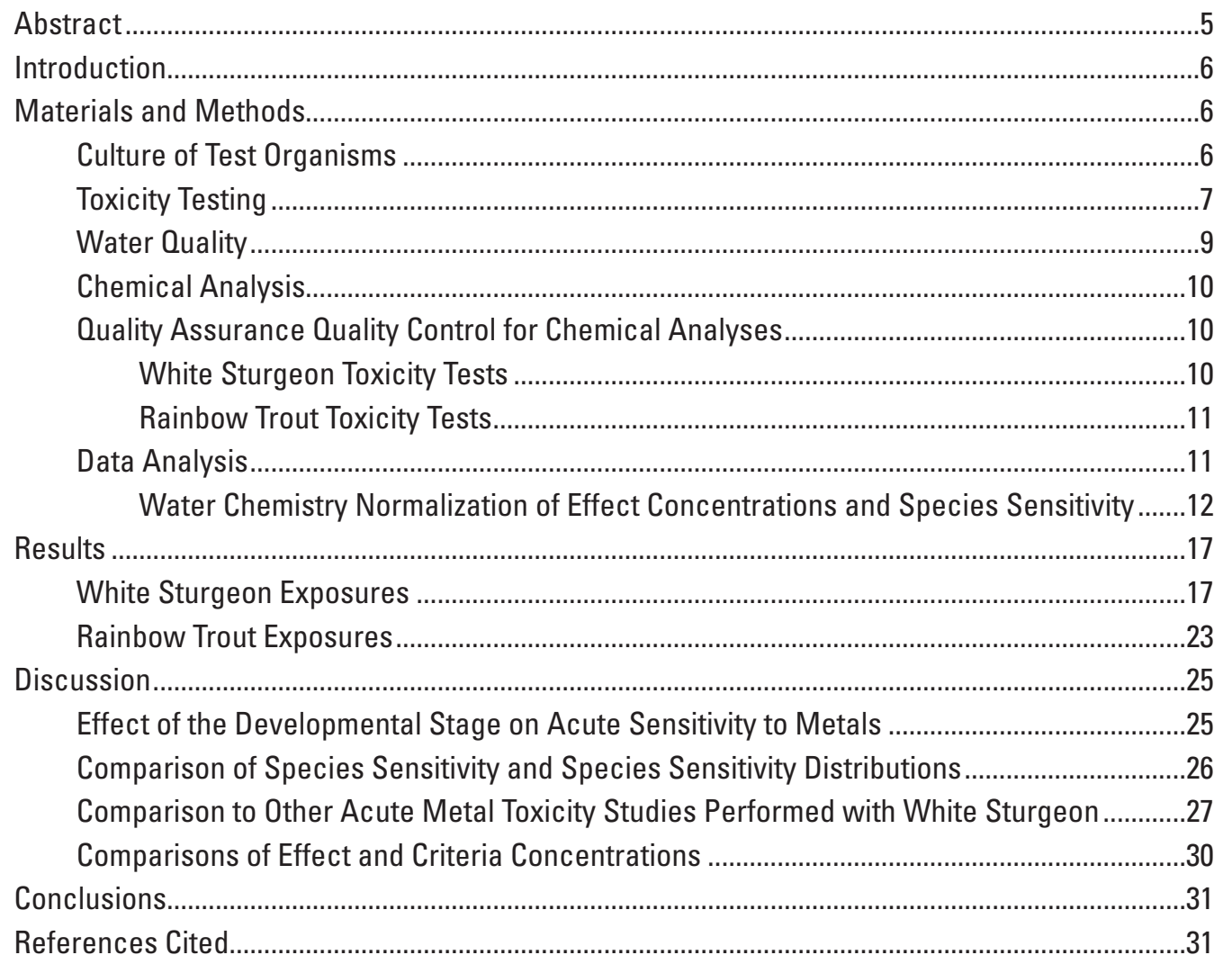




\section{Figures}

A-1. Graphs showing acute 4-day median lethal or effect concentration for cadmium, copper, and zinc for $A$, white sturgeon and $B$, rainbow trout at various life stages, compared to U.S. Environmental Protection Agency water-

quality criteria adjusted to test water-quality characteristics.

A-2. Graphs showing mean percent of surviving white sturgeon at 2 days-post-hatch exhibiting loss of equilibration and immobilization with increasing metal concentration following 4-day of exposures

A-3. Graphs showing swimming behavior variables..................................................................23

A-4. Photographs showing example of swimming paths of white sturgeon digitized using Noldus Ethovision ${ }^{\circledR}$ XT

A-5. Graph showing ranks of various white sturgeon and rainbow trout life stages in species sensitivity distribution from an updated cadmium hardness-toxicity regression and effects database

A-6. Graph showing ranks of various white sturgeon and rainbow trout life stages in species sensitivity distribution from U.S. Environmental Protection Agency database for copper

A-7. Ranks of various white sturgeon (Acipenser transmontanus) and rainbow trout (Oncorhynchus mykiss) life stages in species sensitivity distribution from updated databases for zinc

\section{Tables}

A-1. Summary conditions for conducting acute water-only toxicity tests with white sturgeon and rainbow trout in accordance with American Society for Testing and Materials, the U.S. Environmental Protection Agency, and U.S. Geological Survey-Columbia Quality Assurance Project Plan.

A-2. Mortality and effective mortality of white sturgeon in 4-day acute tests by round ........13

A-3. Mortality and effective mortality of rainbow trout in 4-day acute tests by round ............15

A-4. Cadmium LC50 or EC50 4-day acute value estimates for white sturgeon and rainbow trout with 95-percent confidence intervals in parentheses.

A-5. Copper LC50 or EC50 4-day acute value estimates for white sturgeon and rainbow trout with 95-percent confidence intervals in parentheses

A-6. Zinc LC50 or EC50 4-day acute value estimates for white sturgeon and rainbow trout with 95-percent confidence intervals in parentheses.

A-7. Comparison of 4-day acute LC50 values for white sturgeon (Acipenser transmontanus) to copper at various life stages. 


\title{
Acute Sensitivity of White Sturgeon (Acipenser transmontanus) and Rainbow Trout (Oncorhynchus mykiss) to Copper, Cadmium, or Zinc in Laboratory Water-Only Exposures
}

\author{
By Robin D. Calfee, Edward E. Little, Holly J. Puglis, Erinn Beahan, William G. Brumbaugh, and \\ Christopher A. Mebane
}

\section{Abstract}

The acute toxicity of cadmium $(\mathrm{Cd})$, copper $(\mathrm{Cu})$, and zinc $(\mathrm{Zn})$ to white sturgeon (Acipenser transmontanus) and rainbow trout (Oncorhynchus mykiss) was determined for seven developmental early life stages in flow-through wateronly exposures. Test waters consisted of five concentrations of each metal and a control. Nominal concentrations ranged from 0.01-600 micrograms per liter $(\mu \mathrm{g} / \mathrm{L})$ for cadmium, $0.1-300 \mu \mathrm{g} / \mathrm{L}$ for copper, and $0.4-10,000 \mu \mathrm{g} / \mathrm{L}$ for zinc, with higher exposure concentrations tested with older life stages. Exposures were performed in a water with a hardness of about 100 milligram per liters $(\mathrm{mg} / \mathrm{L}$ ) (as calcium chloride $\left(\mathrm{CaCO}_{3}\right)$ ) and dissolved organic carbon of about $0.4 \mathrm{mg} / \mathrm{L}$. Sturgeon were tested at 2, 16, 30, 44, 61, 72, and 89 dayspost-hatch (dph) and trout were tested at 1, 18, 32, 46, 60, 74, and $95 \mathrm{dph}$. Metal toxicity varied by species and by life stage. The 50-percent lethal concentrations (LC50) were based on mortality; whereas 50-percent effect concentrations (EC50s) were based on mortality, loss of equilibrium, and immobilization. The EC50s were used in comparisons with nationally recommended water-quality criteria (WQC) or to Washington State water-quality standards (WQS). Test acceptability requirement of greater than or equal to $(\geq) 90$ percent control survival was achieved in all exposures with the exception of 16-dph sturgeon exposures where control survival was 65 to 80 percent (hence, the EC50 for 16-dph sturgeon was classified as nondefinitive effect concentrations); however, despite the low control survival, the reductions in the survival of exposed 16-dph sturgeon were concentration dependent. Rainbow trout were more sensitive to cadmium than sturgeon across all life stages with LC50s ranging from 2.77 to greater than $(>) 49.4$ micrograms cadmium per liter $(\mu \mathrm{g} \mathrm{Cd} / \mathrm{L})$ with sensitivity remaining consistent during later stages of development (18-95 dph). Sturgeon LC50s for cadmium ranged from $>47.2$ to $>355 \mu \mathrm{g} \mathrm{Cd} / \mathrm{L}$ with sensitivity increasing during later stages of development (30-89 dph). The LC50 endpoint was used in comparing sensitivity between sturgeon and trout because trout did not exhibit sublethal effects during exposure to cadmium. At $60 \mathrm{dph}$, loss of equilibrium and immobilization were evident and an EC50 was calculated for trout. For copper, sturgeon were more sensitive than trout five out of the seven life stages tested with EC50s ranging from 2.67 to 30.8 micrograms copper per liter $(\mu \mathrm{g} \mathrm{Cu} / \mathrm{L})$. In turn, trout at 74 and 95 dph were more sensitive to copper than sturgeon at 72 and $89 \mathrm{dph}$, indicating that sturgeon become more tolerant as they age whereas older trout become more sensitive to copper exposure. White sturgeon were more sensitive to zinc than rainbow trout for one out of seven life stages tested (EC50 of 147 micrograms zinc per liter ( $\mu \mathrm{g} \mathrm{Zn/L)} \mathrm{for} \mathrm{2-dph} \mathrm{sturgeon}$ and LC50 or EC50 of $>571 \mu \mathrm{g} \mathrm{Zn} / \mathrm{L}$ for 1-dph trout).

Based on the toxicity data that were estimated from the exposures that met test acceptability requirements, the LC50s were similar to EC50s calculated for trout exposed to cadmium, copper, or zinc at each life stage; however, for sturgeon, the EC50 endpoint proved more sensitive, particularly for copper where the EC50s were about 1- to 4-fold lower than the LC50s at each life stage. The rainbow trout LC50 at $46 \mathrm{dph}$ ranked at the 2 nd percentile of a compiled database for cadmium species sensitivity distribution and 72-dph white sturgeon ranked at the 19th percentile (adjusted to a common water hardness). White sturgeon EC50s at 2, 16, and 30 dph were at the $3 \mathrm{rd}(2 \mathrm{dph}), 5$ th (16 dph), and 10th ( $30 \mathrm{dph})$ percentile of the species sensitivity distribution for copper (adjusted based on a biotic ligand model). The EC50 for early life stage white sturgeon ( $2 \mathrm{dph}$ ) exposed to zinc ranked in the 1 st percentile of the species sensitivity distribution whereas older rainbow trout $(95 \mathrm{dph})$ ranked at the 4 th percentile (adjusted based on a biotic ligand model).

The EC50s for white sturgeon across all of the life stages tested were above the U.S. Environmental Protection Agency WQC for cadmium; however, for rainbow trout at 18, 46, 60 and $95 \mathrm{dph}$, the EC50s were below the WQC and all life stages with the exception of 1-dph trout fell below the Washington 
State WQS. For sturgeon aged $2 \mathrm{dph}$, the EC50 was below the WQC for copper and was below the Washington State WQS for all life stages tested. Although classified a nondefinitive effect concentration because of elevated 4-d control mortality, the EC50 for sturgeon at age 16 dph also fell below the WQC and Washington State WQS for copper. Sturgeon at 2 dph was the only life stage where the EC50 essentially was equal to the WQC and fell below the Washington State WQS for zinc. Results of this study will be submitted for consideration as part of a baseline ecological risk assessment being performed at the upper Columbia River in eastern Washington State.

\section{Introduction}

White sturgeon (Acipenser transmontanus) in the trans boundary reach of the upper Columbia River (UCR) have experienced poor recruitment. Recruitment of white sturgeon in the Columbia River essentially has been nonexistent since the early 1980s (Hildebrande and others, 1999). The Columbia River population of white sturgeon from the Grand Coulee Dam area upriver to Revelstoke, Canada, is estimated to be about 1,400 adults with a predicted population decline of 50 percent within the next 10 years; white sturgeon are predicted to be functionally extinct within the next 40 years as a result of sustained recruitment failure, senescence, and death of the adult population (Upper Columbia White Sturgeon Recovery Initiative, 2002). Because embryos and early life stage larvae rarely are seen in the river, and older juveniles (9 to 10 months old) that are released from hatcheries survive well and have good body condition factors, the recruitment failures may reflect sensitivity of one or more early life stages of white sturgeon to contaminants (Howell and McLellan, 2009).

White sturgeon declines have been attributed to various factors such as habitat degradation, water quality impairment, genetic bottlenecks, and predation by introduced species (Beamsderfer and Farr, 1997; Anders, 1998; Jager and others, 2001; Smith and others, 2002; Gadomski and Parsley, 2005; McAdam and others, 2005; McAdam, 2011). Additionally, historic and contemporary metal mining and smelting activities have resulted in the release of metals into the UCR, leading to concerns that metal toxicity might also be a factor that could affect white sturgeon recovery (Upper Columbia White Sturgeon Recovery Initiative, 2002). Contaminants accumulating at the sediment-water interface could potentially render them bioavailable for absorption, ingestion, and aqueous exposure (Kruse and Scarnecchia, 2002). Because white sturgeon enter a negative phototaxis phase and begin hiding within the substrate about 5-7 days (d) after hatching (McAdam, 2011; Conte and others, 1988), vulnerability to contaminant exposure increases while larval sturgeon are inhabiting the sediment-water interface. Limited toxicity data suggest that early life stages of white sturgeon are sensitive to copper (Little and others, 2012; Vardy and others, 2013). There is limited information available to define acute or chronic toxicity thresholds for white sturgeon for metals such as cadmium, copper, and zinc (U.S. Environmental Protection Agency, 2010) and data on other sturgeon species vary considerably in their sensitivity (Dwyer and others, 2005).

A recent study evaluating the acute effects of cadmium, copper, and zinc to white sturgeon (Vardy and others, 2013) suggested that copper was more toxic to early life stage sturgeon compared to other aquatic species. The objectives of the study were to determine the relative acute sensitivity of white sturgeon and rainbow trout (Oncorhynchus mykiss) at various stages of development to cadmium, copper, and zinc in aqueous exposures and identify the most sensitive age group for each species. Another objective of the study was to determine if rainbow trout would be an effective surrogate species for white sturgeon based on their sensitivity to metals. The toxicity data generated from this study were used to evaluate the level of protection of U.S. Environmental Protection Agency (USEPA) acute water-quality criteria (WQC) or Washington State water-quality standards (WQS) for cadmium, copper, or zinc to early life stage white sturgeon inhabiting the UCR.

A companion study evaluated the chronic toxicity of cadmium, copper, zinc, or lead to early life stages of white sturgeon in water-only exposures and also tested rainbow trout under similar test conditions to determine the relative sensitivity between the two species (chapter B). All procedures for the culturing and testing of organisms followed a USEPA approved quality assurance project plan developed for this study (U.S. Geological Survey, 2010).

\section{Materials and Methods}

\section{Culture of Test Organisms}

White sturgeon were obtained from the Washington Department of Fish and Wildlife Program (Sherman Creek Hatchery, Kettle Falls, Washington) as newly fertilized eggs received at the U.S. Geological Survey, Columbia Environmental Research Center (CERC) on July 1, 2010, about 36 hours (h) after fertilization took place on June 29, 2010. The embryos were products of three adult male and three adult female crosses for a total of nine combinations. A total of about 31,000 embryos were sampled impartially from all 9 combination crosses. The embryos were shipped overnight by express in plastic bags packed in coolers chilled to 10 degrees Celsius $\left({ }^{\circ} \mathrm{C}\right)$ using ice packs. Upon arrival at CERC, sturgeon embryos were maintained at $10{ }^{\circ} \mathrm{C}$ in their shipping bags until the water in the culture holding tank was chilled to $10^{\circ} \mathrm{C}$ (during a time period of about 4 hours) using in-line chiller units (Aquatic EcoSystems, Apopka, Florida), and the embryos were then placed in 6-liter MacDonald hatching jars (Aquatic EcoSystems, Apopka, Fla.) with flowing well water diluted with deionized water to a hardness of about 100 milligrams per liter $(\mathrm{mg} / \mathrm{L})$ as calcium carbonate 
$\left(\mathrm{CaCO}_{3}\right)$. The temperature was adjusted on the chiller units, and was increased one degree per day until the target temperature of $15^{\circ} \mathrm{C}$ was reached. The $100 \mathrm{mg} / \mathrm{L}$ hardness culture and toxicity test water was prepared in two 7,000-liters (L) polypropylene tanks by diluting well water of hardness about $300 \mathrm{mg} / \mathrm{L}$ as $\mathrm{CaCO}_{3}$ with deionized water to a hardness of about $100 \mathrm{mg} / \mathrm{L}$ as $\mathrm{CaCO}_{3}$ (alkalinity of about $90 \mathrm{mg} / \mathrm{L}$ as $\mathrm{CaCO}_{3}, \mathrm{pH}$ of about 8.0, and dissolved organic carbon of about 0.4 milligrams carbon per liter $(\mathrm{mg} \mathrm{C} / \mathrm{L})$ ) that approximated the water-quality characteristics of the UCR inhabited by white sturgeon. Water samples were collected weekly to measure water-quality characteristics of the culture water, including measures of dissolved oxygen (DO), temperature, conductivity, $\mathrm{pH}$, alkalinity, hardness, and total ammonia. The average (and standard deviations) water-quality characteristics for culture water were DO (8.3 plus or minus $( \pm) 1.4 \mathrm{mg} / \mathrm{L})$, temperature $\left(15.7 \pm 1.17^{\circ} \mathrm{C}\right)$, conductivity $(260 \pm 4.1$ microseimens per square centimeter $\left(\mu \mathrm{S} / \mathrm{cm}^{2}\right)$ at $\left.25^{\circ} \mathrm{C}\right), \mathrm{pH}(7.9 \pm$ $0.09)$, alkalinity $\left(94 \pm 2.6 \mathrm{mg} / \mathrm{L}\right.$ as $\left.\mathrm{CaCO}_{3}\right)$, hardness $(104 \pm$ $2.7 \mathrm{mg} / \mathrm{L}$ as $\left.\mathrm{CaCO}_{3}\right)$, and total ammonia $(0.18 \pm 0.12 \mathrm{mg} / \mathrm{L}$ as nitrogen). The sturgeon culture was maintained with a $16-\mathrm{h}$ light, 8-h dark photoperiod with an average light intensity ranging from 280-300 lux. Sturgeon started hatching $8 \mathrm{~d}$ after fertilization and continued for a period of four more days. The date of hatch was established as the day when $>50$ percent of the eggs hatched (11-d post fertilization). The yolk sac larvae were then transferred to a 1,850 L flow-through fiberglass tank for holding until testing. Larvae were fed 1-d-old brine shrimp (Artemia sp.) nauplii (Brine Shrimp Direct, Ogden, Utah) starting about 1 week (10 to 12 days-post-hatch (dph)) before the start of exogenous feeding, and at $18 \mathrm{dph}$, were transitioned to chopped and then whole live oligochaetes (Lumbriculus variegatus, California Blackworm Co., Fresno, Calif.). Once larval sturgeon were feeding actively, BioDiet Starter \#2 (Bio-Oregon, Longview, Wash.) a semi-moist commercial food also was provided every 3 hours using an automated feeder. This commercial diet was recommended in the publication, Hatchery Manual for the White Sturgeon (Conte and others, 1988). Sturgeon were fed food of sufficient amount to result in residual of uneaten food typically 2 to $3 \mathrm{~h}$ after each feeding.

Greater than 50 percent of the sturgeon eggs were nonviable (received as nonfertilized eggs). Elevated mortality (about 17 percent) of larvae was observed during the transition phase to exogenous feeding, which was not unexpected because this is a critical developmental stage. As a precautionary measure to ensure adequate numbers of individuals for testing, a second batch of 2,100 larval sturgeon (24 dph) was obtained from Washington Department of Fish and Wildlife Program (Columbia Basin Hatchery, Moses Lake, Wash.) on August 3,2010 . These sturgeon were cohorts from the same adult crosses that previously were received as eggs and thus were of the same age and parentage. The second batch of sturgeon was acclimated to culture conditions for at least $13 \mathrm{~d}$ before use in acute exposures. The side by side comparison of acute copper exposure was initiated using 37-dph sturgeon from culture to determine if the first batch of sturgeon received from the hatchery was similar to the second group of sturgeon received in sensitivity to copper. The 50-percent lethal concentration (LC50) and 50-percent effect concentration (EC50) estimates were comparable, indicating the two groups of sturgeon were similar in their sensitivity to copper. The LC50 for the 37-dph sturgeon from the original group was 18.4 (11.9-28.4 confidence interval) $\mu \mathrm{g} \mathrm{Cu} / \mathrm{L}$ and the LC50 for the second group was 18.8 (9.6-36.6) $\mu \mathrm{g} \mathrm{Cu} / \mathrm{L}$. Sturgeon from the original batch exhibited an EC50 of 11.2 (5.8-21.7) $\mu \mathrm{g} \mathrm{Cu} / \mathrm{L}$ and the EC50 for the second batch was $6.3(2.8-14.3) \mu \mathrm{g} \mathrm{Cu} / \mathrm{L}$. The sturgeon from the second batch was combined with the first batch of sturgeon at $40 \mathrm{dph}$ for use in toxicity tests.

The rainbow trout (Erwin/Arlee strain) were obtained from the U.S. Fish and Wildlife, Ennis National Fish Hatchery (Ennis, Montana). A total of about 10,000 trout eggs were received as eyed eggs on October 5, 2010 and held in incubators at $12{ }^{\circ} \mathrm{C}$ in flowing well water at a hardness of $300 \mathrm{mg} / \mathrm{L}$, then slowly transitioned to $100 \mathrm{mg} / \mathrm{L}$ hardness water for $48 \mathrm{~h}$. About 4 percent of the eggs did not hatch. Yolk sac larvae $(17 \mathrm{dph})$ were then transferred out of the incubators into $500 \mathrm{~L}$ flow-through tanks immediately before yolk sac depletion and swim-up, where the trout were maintained at $12{ }^{\circ} \mathrm{C}$ under similar water and lighting conditions to the sturgeon cultures. Trout at exogenous feeding $(20 \mathrm{dph})$ were fed 1 -d-old brine shrimp (Artemia sp.) nauplii (Brine Shrimp Direct, Ogden, Utah), transitioning to trout chow (Otohime B1-C1; Campbell, Calif.) and flake food (Worldwide Aquatics; Arvin, Calif.) as the larval trout developed.

\section{Toxicity Testing}

Each metal exposure was performed using a modified Mount and Brungs (1967) diluter following guidelines outlined by the American Society for Testing and Materials (American Society for Testing and Materials, 2012a, b, c; table A-1). The water used in testing was targeted for a hardness of $100 \mathrm{mg} / \mathrm{L}$ and dissolved organic carbon of about $0.4 \mathrm{mg} / \mathrm{L}$ (appendix table 1-2) for comparability with earlier testing at the U.S. Geological Survey CERC laboratory (Little and others, 2012) and approximated the water-quality characteristics of the UCR inhabited by white sturgeon. Sturgeon tests were performed at $15^{\circ} \mathrm{C}$ and trout tests at $12{ }^{\circ} \mathrm{C}$. Three intermittent flow-through proportional diluters were used (one for each metal) and provided a control and five concentrations of cadmium, copper, or zinc through 50-percent serial dilutions. The toxicants were delivered to the diluters using a Hamilton ${ }^{\circledR}$ syringe pump (Hamilton, Reno, Nevada). In rounds $1-3$ for the three youngest life stages, four glass replicate chambers were held in a temperature-controlled water bath $(152.5 \times 84 \times 35.5 \mathrm{~cm})$. An in-line 4-way flow splitter was attached to each delivery line to partition the water flow to each of four replicate chambers in the water bath (Brunson and others, 1998). Each test chamber (12x21.5$\mathrm{cm}$ jar) had a hole (4-cm diameter) in the side covered with 
Table A-1. Summary conditions for conducting acute water-only toxicity tests with white sturgeon (Acipenser transmontanus) and rainbow trout (Oncorhynchus mykiss) in accordance with American Society for Testing and Materials (2012a, b), the U.S. Environmental Protection Agency (2002), and U.S. Geological Survey-Columbia Quality Assurance Project Plan (U.S. Geological Survey, 2010).

$\left[{ }^{\circ} \mathrm{C}\right.$, degrees Celsius; cm, centimeter; L, liter; dph, days-post-hatch; <, less than; g, gram; weight/L, weight per liter; h, hour; $\mathrm{mg} / \mathrm{L}, \mathrm{milligram}$ per liter; $\mathrm{CaCO}$, calcium carbonate; $\mu \mathrm{m}$, micrometer; $\mathrm{Cu}$, copper; $\mathrm{Zn}$, zinc; $\mathrm{Cd}$, cadmium; $\geq$, greater than or equal to]

\begin{tabular}{|c|c|}
\hline Parameter & Description \\
\hline \multirow[t]{2}{*}{ Species } & White sturgeon (Acipenser transmontanus). \\
\hline & Rainbow trout (Oncorhynchus mykiss). \\
\hline Test type & Flow through water-only exposures in intermittent proportional diluters. \\
\hline Temperature & Sturgeon: $15^{\circ} \mathrm{C}$ \\
\hline Light quality & Ambient laboratory light. \\
\hline Light intensity & About 200 (lux). \\
\hline Photoperiod & 16-hour light:8-hour dark. \\
\hline \multirow[t]{2}{*}{ Test chamber size } & Rounds $1-3: 12 \times 21.5-\mathrm{cm}$ jar. \\
\hline & Round 4: $15 \times 25.5-\mathrm{cm}$ jar. \\
\hline \multirow[t]{3}{*}{ Test solution volume } & Rounds $1-3: 1 \mathrm{~L}$. \\
\hline & Round 4: 2 L. \\
\hline & Rounds 5-7: 7 L. \\
\hline Water addition & 0.25 liter/chamber/30 minutes ( $2-12$ volume additions/day). \\
\hline \multirow[t]{2}{*}{ Organisms/chamber } & Sturgeon: 10 (2-44 dph; rounds $1-4), 5$ (61-72 dph; rounds 5 and 6), 3 ( $89 \mathrm{dph}$; round 7). \\
\hline & Trout: 10 (1-46 dph; rounds 1-4), 5 (60-94 dph; rounds 5-7). \\
\hline Loading & $\begin{array}{l}<1 \mathrm{~g} \text { fish wet weight } / \mathrm{L} \text { of test solution passing through the chamber over } 24 \mathrm{~h} \text { and }<10 \mathrm{~g} \text { fish wet weight } / \mathrm{L} \text { in } \\
\text { chamber at any given time. }\end{array}$ \\
\hline \multirow[t]{2}{*}{ Replicates } & 4 (2-72 dph; acute exposure rounds $1-6)$. \\
\hline & 8 (89 dph; acute exposure round 7). \\
\hline Duration & 4 days. \\
\hline \multirow[t]{2}{*}{ Age of test organisms } & Sturgeon: $2,16,30,44,61,72,89 \mathrm{dph}$. \\
\hline & Trout: $1,18,32,46,60,74,95$ dph. \\
\hline Feeding & None. \\
\hline Chamber cleaning & None. \\
\hline Test water & $\begin{array}{l}\text { Well water diluted with deionized water: } 100 \mathrm{mg} / \mathrm{L} \text { hardness and alkalinity } 90 \mathrm{mg} / \mathrm{L} \text { as } \mathrm{CaCO}_{3}, \mathrm{pH} 8.0 \text {, dissolved } \\
\text { organic carbon } 0.4 \mathrm{mg} / \mathrm{L} \text {. }\end{array}$ \\
\hline \multirow[t]{2}{*}{ Dilution series } & Five concentrations (50-percent serial dilutions) and control. \\
\hline & Concentrations adjusted by life stage (see tables A-2 and A-3). \\
\hline Chemicals analyses & $\begin{array}{l}\text { Filtered water samples }(0.45 \mu \mathrm{m}) \text { for } \mathrm{Cu}, \mathrm{Zn} \text {, and } \mathrm{Cd} \text { analysis collected twice during exposure (test day } 0 \text { and test } \\
\text { day 4). }\end{array}$ \\
\hline Water quality & $\begin{array}{l}\text { Dissolved oxygen, } \mathrm{pH} \text {, conductivity, hardness, alkalinity, and ammonia collected twice during exposure (test day } 0 \\
\text { and test day 4) and major cations, major anions, and dissolved organic carbon collected once during exposure } \\
\text { (test day 2). }\end{array}$ \\
\hline Aeration & None. \\
\hline Endpoints & Survival, behavior (daily, appendix table 1-1). \\
\hline Test acceptability & Survival $\geq 90$ percent in controls. \\
\hline
\end{tabular}


30 mesh (0.5-millimeter ( $\mathrm{mm})$ opening) stainless steel screen containing $1 \mathrm{~L}$ of water. Test solution flowed directly into test chambers and excess water overflowed to surrounding aquaria through the screen windows, so there was no exchange of test water among replicates. The diluter provided about 250 milliliters $(\mathrm{mL})$ of water to each chamber every 30 minutes (resulting in about 12 volume additions per day to each replicate test chamber). There was a similar setup in round 4, except larger test chambers $(15-\mathrm{x} 25.5-\mathrm{cm}$ jar with a mesh covered hole cut in the side so the jar, which held 2 L of water) were used to maintain acceptable loading rates of sturgeon or trout. In rounds 5-6, four glass replicate chambers were held in each of six 40-L rectangular glass aquaria in a temperaturecontrolled water bath. Each test chamber $(28 \times 13.5 \times 25 \mathrm{~cm})$ had a hole (4-cm diameter) in the side covered with 30 mesh (0.5-mm opening) stainless steel screen and contained $7 \mathrm{~L}$ of water. In rounds 5-6, the diluter also provided about $250 \mathrm{~mL}$ of water to each chamber every 30 minutes (resulting in about two volume additions per day). The same design was used for round 7 , except there were 4 replicate chambers in each of 12 40-L aquaria with a total of 8 replicate chambers for each metal concentration. Test conditions for performing the acute toxicity tests were adjusted by increasing or decreasing metal concentrations, increasing water turnover rate, decreasing the number of fish per replicate chamber, or increasing the number of replicates according to life stage, and are summarized in table A-1. The number of fish, number of replicates, and mass of fish in each exposure chamber were established in accordance with guidance provided in American Society for Testing and Materials (2012c). The fish loading rate in test chambers did not exceed the American Society for Testing and Materials (2012a) guidelines of 1 gram per liter ( $\mathrm{g} / \mathrm{L}$ ) of solution passing through a chamber each day at the end of the exposures and did not exceed $10 \mathrm{~g} / \mathrm{L}$ in the chamber at any time (at less than (<) $17^{\circ} \mathrm{C}$ ). Moreover, water-quality conditions (for example water hardness, alkalinity, $\mathrm{pH}$ ), measured metal concentrations, and ammonia concentrations were not affected by various loading densities throughout the exposures (appendix tables 1-2, 1-5, and 1-6).

Metal salts were obtained from Sigma-Aldrich (St. Louis, Missouri). A stock solution of each metal (copper II sulfate pentahydrate, cadmium chloride hemi-pentahydrate, and zinc chloride) was prepared by adding the American Chemical Society reagent grade ( $>98$ percent purity) metals to deionized water. Test stock solutions were prepared $2 \mathrm{~d}$ before the start of exposures in volumetric flasks and wrapped with aluminum foil to reduce exposure to ambient light. Stock solutions were then delivered to the diluters using a Hamilton ${ }^{\circledR}$ Syringe Dispenser (MicroLab ${ }^{\circledR} 600$ Series, Hamilton Company, Reno, Nev.) and the diluters and test chemicals cycled for at least 2 days before starting the exposures. Fish were not fed $24 \mathrm{~h}$ before and during the acute exposures.

The primary toxicity endpoints measured daily in the acute exposures included mortality, the loss of equilibrium, and immobilization. The 50-percent lethal concentrations (LC50s) were calculated using mortality only, whereas the 50-percent effect concentrations (EC50s) were calculated using mortality plus the loss of equilibrium and immobilization following guidance provided in Stephan and others (1985), U.S. Environmental Protection Agency (2002) and American Society for Testing and Materials (2012a). See the Data Analysis section below for additional details on how LC50s and EC50s were calculated. Death was defined as no movement of gills or appendages and no reaction to gentle prodding. Loss of equilibrium was defined as the inability of fish to maintain an upright position within the water column. Immobilization was defined as the inability to swim or move unless prodded. The loss of equilibrium toxicity endpoint and the immobilization toxicity endpoint are illustrated in two videos in appendix 1 (video 1 and video 2 ).

Other toxicity endpoints including changes in respiration, changes in pigmentation, and position in the water column were documented daily around 9 a.m. (appendix table 1-1). These behavioral endpoints were not used in the calculation of the EC50s. In the chronic exposures described in chapter B, hiding behavior of sturgeon was also documented during the first several weeks of the exposures. Qualitative video samples were collected using a hand-held video camera (Sony ${ }^{\circledR}$ Handycam HDR-CX550V, Creve Coeur Camera, Columbia, Mo.) mounted to a tripod positioned directly overhead the testing chamber to document behavioral effects. These overhead video samples of sturgeon behavior were made on test days 3 and 4 of exposure.

At the end of each $4 \mathrm{~d}$ acute exposure, surviving fish in each replicate chamber were counted and euthanized using tricaine methanesulfonate. Wet weight was determined among select replicate control treatments at the end of the $4 \mathrm{~d}$ exposure to confirm loading rates were within guidelines provided by American Society for Testing and Materials (2012c). Fish were gently blotted with a paper towel to remove excess water before weighing.

Based on observations during the acute metal exposures, an additional study was started in July 2011, using a different strain of white sturgeon larvae from a commercial source from Idaho (Blind Canyon Aqua Ranch, Hagerman, Idaho) to develop protocols for quantifying swimming behavior, including duration, speed, distance, and swimming path tortuosity (American Society for Testing and Materials, 2012b) with the use of digitizing computer software (Noldus Ethovision ${ }^{\circledR}$ XT, Leesburg, Virginia). The 2011 exposures examined 30-dph white sturgeon and followed the same methods as described above with nominal copper exposure concentrations ranging from $0-50 \mu \mathrm{g} / \mathrm{L}$.

\section{Water Quality}

Water temperature was monitored daily in select exposure chambers within each diluter at the control, low, medium, and high treatments. Water quality (dissolved oxygen, $\mathrm{pH}$, conductivity, hardness, alkalinity, ammonia) was measured from a select replicate for each metal in the control, low, medium, and 
high concentrations on test day 0 and on test day 4 following standard methods (Eaton and others, 2005).

\section{Chemical Analysis}

A 20-mL filtered sample was collected for metals analyses from one random replicate chamber for each treatment on test day 0 (just before adding test organisms) and on test day 4 at the end of the exposures. One filtration blank (obtained using high-purity deionized water) was processed with each set of samples. In addition, a duplicate sample was collected from the medium treatment, and unfiltered samples were collected from a control and a medium treatment. The unfiltered control sample was collected to check for filter contamination specifically with a test water sample, whereas the unfiltered medium treatment was sampled to check for the presence of colloidal precipitates $(>0.45$ micrometer $(\mu \mathrm{m}))$ that might be present as a result of the high exposure concentrations for some of the toxicity tests. To collect each sample, about $24 \mathrm{~mL}$ of test water was drawn into a polypropylene syringe to which an acid-rinsed, Teflon ${ }^{\circledR}$ sipper straw was attached. The sipper straw was removed from the syringe and a polypropylene filter cartridge housing a $0.45-\mu \mathrm{m}$ pore size, polyethersulfone membrane (Whatman Puradisc ${ }^{\mathrm{TM}}$, no. 6781-2504, GE Health Care Life Sciences, Piscataway, New Jersey) was attached. About $4 \mathrm{~mL}$ of sample was dispensed through the filter to waste, followed by $20 \mathrm{~mL}$ of sample that was collected in an acid-cleaned, polyethylene bottle. Each sample was acidified to 1 percent volume/volume (v/v) with high-purity, $16 \mathrm{M}$ nitric acid and stored for as many as 3 months before analysis was done by inductively coupled plasma mass spectrometry (U.S. Environmental Protection Agency Method 6020a, ICPMS; Brumbaugh and others, 2007).

Samples obtained for major cation analyses (calcium, magnesium, sodium and strontium) were collected, filtered, and preserved on test day 2 of the exposures in the same manner as those samples collected for metals. For sturgeon toxicity tests, one random replicate from the control and one random replicate from the medium treatment of each metal tested were sampled, whereas for trout toxicity tests, samples were collected only from the control and medium treatments of the $\mathrm{Cu}$ exposure. One filtration blank (obtained using high-purity deionized water) was processed with each set of samples. Analysis was done by inductively coupled plasma atomic emission spectroscopy (ICPAES) according to USEPA method 200.7 (U.S. Environmental Protection Agency, 1994) by Laboratory and Environmental Testing (LET) Labs (Columbia, Mo.).

Samples obtained for major anion analyses (fluoride, chloride, nitrite, nitrate, and sulfate) were collected and filtered in a manner similar to those collected for cations, except that $15 \mathrm{~mL}$ was collected in a high-density polyethylene bottle that had been soaked only in high-purity water (without acid-rinsing), and no preservative was added. For sturgeon tests, one replicate from the control and one replicate from the medium treatment of each metal tested were sampled, whereas for trout toxicity tests, samples were collected only from the control and medium treatments of the $\mathrm{Cu}$ exposure. One filtration blank (obtained using high-purity deionized water) was processed with each set of samples. Samples were stored at $4{ }^{\circ} \mathrm{C}$ for as many as $28 \mathrm{~d}$ before analysis, by ion chromatography at CERC according to USEPA method 9056a (U.S. Environmental Protection Agency, 2007b).

Samples obtained for dissolved organic carbon (DOC) analyses were each drawn using an oven baked $\left(450^{\circ} \mathrm{C}\right)$ glass pipet and collected in a $60 \mathrm{~mL}$, amber glass bottle fitted with a Teflon ${ }^{\circledR}$-lined cap. Except for the initial collections (appendix 6), sample bottles were rinsed, then filled with high-purity deionized water to prevent potential airborne contamination until use. Two or three filtration blanks were processed with each set of samples using commercially available total organic carbon (TOC) free water $(<0.05 \mathrm{mg} \mathrm{C} / \mathrm{L}$; Ep Scientific Products, Thermo Fisher Scientific, Waltham, Massachusetts). About $20 \mathrm{~mL}$ of sample was used to rinse each bottle before collection of a $60-\mathrm{mL}$ sample. Samples were stored at $4{ }^{\circ} \mathrm{C}$ for as many as $48 \mathrm{~h}$ before filtration and preservation to a $\mathrm{pH}<2$ with about $0.1 \mathrm{~mL}$ of 9 molar sulfuric acid $\left(\mathrm{H}_{2} \mathrm{SO}_{4}\right)$. Filtration was done with a vacuum applied to a 47-mm diameter, 0.45 $\mu \mathrm{m}$ pore size nylon membrane (B. Huffman, oral commun., June 2010, Huffman Laboratory, Golden, Colorado) that was mounted on an all-glass filtration support mount. Before each sample filtration, a new membrane was inserted and the membrane and glass support apparatus was rinsed under vacuum with a minimal volume of TOC-free water. Preserved samples were stored at $4{ }^{\circ} \mathrm{C}$ for as many as $28 \mathrm{~d}$ (but more typically 7 to $14 \mathrm{~d}$ ) before analysis according to USEPA method 415.2 (U.S. Environmental Protection Agency, 1983). On three separate dates, duplicate samples from selected treatments were collected for submission for confirmatory DOC analyses by Huffman Laboratory (appendix 6).

\section{Quality Assurance Quality Control for Chemical Analyses}

\section{White Sturgeon Toxicity Tests}

All quality assurance/quality control $(\mathrm{QA} / \mathrm{QC})$ data sheets associated with sturgeon tests were submitted for U.S. Environmental Protection Agency contractor review on March 4, 2011. The QC results associated with measurements for cations, anions, and general water quality parameters were deemed acceptable in accordance with the quality assurance project plan that specified a target accuracy range of 80 to 120 percent and a target precision of less than or equal to $(\leq) 10$ percent relative standard deviation. Problems were encountered with measurements for DOC during the first two weeks of the sturgeon exposures. Blanks collected during the first acute test and during the first 9 days of chronic sturgeon exposures had elevated DOC concentrations (about $1 \mathrm{mg} / \mathrm{L}$ ); therefore, DOC results for those sets of samples were deemed 
invalid. Elevated DOC in blanks during those early collections was attributed to leaching of carbon from the bottle caps. In addition, the measured DOC concentrations of most samples were not within the quantitative range of the analytical method because they were so near the CERC method detection limit (about $0.2 \mathrm{mg} / \mathrm{L}$ ). Consequently, most measured DOC concentrations were considered estimated values and would be flagged with either the U or JN code according to USEPA convention (U.S. Environmental Protection Agency, 1999) because they failed to meet standards for accuracy and precision as stated in the quality assurance plan. The U code applies when the analyte was analyzed for but was not detected. The $\mathrm{JN}$ code applies when the identification of the analyte (its presence) is considered acceptable, but quality assurance criteria indicate that the quantitative values may be outside the normal expected range of precision (that is, the quantitative value is considered estimated). DOC results for the sets of samples that were submitted to Huffman Laboratory for confirmatory analyses were considered valid because standards for accuracy and precision were met (appendix 6).

A summary of the QC results for metal analyses associated with all sturgeon toxicity tests (12 tables) are provided in appendix 3 . A brief summary of metals results for filter blanks, sampling duplicates, spiked samples, and certified reference waters follows. In many instances, sets of acute (this chapter) and chronic (chapter B) water samples were grouped together for analysis; consequently, summaries of spiked samples and certified reference water QC results correspond with samples from the acute and chronic exposures. Metals concentrations in all filter blanks from acute sturgeon tests $(n=14)$ were at or below the respective method detection limits $(<0.05$ to $<0.11 \mu \mathrm{g} / \mathrm{L}$ for $\mathrm{Cu} ;<0.009$ to $<0.045 \mu \mathrm{g} / \mathrm{L}$ for $\mathrm{Cd} ; 0.2$ to $<1.5 \mu \mathrm{g} / \mathrm{L}$ for zinc). The mean relative percent difference (RPD) between sampling duplicates of medium treatments for sturgeon acute tests $(\mathrm{n}=14)$ were as follows: $\mathrm{Cu}-1.8$ percent; $\mathrm{Cd}-1.8$ percent; $\mathrm{Zn}-1.1$ percent. The RPD for analysis duplicates (individual samples analyzed twice) typically was between 0.5 and 1 percent RPD. Mean spike recoveries (standard deviations in parentheses) among all sturgeon test samples were 96.7 (1.7) for $\mathrm{Cu}, 98.3$ (1.4) for $\mathrm{Cd}$, and 101.3 (1.9) for $\mathrm{Zn}$ ( $\mathrm{n}=46$ for each metal). Measured values among three reference water samples analyzed with sturgeon acute test waters were all within the certified range for zinc, and were within 94 to 100 percent of certified ranges for copper, and 97 to 106 percent for cadmium.

\section{Rainbow Trout Toxicity Tests}

All QA/QC data sheets associated with trout tests were submitted for U.S. Environmental Protection Agency contractor review on May 11, 2011. Except for one set of DOC blanks QC results associated with measurements for cations, anions, DOC, and general water quality parameters were deemed acceptable in accordance with the quality assurance project plan that specified a target accuracy range of 80 to 120 percent and a target precision of $\leq 10$ percent relative standard deviation. Additional discussion concerning the evaluation of DOC results is provided in appendix 6. Complete QC results for metal analyses associated with all trout toxicity tests (12 tables) are provided in appendix 4 . A brief summary of metals results for filter blanks, sampling duplicates, spiked samples, and certified reference waters follows. In many instances, sets of acute and chronic water samples were grouped together for analysis; consequently, summaries of spiked samples and certified reference water QC results correspond with samples from the acute and chronic exposures.

Metals concentrations in 13 of 15 filter blanks from acute trout tests were below the respective method detection limits $(<0.037$ to $<0.29 \mu \mathrm{g} / \mathrm{L}$ for $\mathrm{Cu} ;<0.007$ to $<0.020 \mu \mathrm{g} / \mathrm{L}$ for $\mathrm{Cd} ;<0.1$ to $<0.6 \mu \mathrm{g} / \mathrm{L}$ for zinc). One filter blank contained $0.51 \mu \mathrm{g} \mathrm{Cu} / \mathrm{L}$ and $0.6 \mu \mathrm{g} \mathrm{Zn} / \mathrm{L}$ and another blank contained $0.055 \mu \mathrm{g} \mathrm{Cu} / \mathrm{L}$ and $0.15 \mu \mathrm{g} \mathrm{Cd} / \mathrm{L}$; however, none of those concentrations were considered great enough to be of concern. The mean RPD between sampling duplicates of medium treatments for trout acute tests $(\mathrm{n}=13)$ were as follows: $\mathrm{Cu}, 2.1$ percent; $\mathrm{Cd}, 1.4$ percent; $\mathrm{Zn}, 2.3$ percent. The RPD for analysis duplicates (individual samples analyzed twice) typically was between 0.5 and 1 percent RPD. Mean spike recoveries (with standard deviations in parentheses) among all trout test samples were 96.4 (2.8) for copper, 98.0 (2.8) for cadmium, and 100.9 (2.9) for zinc ( $\mathrm{n}=43$ for each metal). Measured values among three reference water samples analyzed with all trout test waters were all within the certified range for zinc, were within 93 to 101 percent of certified ranges for copper, and were within 96 to 100 percent of certified ranges for cadmium.

\section{Data Analysis}

The mean measured concentrations of each metal were used to calculate 4-d effect concentrations for each species at each life stage. The Toxicity Relationship Analysis Program (Erickson, 2012) was used to calculate the 4-d LC50s based on mortality and the 4-d EC50s based on mortality, loss of equilibrium, and immobilization along with 95-percent confidence intervals for each life stage based on the measured metals concentrations. When LC50 or EC50 concentrations could not be estimated because the data did not meet the specific requirements for the model, LC50s or EC50s were reported as less than the highest test concentration where there was 100 percent mortality or greater than the lowest test concentration where there was no significant $(p>0.05)$ difference from the controls. The requirements for the model are the dataset must include at least (1) a control data point (or low exposure data points that adequately indicate the control value for the effect variable), and (2) two data points with effect variable values below the control and above zero (that is, partial effects that provide good information on the steepness of the curve and the location of LC/EC50) with the absolute minimum number of data points being three. Effect concentrations for 10-percent and 20-percent reduction (EC10 and EC20) for mortality, loss of equilibrium, 
and immobilization also were estimated using the Toxicity Relationship Analysis Program (tables A-2 and A-3). For the 2011 copper exposure using 30-dph white sturgeon from Idaho, to quantify swimming behavior such as fish swimming paths, travel distance, time spent swimming, and speed, a digitizing software program was used (Noldus EthoVision ${ }^{\circledR}$ XT, Leesburg, Va.) to analyze video images.

In addition to the LC50s or EC50s, TOXSTAT ${ }^{\circledR}$ (Western EcoSystems, 1996) was used to determine the no-observedeffect concentration (NOEC) and the lowest-observed-effect concentration (LOEC) by analysis of variance with mean comparison made by one-tailed Dunnett's test (U.S. Environmental Protection Agency, 2002). Steel's Many-One Rank test (U.S. Environmental Protection Agency, 2002) was used when the data were not distributed normally or had heterogeneous variances. The level of statistical significance was set at $\mathrm{p}<0.05$.

The methods used to calculate LC50s and EC50s are consistent with guidance provided for calculating effect concentration described in U.S. Environmental Protection Agency (2002), American Society for Testing and Materials (2012c), and Stephan and others (1985). U.S. Environmental Protection Agency (2002) states that death is the effect used for determining toxicity to aquatic organisms in acute toxicity tests and is not as easily determined for some organisms. The criteria typically used in establishing death are (1) no movement of gills or appendages, and (2) no reaction to gentle prodding. Also, the death of some organisms, such as mysids and larval fish, is detected easily because of a change in appearance from transparent or translucent to opaque. General observations of appearance and behavior, such as erratic swimming, loss of reflex, discoloration, excessive mucus production, hyperventilation, opaque eyes, curved spine, hemorrhaging, molting, and cannibalism, should also be noted in the daily record. Additionally, American Society for Testing and Materials (2012c, p. 81) states "Death is the adverse effect most often used for the calculation of results of acute toxicity test...In order to account for the total severe acute adverse of the test material on test organisms, it is desirable to calculate an EC50 based on death plus immobilization, plus loss of equilibrium. Other effects, such as behavior can be used to determine an EC50, but the effect and its definition must always be reported." Stephan and others (1985, p. 28) also state, "when available, 96-h EC50s based on the percentage of fish immobilized plus the percentage of fish killed are used instead of 96-h LC50s for fish; comparable EC50s are used instead of LC50s for other species. Such appropriately defined EC50s better reflect the total severe acute of the test material on the test species than do LC50s or narrowly defined EC50s."

Effect concentrations from tests that met test acceptability requirements are classified as definitive effect concentrations. Therefore, effect concentrations based on toxicity endpoints from tests that did not meet test acceptability requirements (for example, low control survival) were classified as nondefinitive effect concentrations.

\section{Water Chemistry Normalization of Effect Concentrations and Species Sensitivity}

When comparing toxicity test results among different studies, the data should be normalized to account for different water-quality characteristics (Stephan and others, 1985). Similarly, relations between water-quality characteristics and toxicity can be used to extrapolate effects concentrations from laboratory test conditions to ambient conditions, such as from the laboratory waters tested in the study to the water-quality characteristics of the UCR. For cadmium, this data normalization was done using hardness-toxicity relations described in Mebane (2006). For copper and zinc, biotic ligand models (BLMs) were used to normalize effect concentrations to a common set of water-quality characteristics (U.S. Environmental Protection Agency, 2007a for copper; DeForest and VanGenderen, 2012 for zinc).

The BLM-predicted effect concentrations were calculated based on mean measured water-quality characteristics for each test, following the principles described in U.S. Environmental Protection Agency (2007a). Critical accumulation (CAs) at the biotic ligand associated with the effects percentile (for example, CA50, CA20) values for each test EC50 were modeled as the sum of predicted biotic ligand concentrations of copper plus two valence $\left(\mathrm{Cu}^{2+}\right)$ and copper hydroxide plus one valence $\left(\mathrm{CuOH}^{+}\right)$for the copper tests and the sum of zinc plus two valence $\left(\mathrm{Zn}^{2+}\right)$ and zinc hydroxide plus one valence $\left(\mathrm{ZnOH}^{+}\right)$for the zinc tests. This approach was similar to that introduced by Santore and others (2001) for modeling an acute LC50 as a lethal accumulation on the gill associated with 50-percent mortality (LA50) but is generalized to any effects endpoint. The CA values were then used with the BLM to predict effects concentrations for waters with different chemistries than the original test waters. All speciation and toxicity predictions were made using the BLM software version 2.2.3 (HydroQual, 2007 ), using the metal-biotic ligand affinity constants from U.S. Environmental Protection Agency (2007a) for copper and DeForest and VanGenderen (2012) for zinc. A summary of the water composition and original effects concentrations that were used in the BLM modeling with copper, the modeled CA values, and resulting effects concentrations extrapolated to a moderately hard BLM standard water are provided in appendix table 1-7.

When evaluating the sensitivity of white sturgeon and rainbow trout relative to other species tested in other waters, effect concentrations were ranked in a species sensitivity distribution for each metal using databases that are used by the U.S. Environmental Protection Agency to derive acute WQC. The EC50 concentrations for the most sensitive life stage for white sturgeon and for rainbow trout in the study were then compared to the final acute value (FAV) to assess sensitivity in relation to the WQC. When evaluating the protection of the acute WQC (that is, criteria to protect against short-term exposures, also called criterion maximum concentration, or CMC, in U.S. Environmental Protection Agency criteria documents) to white sturgeon and rainbow trout, the EC50s 


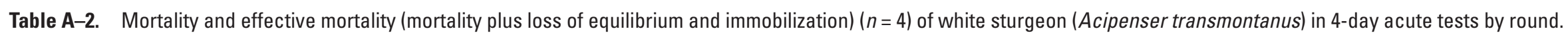

[Yellow shading indicates significant reduction from the control (Dunnett's test or Steel's Many-Rank test; $p<0.05$ ). Acute value (geometric mean [Geomean] of NOEC and LOEC), EC10, EC20, and EC50 with 95 -percent confidence limits (CL) are presented for each endpoint. Values in red (bold italic) were calculated based on data with low control survival and the results should be used with caution. $n$, sample size; dph, days-post-hatch; $\mu \mathrm{g} / \mathrm{L}$, microgram per liter; \%, percent; SD, standard deviation; Mort+LOE+IM, mortality plus loss of equilibrium and immobilization; NOEC, no-observed-effect concentration; <, less than; LOEC,

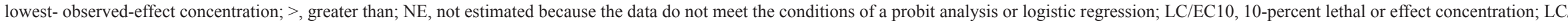
EC20, 20-percent lethal or effect concentration; LC/EC50, 50-percent lethal or effect concentration]

\begin{tabular}{|c|c|c|c|c|c|c|c|c|c|c|c|c|c|c|c|c|c|c|c|}
\hline \multicolumn{5}{|c|}{$\begin{array}{c}\text { Round } 1 \\
2 \mathrm{dph}\end{array}$} & \multicolumn{5}{|c|}{$\begin{array}{l}\text { Round } 2 \\
16 \mathrm{dph}^{1}\end{array}$} & \multicolumn{5}{|c|}{$\begin{array}{c}\text { Round } 3 \\
30 \mathrm{dph}\end{array}$} & \multicolumn{5}{|c|}{$\begin{array}{c}\text { Round } 4 \\
44 \mathrm{dph}\end{array}$} \\
\hline \multirow[t]{2}{*}{$\begin{array}{c}\text { Measured } \\
\text { concentration } \\
\quad(\mu \mathrm{g} / \mathrm{L})\end{array}$} & \multicolumn{2}{|c|}{$\begin{array}{c}\text { Mortality } \\
(\%)\end{array}$} & \multicolumn{2}{|c|}{$\begin{array}{c}\text { Effective } \\
\text { mortality (\%) } \\
\text { Mort+LOE+IM }\end{array}$} & \multirow[t]{2}{*}{$\begin{array}{c}\text { Measured } \\
\text { concentration } \\
(\mu \mathrm{g} / \mathrm{L})\end{array}$} & \multicolumn{2}{|c|}{$\begin{array}{c}\text { Mortality } \\
(\%)\end{array}$} & \multicolumn{2}{|c|}{$\begin{array}{c}\text { Effective } \\
\text { mortality (\%) } \\
\text { Mort+LOE+IM }\end{array}$} & \multirow[t]{2}{*}{$\begin{array}{c}\text { Measured } \\
\text { concentration } \\
(\mu \mathrm{g} / \mathrm{L})\end{array}$} & \multicolumn{2}{|c|}{$\begin{array}{c}\text { Mortality } \\
(\%)\end{array}$} & \multicolumn{2}{|c|}{$\begin{array}{c}\text { Effective } \\
\text { mortality (\%) } \\
\text { Mort+LOE+IM }\end{array}$} & \multirow[t]{2}{*}{$\begin{array}{c}\text { Measured } \\
\text { concentration } \\
(\mu \mathrm{g} / \mathrm{L})\end{array}$} & \multicolumn{2}{|c|}{$\begin{array}{c}\text { Mortality } \\
(\%)\end{array}$} & \multicolumn{2}{|c|}{$\begin{array}{c}\text { Effective } \\
\text { mortality (\%) } \\
\text { Mort+LOE+IN }\end{array}$} \\
\hline & Mean & SD & Mean & SD & & Mean & SD & Mean & SD & & Mean & SD & Mean & SD & & Mean & SD & Mean & SD \\
\hline \multicolumn{20}{|c|}{ Cadmium } \\
\hline 0.01 & 0.0 & 0.00 & 0.0 & 0.00 & 0.02 & 20.0 & 16.33 & 37.50 & 15.00 & 0.01 & 2.5 & 5.00 & 37.5 & 17.08 & 0.05 & 0.0 & 0.00 & 0.0 & 0.00 \\
\hline 2.10 & 0.0 & 0.00 & 0.0 & 0.00 & 8.08 & 5.0 & 5.77 & 27.50 & 48.56 & 16.8 & 0.0 & 0.00 & 12.5 & 15.00 & 19.7 & 25.0 & 25.17 & 60.0 & 16.33 \\
\hline 4.49 & 0.0 & 0.00 & 20.0 & 11.55 & 17.9 & 17.5 & 12.58 & 20.00 & 8.16 & 35.4 & 2.5 & 5.00 & 40.0 & 18.26 & 40.4 & 50.0 & 20.00 & 80.0 & 16.33 \\
\hline 9.69 & 0.0 & 0.00 & 30.0 & 8.16 & 37.8 & 10.0 & 11.54 & 25.00 & 10.00 & 75.5 & 5.0 & 10.00 & 50.0 & 21.60 & 80.4 & 60.0 & 16.33 & 75.0 & 25.17 \\
\hline 19.5 & 0.0 & 0.00 & 55.0 & 33.17 & 80.0 & 17.5 & 12.58 & 35.00 & 12.91 & 168 & 55.0 & 42.03 & 90.0 & 20.00 & 167 & 40.0 & 16.33 & 65.0 & 25.17 \\
\hline 47.2 & 0.0 & 0.00 & 32.5 & 5.00 & 186.5 & 2.5 & 5.00 & 40.00 & 11.55 & 355 & 10.0 & 11.55 & 85.0 & 17.32 & 368 & 55.0 & 25.17 & 90.0 & 11.55 \\
\hline NOEC & 47 & & 2.10 & & & 187 & & 187 & & & 355 & & 75 & & & 20 & & $<20$ & \\
\hline LOEC & $>47$ & & 4.49 & & & $>187$ & & $>187$ & & & $>355$ & & 168 & & & 40 & & 20 & \\
\hline Geomean & $\mathrm{NE}$ & & 3.07 & & & $N E$ & & $N E$ & & & $\mathrm{NE}$ & & 112 & & & 28 & & $<20$ & \\
\hline $\mathrm{LC} / \mathrm{EC} 10(\mathrm{CL})$ & $>47$ & & $\mathrm{NE}$ & & & $N E$ & & $N E$ & & & $\mathrm{NE}$ & & 29 & $(10-82)$ & & $\mathrm{NE}$ & & $\mathrm{NE}$ & \\
\hline $\mathrm{LC} / \mathrm{EC} 20(\mathrm{CL})$ & $>47$ & & NE & & & $N E$ & & $N E$ & & & $\mathrm{NE}$ & & 45 & $(20-97)$ & & $\mathrm{NE}$ & & NE & \\
\hline LC/EC50 (CL) & $>47$ & & $\mathrm{NE}$ & & & $>187$ & & $>187$ & & & $>355$ & & 103 & $(66-161)$ & & $\mathrm{NE}$ & & $\mathrm{NE}$ & \\
\hline \multicolumn{20}{|c|}{ Copper } \\
\hline 0.19 & 0.0 & 0.00 & 0.0 & 0.00 & 0.19 & 35.0 & 5.77 & 52.5 & 9.57 & 0.18 & 0.0 & 0.00 & 22.5 & 12.58 & 0.14 & 0.0 & 0.00 & 15.0 & 19.15 \\
\hline 1.43 & 2.5 & 5.00 & 7.5 & 9.57 & 4.31 & 42.5 & 12.58 & 62.5 & 9.57 & 2.50 & 7.5 & 9.57 & 20.0 & 8.16 & 2.84 & 0.0 & 0.00 & 30.0 & 25.82 \\
\hline 2.66 & 7.5 & 9.57 & 55.0 & 17.32 & 8.42 & 77.5 & 9.57 & 100.0 & 0.00 & 5.16 & 7.5 & 5.00 & 42.5 & 15.00 & 5.40 & 5.0 & 10.00 & 35.0 & 19.15 \\
\hline 5.29 & 7.5 & 9.57 & 90.0 & 14.14 & 16.9 & 95.0 & 10.00 & 100.0 & 0.00 & 10.4 & 30.0 & 8.17 & 95.0 & 10.00 & 10.7 & 5.0 & 10.00 & 55.0 & 10.00 \\
\hline 10.5 & 32.5 & 9.57 & 100.0 & 0.00 & 33.6 & 100.0 & 0.00 & 100.0 & 0.00 & 21.5 & 57.5 & 18.93 & 100.0 & 0.00 & 22.6 & 15.0 & 19.15 & 50.0 & 20.00 \\
\hline 23.6 & 32.5 & 9.57 & 100.0 & 0.00 & 76.8 & 100.0 & 0.00 & 100.0 & 0.00 & 48.7 & 97.5 & 5.00 & 100.0 & 0.00 & 49.8 & 35.0 & 25.17 & 60.0 & 16.33 \\
\hline NOEC & 5.3 & & 1.4 & & & 4.3 & & 4.3 & & & 5.2 & & 5.2 & & & 49.8 & & 5.4 & \\
\hline LOEC & 10.5 & & 2.7 & & & 8.4 & & 8.4 & & & 10.4 & & 10.4 & & & $>50$ & & 10.7 & \\
\hline Geomean & 7.5 & & 2.0 & & & 6.0 & & 6.0 & & & 7.3 & & 7.3 & & & $\mathrm{NE}$ & & 7.6 & \\
\hline $\mathrm{LC} / \mathrm{EC} 10(\mathrm{CL})$ & $\mathrm{NE}$ & & 1.5 & $(1.2-1.8)$ & & 3.4 & $(1.7-7.0)$ & 2.1 & $(0.7-5.8)$ & & 6.4 & $(4.3-9.5)$ & 4.2 & $(2.9-5.9)$ & & $\mathrm{NE}$ & & $\mathrm{NE}$ & \\
\hline LC/EC20 (CL) & $\mathrm{NE}$ & & 1.8 & $(1.5-2.1)$ & & 4.4 & $(2.5-7.7)$ & 2.7 & $(1.2-5.9)$ & & 8.9 & $(6.5-12.0)$ & 4.8 & $(3.7-6.3)$ & & $\mathrm{NE}$ & & $\mathrm{NE}$ & \\
\hline LC/EC50 (CL) & $>23.55$ & & 2.7 & $(2.3-3.1)$ & & 7.1 & $(5.0-10.1)$ & 4.3 & $(2.7-6.9)$ & & 16.4 & $(13.4-20.2)$ & 6.3 & $(5.3-7.6)$ & & $>50$ & & $\mathrm{NE}$ & \\
\hline & & & & & & & & & & Zinc & & & & & & & & & \\
\hline 1.29 & 2.5 & 5.00 & 2.5 & 5.00 & 1.4 & 30.0 & 14.14 & 37.5 & 15.00 & 1.44 & 0.00 & 0.00 & 17.5 & 9.57 & 2.18 & 0.0 & 0.00 & 5.0 & 10.00 \\
\hline 29.9 & 0.0 & 0.00 & 0.0 & 0.00 & 82.0 & 22.5 & 12.58 & 37.5 & 12.58 & 120 & 0.00 & 0.00 & 62.5 & 43.49 & 128 & 0.0 & 0.00 & 10.0 & 20.00 \\
\hline 59.5 & 0.0 & 0.00 & 0.0 & 0.00 & 157 & 5.0 & 5.77 & 12.5 & 9.57 & 242 & 0.00 & 0.00 & 12.5 & 15.00 & 261 & 10.0 & 11.55 & 50.0 & 11.55 \\
\hline 116 & 0.0 & 0.00 & 10.0 & 8.16 & 300 & 7.5 & 9.57 & 7.5 & 9.57 & 464 & 0.00 & 0.00 & 40.0 & 14.14 & 511 & 30.0 & 25.82 & 95.0 & 10.00 \\
\hline 225 & 0.0 & 0.00 & 100.0 & 0.00 & 558 & 7.5 & 5.00 & 15.0 & 10.00 & 900 & 0.00 & 0.00 & 85.0 & 5.77 & 968 & 40.0 & 28.28 & 80.0 & 40.00 \\
\hline 634 & 2.5 & 5.00 & 100.0 & 0.00 & 1,575 & 17.5 & 9.57 & 22.5 & 12.58 & 2,565 & 32.5 & 9.57 & 82.5 & 15.00 & 2,610 & 30.0 & 11.55 & 70.0 & 38.30 \\
\hline NOEC & 634 & & 116 & & & 1,575 & & 1,575 & & & 900 & & 464 & & & 968 & & 128 & \\
\hline LOEC & $>634$ & & 225 & & & $>1,575$ & & $>1,575$ & & & 2,565 & & 900 & & & 2,610 & & 261 & \\
\hline Geomean & $\mathrm{NE}$ & & 162 & & & $N E$ & & $>1,575$ & & & 1,519 & & 646 & & & 1,589 & & 183 & \\
\hline LC/EC10 (CL) & $>634$ & & 90 & $(84-98)^{3}$ & & $N E$ & & $N E$ & & & 1,723 & $(1,085-2,737)^{3}$ & $\mathrm{NE}$ & & & $\mathrm{NE}$ & & $\mathrm{NE}$ & \\
\hline $\mathrm{LC} / \mathrm{EC} 20(\mathrm{CL})$ & $>634$ & & 126 & $(119-133)^{3}$ & & $N E$ & & $N E$ & & & 2,142 & $(1,724-2,662)^{3}$ & $\mathrm{NE}$ & & & $\mathrm{NE}$ & & NE & \\
\hline LC/EC50 (CL) & $>634$ & & 147 & $(134-160)^{3}$ & & $>1,575$ & & $>1,575$ & & & 3,109 & $(2,499-3,868)^{3}$ & $\mathrm{NE}$ & & & $>2,610$ & & NE & \\
\hline
\end{tabular}


Table A-2. Mortality and effective mortality (mortality plus loss of equilibrium and immobilization) $(n=4)$ of white sturgeon (Acipenser transmontanus) in 4-day acute tests by round.-Continued

[Yellow shading indicates significant reduction from the control (Dunnett's test or Steel's Many-Rank test; $p<0.05$ ). Acute value (geometric mean [Geomean] of NOEC and LOEC), EC10, EC20, and EC50 with 95-percent confidence limits (CL) are presented for each endpoint. Values in red (bold italic) were calculated based on data with low control survival and the results should be used with caution. $n$, sample size; dph, days-post-hatch; $\mu \mathrm{g} / \mathrm{L}$, microgram per liter; \%, percent; SD, standard deviation; Mort+LOE+IM, mortality plus loss of equilibrium and immobilization; NOEC, no-observed-effect concentration; $<$, less than; LOEC, lowest-observed-effect concentration; >, greater than; NE, not estimated because the data do not meet the conditions of a probit analysis or logistic regression; LC/EC10, 10-percent lethal or effect concentration; LC/EC20, 20-percent lethal or effect concentration; LC/EC50, 50-percent lethal or effect concentration]

\begin{tabular}{|c|c|c|c|c|c|c|c|c|c|c|c|c|c|c|}
\hline \multicolumn{5}{|c|}{$\begin{array}{l}\text { Round } 5 \\
61 \mathrm{dph} \\
\end{array}$} & \multicolumn{5}{|c|}{$\begin{array}{l}\text { Round } 6 \\
72 \mathrm{dph}\end{array}$} & \multicolumn{5}{|c|}{$\begin{array}{l}\text { Round } 7 \\
89 \mathrm{dph}\end{array}$} \\
\hline \multirow{2}{*}{$\begin{array}{c}\text { Measured } \\
\text { concentration } \\
(\mu \mathrm{g} / \mathrm{L})\end{array}$} & \multicolumn{2}{|c|}{ Mortality (\%) } & \multicolumn{2}{|c|}{$\begin{array}{l}\text { Effective mortality (\%) } \\
\text { Mort+LOE+IM }\end{array}$} & \multirow{2}{*}{$\begin{array}{c}\text { Measured } \\
\text { concentration } \\
(\mu \mathrm{g} / \mathrm{L})\end{array}$} & \multicolumn{2}{|c|}{ Mortality (\%) } & \multicolumn{2}{|c|}{$\begin{array}{l}\text { Effective mortality (\%) } \\
\text { Mort+LOE+IM }\end{array}$} & \multirow{2}{*}{$\begin{array}{c}\text { Measured } \\
\text { concentration } \\
(\mu \mathrm{g} / \mathrm{L})\end{array}$} & \multicolumn{2}{|c|}{ Mortality (\%) } & \multicolumn{2}{|c|}{$\begin{array}{l}\text { Effective mortality }(\%) \\
\text { Mort+LOE+IM }\end{array}$} \\
\hline & Mean & SD & Mean & SD & & Mean & SD & Mean & SD & & Mean & $\mathbf{S D}^{4}$ & Mean & $\mathbf{S D}^{4}$ \\
\hline \multicolumn{15}{|c|}{ Cadmium } \\
\hline 0.02 & 0.0 & 0.00 & 0.0 & 0.00 & 0.02 & 0.0 & 0.00 & 0.0 & 0.00 & 0.02 & 0.0 & 0.00 & 8.3 & 23.57 \\
\hline 34.4 & 70.0 & 11.55 & 95.0 & 10.00 & 8.99 & 0.0 & 0.00 & 75.0 & 25.17 & 17.2 & 16.7 & 35.64 & 79.2 & 30.54 \\
\hline 63.5 & 70.0 & 20.00 & 100.0 & 0.00 & 17.7 & 10.0 & 20.00 & 95.0 & 10.00 & 33.2 & 25.0 & 23.57 & 83.3 & 35.63 \\
\hline 138 & 60.0 & 16.33 & 90.0 & 20.00 & 37.0 & 20.0 & 16.33 & 100.0 & 0.00 & 69.3 & 20.8 & 17.25 & 95.8 & 11.79 \\
\hline 276 & 65.0 & 25.17 & 100.0 & 0.00 & 71.9 & 20.0 & 28.28 & 100.0 & 0.00 & 126 & 41.7 & 29.55 & 91.7 & 23.57 \\
\hline 575 & 80.0 & 16.33 & 100.0 & 0.00 & 150 & 30.0 & 34.64 & 100.0 & 0.00 & 274 & 41.7 & 42.73 & 100.0 & 0.00 \\
\hline NOEC & $<34$ & & $<34$ & & & 150 & & $<9$ & & & 274 & & $<17$ & \\
\hline LOEC & 34 & & 34 & & & $>150$ & & 9 & & & $>274$ & & 17 & \\
\hline Geomean & $<34$ & & $<34$ & & & $\mathrm{NE}$ & & $<9$ & & & $\mathrm{NE}$ & & $<17$ & \\
\hline LC/EC10 (CL) & $<34$ & & $<34$ & & & $\mathrm{NE}$ & & $<9$ & & & $\mathrm{NE}$ & & $\mathrm{NE}$ & \\
\hline LC/EC20 (CL) & $<34$ & & $<34$ & & & NE & & $<9$ & & & $\mathrm{NE}$ & & $\mathrm{NE}$ & \\
\hline LC/EC50 (CL) & $\mathrm{NE}$ & & $<34$ & & & $>150$ & & 6 & ${ }^{5}(3-11)$ & & $>274$ & & $<17$ & \\
\hline \multicolumn{15}{|c|}{ Copper } \\
\hline 0.15 & 0.0 & 0.00 & 0.0 & 0.00 & 0.17 & 0.0 & 0.00 & 0.0 & 0.00 & 0.16 & 0.0 & 0.00 & 0.0 & 0.00 \\
\hline 7.46 & 0.0 & 0.00 & 0.0 & 0.00 & 8.06 & 5.0 & 10.00 & 75.0 & 10.00 & 13.2 & 8.3 & 15.43 & 41.7 & 34.50 \\
\hline 18.2 & 10.0 & 20.00 & 10.0 & 20.00 & 21.9 & 0.0 & 0.00 & 45.0 & 30.00 & 30.8 & 0.0 & 0.00 & 41.7 & 42.72 \\
\hline 44.1 & 0.0 & 0.00 & 80.0 & 16.33 & 44.3 & 0.0 & 0.00 & 50.0 & 20.00 & 63.0 & 8.3 & 15.43 & 91.7 & 15.43 \\
\hline 90.2 & 90.0 & 11.55 & 100.0 & 0.00 & 86.4 & 80.0 & 16.33 & 100.0 & 0.00 & 124 & 91.7 & 15.43 & 100.0 & 0.00 \\
\hline 130 & 100.0 & 0.00 & 100.0 & 0.00 & 183 & 100.0 & 0.00 & 100.0 & 0.00 & 256 & 100.0 & 0.00 & 100.0 & 0.00 \\
\hline NOEC & 44 & & 18 & & & 44 & & 22 & & & 63 & & 31 & \\
\hline LOEC & 90 & & 44 & & & 86 & & 44 & & & 124 & & 63 & \\
\hline Geomean & 63 & & 28 & & & 62 & & 31 & & & 88 & & 44 & \\
\hline LC/EC10 (CL) & $<90$ & & 18 & $(13-26)$ & & 57 & ${ }^{5}(34-96)$ & $\mathrm{NE}$ & & & 67 & $(51-89)$ & 7 & ${ }^{5}(3-14)$ \\
\hline LC/EC20 (CL) & $<90$ & & 22 & $(17-29)$ & & 62 & $5(42-93)$ & $\mathrm{NE}$ & & & 75 & $(60-93)$ & 10 & ${ }^{5}(6-17)$ \\
\hline LC/EC50 (CL) & $<90$ & & 31 & $(25-38)$ & & 74 & ${ }^{5}(60-90)$ & $\mathrm{NE}$ & & & 90 & (77-108) & 22 & ${ }^{5}(16-30)$ \\
\hline \multicolumn{15}{|c|}{ Zinc } \\
\hline 0.5 & 0.0 & 0.00 & 0.0 & 0.00 & 0.50 & 0.0 & 0.00 & 0.0 & 0.00 & 0.78 & 0.0 & 0.00 & 0.00 & 0.00 \\
\hline 253 & 10.0 & 11.55 & 100.0 & 0.00 & 391 & 45.0 & 10.00 & 70.0 & 25.82 & 586 & 37.5 & 37.53 & 100.0 & 0.00 \\
\hline 539 & 60.0 & 16.33 & 90.0 & 20.00 & 810 & 35.0 & 10.00 & 70.0 & 11.55 & 1,210 & 37.5 & 27.82 & 100.0 & 0.00 \\
\hline 1,070 & 70.0 & 20.00 & 95.0 & 10.00 & 1,645 & 45.0 & 37.86 & 85.0 & 19.15 & 2,415 & 45.8 & 35.36 & 100.0 & 0.00 \\
\hline 2,125 & 65.0 & 30.00 & 100.0 & 0.00 & 3,275 & 30.0 & 11.55 & 70.0 & 11.55 & 4,715 & 12.5 & 17.25 & 100.0 & 0.00 \\
\hline 4,295 & 50.0 & 25.82 & 100.0 & 0.00 & 6,365 & 60.0 & 0.00 & 95.0 & 10.00 & 9,330 & 100.0 & 0.00 & 100.0 & 0.00 \\
\hline NOEC & 253 & & $<253$ & & & $<391$ & & $<391$ & & & 4,715 & & $<586$ & \\
\hline LOEC & 539 & & 253 & & & 391 & & 391 & & & 9,330 & & 586 & \\
\hline Geomean & 369 & & $<253$ & & & $<391$ & & $<391$ & & & 6,633 & & $<586$ & \\
\hline LC/EC10 (CL) & $\mathrm{NE}$ & & $<253$ & & & $\mathrm{NE}$ & & $<391$ & & & $\mathrm{NE}$ & & $<586$ & \\
\hline LC/EC20 (CL) & $\mathrm{NE}$ & & $<253$ & & & $\mathrm{NE}$ & & $<391$ & & & $\mathrm{NE}$ & & $<586$ & \\
\hline LC/EC50 (CL) & $\mathrm{NE}$ & & $<253$ & & & $\mathrm{NE}$ & & $<391$ & & & $<9,330$ & & $<586$ & \\
\hline
\end{tabular}

'Control survival for the 16 -dph test was less than 90 percent, thus the EC50 calculation is nondefinitive.

${ }^{2}$ Measured metal concentrations during round 1 zinc exposure and all exposures during round 4 are from day 4 measurements only (see appendix 3 ).

${ }^{3}$ Values are estimated based on data with only one partial kill.

${ }^{4} n=8$.

${ }^{5}$ Values are estimated based on data with only one partial kill. 
Table A-3. Mortality and effective mortality (mortality plus loss of equilibrium and immobilization) ( $n=4$ ) of rainbow trout (Oncorhynchus mykiss) in 4-day acute tests by round.

[Yellow shading indicates significant reduction from the control (Dunnett's test or Steel's Many-Rank test; $p<0.05$ ). Acute value (geometric mean [Geomean] of NOEC and LOEC), EC10, EC20, and EC50 with 95-percent confidence limits (CL) are presented for each endpoint. $n$, sample size; dph, days-post-hatch; $\mu \mathrm{g} / \mathrm{L}$, microgram per liter; \%, percent; SD, standard deviation; Mort+LOE+IM, mortality plus loss of equilibrium and immobilization; NE, not estimated because the data do not meet requirements for probit analysis or logistic regression; NOEC, no-observed-effect concentration; LOEC, lowest-observed-effect concentration; >, greater than; LC/EC10, 10-percent lethal or effect concentration; LC/EC20, 20-percent lethal or effect concentration; LC/EC50, 50-percent lethal or effect concentration; <, less than; NM; not measured]

\begin{tabular}{|c|c|c|c|c|c|c|c|c|c|c|c|c|c|}
\hline \multirow{2}{*}{$\begin{array}{l}\text { Measured } \\
\text { concentration } \\
(\mu \mathrm{g} / \mathrm{L})\end{array}$} & \multicolumn{2}{|c|}{ Mortality (\%) } & \multirow{2}{*}{$\begin{array}{c}\text { Measured } \\
\text { concentration } \\
(\mu \mathrm{g} / \mathrm{L})\end{array}$} & \multicolumn{2}{|c|}{ Mortality (\%) } & \multirow{2}{*}{$\begin{array}{c}\text { Measured } \\
\text { concentration } \\
(\mu \mathrm{g} / \mathrm{L})\end{array}$} & \multicolumn{2}{|c|}{ Mortality (\%) } & \multirow{2}{*}{$\begin{array}{c}\text { Measured } \\
\text { concentration } \\
(\mu \mathrm{g} / \mathrm{L})\end{array}$} & \multicolumn{2}{|c|}{ Mortality (\%) } & \multicolumn{2}{|c|}{$\begin{array}{l}\text { Effective mortality (\%) } \\
\text { Mort+LOE+IM }\end{array}$} \\
\hline & Mean & SD & & Mean & SD & & Mean & SD & & Mean & SD & Mean & SD \\
\hline \multicolumn{14}{|c|}{ Cadmium } \\
\hline 0.01 & 0.0 & 0.00 & 0.01 & 0.0 & 0.00 & 0.01 & 0.0 & 0.00 & 0.01 & 0.0 & 0.00 & $\mathrm{NE}$ & $\mathrm{NE}$ \\
\hline 2.49 & 0.0 & 0.00 & 1.30 & 2.5 & 5.00 & 1.26 & 0.0 & 0.00 & 2.44 & 15.0 & 12.91 & NE & NE \\
\hline 5.33 & 0.0 & 0.00 & 2.67 & 20.0 & 14.14 & 2.59 & 5.0 & 10.00 & 4.86 & 87.5 & 9.57 & $\mathrm{NE}$ & $\mathrm{NE}$ \\
\hline 10.8 & 0.0 & 0.00 & 5.42 & 100.0 & 0.00 & 5.32 & 57.5 & 17.08 & 9.51 & 100.0 & 0.00 & $\mathrm{NE}$ & $\mathrm{NE}$ \\
\hline 22.2 & 0.0 & 0.00 & 11.0 & 100.0 & 0.00 & 10.8 & 100.0 & 0.00 & 20.3 & 100.0 & 0.00 & $\mathrm{NE}$ & $\mathrm{NE}$ \\
\hline 49.4 & 0.0 & 0.00 & 24.1 & 100.0 & 0.00 & 23.8 & 100.0 & 0.00 & 43.2 & 100.0 & 0.00 & $\mathrm{NE}$ & $\mathrm{NE}$ \\
\hline NOEC & 49 & & & 1.30 & & & 2.59 & & & 2.44 & & $\mathrm{NE}$ & NE \\
\hline LOEC & $>49$ & & & 2.67 & & & 5.32 & & & 4.86 & & $\mathrm{NE}$ & $\mathrm{NE}$ \\
\hline Geomean & $\mathrm{NE}$ & & & 1.86 & & & 3.71 & & & 3.44 & & $\mathrm{NE}$ & $\mathrm{NE}$ \\
\hline $\mathrm{LC} / \mathrm{EC} 10(\mathrm{CL})$ & $>49$ & & & $\mathrm{NE}$ & & & 3.09 & $(2.54-3.76)$ & & 0.84 & $(0.42-1.67)$ & NE & $\mathrm{NE}$ \\
\hline LC/EC20 (CL) & $>49$ & & & $\mathrm{NE}$ & & & 3.60 & $(3.08-4.21)$ & & 1.26 & $(0.74-2.15)$ & $\mathrm{NE}$ & $\mathrm{NE}$ \\
\hline LC/EC50 (CL) & $>49$ & & & 2.89 & ${ }^{2}(2.22-3.75)$ & & 4.83 & $(4.28-5.44)$ & & 2.77 & $(2.05-3.73)$ & NE & NE \\
\hline \multicolumn{14}{|c|}{ Copper } \\
\hline 0.14 & 0.0 & 0.00 & 0.12 & 0.0 & 0.00 & 0.23 & 0.0 & 0.00 & 0.26 & 0.0 & 0.00 & 0.0 & 0.00 \\
\hline 11.0 & 0.0 & 0.00 & 11.2 & 0.0 & 0.00 & 10.8 & 2.5 & 5.00 & 14.7 & 2.5 & 5.00 & 2.5 & 5.00 \\
\hline 21.8 & 0.0 & 0.00 & 21.9 & 0.0 & 0.00 & 22.4 & 0.0 & 0.00 & 29.9 & 7.5 & 15.00 & 22.5 & 18.93 \\
\hline 43.3 & 7.5 & 9.57 & 43.6 & 20.0 & 18.26 & 44.2 & 20.0 & 8.17 & 59.6 & 57.5 & 9.57 & 60.0 & 14.14 \\
\hline 87.7 & 90.0 & 11.55 & 88.5 & 92.5 & 5.00 & 89.2 & 87.5 & 15.00 & 121 & 85.0 & 17.32 & 90.0 & 8.16 \\
\hline 196 & 100.0 & 0.00 & 193 & 100.0 & 0.00 & 201 & 100.0 & 0.00 & 263 & 100.0 & 0.00 & 100.0 & 0.00 \\
\hline NOEC & 43 & & & 44 & & & 22 & & & 30 & & 15 & \\
\hline LOEC & 88 & & & 89 & & & 44 & & & 60 & & 30 & \\
\hline Geomean & 62 & & & 62 & & & 31 & & & 42 & & 21 & \\
\hline LC/EC10 (CL) & 45 & $(39-53)$ & & 38 & $(32-45)$ & & 39 & $(31-48)$ & & 21 & $(15-28)$ & 18 & $(13-25)$ \\
\hline LC/EC20 (CL) & 51 & $(44-58)$ & & 44 & $(38-50)$ & & 45 & $(38-53)$ & & 30 & $(23-38)$ & 26 & $(20-33)$ \\
\hline $\mathrm{LC} / \mathrm{EC} 50(\mathrm{CL})$ & 63 & $(57-70)$ & & 57 & $(51-64)$ & & 60 & $(53-68)$ & & 59 & $(49-71)$ & 50 & $(42-60)$ \\
\hline \multicolumn{14}{|c|}{ Zinc } \\
\hline 1.07 & 0.0 & 0.00 & 0.93 & 0.0 & 0.00 & 0.88 & 0.0 & 0.00 & 1.01 & 0.0 & 0.00 & 0.0 & 0.00 \\
\hline 30.3 & 0.0 & 0.00 & 57.5 & 0.0 & 0.00 & 58.3 & 0.0 & 0.00 & 112 & 2.5 & 5.00 & 2.5 & 5.00 \\
\hline 57.7 & 0.0 & 0.00 & 111 & 2.5 & 5.00 & 114 & 0.0 & 0.00 & 216 & 40.0 & 8.17 & 40.0 & 8.16 \\
\hline 109 & 0.0 & 0.00 & 217 & 37.5 & 5.00 & 216 & 7.5 & 5.00 & 410 & 75.0 & 20.82 & 80.0 & 18.26 \\
\hline 192 & 0.0 & 0.00 & 386 & 82.5 & 9.57 & 388 & 42.5 & 32.02 & 729 & 87.5 & 12.58 & 90.0 & 14.14 \\
\hline 571 & 0.0 & 0.00 & 1,120 & 100.0 & 0.00 & 1,140 & 95.0 & 5.77 & 2,220 & 100.0 & 0.00 & 100.0 & 0.00 \\
\hline NOEC & 571 & & & 111 & & & 216 & & & 112 & & 112 & \\
\hline LOEC & $>571$ & & & 217 & & & 388 & & & 216 & & 216 & \\
\hline Geomean & $\mathrm{NE}$ & & & 155 & & & 289 & & & 156 & & 156 & \\
\hline $\mathrm{LC} / \mathrm{EC} 10(\mathrm{CL})$ & $>571$ & & & 145 & $(117-180)$ & & 228 & $(183-284)$ & & 92 & $(66-164)$ & 89 & $(60-130)$ \\
\hline LC/EC20 (CL) & $>571$ & & & 176 & (149-207) & & 288 & (241-344) & & 135 & $(101-181)$ & 129 & $(97-174)$ \\
\hline LC/EC50 (CL) & $>571$ & & & 253 & $(223-287)$ & & 449 & $(381-529)$ & & 282 & $(233-341)$ & 267 & $(221-323)$ \\
\hline
\end{tabular}


Table A-3. Mortality and effective mortality (mortality plus loss of equilibrium and immobilization) $(n=4)$ of rainbow trout (Oncorhynchus mykiss) in 4-day acute tests by round.-Continued

[Yellow shading indicates significant reduction from the control (Dunnett's test or Steel's Many-Rank test; $p<0.05$ ). Acute value (geometric mean [Geomean] of NOEC and LOEC), EC10, EC20, and EC50 with 95-percent confidence limits (CL) are presented for each endpoint. $n$, sample size; dph, days-post-hatch; $\mu \mathrm{g} / \mathrm{L}$, microgram per liter; \%, percent; SD, standard deviation; Mort+LOE+IM, mortality plus loss of equilibrium and immobilization; NE, not estimated because the data do not meet requirements for probit analysis or logistic regression; NOEC, no-observed-effect concentration; LOEC, lowest-observed-effect concentration; >, greater than; LC/EC10, 10-percent lethal or effect concentration; LC/EC20, 20-percent lethal or effect concentration; LC/EC50, 50-percent lethal or effect concentration; <, less than; NM; not measured]

\begin{tabular}{|c|c|c|c|c|c|c|c|c|c|c|}
\hline \multicolumn{5}{|c|}{$\begin{array}{c}\text { Round 5 } \\
60 \mathrm{dph}\end{array}$} & \multicolumn{3}{|c|}{$\begin{array}{l}\text { Round } 6 \\
74 \mathrm{dph}\end{array}$} & \multicolumn{3}{|c|}{$\begin{array}{l}\text { Round } 7 \\
95 \mathrm{dph}\end{array}$} \\
\hline \multirow{2}{*}{$\begin{array}{c}\text { Measured } \\
\text { concentration } \\
(\mu \mathrm{g} / \mathrm{L})\end{array}$} & \multicolumn{2}{|c|}{ Mortality (\%) } & \multicolumn{2}{|c|}{ Effective mortality (\%) Mort+LOE+IM } & \multirow{2}{*}{$\begin{array}{c}\text { Measured } \\
\text { concentration } \\
(\mu \mathrm{g} / \mathrm{L})\end{array}$} & \multicolumn{2}{|c|}{ Mortality (\%) } & \multirow{2}{*}{$\begin{array}{c}\text { Measured } \\
\text { concentration } \\
(\mu \mathrm{g} / \mathrm{L})\end{array}$} & \multicolumn{2}{|c|}{ Mortality (\%) } \\
\hline & Mean & SD & Mean & SD & & Mean & SD & & Mean & $\mathbf{S D}^{4}$ \\
\hline & & & & & Cadmium & & & & & \\
\hline 0.06 & 0.0 & 0.00 & 0.0 & 0.00 & 0.04 & 0.0 & 0.00 & 0.02 & 0.0 & 0.00 \\
\hline 1.40 & 0.0 & 0.00 & 5.0 & 5.77 & 0.63 & 0.0 & 0.00 & 1.36 & 0.0 & 0.00 \\
\hline 2.70 & 17.5 & 15.00 & 25.0 & 12.91 & 1.29 & 0.0 & 0.00 & 2.73 & 28.1 & 15.73 \\
\hline 6.00 & 92.5 & 9.57 & 95.0 & 10.00 & 2.71 & 0.0 & 0.00 & 5.43 & 100.0 & 0.00 \\
\hline NM & 100.0 & 0.00 & 100.0 & 0.00 & 4.93 & 70.0 & 16.33 & 10.3 & 100.0 & 0.00 \\
\hline NM & 100.0 & 0.00 & 100.0 & 0.00 & 10.9 & 100.0 & 0.00 & 22.3 & 100.0 & 0.00 \\
\hline NOEC & 2.70 & & 1.40 & & & 2.71 & & & 1.36 & \\
\hline LOEC & 6.00 & & 2.70 & & & 4.93 & & & 2.73 & \\
\hline Geomean & 4.02 & & 1.94 & & & 3.66 & & & 1.93 & \\
\hline LC/EC10 (CL) & 2.42 & $(2.02-2.90)$ & 1.31 & $(0.90-1.91)$ & & 3.67 & $(2.65-5.07)$ & & 2.41 & $(1.42-4.07)$ \\
\hline LC/EC20 (CL) & 2.80 & $(2.42-3.25)$ & 1.83 & $(1.40-2.40)$ & & 3.95 & $(3.13-5.98)$ & & 2.58 & $(2.05-3.25)$ \\
\hline LC/EC50 (CL) & 3.71 & $(3.27-4.19)$ & 3.48 & $(2.84-4.26)$ & & 4.54 & $(4.10-5.03)$ & & 2.96 & $(2.19-4.01)$ \\
\hline & & & & & Copper & & & & & \\
\hline 0.24 & 0.0 & 0.00 & 0.0 & 0.00 & 0.32 & 0.0 & 0.00 & 0.68 & 7.5 & 9.57 \\
\hline 16.3 & 7.5 & 9.57 & 7.5 & 9.57 & 15.0 & 0.0 & 0.00 & 20.1 & 52.5 & 15.00 \\
\hline 32.0 & 35.0 & 19.15 & 40.0 & 18.26 & 29.8 & 2.5 & 5.00 & 37.9 & 100.0 & 0.00 \\
\hline 70.4 & 80.0 & 8.17 & 80.0 & 8.16 & 61.3 & 50.0 & 8.17 & 85.2 & 100.0 & 0.00 \\
\hline 141 & 92.5 & 5.00 & 92.5 & 5.00 & 93.6 & 100.0 & 0.00 & 161 & 100.0 & 0.00 \\
\hline $\mathrm{NM}$ & 100.0 & 0.00 & 100.0 & 100.00 & 226 & 100.0 & 0.00 & 348 & 100.0 & 0.00 \\
\hline NOEC & 16 & & 16 & & & 30 & & & $<20$ & \\
\hline LOEC & 32 & & 32 & & & 61 & & & 20 & \\
\hline Geomean & 23 & & 23 & & & 43 & & & $<20$ & \\
\hline LC/EC10 (CL) & 14 & $(9-21)$ & 14 & $(9-21)$ & & 46 & $(37-57)$ & & 8 & ${ }^{5}(5-14)$ \\
\hline $\mathrm{LC} / \mathrm{EC} 20(\mathrm{CL})$ & 20 & $(15-27)$ & 20 & $(15-27)$ & & 50 & $(42-60)$ & & 11 & ${ }^{5}(7-17)$ \\
\hline LC/EC50 (CL) & 42 & $(35-52)$ & 41 & $(35-50)$ & & 60 & $(55-66)$ & & 19 & ${ }^{5}(16-23)$ \\
\hline & & & & & Zinc & & & & & \\
\hline 1.30 & 0.0 & 0.00 & 0.00 & 0.00 & 1.29 & 0.0 & 0.00 & 0.78 & 0.0 & 0.00 \\
\hline 119 & 10.0 & 11.55 & 10.00 & 11.55 & 57.6 & 0.0 & 0.00 & 106 & 0.0 & 0.00 \\
\hline 236 & 40.0 & 24.50 & 50.00 & 24.49 & 104 & 2.5 & 5.00 & 211 & 43.8 & 12.50 \\
\hline 465 & 87.5 & 9.57 & 95.00 & 5.77 & 202 & 20.0 & 0.00 & 409 & 96.9 & 6.25 \\
\hline NM & 100.0 & 0.00 & 100.00 & 0.00 & 399 & 55.0 & 12.91 & 785 & 100.0 & 0.00 \\
\hline NM & 100.0 & 0.00 & 100.00 & 0.00 & 839 & 95.0 & 5.77 & 1,780 & 100.0 & 0.00 \\
\hline NOEC & 119 & & 119.00 & & & 104 & & & 106 & \\
\hline LOEC & 236 & & 236.00 & & & 202 & & & 211 & \\
\hline Geomean & 168 & & 167.58 & & & 145 & & & 149 & \\
\hline $\mathrm{LC} / \mathrm{EC} 10(\mathrm{CL})$ & 68 & (33-141) & 119.00 & & & 162 & $(128-206)$ & & 152 & $(122-188)$ \\
\hline LC/EC20 (CL) & 109 & $(68-176)$ & $>119$ & & & 210 & (174-254) & & 174 & $(148-206)$ \\
\hline LC/EC50 (CL) & 268 & $(207-349)$ & 223.79 & $(177-282)$ & & 346 & $(297-403)$ & & 228 & $(200-259)$ \\
\hline
\end{tabular}

'Effective mortality (EC50) was measured in rounds 4 and 5 only due to the presence of sublethal effects (loss of equilibrium and immobilization).

${ }^{2}$ Values are estimated based on data with only one partial kill.

${ }^{3}$ Measured metal concentrations during round 5 are from day 4 measurements only (see appendix 4 and 5 ).

${ }^{4} n=8$.

sValues are estimated based on data with only one partial kill. 
obtained in the study were compared to 2 times the CMC. The reason for comparing test values to 2 times the $\mathrm{CMC}$ instead of directly to the CMC may not be intuitive, and takes some explanation. In U.S. Environmental Protection Agency criteria derivation, 2 times the $\mathrm{CMC}$ is the same as the final acute value (FAV). The FAV effectively is an EC50 that represents a hypothetical species with sensitivity equal to the 5 th percentile of the species sensitivity distribution (SSD). The SSD, despite the common use of the word species, is calculated from the rank ordered distribution of all available genus mean acute values (Stephan, 2002). In the criteria development, the FAV is divided by two in order to extrapolate from a concentration that would likely be extremely harmful to sensitive species in short-term exposures (kill 50 percent of the population) to a concentration expected to kill few, if any, individuals (Stephan and others, 1985; Stephan, 2002). To maintain a consistent basis for comparison (test EC50s as compared to the EC50 representing the 5 th percentile most sensitive species), test EC50s were compared with 2 times the CMC.

Acute EC50s were compared to the FAVs used to develop acute WQC or the FAVs used to develop the Washington State acute WQS to determine if effect concentrations for white sturgeon and rainbow trout were below the nationally recommended WQC or Washington State WQS.

\section{Results}

Water quality measurements are summarized in appendix table 1-2. Water temperature during the exposures was consistently $\pm 1{ }^{\circ} \mathrm{C}$ of the required test temperature for each species (table A-1). Concentrations of ammonia and dissolved oxygen were within acceptable limits throughout all of the exposures for each metal at each life stage for each species (American Society for Testing and Materials, 2012a, b, c). Total ammonia concentration was $<0.34 \mathrm{mg}$ nitrogen $(\mathrm{N}) / \mathrm{L}$ during all exposures for each species, and mean dissolved oxygen concentrations during all metal exposures ranged from 8.5 to $9.7 \mathrm{mg} / \mathrm{L}$ in the sturgeon tests and from 8.7 to $10.8 \mathrm{mg} / \mathrm{L}$ in the trout tests (appendix table 1-2). Water temperature, $\mathrm{pH}$, conductivity, hardness, and alkalinity remained consistent throughout the duration of the individual tests for the sturgeon and trout exposures (appendix table 1-2). The major cation and anion concentrations remained consistent throughout the exposures for all life stages tested for each species (appendix tables 1-3 and 1-4). The analyses for DOC were done in-house and also by Huffman Laboratory (Golden, Colo.). Because of instrument bias and differences in method detection limits between laboratory analyses, the DOC concentration of the test waters in the study was based on an estimated concentration of $0.4 \mathrm{mg} / \mathrm{L}$ (appendix 6).

Chemical analyses for copper, cadmium, and zinc indicated that mean concentrations of each metal typically ranged from 80 to 120 percent of the nominal concentrations for the acute exposures for each species (appendix tables 1-5 and
1-6). The mean metal concentrations were calculated using test day 0 and test day 4 values for each exposure. During round 4 of the sturgeon exposures and round 5 of the trout exposures, measured concentrations were below 80 percent of the nominal concentrations on test day 0 ; therefore, only the test day 4 measured concentrations were used for calculation of the acute effect concentrations for round 4 of the sturgeon exposures and round 5 of the trout exposures (appendix tables 1-5 and 1-6). Across all rounds of acute tests the mean relative percent change between concentrations measured on test day 4 to that of test day 0 for treatments 1 through 5 ranged as follows: Sturgeon exposures $-\mathrm{Cu},+8$ to +18 percent; $\mathrm{Cd}$, +6 to +28 percent; $\mathrm{Zn},+15$ to +31 percent; Trout exposures $-\mathrm{Cu},+4$ to +17 percent; $\mathrm{Cd},-3$ to +3 percent; $\mathrm{Zn},+7$ to +12 percent.

\section{White Sturgeon Exposures}

There was no mortality in the control treatments during the 4-d exposures across each life stage for each metal exposure, except for exposures started with 16-dph sturgeon. Sturgeon mortality in the control treatments during exposures started with 16-dph fish was 20 percent for the cadmium exposure, 35 percent for the copper exposure, and 30 percent for the zinc exposure (table A-2) and thus greater than the test acceptability requirement of 10 percent (U.S. Geological Survey, 2010). Hence, the LC50 and EC50 for the 16-dph sturgeon were classified as nondefinitive effect concentrations.

Metal toxicity varied across life stages as reflected by the mortality, loss of equilibration, and immobilization toxicity endpoints (fig. A-1). The EC50s proved to be a more sensitive toxicity endpoint where loss of equilibrium and immobilization in addition to mortality were used to estimate effect concentrations (fig. A-1; tables A4 to A6). Of the surviving individuals from each metal exposure, loss of equilibrium or immobilization generally increased with increasing metal concentration by test day 4 (fig. A-1).

Sturgeon exposed to cadmium exhibited increased sensitivity at later stages of development with the most sensitive life stage being $72 \mathrm{dph}$ with an EC50 of $5.61 \mu \mathrm{g} \mathrm{Cd} / \mathrm{L}$, whereas the LC50 was estimated to be $>149.5 \mu \mathrm{g} \mathrm{Cd} / \mathrm{L}$ (table A-4). The percentage of sturgeon exhibiting the loss of equilibrium and immobilization tended to increase with increasing concentration (fig. A-2). The most prevalent consequence of cadmium exposure was immobilization and loss of equilibrium. Immobilization was evident as fish lying without motion on their sides during the 5-minute observation and had to be prodded to confirm they were still alive. Loss of equilibrium also was evident as fish swimming on their sides or upside down in the test chambers during 5-minute observations (for example, see video 1 in appendix 1). At $72 \mathrm{dph}$, the LOEC based on immobilization, loss of equilibrium, and mortality was $9 \mu \mathrm{g} \mathrm{Cd} / \mathrm{L}$ and the NOEC was estimated to be $<9 \mu \mathrm{g} \mathrm{Cd} / \mathrm{L}$ (table A-2). 

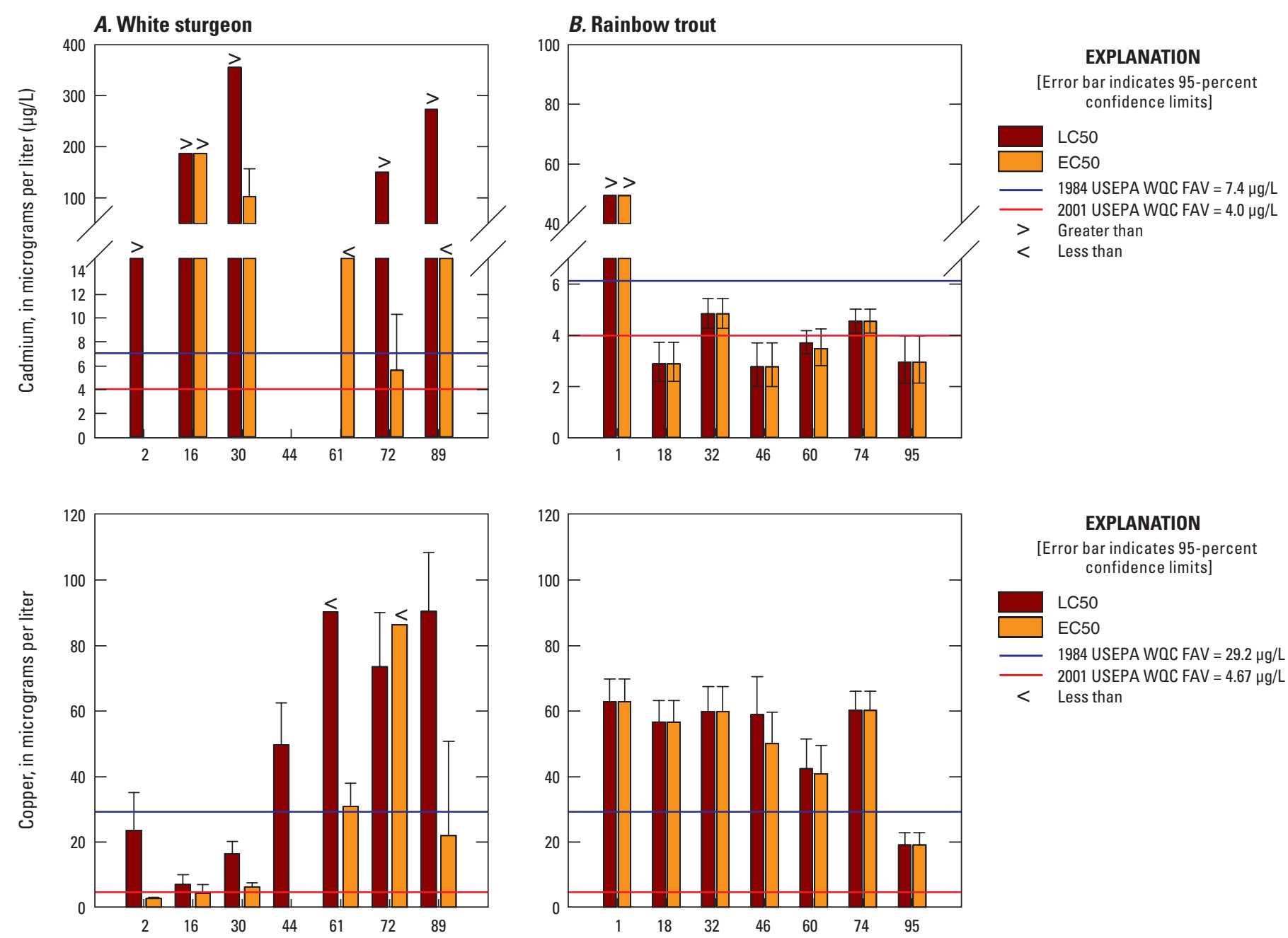

\section{EXPLANATION}

[Error bar indicates 95-percent confidence limits]
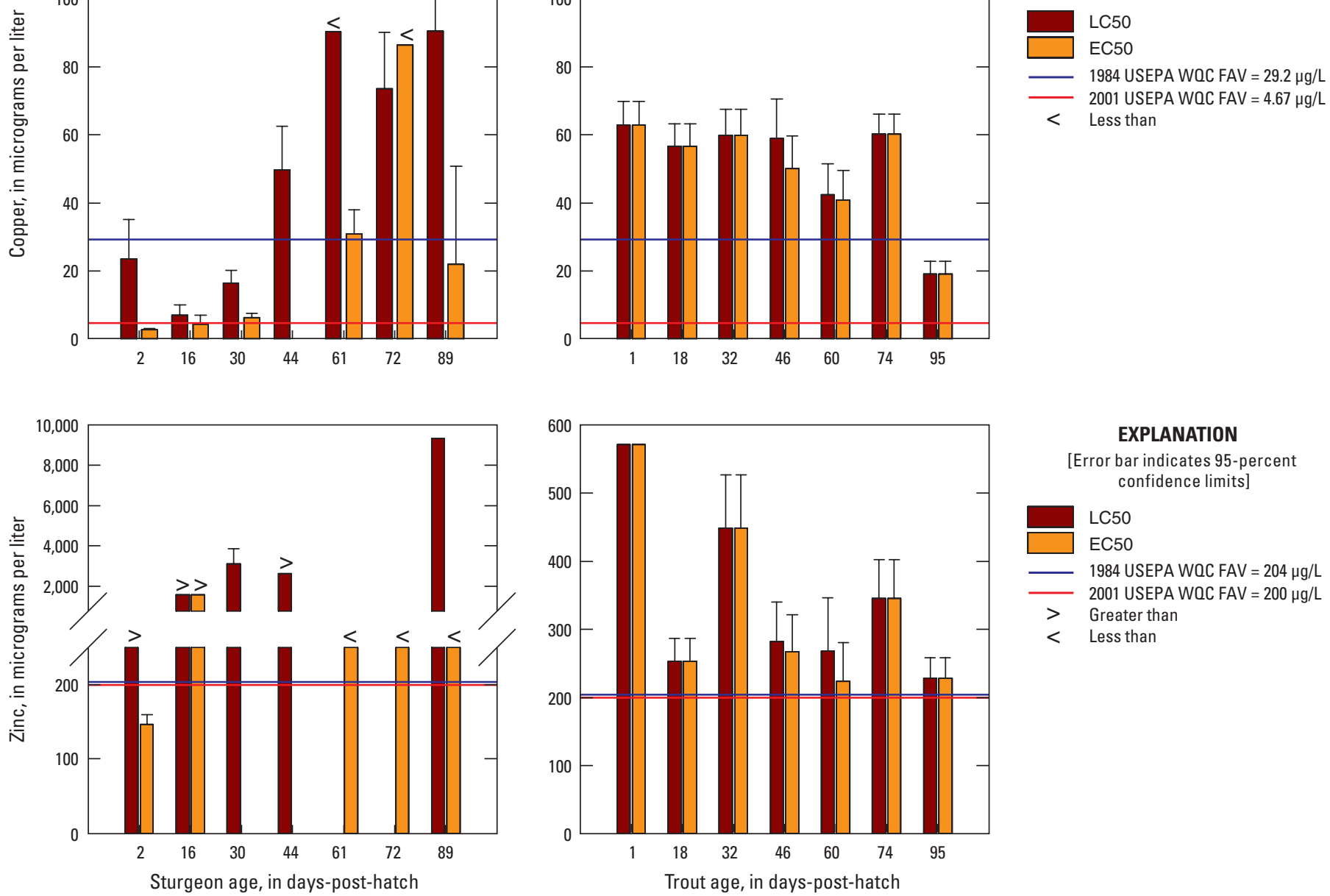

\section{EXPLANATION}

[Error bar indicates 95-percent confidence limits]

LC50 EC50

1984 USEPA WQC FAV $=204 \mu \mathrm{g} / \mathrm{L}$ 2001 USEPA WQC FAV $=200 \mu \mathrm{g} / \mathrm{L}$

$>$ Greater than

$<$ Less than

Figure A-1. Acute 4-day median lethal (LC50) or effect (EC50) concentration for cadmium, copper, and zinc for $A$, white sturgeon (Acipenser transmontanus) and $B$, rainbow trout (Oncorhynchus mykiss) at various life stages, compared to U.S. Environmental Protection Agency (USEPA) water-quality criteria (WOC) adjusted to test water-quality characteristics. [LC50, 50-percent lethal concentration; EC50, 50-percent effective concentration; FAV, final acute value] 
Table A-4. Cadmium LC50 or EC50 4-day acute value estimates for white sturgeon (Acipenser transmontanus) and rainbow trout (Oncorhynchus mykiss) with 95-percent confidence intervals in parentheses.

[Average fish weights and lengths ( $n=10$ for white sturgeon; $n=30$ for rainbow trout) standard deviation in parentheses. Yellow shading represents the most sensitive life stage for each species. $n$, sample size; dph, days-post-hatch; g, gram; mm, millimeter; LC50, 50-percent lethal concentration; $\mu \mathrm{g} / \mathrm{L}$, microgram per liter; EC50, 50-percent effective concentration; LOE, loss of equilibrium; NM, not measured; >, greater than; NE, not estimated because the data did not meet requirements for probit analysis; <, less than; WQC, water-quality criterion; FAV, final acute value]

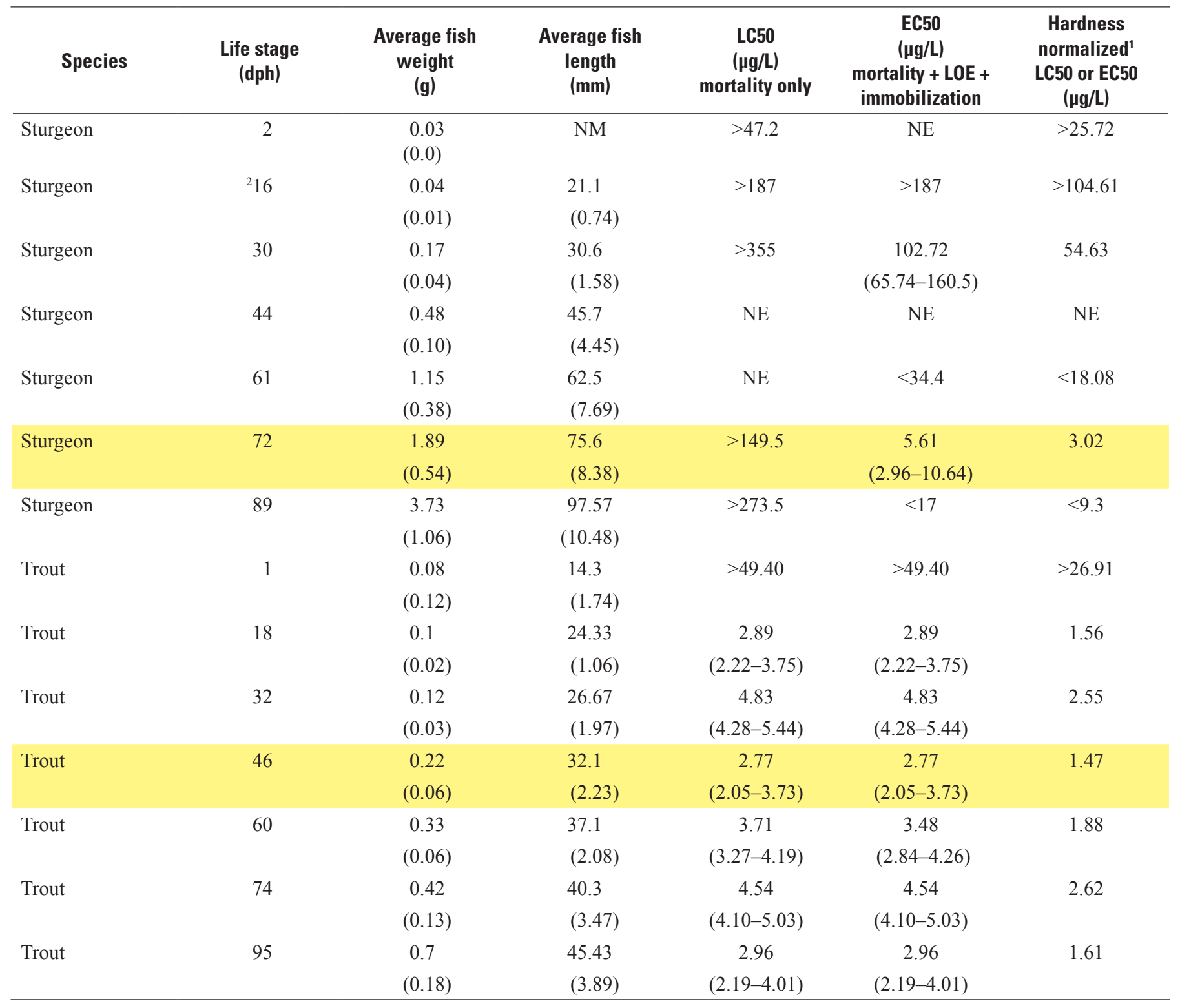

${ }^{1}$ U.S. Environmental Protection Agency (2001) WQC FAV = 4.0 $\mu \mathrm{g} / \mathrm{L}$ and U.S. Environmental Protection Agency (1984) WQC FAV = $7.4 \mu \mathrm{g} / \mathrm{L}$ for $100 \mathrm{mil}-$ ligrams per liter hardness water. The Washington State Department of Ecology (2006) water-quality standards are based upon (U.S. Environmental Protection Agency, 1984).

${ }^{2}$ Control survival for the 16 -dph test was less than 90 percent, thus the EC50 calculation is nondefinitive. 
Table A-5. Copper LC50 or EC50 4-day acute value estimates for white sturgeon (Acipenser transmontanus) and rainbow trout (Oncorhynchus mykiss) with 95-percent confidence intervals in parentheses.

[Average fish weights and lengths ( $n=10$ for white sturgeon; $n=30$ for rainbow trout) standard deviation in parentheses. Yellow shading represents the most sensitive life stage for each species. $n$, sample size; dph, days-post-hatch; g, gram; cm, centimeter; LC50, 50-percent lethal concentration; $\mu \mathrm{g} / \mathrm{L}$, microgram per liter; EC50, 50-percent effect concentration; LOE, loss of equilibrium; USEPA, U.S. Environmental Protection Agency; BLM, biotic ligand model; FAV, final acute value; NM, not measured; >, greater than; NE, not estimated because the data did not meet requirements for probit analysis; <, less than; DOC, dissolved organic carbon]

\begin{tabular}{|c|c|c|c|c|c|c|c|c|}
\hline Species & $\begin{array}{l}\text { Life stage } \\
\text { (dph) }\end{array}$ & $\begin{array}{l}\text { Average fish } \\
\text { weight } \\
\text { (g) }\end{array}$ & $\begin{array}{l}\text { Average fish } \\
\text { length } \\
\text { (cm) }\end{array}$ & $\begin{array}{c}\text { LC50 } \\
\text { ( } \mu \mathrm{g} / \mathrm{L}) \\
\text { mortality } \\
\text { only }\end{array}$ & $\begin{array}{c}\text { EC50 } \\
(\mu \mathrm{g} / \mathrm{L}) \\
\text { mortality + } \\
\text { LOE + } \\
\text { immobilization }\end{array}$ & $\begin{array}{c}\text { EC50 } \\
\text { normalized for } \\
\text { USEPA's “BLM } \\
\text { standard" } \\
\text { water }^{1} \\
\text { ( } \mu \mathrm{g} / \mathrm{L})\end{array}$ & $\begin{array}{l}\text { Hardness- } \\
\text { dependent } \\
\text { acute FAV }{ }^{2} \text { for } \\
\text { hardness of the } \\
\text { test waters } \\
(\mu \mathrm{g} / \mathrm{L})\end{array}$ & $\begin{array}{c}\text { BLM-based } \\
\text { acute } \\
\text { FAV }^{3} \text { for test } \\
\text { water chemistry } \\
(\mu \mathrm{g} / \mathrm{L})\end{array}$ \\
\hline Sturgeon & 2 & $\begin{array}{l}0.03 \\
(0.0)\end{array}$ & NM & $>23.6$ & $\begin{array}{c}2.67 \\
(2.33-3.05)\end{array}$ & 1.51 & 35.8 & 7.9 \\
\hline Sturgeon & 30 & $\begin{array}{c}0.15 \\
(0.04)\end{array}$ & $\begin{array}{l}29.2 \\
(2.62)\end{array}$ & $\begin{array}{c}16.4 \\
(13.4-20.2)\end{array}$ & $\begin{array}{c}6.31 \\
(5.26-7.57)\end{array}$ & 4.2 & 35.8 & 7.0 \\
\hline Sturgeon & 44 & $\begin{array}{c}0.46 \\
(0.11)\end{array}$ & $\begin{array}{l}44.9 \\
(3.90)\end{array}$ & $>49.8$ & $\mathrm{NE}$ & ${ }^{5}>34.1$ & 34.6 & 7.0 \\
\hline Sturgeon & 72 & $\begin{array}{c}2.02 \\
(0.80)\end{array}$ & $\begin{array}{c}77.7 \\
(11.08)\end{array}$ & $\begin{array}{c}74 \\
(60-90)\end{array}$ & $\mathrm{NE}$ & 58.96 & 34.1 & 6.4 \\
\hline Sturgeon & 89 & $\begin{array}{c}3.73 \\
(1.06)\end{array}$ & $\begin{array}{c}97.57 \\
(10.48)\end{array}$ & $\begin{array}{c}90 \\
(77-108)\end{array}$ & $\begin{array}{c}21.9 \\
(15.9-30.3)\end{array}$ & 17.25 & 32.4 & 6.4 \\
\hline Trout & 1 & $\begin{array}{c}0.08 \\
(0.12)\end{array}$ & $\begin{array}{l}14.3 \\
(1.74)\end{array}$ & $\begin{array}{c}62.9 \\
(56.6-69.9)\end{array}$ & $\begin{array}{c}62.9 \\
(56.6-69.9)\end{array}$ & 47.8 & 32.4 & 6.4 \\
\hline Trout & 18 & $\begin{array}{c}0.10 \\
(0.02)\end{array}$ & $\begin{array}{l}24.33 \\
(1.06)\end{array}$ & $\begin{array}{c}56.6 \\
(50.6-63.4)\end{array}$ & $\begin{array}{c}56.6 \\
(50.6-63.4)\end{array}$ & 43.4 & 35.2 & 5.9 \\
\hline Trout & 32 & $\begin{array}{c}0.12 \\
(0.03)\end{array}$ & $\begin{array}{l}26.67 \\
(1.97)\end{array}$ & $\begin{array}{c}59.9 \\
(53.1-67.7)\end{array}$ & $\begin{array}{c}59.9 \\
(53.1-67.7)\end{array}$ & 42.42 & 35.8 & 6.6 \\
\hline Trout & 74 & $\begin{array}{c}0.41 \\
(0.12)\end{array}$ & $\begin{array}{l}40.2 \\
(3.16)\end{array}$ & $\begin{array}{c}60.6 \\
(54.9-66.2)\end{array}$ & $\begin{array}{c}60.6 \\
(54.9-66.2)\end{array}$ & 44.34 & 35.6 & 6.3 \\
\hline Trout & 95 & $\begin{array}{c}0.70 \\
(0.18)\end{array}$ & $\begin{array}{l}45.43 \\
(3.89)\end{array}$ & $\begin{array}{c}19.1 \\
(15.8-23.0)\end{array}$ & $\begin{array}{c}19.1 \\
(15.8-23.0)\end{array}$ & 15.24 & 34.4 & 6.2 \\
\hline
\end{tabular}

${ }^{1}$ For BLM-normalized EC50s, the BLM was used to extrapolate the actual EC50s to those expected for the "BLM standard" water conditions, which is a moderately hard water, with $\mathrm{pH}$ of 7.5 and $0.5 \mathrm{mg} / \mathrm{L}$ DOC, following the approach used by U.S. Environmental Protection Agency (2007a). The FAV for "BLM standard" water is $4.67 \mu \mathrm{g} / \mathrm{L}$ (U.S. Environmental Protection Agency, 2007a).

${ }^{2}$ U.S. Environmental Protection Agency (1985) FAV, calculated for the test hardness, which is equivalent to 2x the State of Washington acute water hardness standard for copper.

${ }^{3}$ U.S. Environmental Protection Agency (2007a) FAV, calculated for the individual measured test water chemistries.

${ }^{4}$ Control survival for the 16-dph test was less than 90 percent, thus the EC50 calculation is nondefinitive.

${ }^{5} \mathrm{BLM}$ normalized value is based on the LC50 . 
Table A-6. Zinc LC50 or EC50 4-day acute value estimates for white sturgeon (Acipenser transmontanus) and rainbow trout (Oncorhynchus mykiss) with 95-percent confidence intervals in parentheses.

[Average fish weights and lengths ( $n=10$ for white sturgeon; $n=30$ for rainbow trout) standard deviation in parentheses. Yellow shading represents the most sensitive life stage for each species. $n$, sample size; dph, days-post-hatch; g, gram; cm, centimeter; LC50, 50-percent lethal concentration; $\mu \mathrm{g} / \mathrm{L}$, microgram per liter; EC50, 50-percent effect concentration; LOE, loss of equilibrium; BLM, biotic ligand model; NM, not measured; >, greather than; NE, not estimated because the data do not meet requirements for probit analysis $<$, less than; FAV, final acute value]

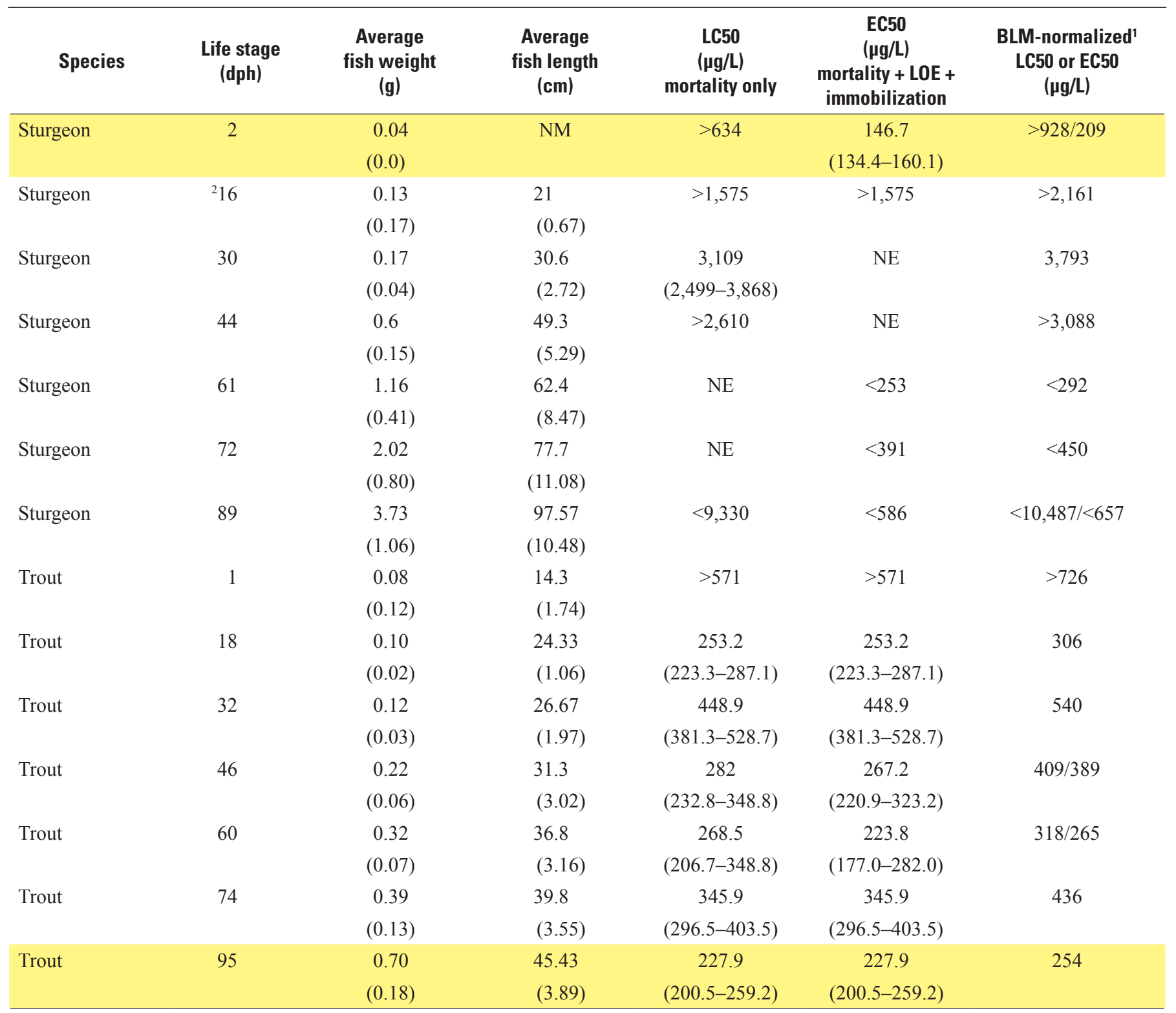

${ }^{1} 1996$ U.S. Environmental Protection Agency hardness-based FAV $=204 \mathrm{mg} / \mathrm{L}$ for moderately hard water and 2011 DeForest and Van Genderen revised $\mathrm{BLM} F A V=261 \mu \mathrm{g} / \mathrm{L}$ for moderately hard water.

${ }^{2}$ Control survival for the 16-dph test was less than 90 percent, thus the EC50 calculation is nondefinitive. 

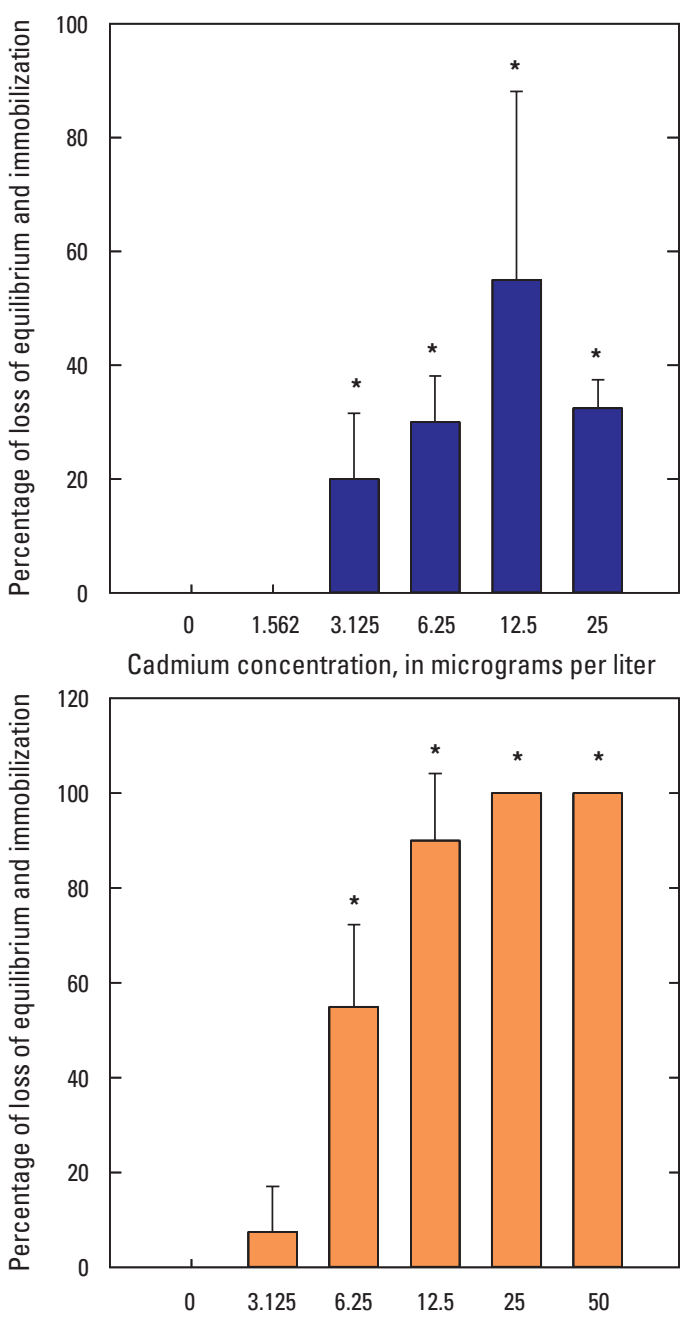

Copper concentration, in micrograms per liter

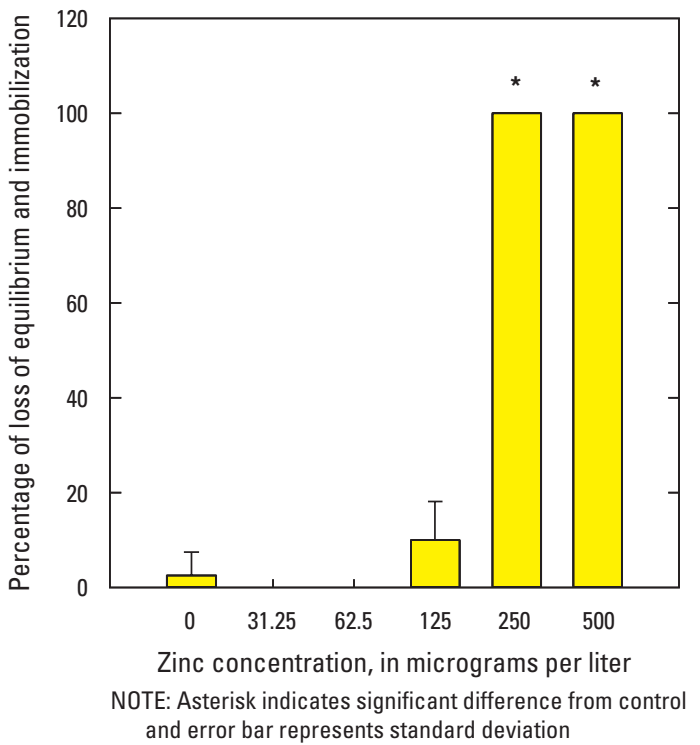

Figure A-2. Mean percent of surviving white sturgeon (Acipenser transmontanus) at 2 days-post-hatch (dph) exhibiting loss of equilibration and immobilization with increasing metal concentration following 4day (d) of exposures. Sturgeon were $6 \mathrm{dph}$ at the end of the 4-d exposures.
The copper EC50s for sturgeon at early life stages substantially were different than the copper LC50s based on mortality only (table A-5). Sturgeon began to lose equilibrium or were immobile quite rapidly often within the first $24 \mathrm{~h}$ of exposure. Sturgeon were extremely sensitive to copper exposure. The 2-dph sturgeon were the most sensitive life stage with a EC50 of $2.67 \mu \mathrm{g} \mathrm{Cu} / \mathrm{L}$ (table A-5). The greatest mortality was observed in the highest test concentration $(23.6 \mu \mathrm{g} \mathrm{Cu} / \mathrm{L})$ with 33 percent, so the LC50 estimate would be $>23.6 \mu \mathrm{g} \mathrm{Cu} / \mathrm{L}$ (tables A-2 and A-5). The nondefinitive EC50 and LC50 were $4.32 \mu \mathrm{g} \mathrm{Cu} / \mathrm{L}$ and $7.14 \mu \mathrm{g} \mathrm{Cu} / \mathrm{L}$, respectively, for 16-dph sturgeon. The EC50 for 30-dph sturgeon was $6.31 \mu \mathrm{g} \mathrm{Cu} / \mathrm{L}$ and the LC50 was $16.4 \mu \mathrm{g} \mathrm{Cu} / \mathrm{L}$ for 30-dph sturgeon (table A-5). The toxicity of copper primarily was evident as immobilization and loss of equilibrium among exposed sturgeon. During the early life stages of development (2-44 dph), the LOECs ranged from 2.66 to $10.7 \mu \mathrm{g} \mathrm{Cu} / \mathrm{L}$ and the NOECs ranged from 1.43 to $5.40 \mu \mathrm{g} \mathrm{Cu} / \mathrm{L}$ (table A-2). Sturgeon at later stages of development were less sensitive to copper exposure with EC50s ranging from 21.9 to $30.8 \mu \mathrm{g} \mathrm{Cu} / \mathrm{L}$ for 44 to 89 -dph sturgeon (table A-5).

Sturgeon at $2 \mathrm{dph}$ was the life stage most sensitive to zinc exposure with an EC50 of $146.7 \mu \mathrm{g} \mathrm{Zn/L} \mathrm{(table} \mathrm{A-6).}$ The percentage of sturgeon exhibiting a loss of equilibrium and immobilization increased with increasing zinc concentration (fig. A-2). Other secondary effects consisted of initial hyperactivity of fish transitioning to lethargy (not included in the EC50 estimates; appendix table 1-1) by the end of the exposure period. The LOEC was $225 \mu \mathrm{g} \mathrm{Zn/L}$ and the NOEC was $116 \mu \mathrm{g} \mathrm{Zn/L} \mathrm{(table} \mathrm{A-2)} \mathrm{at} 2 \mathrm{dph}$. Physical abnormalities such as bloated abdomens were also observed at later life stages (61-89 dph) during exposure to concentrations of zinc $>500 \mu \mathrm{g} / \mathrm{L}$, and therefore may have affected loss of equilibrium causing fish to swim upside down, or on their sides (video1 in appendix 1).

To further quantify abnormal swimming, a separate study was performed in 2011 with a strain of white sturgeon from the Snake River in Idaho. Swimming velocity, time spent moving, distance travelled of 30-dph sturgeon all significantly decreased (fig. A-3) and swimming path was significantly reduced with increasing copper concentration (fig. A-4). The LC50 for 30-dph white sturgeon exposed to copper for $96 \mathrm{~h}$ was estimated to be $40.3 \mu \mathrm{g} \mathrm{Cu} / \mathrm{L}$, which suggests the Idaho strain of white sturgeon were less sensitive to copper exposure at $30 \mathrm{dph}$ than sturgeon of the same age from the Washington Department of Fish and Wildlife Program (Columbia Basin Hatchery, Moses Lake, Wash.) that had an estimated LC50 of $16.4 \mu \mathrm{g} \mathrm{Cu} / \mathrm{L}$ (table A-5); however, when taking into account the loss of equilibrium and immobilization the strains were similar in sensitivity to copper. The estimated EC50 for the Idaho strain white sturgeon was about $2.4-5.0 \mu \mathrm{g} \mathrm{Cu} / \mathrm{L}$ and the EC50 for 30-dph white sturgeon from the Columbia Basin strain was $6.3 \mu \mathrm{g} \mathrm{Cu} / \mathrm{L}$. 

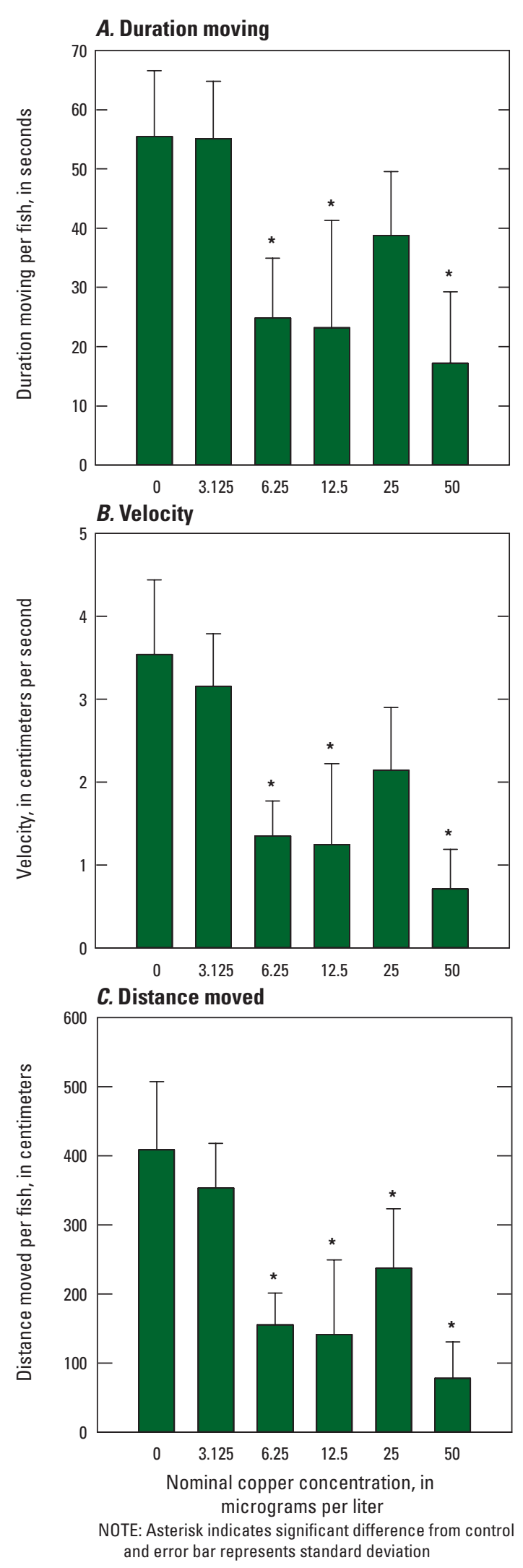

\section{Rainbow Trout Exposures}

There was no mortality in the control treatments during the 4-d exposures across each life stage tested for each metal (table A-3). Loss of equilibrium and immobilization were not observed in trout during exposure to cadmium across all life stages except at $60 \mathrm{dph}$; however, there were no substantial differences between the EC50s and LC50s, therefore the reported effect concentrations at each life stage were LC50s based only on mortality (table A-3). The sensitivity of trout to cadmium was consistent with LC50s ranging from 2.77 to $4.83 \mu \mathrm{g} \mathrm{Cd} / \mathrm{L}$ across the six life stages tested (table A-4), with 46-dph trout being the most sensitive life stage with an LC50 of $2.77 \mu \mathrm{g} \mathrm{Cd} / \mathrm{L}$. Trout at $1 \mathrm{dph}$ were less sensitive to cadmium with an LC50 >49.4 $\mu \mathrm{g} \mathrm{Cd} / \mathrm{L}$ (table A-4). The more conservative thresholds were also consistent across life stage with LOECs ranging from 2.67 to $6.0 \mu \mathrm{g} \mathrm{Cd} / \mathrm{L}$ and the NOECs ranging from 1.30 to $2.70 \mu \mathrm{g} \mathrm{Cd} / \mathrm{L}$ (table A-4).

Trout sensitivity to copper increased with later stages of development (table A-5). Effect concentrations for each life stage were based on mortality only and reported as LC50s, given that trout did not typically exhibit loss of equilibrium or immobilization in the copper exposures. From 1 to $74 \mathrm{dph}$, the sensitivity of trout to copper was consistent with LC50s ranging from 42.4 to $62.9 \mu \mathrm{g} \mathrm{Cu} / \mathrm{L}$ (table A-5). Trout at $95 \mathrm{dph}$ was the most sensitive life stage with an LC50 of $19.1 \mu \mathrm{g} \mathrm{Cu} / \mathrm{L}$ (table A-5). The LOEC at $95 \mathrm{dph}$ of $20 \mu \mathrm{g} \mathrm{Cu} / \mathrm{L}$ was similar to the $\mathrm{LC} 50$ of $19.1 \mu \mathrm{g} \mathrm{Cu} / \mathrm{L}$. (table A-3). Trout exhibited some loss of equilibrium at 46 and $60 \mathrm{dph}$ during exposure to copper within a concentration range of 13-50 $\mu \mathrm{g} \mathrm{Cu} / \mathrm{L}$; however, the effects were minimal with no substantial difference between the EC50 and LC50 at those life stages (fig. A-1; tables A-3 and A-5).

The sensitivity of trout to zinc was relatively consistent across life stages tested. Effect concentrations for each life stage were based on mortality only and reported as LC50s. From 18 to $95 \mathrm{dph}, \mathrm{LC} 50$ s ranged from 228 to $449 \mu \mathrm{g} \mathrm{Zn/L}$ (table A-6). Trout at $1 \mathrm{dph}$ were less sensitive with an LC50 $>571 \mu \mathrm{g} \mathrm{Zn/L} \mathrm{(table} \mathrm{A-6).} \mathrm{The} \mathrm{LOECs} \mathrm{were} \mathrm{consistent}$ across life stage and ranged from 202 to $388 \mu \mathrm{g} \mathrm{Zn} / \mathrm{L}$ for 18 to $95 \mathrm{dph}$ trout and the NOECs ranged from 104 to $216 \mu \mathrm{g}$ $\mathrm{Zn} / \mathrm{L}$ (table A-3). Loss of equilibrium also was observed at the 46- and 60-dph stage of development for zinc within a concentration range of 220-350 $\mu \mathrm{g} \mathrm{Zn/L}$; however, the effects were minimal with no substantial difference between the EC50 and LC50 at those life stages (fig. A-1; tables A-3 and A-6). Other effects of zinc on trout at 46 and 60 dph were increased respiration and immobilization; however, effects on respiration were a secondary observation and were not included in the calculation of the EC50s.

Figure A-3. Swimming behavior variables $A$, duration of movement among 30-days-post-hatch fish; $B$, speed of swimming; and $C$, distance moved impaired with increasing concentration of surviving white sturgeon (Acipenser transmontanus) exposed to copper after 4 days. These exposures were performed in 2011 in a separate study with a Snake River, Idaho strain of white sturgeon (see Methods section in chapter A). 


\section{A. Swimming paths of white sturgeon from control treatment}

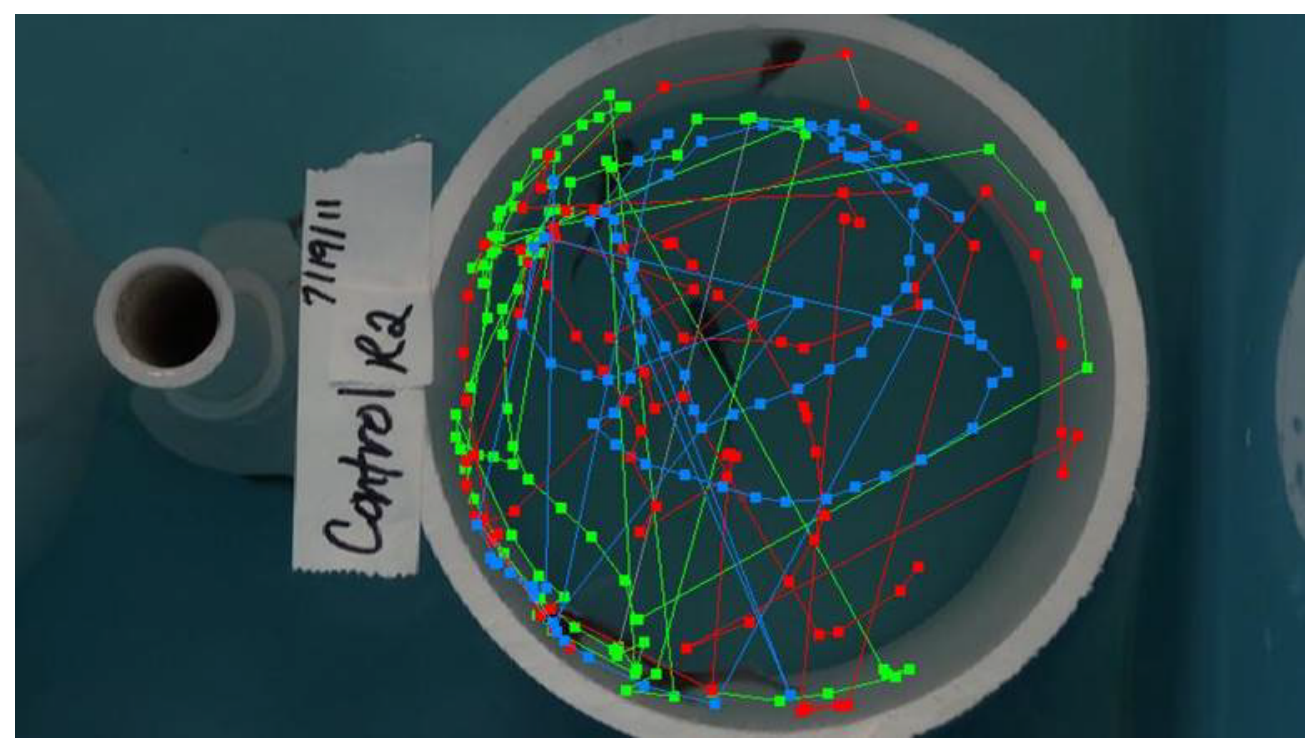

\section{B. Swimming paths of white sturgeon from high copper treatment}

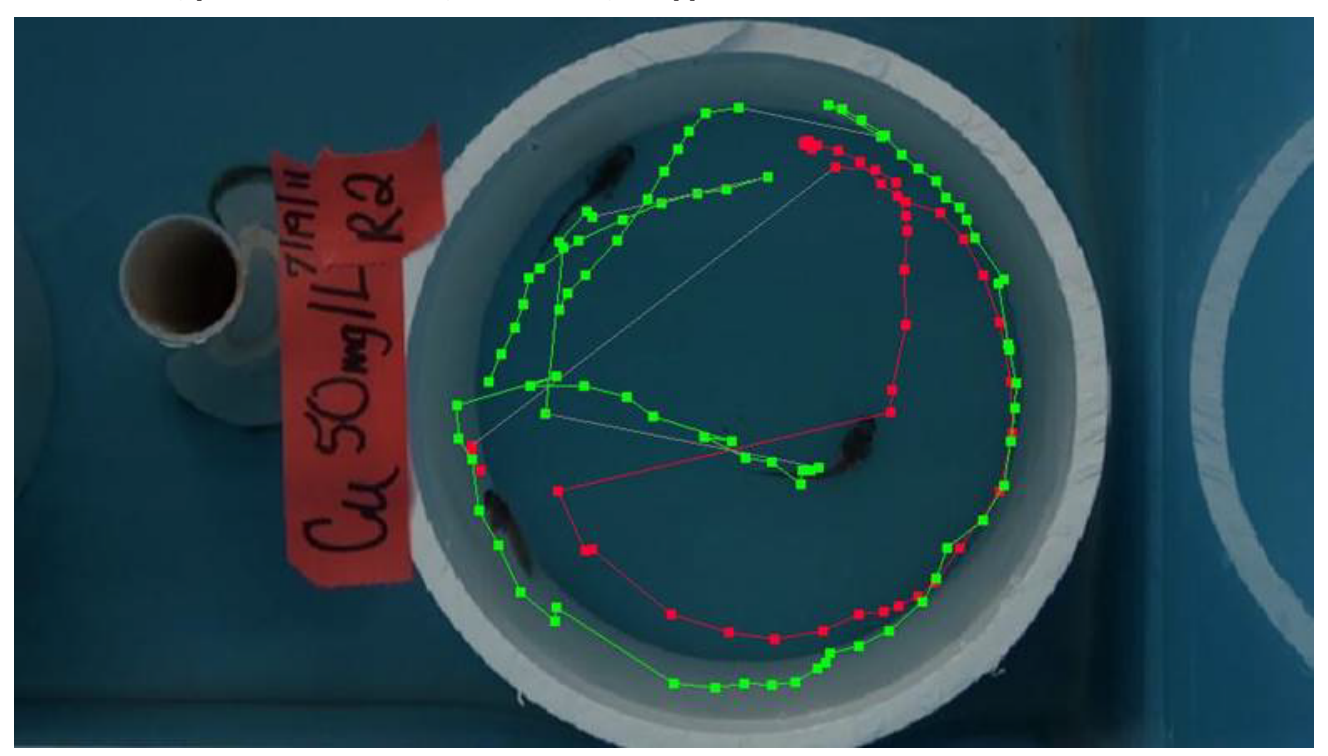

Figure A-4. Example of swimming paths of white sturgeon (Acipenser transmontanus) digitized using Noldus Ethovision ${ }^{\circ} \mathrm{XT}$ from $A$, a control replicate ( $\mathrm{n}=5$ fish) and $B$, from a high concentration (50 micrograms copper per liter ( $\mu \mathrm{g} \mathrm{Cu} / \mathrm{L}$ ) replicate $(\mathrm{n}=3$ fish) after a 4-day copper exposure. Please note the number of swimming paths does not represent the number of fish present in the chamber because of inactivity. These exposures were performed in 2011 in a separate study with a Snake River, Idaho strain of white sturgeon (see Methods section in chapter A). 


\section{Discussion}

\section{Effect of the Developmental Stage on Acute Sensitivity to Metals}

Acute sensitivity thresholds to cadmium, copper, and zinc were determined across seven early life stages of development for white sturgeon and rainbow trout, and were compared between species at each life stage to determine the feasibility of using rainbow trout as a surrogate test species for white sturgeon. Sturgeon sensitivity to metal exposure varied with life stage with the early life stages being more vulnerable, specifically to copper. During the toxicity tests and those reported by Little and others (2012), it became apparent that white sturgeon were severely impaired at concentrations that were not lethal. These impaired responses would result in death in the natural environment for white sturgeon and are referred to as ecologically dead (Scott and Sloman, 2004). Thus, EC50s were calculated based on immobilization or loss of equilibrium in addition to LC50s based on mortality alone during the exposures.

In three of the seven life stages tested $(2,16$, and 30 dph), sturgeon were highly sensitive to copper exposure with EC50s ranging from 2.67 to $6.31 \mu \mathrm{g} \mathrm{Cu} / \mathrm{L}$ compared to other life stages of sturgeon tested (table A-5; the 16-dph EC50s for sturgeon were classified as nondefinitive effect concentrations). Older (72 and $89 \mathrm{dph}$ ) sturgeon were relatively insensitive to copper at concentrations as great as 30 times higher than the threshold for early life stage sturgeon. Early life stages of trout were less sensitive to copper at concentrations as many as 30 times higher than the threshold for early life stages of sturgeon; however, older life stages (74 and 95 dph) of trout were more sensitive to copper than the older life stages of sturgeon. For this reason, rainbow trout would not serve as a good surrogate species for the protection of white sturgeon from exposure to copper.

Body size or developmental stage is an important factor modifying the toxicity of chemicals to aquatic organisms (Rand and others, 1995; Hendriks and Heikens, 2001); however, unifying explanations for differences in response across species remain elusive. Juvenile organisms often are considered more susceptible to substances than adults of the same species. This has been presumed to be related to the greater ratio of body surface area to volume that in turn affects relative uptake and excretion rates, and incomplete development of detoxification mechanisms such as metallothionein (Rand and others, 1995; Hendriks and Heikens, 2001). With copper, Grosell and others (2002) demonstrated situations where smaller animals may be more sensitive than large animals because these organisms exhibit higher sodium turnover rates. These principles and patterns suggest that smaller organisms also would have higher calcium turnover rates and in turn, smaller organisms would be more sensitive to calcium antagonists such as cadmium, lead, and zinc.
The results of the sturgeon copper exposures were consistent with this smaller and more sensitive rule of thumb, as have previous studies with other fish such as sculpin (Cottus spp.) and fathead minnow (Pimephales promelas; Klaine and others, 1996; Besser and others, 2007; Mebane, 2006); however, for the trout tests, the older and larger fish tended to be more sensitive (tables A-3 to A-6). This reversal in the general expectation that smaller fish would be more sensitive has been reported previously with rainbow trout as well as other species (Anderson and Weber, 1975). At least with some salmonids, within the swim-up life stage (that is, after the fish have been feeding rather than relying on energy from their yolk sac), fish may initially lose resistance with increasing size. As the fish get older and larger, this pattern appears to reverse with the fish (Hedtke and others, 1982; Hansen and others, 2002; Mebane and others, 2012).

At present, mechanistic explanations for these differing metals sensitivity response patterns with size or early developmental stage of the different fish species are speculative. Juvenile fish undergo marked physiological and morphological changes as the fish metamorphose from larval to juvenile life stages. With white sturgeon, two concurrent changes during the early development are the transition from relying on the yolk sac for nourishment to external feeding and the transition from passive gas exchange through the body surface to active gill gas exchange (Gisbert, 1999). These changes in osmoregulation and respiration from through the body skin to through the gills likely increase oxygen supply to organs resulting in stronger swimming behaviors that allow larvae to inhabit changing environments (Gisbert, 1999). The transition from passive gas exchange through the body skin to gills in the early development of fish is preceded by a transition from ion regulation through the body skin to the gills (Rombough, 2002; Fu and others, 2010). Because the toxicity of cadmium, copper, lead, and zinc are related to ion regulation disruption, the differing patterns of size and sensitivity to at least copper and zinc suggests possible connections with the timing of changes in ion regulation.

The behavioral responses of white sturgeon from additional copper exposures performed in 2011 with a different strain of white sturgeon from the Snake River, Idaho (see Methods section) are summarized in figures A-3 and A-4. The objective of this additional study was to quantify effects of copper on white sturgeon swimming velocity, duration moving, and distance travelled. Each of these behaviors decreased with increasing copper concentration (fig. A-3). Swimming behavior variables were significantly different in the high exposure as compared to the control specifically for swimming paths (fig. A-4) and were significantly different with increasing metal concentration (fig. A-3). The results of this additional study help to illustrate how behavior of early life stage white sturgeon was affected at below lethal concentrations of copper and support the 2010 acute data where loss of equilibrium and immobilization were sublethal effects and used in the calculation of EC50s. 


\section{Comparison of Species Sensitivity and Species Sensitivity Distributions}

Rainbow trout were more sensitive to cadmium exposure than white sturgeon for all life stages tested. As with white sturgeon, there was an increase in sensitivity with age for rainbow trout during the companion study (chapter B) where acute toxicity was assessed during the first 4 days of the chronic exposure. In chapter B, the 1-dph 4-d EC50 was $>12 \mu \mathrm{g} \mathrm{Cd} / \mathrm{L}$, whereas the 26-dph 4-d EC50 was $5.14 \mu \mathrm{g} \mathrm{Cd} / \mathrm{L}$, suggesting older trout become more sensitive to exposure to cadmium (appendix table 2-7). At $46 \mathrm{dph}$, trout in the current study especially were sensitive to cadmium relative to other species and was in the 2 nd percentile in a compiled cadmium acute toxicity database for the species sensitivity distribution with a hardness normalized EC50 of $1.47 \mu \mathrm{g} \mathrm{Cd} / \mathrm{L}$ (fig. A-5; table A-4); however, white sturgeon were among the most sensitive of species at about $72 \mathrm{dph}$ (19th percentile; fig. A-5) with a hardness normalized EC50 of $3.02 \mu \mathrm{g} \mathrm{Cd} / \mathrm{L}$ (table A-4). Based on these results, rainbow trout could serve as a surrogate species for the protection of white sturgeon in acute exposures to cadmium.

White sturgeon were more sensitive than rainbow trout to copper at 2,16,30,44, and $61 \mathrm{dph}$ and less sensitive at 72 and $89 \mathrm{dph}$. The copper effect concentrations for older life stages of sturgeon were as many as 30 times higher than the threshold for the earlier life stages of sturgeon. It was the opposite effect for rainbow trout. Early life stages of rainbow trout (1 to $74 \mathrm{dph}$ ) were less sensitive to copper at concentrations as much as 30 times higher than the threshold for early life stage white sturgeon and older life stages of rainbow trout (74 and $95 \mathrm{dph}$ ) trout were more sensitive to copper than the older life stage of white sturgeon. The 2-dph life stage for white sturgeon was the most sensitive life stage tested in the current study and ranked at the 3rd percentile in a compiled copper acute toxicity database for species sensitivity distribution making it the most sensitive species with a BLM-normalized EC50 of $1.51 \mu \mathrm{g} \mathrm{Cu} / \mathrm{L}$ (table A-5; fig. A-6). Based on these findings, rainbow trout would not serve as a good surrogate species for protecting white sturgeon from acute copper exposure.

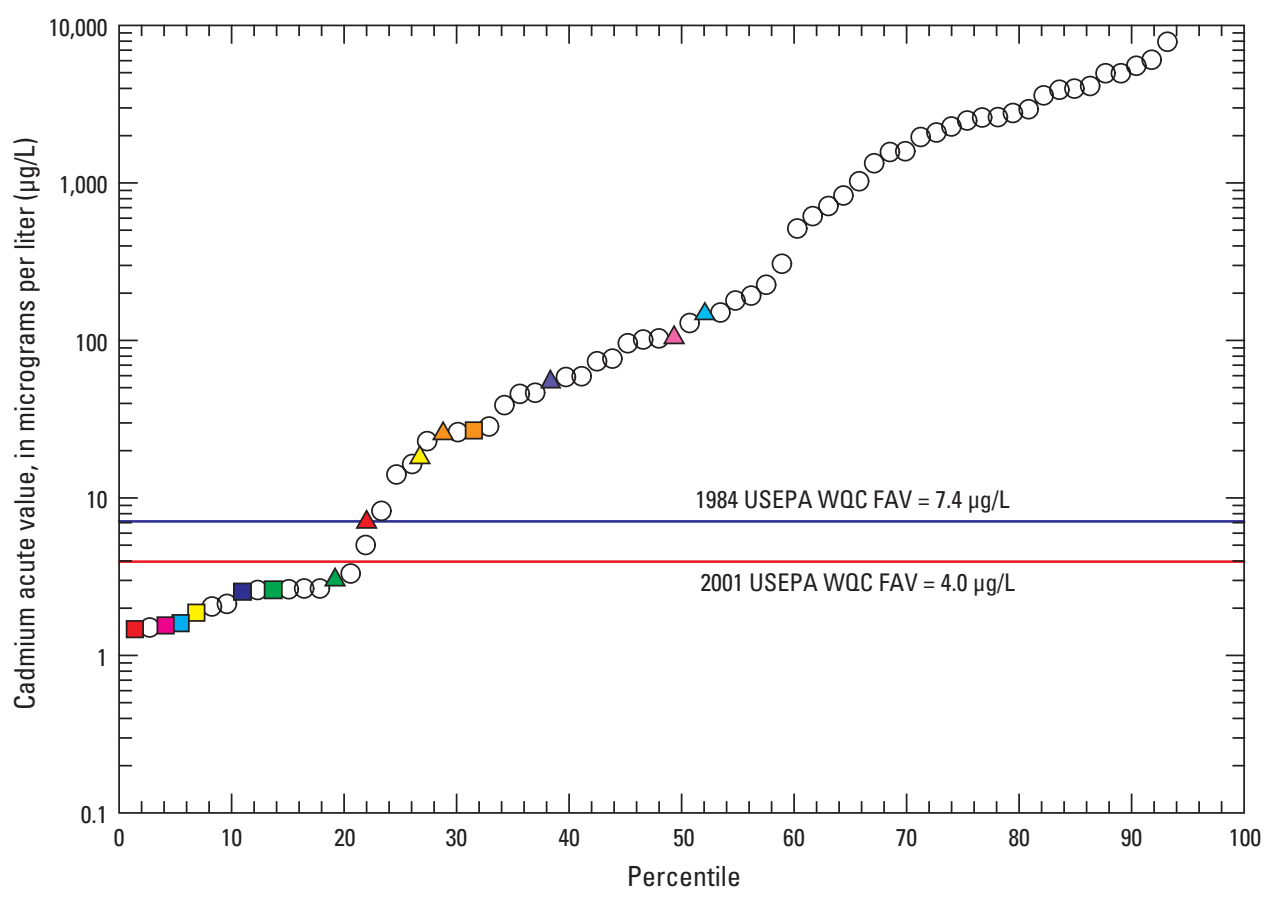

\author{
EXPLANATION \\ [dph, days-post-hatch] \\ Genera listed in Mebane (2006) \\ $\square$ Rainbow trout $1 \mathrm{dph}$ \\ $\square$ Rainbow trout $74 \mathrm{dph}$ \\ $\square$ Rainbow trout $32 \mathrm{dph}$ \\ $\square \quad$ Rainbow trout $60 \mathrm{dph}$ \\ $\square \quad$ Rainbow trout $95 \mathrm{dph}$ \\ $\square$ Rainbow trout $18 \mathrm{dph}$ \\ $\square \quad$ Rainbow trout $46 \mathrm{dph}$ \\ $\triangle$ White sturgeon $89 \mathrm{dph}$ \\ $\triangle$ White sturgeon $16 \mathrm{dph}^{*}$ \\ $\triangle$ White sturgeon $30 \mathrm{dph}$ \\ $\triangle$ White sturgeon $2 \mathrm{dph}$ \\ $\triangle$ White sturgeon $61 \mathrm{dph}$ \\ $\triangle$ White sturgeon $44 \mathrm{dph}$ \\ $\triangle$ White sturgeon $72 \mathrm{dph}$ \\ NOTE: Asterisk indicates control survival was \\ less than 90 percent during the exposures \\ started with 16-dph sturgeon and result \\ should be interpreted with caution because \\ of low control survival
}

Figure A-5. Ranks of various white sturgeon (Acipenser transmontanus) and rainbow trout (Oncorhynchus mykiss) life stages in species sensitivity distribution from an updated cadmium hardness-toxicity regression and effects database (Mebane, 2006). The EC50 values are normalized to a water hardness of 100 milligrams per liter for comparability with U.S. Environmental Protection Agency $(1984,2001)$ criteria. [EC50, 50-percent effect concentration; USEPA, U.S. Environmental Protection Agency; WQC, waterquality criteria; FAV, final acute value] 


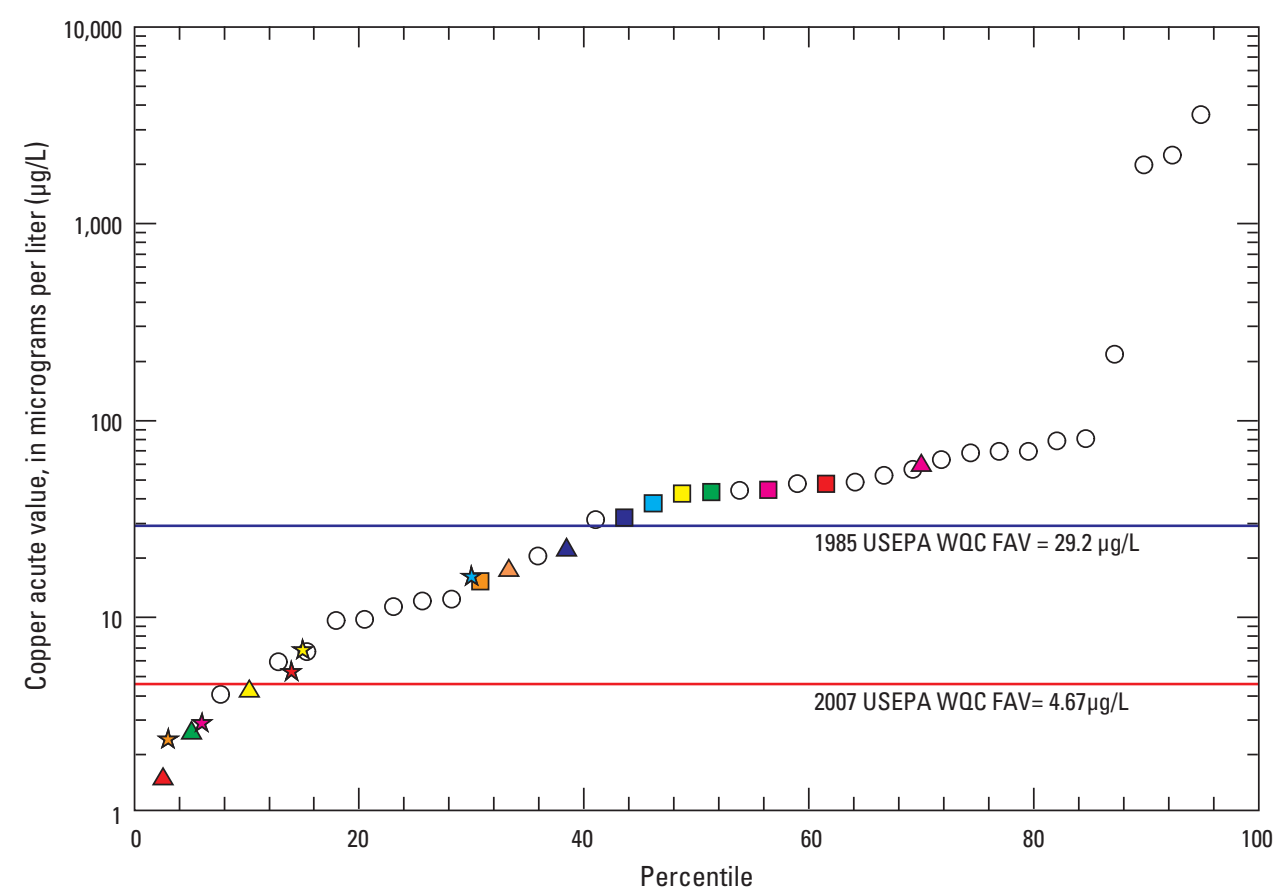

EXPLANATION

[dph, days-post-hatch]

O Genera listed in U.S. Environmental Protection Agency (2007a)

$\Delta$ White sturgeon $72 \mathrm{dph}$

$\Delta$ White sturgeon $61 \mathrm{dph}$

$\triangle$ White sturgeon $89 \mathrm{dph}$

$\triangle$ White sturgeon $30 \mathrm{dph}$

$\triangle$ White sturgeon $16 \mathrm{dph}^{*}$

$\Delta$ White sturgeon $2 \mathrm{dph}$

$\square$ Rainbow trout $1 \mathrm{dph}$

$\square$ Rainbow trout $74 \mathrm{dph}$

$\square$ Rainbow trout $18 \mathrm{dph}$

$\square$ Rainbow trout $32 \mathrm{dph}$

Rainbow trout $46 \mathrm{dph}$

- Rainbow trout $60 \mathrm{dph}$

$\square$ Rainbow trout $95 \mathrm{dph}$

$\star$ White strugeon $8 \mathrm{dph}$ (Vardy and others, 2013)

\# White sturgeon $100 \mathrm{dph}$ (Vardy and others, 2013)

t White sturgeon $45 \mathrm{dph}$ (Vardy and others, 2013)

Ł White sturgeon $15 \mathrm{dph}$ (Vardy and others, 2013)

W. White sturgeon $40 \mathrm{dph}$ (Vardy and others, 2013)

NOTE: Asterisk indicates control survival was less than 90 percent during the exposures started with 16-dph sturgeon and result should be interpreted with caution because of low control survival

Figure A-6. Ranks of various white sturgeon (Acipenser transmontanus) and rainbow trout (Oncorhynchus mykiss) life stages in species sensitivity distribution from U.S. Environmental Protection Agency database for copper (2007a). The EC50 values are normalized to a moderately hard water composition with water hardness of $85 \mathrm{mg} / \mathrm{L}$ and DOC of $0.5 \mathrm{mg} / \mathrm{L}$ for comparability with U.S. Environmental Protection Agency (2007a). The EC50 for 44-dph white sturgeon is not included in the species sensitivity distribution because the endpoint could not be estimated. [EC50, 50-percent effect concentration; mg/L, milligrams per liter; DOC, dissolved organic carbon; USEPA, U.S. Environmental Protection Agency; WQC, water-quality criteria; FAV, final acute value]

Much like cadmium, zinc toxicity varied by life stage for white sturgeon and was somewhat consistent for rainbow trout across all life stages, except for 1-dph rainbow trout that were less sensitive compared to the other six life stages of rainbow trout tested or compared to 2-dph white sturgeon (table A-6). In chapter B, the 1-dph 4-d EC50 for trout at the start of the chronic exposures was $>748 \mu \mathrm{g} \mathrm{Zn/L}$, whereas at the 26-dph 4-d EC50 for rainbow trout at the start of the chronic exposures was $267 \mu \mathrm{g} \mathrm{Zn} / \mathrm{L}$, suggesting older rainbow trout become more sensitive to exposure to zinc (appendix table 2-7). White sturgeon and rainbow trout were ranked highly sensitive in the species sensitivity distribution for zinc when compared to other species (fig. A-7). White sturgeon at $2 \mathrm{dph}$ were extremely sensitive to exposure to zinc with a BLM-normalized EC50 of $209 \mu \mathrm{g} \mathrm{Zn} / \mathrm{L}$, ranked at the ${ }^{1 s t}$ percentile in a compiled zinc acute toxicity database for the species sensitivity distribution (table A-6; fig. A-7), and were more sensitive than rainbow trout at that life stage, whereas rankings rose to the 35 th percentile (fig. A-7) for older life stages of white sturgeon. Rainbow trout at $95 \mathrm{dph}$ was the most sensitive life stage to zinc in the current study and ranked at the 4th percentile of the species sensitivity distribution (table A-6; fig. A-7) with an LC50 of $228 \mu \mathrm{g} \mathrm{Zn/L}$, suggesting rainbow trout might not serve as a good surrogate species for the protection of white sturgeon from acute zinc exposure.

\section{Comparison to Other Acute Metal Toxicity Studies Performed with White Sturgeon}

Evaluation of the toxicity of metals to aquatic organisms requires consideration of site-specific water quality variables (water hardness, $\mathrm{pH}, \mathrm{DOC}$, temperature, major anions, major cations) that can alter the availability and toxicity of metals, including copper and zinc (U.S. Environmental Protection Agency, 2007a; Meyer and others, 2012). For instance, Cardno Entrix and University of Saskatchewan (2011) performed a series of 4-d exposures with 8- to 10-dph white sturgeon using Columbia River water and laboratory water (dechlorinated City of Saskatoon water) adjusted to a hardness of $70 \mathrm{mg} / \mathrm{L}$ mixed with reverse osmosis water. The 4-d LC50s for copper, cadmium, and zinc varied between water type (that is, river water vs. laboratory water; Cardno Entrix and University of Saskatchewan, 2011). The LC50s for the cadmium and zinc exposures performed in river water proved to be more sensitive than the LC50s generated for laboratory water, whereas the opposite was reported for the copper exposures with an $\mathrm{LC} 50$ of $44 \mu \mathrm{g} \mathrm{Cu} / \mathrm{L}$ for river water compared to an LC50 of $30 \mu \mathrm{g} \mathrm{Cu} / \mathrm{L}$ for laboratory water suggesting differences in water quality variables can alter the toxicity of metals. Unfortunately, DOC was not reported in the Columbia River water (Cardno Entrix and University of Saskatchewan, 2011). 


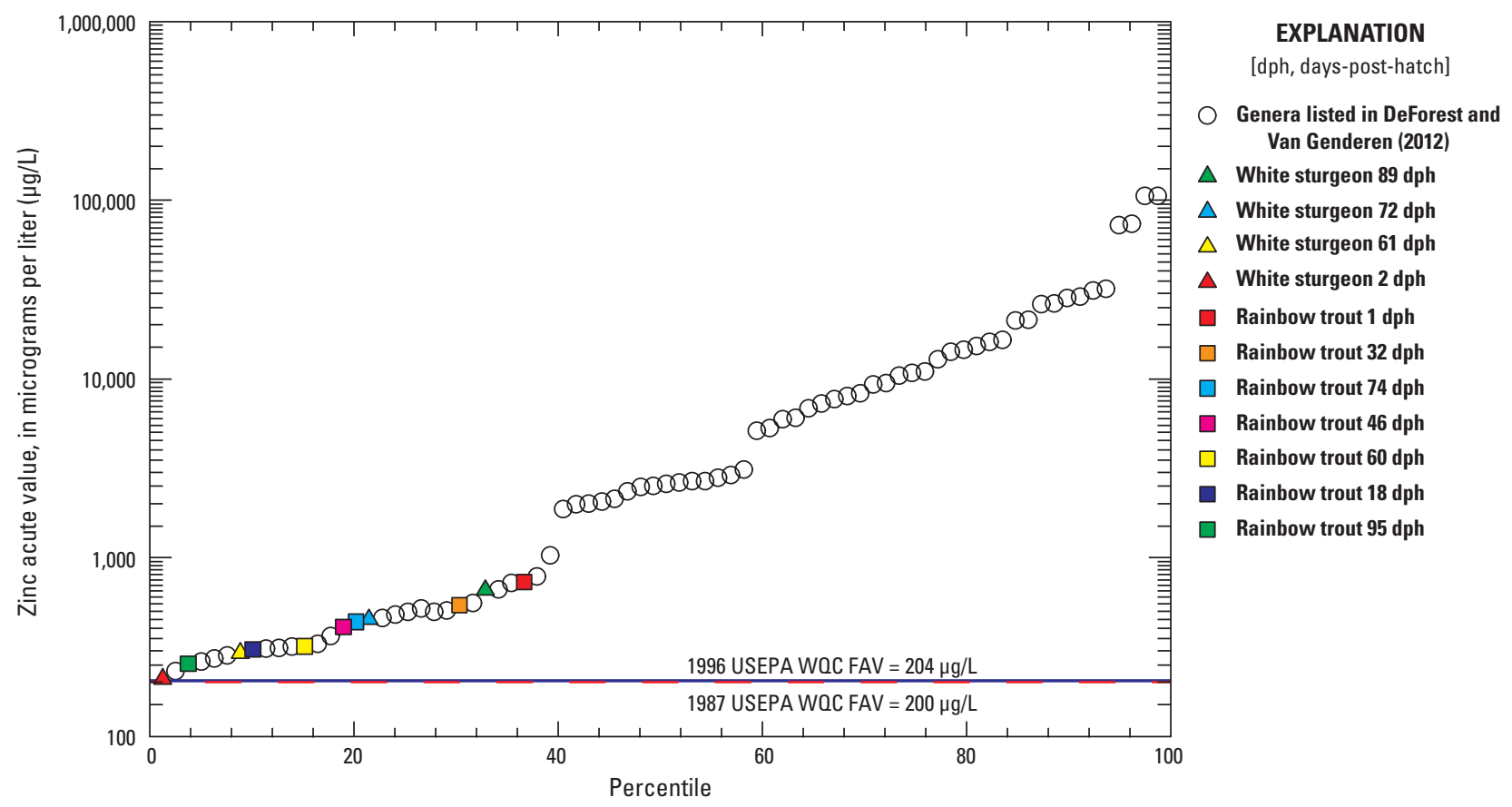

Figure A-7. Ranks of various white sturgeon (Acipenser transmontanus) and rainbow trout (Oncorhynchus mykiss) life stages in species sensitivity distribution from updated databases for zinc (DeForest and Van Genderen, 2012). The EC50 values are normalized to a moderately hard water composition with water hardness of $85 \mathrm{mg} / \mathrm{L}$ and DOC of $0.5 \mathrm{mg} / \mathrm{L}$ for comparability with DeForest and Van Genderen (2012) and U.S. Environmental Protection Agency (1987) aquatic life criteria for zinc, which are the bases of the currently recommended U.S. Environmental Protection Agency criteria and Washington State Department of Ecology (2006) water-quality standards, respectively. The EC50s for 16- and 44-dph white sturgeon are not included in the species sensitivity distribution because the endpoint was estimated at greater than the highest concentration tested. [EC50, 50-percent effect concentration; mg/L, milligrams per liter; DOC, dissolved organic carbon; USEPA, U.S. Environmental Protection Agency; WOC, water-quality criteria; FAV, final acute value]

Toxicity values for metals vary among studies because of water-quality characteristics of the exposures conditions. Certain variables, such as water hardness and DOC, have predictable effects on the bioavailability of metals and thus can be used to normalize toxicity for different exposure conditions. When comparing acute toxicity data from other studies to toxicity data in the current study, the data from all the studies were recalculated and normalized using the BLM (U.S. Environmental Protection Agency, 2007a) based on standard water with hardness value of $85 \mathrm{mg} / \mathrm{L}$ and DOC concentration of $0.5 \mathrm{mg} / \mathrm{L}$ for comparability, specifically for copper exposures.

Vardy and others (2013) tested life stages of white sturgeon similar to the current study and the results were comparable (table A-7). White sturgeon at $15 \mathrm{dph}$ had a BLM-normalized 4-d LC50 of $2.9 \mu \mathrm{g} \mathrm{Cu} / \mathrm{L}$ (Vardy and others, 2013) compared to the nondefinitive BLM-normalized LC50 of $4.4 \mu \mathrm{g} \mathrm{Cu} / \mathrm{L}$ for 16 -dph white sturgeon in the present study. The lowest copper effect concentration reported by Vardy and others (2013) was BLM-normalized 4-d LC50 of $2.4 \mu \mathrm{g} \mathrm{Cu} / \mathrm{L}$ for 40-dph white sturgeon, whereas the most sensitive life stage in the current study was 2-dph white sturgeon with a BLM-normalized 4-d EC50 of $1.51 \mu \mathrm{g} \mathrm{Cu} / \mathrm{L}$ (tables A-5 and A-7). Although in Vardy and others (2013) the most sensitive life stage observed for copper was white sturgeon at $40 \mathrm{dph}$, whereas in the current study white sturgeon at 2 dph were more sensitive, the differences in sensitivity could be because of the different sturgeon populations that were tested. Moreover, early life stages of white sturgeon in the age range of 2-40 dph proved to be sensitive to copper exposure in both studies.

Little and others (2012) also determined endangered Kootenai white sturgeon at $38 \mathrm{dph}$ were sensitive to copper exposure with a BLM-normalized 4-d LC50 of $2.3 \mu \mathrm{g} \mathrm{Cu} / \mathrm{L}$, which is similar to the U.S. Environmental Protection Agency WQC for copper of $2.3 \mu \mathrm{g} \mathrm{Cu} / \mathrm{L}$ (U.S. Environmental Protection Agency, 2007a). The BLM-normalized LC50 for previously tested Columbia River white sturgeon at 26 dph was comparable at $2.2 \mu \mathrm{g} \mathrm{Cu} / \mathrm{L}$ (Little and others, 2012), indicating sturgeon in the age range of 2-40 dph had copper sensitivity thresholds below the U.S. Environmental Protection Agency (2007a) BLM-based WQC for copper of $2.3 \mu \mathrm{g} \mathrm{Cu} / \mathrm{L}$. Loss of equilibrium or immobilization was observed but not an endpoint reported by Little and others (2012); however, sensitivity based on mortality only (LC50) indicated the endangered Kootenai white sturgeon are more sensitive to copper during the early life stages. The 4-d EC50 (8.06 $\mu \mathrm{g} \mathrm{Cu} / \mathrm{L})$ for 2-dph sturgeon obtained from the companion chronic exposure (appendix table 2-5) substantially was lower than the 4-d 
Table A-7. Comparison of 4-day acute LC50 values for white sturgeon (Acipenser transmontanus) to copper at various life stages.

[Toxicity data for copper reported in Vardy and others (2013) were normalized using biotic ligand model (BLM) based on moderately hard reconstituted water (hardness $85 \mathrm{mg} / \mathrm{L}$, dissolved organic carbon $0.5 \mathrm{mg} / \mathrm{L}$ ). mg/L, milligram per liter; dph, days-post-hatch; h, hours; LC50, lethal concentration to 50 percent; $\mu \mathrm{g} \mathrm{Cu} / \mathrm{L}$, micrograms copper per liter; USEPA, U.S. Environmental Protection Agency; FAV, final acute value; >, greater than; <, less than; DOC, dissolved organic carbon; WQC, waterquality criteria; $\mathrm{CMC}$, criterion maximum concentration]

\begin{tabular}{|c|c|c|c|c|}
\hline Reference & $\begin{array}{l}\text { Life stage } \\
\quad \text { (dph) }\end{array}$ & $\begin{array}{l}\text { Reported } 96 \mathrm{~h} \\
\text { LC50 } \\
(\mu \mathrm{g} \mathrm{Cu} / \mathrm{L})\end{array}$ & $\begin{array}{l}\text { BLM-adjusted } \\
\text { LC50 to USEPA } \\
\text { standard water } \\
\quad(\mu \mathrm{g} \mathrm{Cu} / \mathrm{L})^{1}\end{array}$ & $\begin{array}{c}\text { BLM-adjusted } \\
\text { FAV based on test } \\
\text { water chemistry } \\
(\mu \mathrm{g} \mathrm{Cu} / \mathrm{L})^{2}\end{array}$ \\
\hline This study & 2 & $>23.6$ & $>16.2$ & 7.9 \\
\hline $\begin{array}{l}\text { Companion study } \\
\text { (Wang and others, chapter 2) }\end{array}$ & 2 & 8.06 & 4.9 & 7.7 \\
\hline Vardy and others (2013) & 8 & 22 & 5.3 & 19.4 \\
\hline $\begin{array}{l}\text { Markus Hecker, } \\
\text { University of Saskatchewan, } \\
\text { written commun., } 2011\end{array}$ & 8 & 17.2 & & \\
\hline $\begin{array}{l}\text { Entrix and University of Sas- } \\
\text { katchewan (2011) }\end{array}$ & $8-10$ & 30 & & \\
\hline Vardy and others (2013) & 15 & 10 & 2.9 & 16 \\
\hline This study & ${ }^{3} 16$ & 7.1 & 4.4 & 7.6 \\
\hline Little and others (2012) & 26 & 4.5 & ${ }^{4} 2.2$ & \\
\hline Little and others (2012) & 27 & 6.8 & 8.2 & \\
\hline This study & 30 & 16.4 & 11.8 & 7 \\
\hline Little and others (2012) & 38 & 4.1 & ${ }^{4} 2.3$ & \\
\hline $\begin{array}{l}\text { Markus Hecker, } \\
\text { University of Saskatchewan, } \\
\text { written commun., } 2011\end{array}$ & 40 & 11.7 & & \\
\hline Vardy and others (2013) & 40 & 9 & 2.4 & 17.1 \\
\hline Little and others (2012) & 40 & 4.7 & 5.5 & \\
\hline This study & 44 & $>50$ & $>34.1$ & 7 \\
\hline Vardy and others (2013) & 45 & 17 & 6.8 & 11.6 \\
\hline This study & 61 & $<90$ & $<56$ & 7 \\
\hline This study & 72 & 74 & 51.3 & 6.4 \\
\hline This study & 89 & 90 & 62.9 & 6.4 \\
\hline Vardy and others (2013) & 100 & 54 & 16.1 & 17.1 \\
\hline
\end{tabular}

${ }^{1}$ For BLM-normalized LC50s, the BLM was used to extrapolate the actual LC50s to those expected for the "BLM-standard" water conditions, which is a moderately hard water, with $\mathrm{pH}$ of 7.5 and $0.5 \mathrm{mg} / \mathrm{L} \mathrm{DOC}$, following the approach used by U.S. Environmental Protection Agency (2007a). The FAV for "BLM standard" water is $4.67 \mu \mathrm{g} / \mathrm{L}$ (U.S. Environmental Protection Agency, 2007a).

${ }^{2}$ U.S. Environmental Protection Agency (2007a) FAV, calculated for the individual measured test water chemistries.

${ }^{3}$ Control survival for the 16-dph test was less than 90 percent, thus the EC50 calculation is not definitive.

${ }^{4}$ Value is at or below the 2007 U.S. Environmental Protection Agency WQC for copper CMC $=2.3 \mu \mathrm{g} / \mathrm{L}$. 
LC50 ( $>23.6 \mu \mathrm{g} \mathrm{Cu} / \mathrm{L})$ generated for the acute exposure during round 1 where 2-dph sturgeon were tested; however, when immobilization was included in the calculation of a 4-d EC50 for the chronic study, sensitivity of 2-dph sturgeon at the start of the chronic copper exposures was more comparable to the acute exposure round 1 (chapter B, 4-d EC50 of $5.29 \mu \mathrm{g} \mathrm{Cu} / \mathrm{L}$ as compared to chapter A, 4-d EC50 of $2.7 \mu \mathrm{g} \mathrm{Cu} / \mathrm{L}$ ). Interestingly, when the LC50s reported by Vardy and others (2013) and Little and others (2012) are BLM-normalized to moderately hard water with water hardness of $85 \mathrm{mg} / \mathrm{L}$ and DOC of $0.5 \mathrm{mg} / \mathrm{L}$ (U.S. Environmental Protection Agency, 2007a), the LC50s are similar to EC50s in the acute (chapter A) and chronic (chapter B) parts of the current study with BLM-normalized LC50s ranging from 2.4-16.1 $\mu \mathrm{g} \mathrm{Cu} / \mathrm{L}$ for sturgeon 8-100 dph (table A-7).

Although the acute and chronic exposures were performed using the same age of sturgeon from the same cohort, differences in the EC50s generated during the current study and at the start of the chronic exposures may have been because of the test chamber configuration. No substrate was used in the acute exposures in the current study to enable observations of fish exhibiting loss of equilibrium and immobilization in addition to daily behavioral observations. Immobilization is a severe effect, however under some circumstances, the loss of locomotory movements may be reversible endpoints if the stressor is eliminated before death. Examples include recovery from loss of equilibrium during electrofishing capture, anesthetics such as clove oil or tricaine methanesulfonate (MS-222), or thermal stress (for example, Lydy and Wissing, 1988). The copper 4-d EC50 generated during the chronic exposure $(5.3 \mu \mathrm{g} \mathrm{Cu} / \mathrm{L})$ was 2 -fold greater (chapter B) than the 2-dph 4-d EC50 generated in the current study. Another difference was that in the companion chronic exposure, the EC50 was calculated using mortality and immobilization, whereas mortality, immobilization, and loss of equilibrium were included in the estimated EC50s in the current study. Nonetheless, early life stage 2-dph sturgeon proved to be sensitive to copper during the chronic exposures (chapter B) and in the acute exposures in the current study. When examining older sturgeon larvae (27-30 dph), the 4-d EC50s generated between the two studies were similar (chapter A, 30-dph 4-d EC50 of $6.31 \mu \mathrm{g} \mathrm{Cu} / \mathrm{L}$; chapter B, 27-dph 4-d EC50 of $7.36 \mu \mathrm{g} \mathrm{Cu} / \mathrm{L}$; appendix table 2-5) suggesting 27- to 30-dph sturgeon also were sensitive to copper exposure.

White sturgeon at 2 dph was the most sensitive life stage tested relative to the sensitivity to copper of other species (that is, the 3rd percentile in a compiled toxicity database; fig. A-6), even when compared to other sturgeon species that were tested at older life stages (Dwyer and others, 2005). Rainbow trout at $95 \mathrm{dph}$, in contrast, were ranked at the 30th percentile in sensitivity to copper. This finding is consistent with those obtained in the companion study on chronic sensitivity where acute sensitivity was examined in the first 4 days of a 53-day exposure initiated with 2-dph sturgeon (chapter B).

An important caution when interpreting the ranked sensitivity of copper BLM-normalized tests is that uncertainties in
DOC concentrations could lead to different interpretations of relative species sensitivity. Individual measurements of DOC in test chambers, as analyzed by Huffman Laboratory, ranged from about 0.3 to $0.5 \mathrm{mg} / \mathrm{L}$, and the best estimate of DOC in test exposures was $0.4 \mathrm{mg} / \mathrm{L}$ (appendix 6). This value was used in the extrapolations of measured test values to what those values might have been if tested in standardized moderately hard water with $0.5 \mathrm{mg} / \mathrm{L}$ DOC (that is, BLM normalization in table A-7).

White sturgeon were less sensitive to cadmium exposure during the early life stages and tended to become more sensitive with the older life stages. This is consistent with what was documented in the companion study (chapter B) during the first 4 days of the second phase of the chronic exposure, where the sturgeon 4-d EC50 for cadmium at $27 \mathrm{dph}$ was $>11.0 \mu \mathrm{g} \mathrm{Cd} / \mathrm{L}$ (appendix table 2-5) and the 4-d EC50 for 30-dph sturgeon was $102.7 \mu \mathrm{g} \mathrm{Cd} / \mathrm{L}$ in the current study (table A-4). This result could possibly be because of the size differences at each life stage. The most sensitive life stage for white sturgeon in the current study was at $72 \mathrm{dph}$ with a hardness-adjusted EC50 of $3.02 \mu \mathrm{g} \mathrm{Cd} / \mathrm{L}$ (table A-4) ranking in the species sensitivity distribution at the 19th percentile in a compiled cadmium toxicity database (fig. A-5).

Zinc toxicity varied by life stage for white sturgeon. The reported EC50s in table A-6 were normalized to a compiled BLM toxicity database for zinc (DeForest and Van Genderen, 2012) and tended to be more conservative, sometimes 37 percent more conservative, for white sturgeon. White sturgeon at 2 dph of development were most vulnerable to zinc toxicity with a BLM-normalized EC50 of $209 \mu \mathrm{g} / \mathrm{L}$ (table A-6). In the companion study, zinc toxicity at the start of the chronic exposures was consistent for white sturgeon at $2 \mathrm{dph}$ (4-d

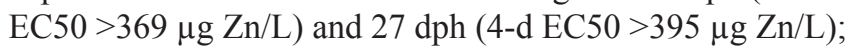
however, the chronic exposure concentrations were quite lower than the concentrations used during the acute exposures (table A-2; appendix table 2-5).

\section{Comparisons of Effect and Criteria Concentrations}

An objective of the study was to determine if concentrations of cadmium, copper, and zinc in the UCR could result in acute toxicity to white sturgeon. The data generated during this study necessitates extrapolating effects concentrations obtained in CERC laboratory waters to the UCR. For maximum internal comparability of test results with different species and life stages, tests were performed using the same test waters. These test conditions had a slightly higher water hardness and lower DOC than waters from the UCR. The median test water hardness in the acute tests in the current study was $103 \mathrm{mg} / \mathrm{L}$, ranging from 95 to $108 \mathrm{mg} / \mathrm{L}$ at a DOC of about $0.4 \mathrm{mg} / \mathrm{L}$ (appendix table 1-2; appendix 6). In contrast, the median water hardness in the UCR at Northport, Wash. was $63 \mathrm{mg} / \mathrm{L}$, ranging from 54 to $76 \mathrm{mg} / \mathrm{L}$ in monthly sampling by the U.S. Geological Survey from 1995 to 2000. During this 
period, the median DOC was $1.3 \mathrm{mg} / \mathrm{L}$, ranging from 0.9 to $2.6 \mathrm{mg} / \mathrm{L}$ (http://waterdata.usgs.gov/nwis, site 12400520).

The median UCR characteristics for a given copper concentration would be about 2.5 -fold less toxic in the UCR water compared to CERC laboratory water, using a BLM to compare the relative toxicities of copper (U.S. Environmental Protection Agency, 2007a). With zinc, the toxicity of a given concentration would be about 1.3-fold less toxic in the UCR water compared to CERC laboratory water, using the BLM of DeForest and VanGenderen (2012) to compare the relative toxicities of zinc. With cadmium, BLMs are less developed than for copper or zinc. A given concentration of cadmium was estimated to be about 1.5 fold more toxic in the UCR than in the CERC laboratory water, using hardness-toxicity relations (Mebane, 2006). Thus, absolute effect concentrations from the tests in the current study should not be extrapolated directly to UCR conditions, and instead these effect concentrations for test water in the current study were compared to the BLM or hardness-dependent U.S. Environmental Protection Agency water-quality criteria (WQC) and to the Washington State water-quality standards (WQS; Department of Ecology, 2006), calculated for test water conditions.

Effect concentrations for cadmium based on water hardness varied among life stage for white sturgeon (table A-4). The most sensitive life stage for white sturgeon was at $72 \mathrm{dph}$ with an EC50 of $5.6 \mu \mathrm{g} / \mathrm{L}$. This value is greater than the U.S. Environmental Protection Agency (1984) FAV of $4.0 \mu \mathrm{g} \mathrm{Cd} / \mathrm{L}$, calculated for the test hardness of $100 \mathrm{mg} / \mathrm{L}$. In contrast, four of the seven rainbow trout life stages tested resulted in cadmium EC50s that were lower than the U.S. Environmental Protection Agency (1984) FAV values calculated for the hardness of each test. The cadmium hardness adjusted EC50 for 72-dph sturgeon was below the U.S. Environmental Protection Agency (2001) acute WQC for cadmium (FAV of $4.0 \mu \mathrm{g} \mathrm{Cd} / \mathrm{L}$ ) and below the Washington State WQS for acute toxicity of cadmium $(7.4 \mu \mathrm{g} \mathrm{Cd} / \mathrm{L})$; however, rainbow trout at $18,46,60$, and 95 dph all had cadmium EC50s below the acute WQC and all life stages with the exception of $1 \mathrm{dph}$ fell below the state of Washington State WQS for the acute toxicity of cadmium.

The $\mathrm{Cu}$ EC50s for white sturgeon at ages 2 and $30 \mathrm{dph}$ were lower than the U.S. Environmental Protection Agency (2007a) BLM-based FAV concentrations calculated for test conditions, as was the EC50 for white sturgeon at $16 \mathrm{dph}$, although the EC50 for 16-dph sturgeon was classified as a nondefintive effect concentration because control survival in that test was less than 90 percent (table A-5). The EC50s for these developmental stages ranged from about 2.7 to $6.3 \mu \mathrm{g} \mathrm{Cu} / \mathrm{L}$ compared to the BLM-based FAV values of 7.0 to $7.9 \mu \mathrm{g} \mathrm{Cu} / \mathrm{L}$ for the test conditions. In contrast, the U.S. Environmental Protection Agency (1985) hardness-based FAVs were much higher than test EC50 (FAV about $36 \mu \mathrm{g} \mathrm{Cu} / \mathrm{L}$ as compared to EC50s ranging from 2.7 to $6.3 \mu \mathrm{g} \mathrm{Cu} / \mathrm{L}$ ). The rainbow trout EC50s at 60 and 95 dph were lower than the U.S. Environmental Protection Agency (1985) hardness-based FAVs that were used to define the Washington State WQS for acute $\mathrm{Cu}$ exposures $(29.2 \mu \mathrm{g} \mathrm{Cu} / \mathrm{L})$. In turn, the rainbow trout copper EC50s at all life stages tested (table A-5) were all greater than the U.S. Environmental Protection Agency (2007a) BLM-based FAV concentration calculated for test conditions.

The Zn EC50s for the most sensitive life stage of white sturgeon was at $2 \mathrm{dph}$ with an EC50 of $146.7 \mu \mathrm{g} \mathrm{Zn/L}$ (table A-6). The U.S. Environmental Protection Agency (1996) zinc FAV is higher, $204 \mu \mathrm{g} \mathrm{Zn/L}$ for the test water hardness of $100 \mathrm{mg} / \mathrm{L}$, and the Washington State WQS for zinc is similar with a FAV of $200 \mu \mathrm{g} \mathrm{Zn} / \mathrm{L}$ (Washington State Department of Ecology, 2006). The rainbow trout EC50s at all life stages tested (table A-6) were also greater than the U.S. Environmental Protection Agency (1996) hardness-based FAV (204 $\mu \mathrm{g} \mathrm{Zn/L).}$

\section{Conclusions}

White sturgeon were more sensitive to copper than rainbow trout for five of the seven life stages tested. Sturgeon at 2, 16, and 30 days-post-hatch (dph) were highly sensitive to copper, whereas older life stages were less sensitive. Early life stage white sturgeon, specifically at $2 \mathrm{dph}$, were highly sensitive to zinc and the 2-dph life stage of white sturgeon was the only life stage that was more sensitive than rainbow trout at any life stage tested. White sturgeon tended to become more sensitive to cadmium with older life stages; however, when compared with rainbow trout, sturgeon considerably were less sensitive. Immobilization and loss of equilibrium were affected by metal exposure, particularly for copper and zinc. The U.S. Environmental Protection Agency (USEPA) acute water-quality criteria (WQC) would be protective of rainbow trout from exposure to copper, and zinc; however, for cadmium, the WQC and Washington State water-quality standard (WQS) would not necessarily be protective of rainbow trout. For this reason, rainbow trout would not be a good surrogate for protectiveness of white sturgeon. For early life stage white sturgeon, the WQC may not adequately be protective from exposure to copper or zinc, but would be protective from cadmium exposures at all life stages. The Washington State WQS would also be protective of white sturgeon exposed to cadmium except for the 72-dph life stage. However for copper and zinc the Washington State WQS would not necessarily protect the early life stages of white sturgeon from acute exposure.

\section{References Cited}

American Society for Testing and Materials, 2012a, Standard guide for performing early life-sage toxicity tests with fishes, E1241-05, in Annual Book of ASTM Standards, West Conshohocken, Pa., ASTM International, v. 11.06, p. 287-315. 
American Society for Testing and Materials, 2012b, Standard guide for measurement of behavior during fish toxicity tests, E1711-95 (2008), in Annual Book of ASTM Standards, West Conshohocken, Pa., ASTM International, v. 11.06, p. 952-963.

American Society for Testing and Materials, 2012c, Standard guide for performing acute toxicity tests on test materials with fishes, macroinvertebrates, and amphibians, E729-96 (2007), in Annual Book of ASTM Standards, West Conshohocken, Pa., ASTM International, v. 11.06, p. 67-89.

Anders, P.J., 1998, Conservation aquaculture and endangered species - Can objective science prevail over risk anxiety?: Fisheries Management Perspective, v. 23, no. 11, p. 28-31.

Anderson, P.D., and Weber, L.J., 1975, Toxic response as a quantitative function of body size: Toxicology and Applied Pharmacology, v. 33, no. 3, p. 471-483.

Beamsderfer, R.C.P., and Farr, R.A., 1997, Alternatives for the protection and restoration of sturgeons and their habitat: Environmental Biology of Fishes, v. 48, no. 1-4, p. 407417.

Besser, J.M., Mebane, C.A., Mount, D.R., Ivey, C.D., Kunz, J.L., Greer, E.I., May, T.W., and Ingersoll, C.G., 2007, Relative sensitivity of mottled sculpins (Cottus bairdi) and rainbow trout (Oncorhynchus mykiss) to toxicity of metals associated with mining activities: Environmental Toxicology and Chemistry, v. 26, no. 8, p. 1,657-1,665. (Also available at $h t t p: / / d x$.doi.org/10.1897/06-571R.1.).

Brumbaugh, W.G., May, T.W., Besser, J.M., Allert, A.L., and Schmitt, C.J., 2007, Assessment of elemental concentrations in streams of the New Lead Belt in southeastern Missouri, 2002-05: U.S. Geological Survey Scientific Investigations Report 2007-5057, $57 \mathrm{p}$.

Brunson, E.L., Canfield, T.J., Dwyer, F.J., Kemble, N.E., and Ingersoll, C.G., 1998, Assessing bioaccumulation of contaminants from sediments from the upper Mississippi River using field-collected oligochaetes and laboratory-exposed Lumbriculus variegatus: Archives of Environmental Contamination and Toxicology, v. 5, p. 191-201.

Cardno Entrix and University of Saskatchewan, 2011, Acute water exposures of cadmium, copper, and zinc to early lifestages of white sturgeon (Acipenser transmontanus): Report to Teck American Incorporated, $15 \mathrm{p}$.

Conte, F.S., Doroshov, S.I., Lutes, P.B., and Strange, E.M., 1988, Hatchery manual for the white sturgeon (Acipenser transmontanus, Richardson) with application to other North American Acipenseridae: Oakland, Calif., University of California, $104 \mathrm{p}$.
DeForest, D.K., and Van Genderen, E.J., 2012, Application of U.S. EPA guidelines in a bioavailability-based assessment of ambient water-quality criteria for zinc in freshwater: Environmental Toxicology and Chemistry, v. 31, no. 6, p. $1,264-1,272$.

Dwyer, F.J., Mayer, F.L., Sappington, L.C., Buckler, D.R., Bridges, C.M., Greer, I.E., Hardesty, D.K., Henke, C.E., Ingersoll, C.G., Kunz, J.L., Whites, D.W., Augspurger, T., Mount, D.R., Hattala, K., and Neuderferv, G.N., 2005, Assessing contaminant sensitivity of endangered and threatened aquatic species-Part I, Acute toxicity of five chemicals: Archives of Environmental Contamination and Toxicology, v. 48, no. 2, p. 143-154.

Eaton, A.D., Clesceri, L.S., Rice, E.W., and Greenberg, A.E., 2005, Standard methods for the examination of water and wastewater (21st ed.): Washington, D.C., American Public Health Association, Water Environment Federation, American Water Works Association, 1,368 p.

Erickson, R.J., 2012, Toxicity Relationship Analysis Program (TRAP), version 1.21, EPA/600/C-11/002: Washington, D.C., U.S. Environmental Protection Agency.

Fu, C., Wilson, J.M., Rombough, P.J., and Brauner, C.J., 2010, Ions first $-\mathrm{Na}+$ uptake shifts from the skin to the gills before $\mathrm{O} 2$ uptake in developing rainbow trout, Oncorhynchus mykiss-Proceedings of the Royal Society B: Biological Sciences, v. 277, no. 1687, p. 1,553-1,560.

Gadomski, D.M., and Parsley, M.J., 2005, Laboratory studies on the vulnerability of young white sturgeon to predation: North American Journal of Fisheries Management, v. 25, no. 2, p. 667-674.

Gisbert, E., 1999, Early development and allometric growth patterns in Siberian sturgeon and their ecological significance: Journal of Fish Biology, v. 54, no. 4, p. 852-862.

Grosell, M., Nielsen, C., and Bianchini, A., 2002, Sodium turnover rate determines sensitivity to acute copper and silver exposure in freshwater animals: Comparative Biochemistry and Physiology Part C-Toxicology and Pharmacology, v. 133, no. 1-2, p. 287-303.

Hansen, J.A., Welsh, P.G., Lipton, J., Cacela, D., and Dailey, A.D., 2002, Relative sensitivity of bull trout (Salvelinus confluentus) and rainbow trout (Oncorhynchus mykiss) to acute exposures of cadmium and zinc: Environmental Toxicology and Chemistry, v. 21, no. 1, p. 67-75.

Hedtke, J.L., Robinson-Wilson, E., and Weber, L.J., 1982, Influence of body size and developmental stage of coho salmon (Oncorhynchus kisutch) on lethality of several toxicants: Fundamental and Applied Toxicology, v. 2, no. 2, p. 67-72. 
Hendriks, A.J., and Heikens, A., 2001, The power of size. 2. Rate constants and equilibrium ratios for accumulation of inorganic substances related to species weight: Environmental Toxicology and Chemistry, v. 20, no. 7, p. 1,421-1,437.

Hildebrand, L., McLeod, C., and McKenzie, S., 1999, Status and management of white sturgeon in the Columbia River in British Columbia, Canada-An overview: Journal of Applied Ichthyology, v. 15, no. 4-5, p. 164-172.

Howell, M.D., and McLellan, J.G., 2009, Lake Roosevelt white sturgeon recovery project annual progress report January 2003-March 2004: Portland, Oregon, United States Department of Energy, Bonneville Power Administration, $43 \mathrm{p}$.

HydroQual, 2007, The biotic ligand model Windows interface, Version 2.2.3-User's guide and reference manual: Mahwah, New Jersey, HydroQual, 43 p.

Jager, H.I., Van Winkle, W., Chandler, J.A., Lepla, K.B., Bates, P., and Counihan, T.D., 2001, A simulation study of factors controlling white sturgeon recruitment in the Snake River, in Van Winkle W., Anders P.J., Secor, D.H., and Dixon, D.A., eds., Biology, management, and protection of North American sturgeon-Twenty-eighth symposium: Bethesda, Maryland, American Fisheries Society, p. 127150 .

Klaine, S.J., Bills, T.L., Wenholz, M.D., Point, T.W.L., Cobb, G.P., and Forsythe, B.L., II, 1996, Influence of age sensitivity on the acute toxicity of silver to fathead minnows at various quality parameters, in The 4th international conference proceedings: transport, fate and effects of silver in the environment: Madison, Wisconsin, University of Wisconsin. (Also available at http://digital.library.wisc. edu/1711.dl/EcoNatRes.Argentumv04).

Kruse, G.O., and Scarnecchia, D.L., 2002, Assessment of bioaccumulated metal and organochlorine compounds in relation to physiological biomarkers in Kootenai River white sturgeon: Journal of Applied Ichthyology, v. 18, no. 4-6, p. $430-438$.

Little, E.E., Calfee, R.D., and Linder, G., 2012, Toxicity of copper to early life stages of Kootenai River white sturgeon, Columbia River white sturgeon, and rainbow trout: Archives of Environmental Contamination and Toxicology, v. 63 , no. 3 , p. $400-408$.

Lydy, M.J., and Wissing, T.E., 1988, Effect of sublethal concentrations of copper on the critical thermal maxima (CTMax) of the fantail (Etheostoma flabellare) and johnny (E. nigrum) darters: Aquatic Toxicology, v. 12, p. 311-322.
McAdam, S.O., 2011, Effects of substrate condition on habitat use and survival by white sturgeon (Acipenser transmontanus) larvae and potential implications for recruitment: Canadian Journal of Fisheries and Aquatic Sciences, v. 68, no. 5 , p. $812-822$.

McAdam, S.O., Walters, C.J., and Nistor, C., 2005, Linkages between white sturgeon recruitment and altered bed substrates in the Nechako River, Canada: Transactions of the American Fisheries Society, v. 134, no. 6, p. 1,448-1,456.

Mebane, C.A., 2006, Cadmium risks to freshwater life-Derivation and validation of low-effect criteria values using laboratory and field studies, version 1.2: U.S. Geological Survey Scientific Investigations Report 2006-5245, 130 p.

Mebane, C.A., Dillon, F.S., and Hennessey, D.P., 2012, Acute toxicity of cadmium, lead, and zinc and their mixtures to stream resident fish and invertebrates: Environmental Toxicology and Chemistry, v. 31, no. 6, p. 1,334-1,338.

Meyer, J.S., Adams, W.J., DeForest, D.K., Dwyer, R.L., Gensemer, R.W., Gorsuch, J.W., Johnston, R.K., Santore, R.C., and Van Gendren, E., 2012, Water chemistry matters in metal toxicity papers: Environmental Toxicology and Chemistry, v. 31, no. 4, p. 689-690.

Mount, D.I., and Brungs, W.A., 1967, A simplified dosing apparatus for fish toxicological studies: Water Research, v. 1, no. 1, p. 21-29.

Rand, G.M., Wells, P.G., and McCarty, L.S., 1995, Introduction to aquatic toxicology, in Rand, G.M., ed., Fundamentals of aquatic toxicology - Effects, environmental fate, and risk assessment ( $2 \mathrm{~d}$ ed.): Washington, D.C., Taylor and Francis, p. 3-67.

Rombough, P.J., 2002, Gills are needed for ionoregulation before they are needed for $\mathrm{O} 2$ uptake in developing zebrafish, Danio rerio: Journal of Experimental Biology, v. 205, no. 12 , p. 1,787-1,794.

Santore, R.C., Paquin, P.R., Di Toro, D.M., Allen, H.E., and Meyer, J.S., 2001, Biotic ligand model of the acute toxicity of metals. 2. Application to acute copper toxicity in freshwater fish and Daphnia: Environmental Toxicology and Chemistry, v. 20, no. 10, p. 2,397-2,402.

Scott, G.R., and Sloman, K.A., 2004, The effects of environmental pollutants on complex fish behaviour-Integrating behavioural and physiological indicators of toxicity: Aquatic Toxicology, v. 68, no. 4, p. 369-392.

Smith, C.T., Nelson, R.J., Pollard, S., Rubidge, E., McKay, S.J., Rodzen, J., May, B., and Koop, B., 2002, Population genetic analysis of white sturgeon (Acipenser transmontanus) in the Fraser River: Journal of Applied Ichthyology, v. 18, no. 4-6, p. 307-312. 
Stephan, C.E., 2002, Use of species sensitivity distributions in the derivation of water-quality criteria for aquatic life by the U.S. Environmental Protection Agency, in Posthuma, L., Suter, G.W., II, and Traas, T.P., eds., Species sensitivity distributions in ecotoxicology: Boca Raton, Florida, CRC Press, p. 211-220.

Stephan, C.E., Mount, D.I., Hansen, D.J., Gentile, J.H., Chapman, G.A., and Brungs, W.A., 1985, Guidelines for deriving numerical national water-quality criteria for the protection of aquatic organisms and their uses: Duluth, Narragansett, and Corvallis, U.S. Environmental Protection Agency, EPA 822-R-85-100, NTIS PB85 227049, 98 p. (Also available at $h$ ttp://epa.gov/waterscience/criteria/aqlife.html).

U.S. Environmental Protection Agency, 1983, Method 415.2 Total organic carbon, in Methods for chemical analysis of water and wastes, Washington, D.C., U.S. Environmental Protection Agency, EPA/600/4-79-020, 552 p.

U.S. Environmental Protection Agency, 1984, Ambient waterquality criteria for cadmium: Duluth, Minn., U.S. Environmental Protection Agency, EPA 440/5-84-032, 133 pp.

U.S. Environmental Protection Agency, 1985, Ambient waterquality criteria for copper-1984: Duluth, Minn., U.S. Environmental Protection Agency, EPA 440/5-84-031, p. 142.

U.S. Environmental Protection Agency, 1987, Ambient waterquality criteria for zinc: Washington, D.C., U.S. Environmental Protection Agency, EPA 440/5-87-003, 194 p.

U.S. Environmental Protection Agency, 1994, Method 200.7-Determination of metals and trace metals in water and wastes by inductively coupled plasma-atomic emission spectrometry, revision 4.4.: Cincinnati, Ohio, U.S. Environmental Protection Agency, 58 p.

U.S. Environmental Protection Agency, 1996, Water-quality criteria documents for the protection of aquatic life in ambient water, 1995 updates, EPA-820-B-96-001: Washington, D.C., U.S. Environmental Protection Agency 114 p.

U.S. Environmental Protection Agency, 1999, Data validation standard operating procedures for contract laboratory program routine analytical services: Athens, Ga., U.S. Environmental Protection Agency, Science and ecosystem support division, Office of Quality Assurance, Revision 2.1, 32 p.

U.S. Environmental Protection Agency, 2001, 2001 Update of ambient water quality criteria for cadmium, EPA822-R-01-001: Washington, D.C., U.S. Environmental Protection Agency, 266 p.

U.S. Environmental Protection Agency, 2002, Short-term methods for estimating the chronic toxicity of effluents and receiving water to freshwater organisms, EPA/821/R-02/013 (5th ed.): Washington, D.C., U.S. Environmental Protection Agency, $335 \mathrm{p}$.
U.S. Environmental Protection Agency, 2007a, Aquatic life ambient freshwater-quality criteria-Copper: Washington, D.C., Office of Water, EPA-822-R-07-001. p. 48.

U.S. Environmental Protection Agency, 2007b, Method 9056-Determination of inorganic anions by ion chromatography, in SW-846 Online-Test methods for evaluating solid waste, physical/chemical methods. (Also available at http://www.epa.gov/osw/hazard/testmethods/sw846/ $\left.p d f_{s} / 9056 a . p d f\right)$.

U.S. Environmental Protection Agency, 2010, U.S. Environmental Protection Agency technical team level of effort for investigations on the effects of exposures of White Sturgeon to chemicals of interest in the Upper Columbia River (written commun. from Helen Bottcher, USEPA, Seattle Wash., February 4, 2010).

U.S. Geological Survey, 2010, USGS-Columbia Quality Assurance Project Plan for an evaluation of the acute or chronic toxicity of individual chemicals of interest to white sturgeon (Acipenser transmontanus) and rainbow trout (Oncorhynchus mykiss) in water-only exposures: Columbia, Missouri, U.S. Geological Survey, Columbia Environmental Research Center $41 \mathrm{p}$.

Upper Columbia White Sturgeon Recovery Initiative, 2002, Upper Columbia White Sturgeon Recovery Plan: accessed December 2012 at http://uppercolumbiasturgeon.org.

Vardy, D.W., Oellers, J., Doering, J.A., Hollert, H., Giesy, J.P., and Hecker, M., 2013, Sensitivity of early life stages of white sturgeon, rainbow trout, and fathead minnow to copper: Ecotoxicology, v. 22, no. 1, p. 139-147.

Vardy, D.W., Tompsett, A.R., Sigurdson, J.L., Doering, J.A., Zhang, X., Giesy, J.P., and Hecker, M., 2011, Effects of subchronic exposure of early life stages of white sturgeon (Acipenser transmontanus) to copper, cadmium, and zinc: Environmental Toxicology and Chemistry, v. 30, p. 2,4972,505 .

Washington State Department of Ecology, 2006, Water-quality standards for surface waters of the State of Washington: Olympia, Washington, Washington State Department of Ecology, Chapter A73-201A WAC, 108 p.

Western EcoSystems, 1996, TOXSTAT, version 3.5: Cheyenne, Wyo., $38 \mathrm{p}$. 


\section{Chronic Sensitivity of White Sturgeon (Acipenser transmontanus) and Rainbow Trout (Oncorhynchus mykiss) to Cadmium, Copper, Lead, or Zinc in Laboratory Water- Only Exposures}

By Ning Wang, Christopher G. Ingersoll, Rebecca A. Dorman, James L. Kunz, Doug K. Hardesty, William G. Brumbaugh, and Christopher A. Mebane,

Chapter B of

Acute and Chronic Sensitivity of White Sturgeon (Acipenser transmontanus) and Rainbow Trout (Oncorhynchus mykiss) to Cadmium, Copper, Lead, or Zinc in Laboratory Water-Only Exposures

Edited by Christopher G. Ingersoll and Christopher A. Mebane

Prepared in cooperation with the U.S. Environmental Protection Agency and Teck American, Inc.

Scientific Investigations Report 2013-5204 


\title{
U.S. Department of the Interior SALLY JEWELL, Secretary
}

\author{
U.S. Geological Survey \\ Suzette M. Kimball, Acting Director
}

\author{
U.S. Geological Survey, Reston, Virginia: 2014
}

For more information on the USGS - the Federal source for science about the Earth, its natural and living resources, natural hazards, and the environment, visit http://www.usgs.gov or call 1-888-ASK-USGS.

For an overview of USGS information products, including maps, imagery, and publications, visit http://www.usgs.gov/ pubprod

To order this and other USGS information products, visit http://store.usgs.gov

Any use of trade, firm, or product names is for descriptive purposes only and does not imply endorsement by the U.S. Government.

Although this information product, for the most part, is in the public domain, it also may contain copyrighted materials as noted in the text. Permission to reproduce copyrighted items must be secured from the copyright owner.

Suggested citation for the volume:

Ingersoll, C.G., and Mebane, C.A., eds., 2014, Acute and chronic sensitivity of white sturgeon (Acipenser transmontanus) and rainbow trout (Oncorhynchus mykiss) to cadmium, copper, lead, or zinc in laboratory water-only exposures:

U.S. Geological Survey Scientific Investigations Report 2013-5204, 70 p., plus appendixes, http://dx.doi.org/10.3133/ sir20135204.

Suggested citation for this chapter:

Wang, Ning, Ingersoll, C.G., Dorman, R.A., Kunz, J.L., Hardesty, D.K., Brumbaugh, W.G., and Mebane, C.A., 2014, Chronic sensitivity of white sturgeon (Acipenser transmontanus) and rainbow trout (Oncorhynchus mykiss) to cadmium, copper, lead, or zinc in laboratory water-only exposures, chap. A of Ingersoll, C.G., and Mebane, C.A., eds., 2014, Acute and chronic sensitivity of white sturgeon (Acipenser transmontanus) and rainbow trout (Oncorhynchus mykiss) to cadmium, copper, lead, or zinc in laboratory water-only exposures: U.S. Geological Survey Scientific Investigations Report 2013-5204, p. 35-70.

ISSN 2328-0328 (online) 


\section{Contents}

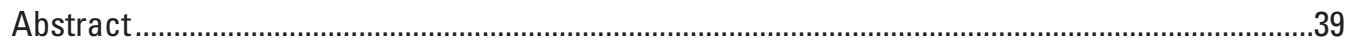

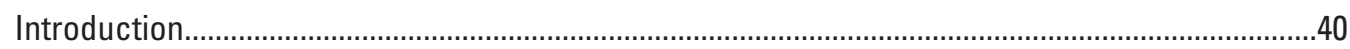

Methods

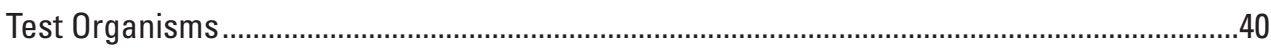

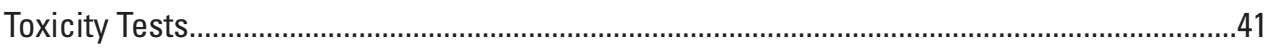

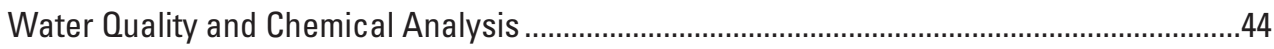

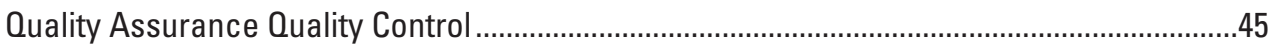

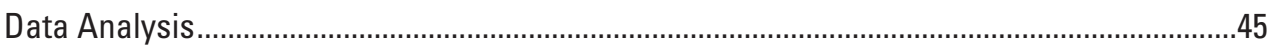

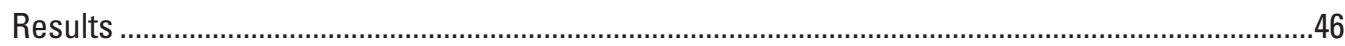

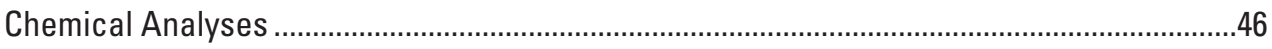

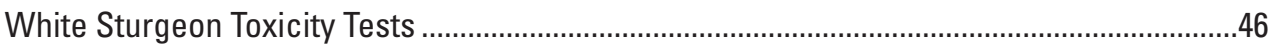

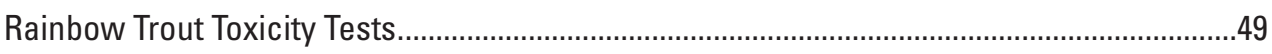

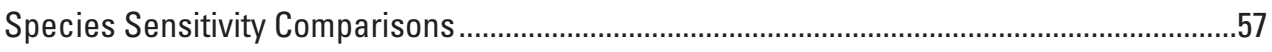

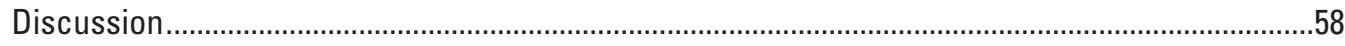

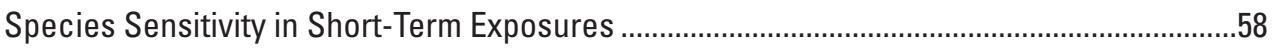

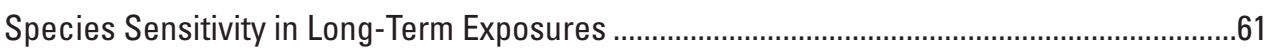

Comparison to Other Studies with White Sturgeon ………..................................................61

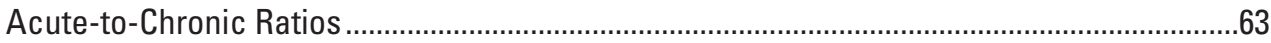

Effect of the Age of Fish on Sensitivity to Metals.............................................................63

Implications of Uncertainty in DOC Measurements on Estimates of the Sensitivity of

White Sturgeon to Copper .........................................................................................65

Developmental Behavior of White Sturgeon Larvae ...............................................................66

Pseudo Control Replicates in 53-day White Sturgeon CC Exposures.....................................66

High Light Intensity during White Sturgeon C1/CC Exposures.................................................66

Variation in Control Survival and Growth among Replicates or Exposure Systems................66

Higher Loading Density at the End of Sturgeon CC 53-day and C2 28-day Exposures............67

Elevated Mortalities at the Onset of Exogenous Feeding ...................................................67

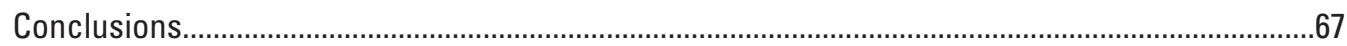

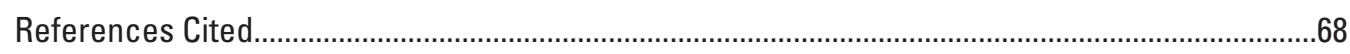

\section{Figures}

B-1. Photographs showing examples of hiding behavior and immobilization of white sturgeon on test day 8 in the 53-day exposure starting with 2-days-post-hatch larvae

B-2. Graphs showing mean percentage of mortality, mortality plus immobilization, or mortality plus immobilization and lack of hiding of white sturgeon during the first 4 and 8 days of the 53-day exposures starting with 2-days-post-hatch larvae

B-3. Graph showing cumulative survival of white sturgeon in the controls during the 53-day test period in the four metal exposures starting with 2-days-post-hatch larvae. 
B-4. Graph showing acute 4-day 50-percent lethal concentrations for the four metals in the first 4 days of 28-day exposures starting with 27-days-post-hatch white sturgeon and 26-days-post-hatch rainbow trout

B-5. Graphs showing acute 4-day and short-term 8-day A, 50-percent lethal concentration or $B, 20$-percent effect concentration for copper during the first 4 and 8 days of the 53-day exposures starting with 2-days-post-hatch white sturgeon, compared to U.S. Environmental Protection Agency water-quality criteria and Washington State water-quality standards for copper adjusted to test water-quality characteristics

B-6. Graphing showing twenty-percent effect concentrations for four metals based on the most sensitive endpoint in three chronic exposures with different life stages of white sturgeon and rainbow trout, compared to the U.S. Environmental Protection Agency chronic water-quality criterion and the Washington State chronic water-quality standard adjusted to test water-quality characteristics

B-7. Graphs showing ranks of white sturgeon and rainbow trout in species sensitivity distribution from compiled databases for cadmium, copper, lead, and zinc

\section{Tables}

B-1. Summary conditions for conducting chronic water-only toxicity tests with white sturgeon and rainbow trout following standard test methods recommended by the American Society for Testing and Materials, the U.S. Environmental Protection Agency, and U.S. Geological Survey-Columbia Quality Assurance Project Plan

B-2. Chronic responses of white sturgeon and effect concentrations in 53-day exposures to four metals starting with 2-days-post-hatch larval sturgeon...

B-3. Chronic responses of white sturgeon and effect concentrations in 28-day exposures starting with 27-days-post-hatch juvenile sturgeon

B-4. Chronic responses of rainbow trout and effect concentrations in 52-day exposures starting with 1-day-post-hatch larval trout.

B-5. Chronic responses of rainbow trout and effect concentrations in 21-day exposures starting with 1-day-post-hatch larvae or in 28-day exposures with 26-days-post-hatch juveniles

B-6. Comparison of toxicity data from three studies on chronic cadmium, copper, or zinc toxicity to white sturgeon, U.S. Environmental Protection Agency chronic water-quality criterion, and Washington State chronic water-quality standard

B-7. Acute-to-chronic ratio based on acute and chronic effect concentrations in four chronic metal exposures with white sturgeon and rainbow trout 


\title{
Chronic Sensitivity of White Sturgeon (Acipenser transmontanus) and Rainbow Trout (Oncorhynchus mykiss) to Cadmium, Copper, Lead, or Zinc in Laboratory Water-Only Exposures
}

\author{
By Ning Wang, Christopher G. Ingersoll, Rebecca A. Dorman, James L. Kunz, Doug K. Hardesty, \\ William G. Brumbaugh, and Christopher A. Mebane
}

\section{Abstract}

White sturgeon (Acipenser transmontanus) are experiencing poor recruitment in the trans boundary reach of the upper Columbia River (UCR) in eastern Washington State. Limited toxicity data indicated that early life stages of white sturgeon were sensitive to metals; however, insufficient information is available to define acute or chronic toxicity thresholds for metals for this species. The objectives of this study were to (1) evaluate comparative sensitivity of white sturgeon and commonly tested rainbow trout (Oncorhynchus mykiss) to cadmium, copper, lead, or zinc in chronic water-only exposures; and (2) determine if U.S Environmental Protection Agency national recommended chronic water-quality criteria (WQC) or Washington State chronic water-quality standards (WQS) are protective of white sturgeon to the metal exposures. For each of the four metals, three chronic toxicity tests were performed in 2010 in four intermittent flow-through proportional diluters: (1) chronic life-stage 1 exposures (about 3 weeks) starting with 1- or 2-days-post-hatch (dph) larvae, (2) chronic life-stage 2 exposures (about 4 weeks) starting with 26- or 27-dph juveniles, and (3) chronic continuous exposures (about 8 weeks) starting with 1- or 2-dph larvae. All toxicity tests met test acceptability requirements, except the 53-day (d) chronic continuous exposures starting with 2-dph sturgeon, where the mean control survival ranged from 39 to 71 percent on test day 25 and ranged from 33 to 68 percent on test day 53 in the four metal exposures. The control mortality primarily was observed from about 17 to $22 \mathrm{dph}$ during transition to exogenous feeding in the 53-d exposures. Effect concentrations from tests that met test acceptability requirements are classified as definitive effect concentrations. Effect concentrations from the 53-d exposures that did not meet test acceptability requirements (low control survival) were classified as nondefinitive effect concentrations.
Based on the most sensitive endpoint among the survival, wet weight, dry weight, or biomass, the 20-percent effect concentrations (EC20s) for cadmium were similar between the two fish species, whereas the EC20s for copper, lead, or zinc for the sturgeon were about 4- to 21-fold lower than those EC20s for the trout. The definitive EC20s for white sturgeon were in the low percentile of freshwater species sensitivity distribution in a compiled toxicity database for copper (9th percentile) and in the middle percentile for cadmium (55th percentile), lead (50th percentile), or zinc (40th percentile); however, the EC20s for rainbow trout were in the high percentiles for copper, lead, and zinc (about 68th to 82th percentile), but in a low percentile for cadmium (23rd percentile).

The definitive EC20s for the four metals in the trout tests and EC20s for cadmium, lead, and zinc in the sturgeon tests with the two life stages of fish were above the chronic WQC and the Washington State WQS, whereas the sturgeon EC20s for copper were about equal to the chronic WQC and more than 4-fold lower than the Washington State WQS for copper. The results of these comparisons did not change when including the nondefinitive EC20s obtained from the longer-term 53-d sturgeon exposure that did not meet test acceptability requirement because of the low control survival. Exceptions were that a nondefinitive EC20 for copper or zinc based on dry weight in the sturgeon 53-d exposure was even below the WQC and Washington State WQS for copper or zinc.

A repeated 24-d copper toxicity test was performed in 2012, starting 1-dph sturgeon under similar test conditions to the 2010 study. Mean control survival was 93 percent and met the test acceptability requirement of $\geq 80$ percent control survival. The EC20s obtained from the repeated testing with a high control survival were similar to those obtained in the 53-d copper exposure performed in 2010 with a low control survival, and also were below the chronic WQC or Washington State WQS for copper. 
The acute 4-d EC50 (estimated based on mortality plus immobilization) for copper in the first 4 days of the chronic exposures with the sturgeon was below the final acute value used to derive acute WQC and 3-fold lower than the Washington State acute WQS for copper. In addition, the short-term 8-d copper EC20 based on mortality plus immobilization or the EC20 based on mortality, immobilization, and lack of hiding in the sturgeon exposure were below the chronic WQC and below the Washington State chronic WQS for copper.

These results of this study indicate that (1) white sturgeon and rainbow trout exhibited a similar chronic sensitivity to cadmium, but white sturgeon were more sensitive to copper, lead, or zinc compared to rainbow trout; (2) white sturgeon was highly sensitive to chronic copper exposure, moderately sensitive to lead or zinc, and relatively insensitive to cadmium in compiled toxicity databases; (3) the chronic national WQC and Washington State WQS would be adequately protective of rainbow trout to exposure to each of the four tested metals and white sturgeon to exposure to cadmium or lead, but might not be adequately protective of white sturgeon to exposures to copper or zinc; and (4) the acute WQC and Washington State acute WQS for copper would not necessarily be protective of white sturgeon. Additionally, the survival and behavior of newly hatched white sturgeon rapidly were impaired within a 4-d or 8-d exposure period at the concentrations at or below the chronic WQC or below the Washington State chronic WQS for copper. Results of this study will be submitted for consideration as part of a baseline ecological risk assessment being performed at the UCR in eastern Washington State. All procedures for the culturing and testing of organisms followed a USEPA approved quality assurance project plan developed for this study (U.S. Geological Survey, 2010).

\section{Introduction}

The recruitment of white sturgeon (Acipenser transmontanus) has been low in the trans boundary reach of the upper Columbia River (UCR) in eastern Washington State since at least the 1980s (Upper Columbia White Sturgeon Recovery Initiative, 2002). Environmental contamination has been identified as one of several contributing factors to the declines of white sturgeon (Upper Columbia White Sturgeon Recovery Initiative, 2002). Limited toxicity data indicated that early life stages of white sturgeon are sensitive to metals (Vardy and others, 2011 and 2013; Little and others, 2012). In acute 4-day (d) exposures with larval white sturgeon, Little and others (2012) reported that the 50-percent lethal concentrations (LC50) for copper were at or below the U.S. Environmental Protection Agency (USEPA) acute water-quality criterion (WQC; U.S. Environmental Protection Agency, 2007a). In chronic 66-d exposures starting with newly fertilized eggs of white sturgeon, Vardy and others (2011) reported that the 20-percent lethal effect concentrations (LC20s) for copper, cadmium, or zinc generally were within a factor of two of the chronic values of the most sensitive fish species in the databases of the WQC for the three metals; however, there were some uncertainties in the chronic exposures performed by Vardy and others (2011), including (1) low control survival (37 percent), (2) more control fish tested in each replicate compared to other treatments, (3) limited replication of treatments $(\mathrm{n}=2)$, (4) lack of reported growth data (such as dry weight), and (5) wide dilution factors for exposure concentrations (6- to 8-fold dilutions). Additional studies are needed to generate more toxicity data to better define lethal and sublethal toxicity thresholds for metals for white sturgeon (U.S. Environmental Protection Agency, 2010).

The objective of the study was to evaluate the chronic toxicity of cadmium, copper, lead, or zinc to early life stages of white sturgeon in water-only exposures. Toxicity tests also were performed with commonly tested rainbow trout (Oncorhynchus mykiss) under similar test conditions to determine the relative sensitivity between white sturgeon and rainbow trout to the four metals. Toxicity data generated from this study were used to evaluate the sensitivity of early life stages of white sturgeon and rainbow trout relative to other test organisms. Toxicity data generated from this study also were used to evaluate the level of protection of USEPA WQC or Washington State water-quality standards (WQS) for cadmium, copper, lead, or zinc to white sturgeon inhabiting the UCR. Two companion studies evaluated the acute toxicity of cadmium, copper, or zinc to the sturgeon and the trout at various life stages (chapter A) and the toxicity of whole sediments from the UCR to white sturgeon (Markus Hecker, oral commun., University of Saskatchewan, Saskatoon, Canada).

\section{Methods}

\section{Test Organisms}

The same batch of eggs of white sturgeon and rainbow trout described in the chapter A acute toxicity study were used in this chapter B chronic toxicity study. Adult sturgeon were caught on June 17 and 18, 2010, from Five Mile Creek, about 1 mile downstream of Northport, Washington, on the Columbia River. The sturgeon were transferred to the Sherman Creek Hatchery, Kettle Falls, Wash., for spawning. Newly fertilized eggs from three male sturgeon and three female sturgeon were shipped within 24 hours (h) to the toxicity testing laboratory, the U.S. Geological Survey (USGS) Columbia Environmental Research Center (CERC), Columbia, Missouri, on June 29, 2010. The eggs of rainbow trout at eyed stage were obtained from Ennis National Fish Hatchery, Ennis, Montana in September 2010. The sturgeon eggs were held in 9-liter (L) MacDonald hatching jars (Aquatic EcoSystems, Apopka, Florida) at $15 \pm 1{ }^{\circ} \mathrm{C}$ (within 1 degree Celsius) and the trout eggs were held in a vertical-tray incubation box at $12 \pm 1{ }^{\circ} \mathrm{C}$ in test water. The culture and toxicity test water was prepared in two 7,000-L polypropylene tanks by diluting well water 
of hardness about 300 milligram per liter $(\mathrm{mg} / \mathrm{L})$ as calcium carbonate $\left(\mathrm{CaCO}_{3}\right.$, with deionized water to a hardness of about $100 \mathrm{mg} / \mathrm{L}$ as $\mathrm{CaCO}_{3}$ [alkalinity of about $90 \mathrm{mg} / \mathrm{L}$ as $\mathrm{CaCO}_{3}$, $\mathrm{pH}$ of about 8.0, and dissolved organic carbon of about $0.4 \mathrm{mg}$ carbon $(\mathrm{C}) / \mathrm{L}]$. The $100 \mathrm{mg} / \mathrm{L}$ hardness water was prepared to be representative of the water-quality characteristics of the UCR inhabited by white sturgeon (see chapter A for additional details). The sturgeon started hatching $8 \mathrm{~d}$ after fertilization and all fish hatched within $4 \mathrm{~d}$. A hatch day was established when about 50-percent fish hatched. Hatched fish were reared in flow-through holding tanks with the test water at test temperature before the beginning of the metal exposures.

\section{Toxicity Tests}

Three chronic toxicity tests with two life stages of white sturgeon and rainbow trout were performed following guidance outlined in American Society of Testing and Materials (2012a, b, c). Guidance for performing chronic toxicity of effluents and receiving waters (U.S. Environmental Protection Agency, 2002) also was used for methods that were not addressed in American Society for Testing and Materials (2012a, b, c). The chronic toxicity studies included the following tests:

\section{White sturgeon toxicity tests:}

- C1: Chronic life-stage 1 exposure started with 2-dph larval sturgeon in a 25-d exposure

- C2: Chronic life-stage 2 exposure started with 27-dph swim-up juvenile sturgeon in a 28-d exposure

- CC: Chronic life stages 1 and 2 continuous exposure started with 2-dph larval sturgeon in a 53-d exposure

Rainbow trout toxicity tests:

- C1: Chronic life-stage 1 exposure started with 1-dph larval trout in a $21-\mathrm{d}$ exposure

- C2: Chronic life-stage 2 exposure started with 26-dph swim-up juvenile trout in a 28-d exposure

- CC: Chronic life stages 1 and 2 continuous exposure started with 1-dph larval trout in a 52-d exposure

The original plan was to perform the $\mathrm{CC}$ exposures for 56 days (U.S. Geological Survey, 2010). However, there were logistical constraints for performing the study for 56 days, so the CC exposure was performed for 53 days in the sturgeon test and 52 days in the trout test. Test conditions are summarized in table $\mathrm{B}-1$. Four toxicants, cadmium chloride hemi(pentahydrate) $\left(\mathrm{CdCl}_{2} 2.5 \mathrm{H}_{2} \mathrm{O}, 98\right.$-percent purity), copper (II) sulfate pentahydrate $\left(\mathrm{CuSO}_{4} 5 \mathrm{H}_{2} \mathrm{O}, 98\right.$-percent purity), lead (II) nitrate $\left[\mathrm{Pb}\left(\mathrm{NO}_{3}\right)_{2}, 99\right.$-percent purity], and zinc chloride $\left(\mathrm{ZnCl}_{2}, 98\right.$-percent purity) were obtained from SigmaAldrich, St. Louis, Mo. A stock solution of each toxicant was prepared by adding the toxicant to deionized water.
Toxicity tests with one fish species were performed concurrently in four intermittent flow-through proportional diluters, each containing one of the four toxicants delivered to the diluters using a Hamilton ${ }^{\circledR}$ syringe pump (Hamilton ${ }^{\circledR}$, Reno, Nevada). Each diluter dispensed five chemical concentrations with a dilution factor of 0.5 plus a control. Four glass replicate chambers were held in each of 1240 -L rectangular glass aquaria in a temperature-controlled water bath. An in-line 4-way flow splitter was attached to each delivery line to partition the water flow to each of four replicate chambers in the glass aquaria (Brunson and others, 1998). Each test chamber $(28 \times 13.5 \times 25$ centimeter $(\mathrm{cm}))$ contained $7 \mathrm{~L}$ of water and had an exit port (4-cm diameter) in the side covered by a 30 mesh $(0.5$-millimeter $(\mathrm{mm})$ opening) stainless steel screen. Test solution flowed directly into test chambers and excess water flowed through the exit port to surrounding aquaria through the screen windows, so there was no exchange of test water among replicates. The diluter provided about 250 milliliter $(\mathrm{mL})$ of water to each chamber every 30 minutes (about two volume additions per day). The water delivery frequency was increased to once every 15 minutes during the last 2 weeks of the 53-d $\mathrm{CC}$ and 28-d C2 sturgeon exposures because of increased size of the fish. An air stone also was added in each chamber for gentle aeration when the concentrations of dissolved oxygen in the sturgeon test chambers were reduced to about $5 \mathrm{mg} / \mathrm{L}$ in the last week of the sturgeon 53-d CC exposures and in the last week of the sturgeon 28-d C2 exposures. Before the yolk sac is absorbed, the sturgeon larvae have a hiding phase, possibly to evade predators or to avoid strong water currents (Parsley and others, 2002). Thus, about 20 pieces of smooth stone (about 2-cm diameter; red chocolate pebbles, GeoSystem Substrate, Rolf C. Hagen, Inc., Montreal, Quebec, Canada) were placed impartially in each replicate test chamber in the sturgeon tests starting with newly hatched sturgeon to provide refuge through an about 2-week hiding phase.

Water temperature was monitored daily and maintained at $15 \pm 1{ }^{\circ} \mathrm{C}$ for the sturgeon tests and $12 \pm 1{ }^{\circ} \mathrm{C}$ for the trout tests in a water bath for each diluter using a 1/3 horse-power Prime Chiller (Current, Vista, California). The Prime Chiller was controlled by a digital temperature controller that maintained the designed temperature of the water within $1{ }^{\circ} \mathrm{C}$ of its set point. Water was circulated continuously from the water bath through the chiller and back to the water bath using an in-line magnetic drive pump (Iwaki America Inc., Holliston, Massachusetts), and a uniform temperature was maintained throughout the water bath. The water used for the exposure was maintained at test temperature before being delivered to the diluter backboard, which was accomplished by chilling the water to test temperature by a Cyclone CY-4 chiller (Aqualogic Inc., San Diego, Calif.) in a high-density polyethylene tank (inside dimensions: $44.5 \times 30 \times 28.5 \mathrm{~cm}$ ). The water level in the tank was maintained at a volume of about $30 \mathrm{~L}$ using a float valve. Water was circulated constantly in the tank with a submersible pump that ensured a uniform temperature throughout the tank. When the diluter cycled, the chilled water was pumped by a 12-volt diaphragm pump to the diluter. 


\section{Acute and Chronic Sensitivity of White Sturgeon and Rainbow Trout to Cadmium, Copper, Lead, or Zinc}

Table B-1. Summary conditions for conducting chronic water-only toxicity tests with white sturgeon (Acipenser transmontanus) and rainbow trout (Oncorhynchus mykiss) following standard test methods recommended by the American Society for Testing and Materials $(2012 a, b)$, the U.S. Environmental Protection Agency (2002), and U.S. Geological Survey-Columbia Quality Assurance Project Plan (U.S. Geological Survey 2010).

$\left[{ }^{\circ} \mathrm{C}\right.$, degree Celsius; L, liter; $\mathrm{CC}$, chronic continuous exposure; $\mathrm{C} 1$, chronic life stage 1 exposure; $\mathrm{C} 2$, chronic life stage 2 exposure; $<$, less than; g, gram; weight/L, weight per liter; dph, days-post-hatch; $\mathrm{mg} / \mathrm{L}$, milligram per liter; $\mathrm{CaCO}_{3}$, calcium carbonate; $\mu \mathrm{g} / \mathrm{L}$, microgram per liter; $\geq$, greater than or equal to]

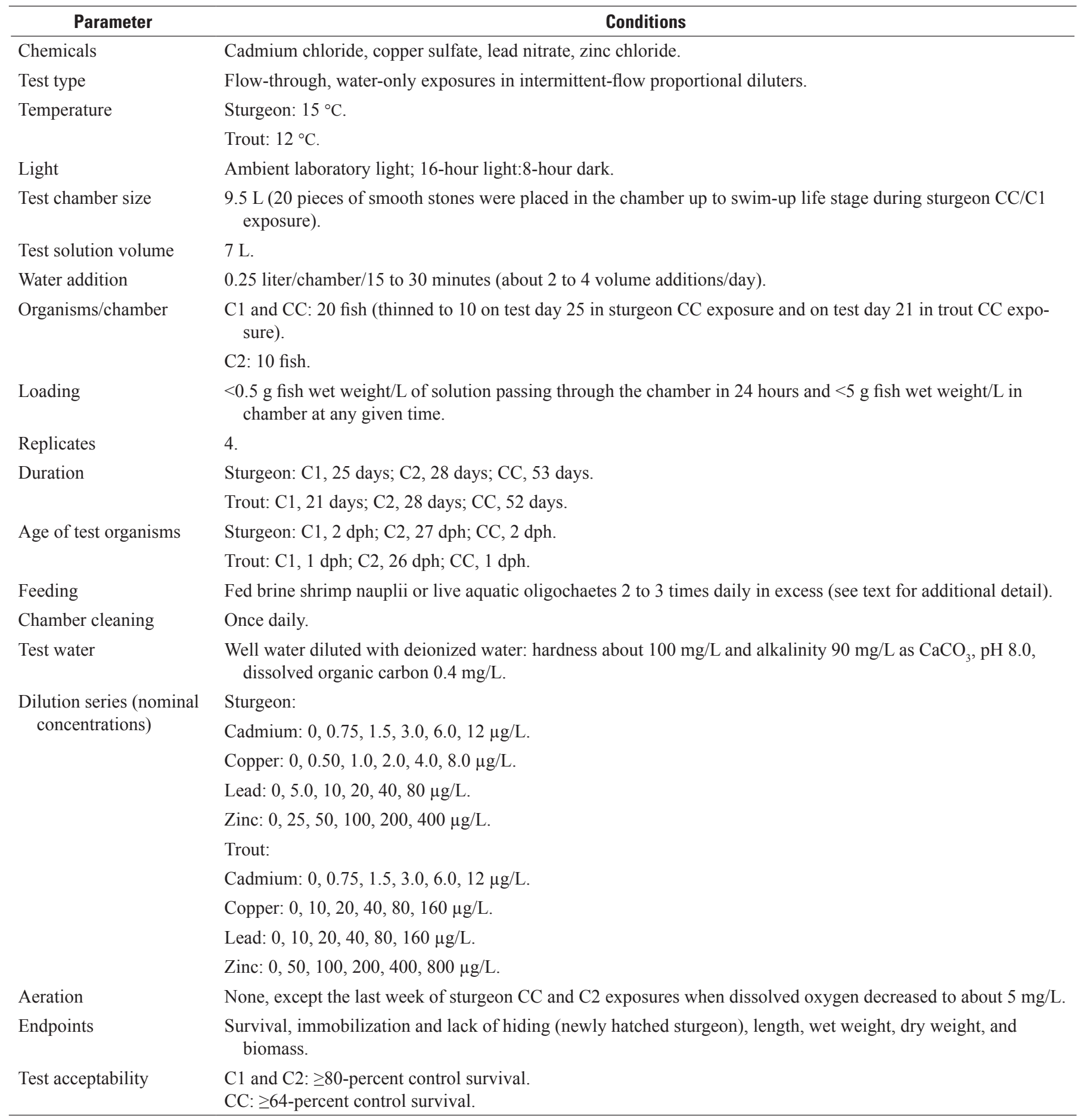


Overhead full-spectrum fluorescent lamps were used for lighting with a photoperiod of 16-hour light to 8-hour dark. The light intensity was designed as about 200 to 500 lux, but inadvertently was set higher during the first 21-d sturgeon $\mathrm{C} 1$ and $\mathrm{CC}$ exposures starting with newly hatched larvae. The measured light intensity values for the four diluters initially ranged from about 900 to 1,300 lux. These values were close to a recommended upper range of light intensity of 10-20 microeinstein per square meter per second (about 500 to 1000 lux) for estimating chronic toxicity of effluents and receiving waters (U.S. Environmental Protection Agency, 2002). The light intensity was reduced to about 400 lux on test day 21 and maintained for the rest of the sturgeon $\mathrm{C} 1$ and $\mathrm{CC}$ exposures, and was set at about 400 lux for the $\mathrm{C} 2$ exposure starting with the 27 -dph juvenile sturgeon. In the trout $\mathrm{C} 1$ and $\mathrm{CC}$ exposures, the newly hatched trout were held at a low-light intensity of about 70 lux for the first $10 \mathrm{~d}$ of the exposures, and afterwards, the light intensity was increased to about 400 lux based on guidance provided in Environment Canada (1998). A study was performed in 2012 to evaluate the effect of lighting on performance of newly hatched sturgeon in a 25-d water-only exposure (appendix 8).

Because of the limited number of larval sturgeon available for testing (fewer high quality eggs were provided by the hatchery, see details in chapter A), the sturgeon $\mathrm{C} 1$ and $\mathrm{CC}$ exposures were combined. At the beginning of the tests, 20 2-dph larval sturgeon were transferred impartially from the culture tank into each of four replicate chambers per concentrations per toxicant. Twenty fish also were sampled impartially for initial size measurements. Mean initial sizes of larval sturgeon were $13.0 \pm 0.7 \mathrm{~mm}$ total length ( \pm standard deviation; $\mathrm{n}=20$ ) and $0.022 \mathrm{~g}$ wet weight (based on weighing in a group of the 20 fish). On test day 25, surviving fish were thinned (American Society for Testing and Materials, 2012a) to 10 fish per chamber by impartially catching and removing fish with a net (one fish per catch). After thinning, the fish were held until the end of the 53-d CC exposures. At the beginning of the sturgeon $\mathrm{C} 2$ exposures, 10 27-dph juvenile sturgeon (mean total length $=25.6 \pm 2.1 \mathrm{~mm}, \mathrm{n}=20$; mean wet weight 0.12 gram (g)) were transferred impartially into each of four replicate chambers per concentration per toxicant.

At the beginning of the trout $\mathrm{C} 1$ and $\mathrm{CC}$ exposures, 20 1-dph larval trout (mean total length $=16.7 \pm 1.3 \mathrm{~mm}, \mathrm{n}=20$; mean wet weight $0.081 \mathrm{~g}$ ) were transferred impartially into each of four replicate chambers per concentration per toxicant in the $\mathrm{C} 1$ exposure and into each of four replicate chambers in the $\mathrm{CC}$ exposure. The $\mathrm{C} 1$ and $\mathrm{CC}$ exposures with each toxicant started concurrently in each of the four diluters. The trout in the $\mathrm{CC}$ exposures were thinned impartially to 10 fish per chamber on test day 21 and held until the end of the 52-d $\mathrm{CC}$ exposures. At the beginning of the trout $\mathrm{C} 2$ exposures, 10 26-dph juvenile trout (mean length $=24.7 \pm 1.1 \mathrm{~mm}, \mathrm{n}=20$; mean wet weight $=0.13 \mathrm{~g}$ ) were transferred impartially into each of four replicate chambers per concentration per toxicant.

For the $\mathrm{C} 1$ and $\mathrm{CC}$ exposures starting with newly hatched larvae, food was provided starting on test day 9 for the sturgeon test and on test day 12 for the trout test before the swim-up life stage (at least $2 \mathrm{~d}$ before the onset of exogenous feeding). The exogenous feeding was confirmed by the observation of feeding activity and feces. The fish were fed less than 1-d-old brine shrimp (Artemia) nauplii (Brine Shrimp Direct, Ogden, Utah) three times daily at an interval of $4 \mathrm{~h}$ during the week and two times daily at an interval of $6 \mathrm{~h}$ during the weekend. Sufficient numbers of nauplii were provided to assure that some remained alive in the test chamber for about $2 \mathrm{~h}$. In addition, a minimal amount of laboratorycultured aquatic oligochaetes (Lumbriculus variegatus) were added into each chamber to determine the readiness of fish to feed oligochaetes. The oligochaetes initially were cut into pieces (about 5-mm length) to facilitate initial feeding of larval fish. Specifically, five oligochaetes were cut with a razor blade into pieces and placed into each test chamber in the morning. If most of oligochaetes were eaten within 2 to 3 hours, another five oligochaetes were placed in the afternoon. When the fish were large enough to begin feeding on oligochaetes, more oligochaetes were added and the amount of brine shrimp was reduced gradually until the fish were fed only oligochaetes twice daily in excess (food available for at least $4 \mathrm{~h}$ after each feeding). The number of oligochaetes provided to each chamber was recorded daily and feeding amount was adjusted according to remaining food amount and time after each feeding. When the sturgeon were over $25 \mathrm{dph}$ and the trout were over $32 \mathrm{dph}$, only whole oligochaetes were provided. Before daily feeding, uneaten food and debris were removed by siphoning with a glass tube from the bottom of the chambers.

Dead fish were removed and general changes in behavior were recorded daily. In addition, the number of the surviving fish, the fish exhibiting immobilization (lying down on their side and lack of movement), and the fish exhibiting lack of hiding (not actively hiding along the edges of stones) were counted in the morning about 9:00 a.m. on test days 4 and 8 . Fish were not fed for $24 \mathrm{~h}$ before sampling for growth measurements at the end of an exposure. At the end of the tests, surviving fish in each replicate chamber were counted and euthanized with an overdose of tricaine methanesulfonate (Western Chemical Inc., Ferndale, Wash.). Wet weight of surviving fish per replicate was determined after gently blotting fish on a dry paper towel, and the fish were preserved in 10-percent formalin for subsequent measurement of total length of individual fish. After length measurements, dry weight of fish per replicate was determined by drying fish at $60{ }^{\circ} \mathrm{C}$ for $48 \mathrm{~h}$. Mean wet or dry weight per individual fish were calculated by dividing the total wet or dry weight per replicate by the number of surviving fish in the replicate.

The overall survival for each replicate in the sturgeon 53-d CC exposures or in the trout 52-d CC exposures was calculated as the product of percent survival to the time of fish thinning multiplied by percent survival from the time of fish thinning through the end of the exposure. The test acceptability requirement for these longer-term tests was set at greater than or equal to $(\geq)$ 64-percent overall control survival 
( 80 percent multiplied by 80 percent; U.S. Geological Survey, 2010; table B-1). For the 21- to 28-d C1 and C2 exposures, the test acceptability requirement was established as $\geq 80$-percent control survival as recommended for some other fish species by American Society for Testing and Materials (2012a; table B-1). In addition, for the observation of acute 4-d effect or short-term 8-d effect during the chronic tests, the acute toxicity test acceptability requirement of $\geq 90$-percent control survival (American Society for Testing and Materials, 2012c) and the short-term toxicity test acceptability requirement of $\geq 80$-percent control survival (U.S. Environmental Protection Agency, 2002) were applied.

\section{Water Quality and Chemical Analysis}

Dissolved oxygen, $\mathrm{pH}$, conductivity, hardness, alkalinity, and ammonia were measured weekly using standard methods (Eaton and other, 2005) on composite water samples collected from the replicates in the control, medium, and high concentrations in each exposure. Dissolved oxygen was measured more frequently (at least once every other day) in the $\mathrm{C} 2$ exposures with juvenile fish or in the last few weeks of the $\mathrm{CC}$ exposures as the fish became larger. Water samples for the analyses of major cations (calcium, magnesium, potassium, sodium, and strontium) and major anions (chloride, fluoride, nitrate, nitrite, and sulfate) were collected biweekly on composite samples from the replicates in the control and medium exposure concentrations of each of the four diluters.

Water samples for analyses of dissolved organic carbon (DOC) were collected weekly on composite samples from the replicates in the control, medium, and high exposure concentrations in each of the four metal exposures. Duplicate test water samples were collected for DOC during three separate weekly sampling periods and were submitted to Huffman Laboratory (Golden, Colorado) for confirmatory analysis. Samples obtained for DOC analyses were each drawn from mid-depth of the exposure chambers using an oven baked $\left(450{ }^{\circ} \mathrm{C}\right)$ glass pipet and collected in a $60-\mathrm{mL}$, amber glass bottle fitted with a Teflon ${ }^{\circledR}$-lined cap. Except for the initial collections (appendix 6), sample bottles were rinsed, then filled with high-purity deionized water to prevent potential airborne contamination until use. Two or three filtration blanks were processed with each set of samples using commercially available total organic carbon (TOC) free water $(<0.05 \mathrm{mg}$ C/L; Ep Scientific Products, Thermo Fisher Scientific, Waltham, Mass.). About $20 \mathrm{~mL}$ of sample was used to rinse each bottle before collection of a $60-\mathrm{mL}$ sample. Samples were stored at $4{ }^{\circ} \mathrm{C}$ for as many as $48 \mathrm{~h}$ before filtration through a 0.45 -micrometer $(\mu \mathrm{m})$ pore size nylon membrane that was situated on a $450{ }^{\circ} \mathrm{C}$-baked glass support module and then preserved by acidification to a pH less than $(<) 2$ by addition of about $0.1 \mathrm{~mL}$ of a 9 molar solution of sulfuric acid.

During the 53-d sturgeon test with copper, one 0.6-L composite water sample was obtained for measurement of particulate organic carbon (POC) by combining $150-\mathrm{mL}$ samples collected from each of the four replicate control treatments. The composite sample was collected on test day 48, in a manner similar to that for sampling for DOC analyses, but a 1-L bottle that previously contained certified TOC-free water was used for the collection. During the 52-d rainbow trout tests with cadmium, copper, or zinc, two 1-L composite samples were collected from control treatment, also using 1-L bottles that previously contained certified TOC-free water. These samples were collected on test day 48; one sample before stirring the water of the test chambers and the second one immediately after stirring the water. Stirring was done to temporarily suspend any particulate matter present in the bottom of the test chambers. The POC samples were collected near the end of trout studies when fish were largest; thus, stirred samples were assumed to reflect the maximum possible POC concentrations. Upon transfer to the laboratory, each sample for POC was shaken, then immediately filtered through a total of one to three glass fiber filters, which subsequently were treated with diluted hydrochloric acid to remove inorganic carbon. The filters containing the particulates were then combusted in pure oxygen and the evolved carbon dioxide was trapped in a buffer and the carbon measured by colorimetric detection following USEPA method 9060A (U.S. Environmental Protection Agency, 2004). A method blank for POC was prepared and measured after filtering a $0.3-\mathrm{L}$ volume of TOC-free water; sample results for POC were blank corrected based on that measurement. Samples analyzed at the CERC for DOC were determined using persulfate ultraviolet oxidation followed by colorimetric detection following USEPA method 415.2 (U.S. Environmental Protection Agency, 1983). Method detection limits for DOC or POC ranged from 0.1 to $0.2 \mathrm{mg} \mathrm{C} / \mathrm{L}$. Confirmatory DOC analyses done by the Huffman Laboratory were done using a TOC analyzer (OI Analytical Model 700) following combustion oxidation with infrared detection (USEPA method 415.1 (U.S. Environmental Protection Agency, 1983); the method detection limit was $0.05 \mathrm{mg} \mathrm{C} / \mathrm{L}$. Water samples for major cation analyses were filtered through a $0.45-\mu \mathrm{m}$ pore size polyether-sulfone (PES) membrane housed in a polypropylene cartridge (Whatman Puradisc ${ }^{\mathrm{TM}}$, no. 6781-2504; GE Health Care Life Sciences, Piscataway, New Jersey) and were stabilized immediately by adding concentrated nitric acid (16 molar) to each sample at a volume proportion of 1:100. Major cations were analyzed for by Laboratory and Environmental Testing (LET, Columbia, Mo.) using inductively coupled plasma atomic emission spectroscopy according to the USEPA method 200.7 (U.S. Environmental Protection Agency, 1994). Major anions were analyzed at the CERC using ion chromatography according to USEPA method 9056A (U.S. Environmental Protection Agency, 2007b).

Water samples for the analysis of cadmium, copper, lead, or zinc were collected weekly on composite samples from the replicates for each exposure concentration for each metal. About $24 \mathrm{~mL}$ of water were drawn from mid-depth of each exposure chamber with an all polypropylene syringe fitted with a tetra-fluoroethylene sipper straw. The sample was then dispensed through a $0.45-\mu \mathrm{m}$ pore size PES membrane filter 
into an acid-cleaned polyethylene bottle after discarding the first $4 \mathrm{~mL}$ of filtrate to rinse and equilibrate the filter cartridge. Each 20 -mL sample was stabilized within $24 \mathrm{~h}$ by adding $0.2 \mathrm{~mL}$ of concentrated nitric acid. Concentrations of the four metals were determined by inductively coupled plasma-mass spectrometry (PE/SCIEX ELAN DRCe, PerkinElmer, Norwalk, Connecticut) in accordance with USEPA method 6020A (U.S. Environmental Protection Agency, 2007c). Sample solutions were delivered automatically to the mass spectrometer by means of a software-controlled CETAC ASX-500/ADX100 autosampler/autodiluter system (CETAC Technologies, Omaha, Nebraska). Internal standards consisted of rhodium $(10 \mu \mathrm{g} / \mathrm{L})$, niobium $(20 \mu \mathrm{g} / \mathrm{L})$, and iridium $(20 \mu \mathrm{g} / \mathrm{L})$.

\section{Quality Assurance Quality Control}

Quality control check samples associated with measurements for cations, anions, and general water quality parameters were reviewed by a USEPA contractor and results were deemed acceptable in accordance with the quality assurance project plan that specified a target accuracy range of 80 to 120 percent, and a target precision of less than or equal to 10 percent relative standard deviation. As stated in chapter A, problems were evident with DOC measurements. Blanks collected during the first 9 days of chronic sturgeon tests had elevated DOC concentrations (about $1 \mathrm{mg} / \mathrm{L}$ ); consequently, DOC results for those sets of samples were deemed invalid (appendix 6). In addition, most DOC concentrations measured at the CERC laboratory were near the method detection limit of about $0.2 \mathrm{mg} / \mathrm{L}$; therefore; measured DOC concentrations of most water samples would not be categorized as being within the quantitative range of the analytical method. Thus, most measured DOC concentrations are considered only as estimated values, and targets for accuracy and precision stated in the quality assurance plan were not applicable for DOC results (see also Quality Assurance Quality Control for Chemical Analyses section in chapter A). Furthermore, DOC results as measured by the CERC laboratory probably were biased low by about $0.2 \mathrm{mg} / \mathrm{L}$, so DOC results for the sets of samples that were submitted to Huffman Laboratory for confirmatory analyses were considered to be more reliable, in part because of a lower detection limit. Additional discussion concerning the evaluation of DOC results is provided in appendix 6 .

Quality assurance procedures and quality control results for metal analyses, including analyses of water reference solutions, duplicate samples, spiked samples, method blanks, and method detection limits, were reviewed by a USEPA contractor and all were within targets as specified in the quality assurance plan. In most instances, sets of water samples from chronic tests (this chapter) and acute tests (chapter A) were grouped together for analysis; consequently, results for spiked samples, duplicate analyses, and certified reference waters corresponded with samples from the acute and chronic exposures. Summaries of those quality control measurements are provided in the Quality Assurance Quality Control for
Chemical Analyses section of chapter A, and complete quality control results are described in appendix 3 (sturgeon tests) and appendix 4 (rainbow trout tests).

\section{Data Analysis}

Effect concentrations for 10-percent, 20-percent, and 50-percent reduction (EC10, EC20, and EC50) for survival, individual length, and wet or dry weight, or biomass (total dry weight of surviving fish in a replicate) were estimated using the Toxicity Response Analysis Program (Erickson, 2012). The no-observed-effect concentration (NOEC) and lowestobserved-effect concentration (LOEC) for all endpoints also were determined with TOXSTAT ${ }^{\circledR}$ software (Western EcoSystems, 1996) by analysis of variance with mean comparison made by one-tailed Dunnett's test (or Bonferroni t-test when the number of replicates were not the same for all concentrations; U.S. Environmental Protection Agency, 2002). If the data were not distributed normally (Shapiro-Wilk's test ) or did not have equal variances (Bartlett's test), Steel's manyone rank test or Wilcoxon rank sum test with Bonferroni adjustment were used for the determinations of the NOEC and LOEC (U.S. Environmental Protection Agency, 2002). Steel's many-one rank test was used to determine the differences in (1) mortality, (2) mortality plus immobilization, or (3) mortality plus immobilization and lack of hiding between the control and any exposure treatment during the first 4 and 8 days of the 53-d exposures, starting with 2-dph sturgeon. The level of statistical significance was set at $p \leq 0.05$. The 4-d and 8-d 50-percent lethal concentrations (LC50s) based on mortality, EC50s based on mortality plus immobilization, and EC50s based on mortality plus immobilization and lack of hiding also were calculated for the sturgeon exposures. Effect concentrations from tests that met test acceptability requirements are classified as definitive effect concentrations. Effect concentrations from tests that did not meet test acceptability requirements (for example, low control survival) were not calculated or classified as nondefinitive effect concentrations (for example, growth data from the 53-d sturgeon CC exposures).

More extensive databases have been developed in the manner described by Stephan and others (1985) since USEPA formal criteria publications, including a cadmium database (Mebane, 2006), a lead database (Jasim Chowdhury, International Lead Zinc Research Organization, Durham, North Carolina, unpub. data, 2013), and a zinc database (DeForest and Van Genderen, 2012). To compare the relative sensitivity of white sturgeon and rainbow trout to other species, the most sensitive chronic values obtained from the present study with the sturgeon or trout were compared to species mean chronic values (SMCVs) for all freshwater species in these toxicity databases. For the sensitivity comparisons, the cadmium toxicity data generated from this study were normalized to a water hardness of $50 \mathrm{mg} / \mathrm{L}$ based on the equations in the database for cadmium (Mebane, 2006), and copper, lead, or 
zinc toxicity data were normalized using biotic ligand models (BLMs) and measured water-quality characteristics in appendix tables $2-1$ and $2-2$. The BLM-normalized toxicity values were estimated for a moderately hard reconstituted water recipe following the approach described in the USEPA WQC for copper (U.S. Environmental Protection Agency, 2007a). The calculations of the BLM-normalized effect concentrations for copper were made using the BLM software version 2.2.3 (HydroQual, 2007). The calculations of the BLM-normalized effect concentrations for zinc were made using a zinc BLM (DeForest and Van Genderen, 2012). The lead effect concentrations were normalized using a lead BLM developed by International Lead Zinc Research Organization (Jasim Chowdhury, Durham, N.C., unpub. data, 2013). A summary of the water composition and original effects concentrations that were used in the BLM modeling with copper, the modeled critical accumulation CA values, and resulting effects concentrations extrapolated to a moderately hard BLM standard water are given in appendix table 1-7.

The 4-d acute EC50s obtained in the present study at the start of the chronic exposures were compared to the final acute value (FAV) in the existing WQC (hardness-based criterion for cadmium, lead, or zinc, and BLM-based criterion for copper; U.S. Environmental Protection Agency, 2012). The FAV is used to derive the acute criterion, that is, criterion maximum concentration=1/2 FAV). Acute EC50s also were compared to Washington State acute WQS. Chronic EC20s were compared to the final chronic value (that is, chronic WQC) or Washington State chronic WQS.

\section{Results}

\section{Chemical Analyses}

Measured concentrations of cadmium, copper, or zinc were 80 to 100 percent of nominal concentrations in various exposures in the sturgeon and trout tests (appendix tables 2-3 and 2-4). Measured concentrations of the metals were used for the calculation of effect concentrations of these four metals. As expected, the measured concentrations of lead consistently were lower than nominal concentrations because of limited solubility of lead in the test water, and the measured concentrations of lead were 46 to 76 percent of nominal concentrations (appendix tables 2-3 and 2-4). Mean values of general water-quality characteristics in test water were similar during various exposure periods within a metal exposure and among four metal exposures in the sturgeon and trout tests, and were close to the nominal values of diluted well water of a hardness of about $100 \mathrm{mg} / \mathrm{L}$ as $\mathrm{CaCO}_{3}$, alkalinity of about $90 \mathrm{mg} / \mathrm{L}$ as $\mathrm{CaCO}_{3}$, conductivity of about 250 microseimens per centimeter at $25^{\circ} \mathrm{C}$, and $\mathrm{pH}$ of 8.0 (appendix table $2-1$ ). The concentrations of total ammonia nitrogen $(\mathrm{N})$ were low in all exposures with a mean value of $<0.2 \mathrm{mg} \mathrm{N} / \mathrm{L}$ (appendix table $2-1$ ). The concentration of dissolved oxygen typically ranged from
7.0 to $9.0 \mathrm{mg} / \mathrm{L}$ and was never below $5.0 \mathrm{mg} / \mathrm{L}$. Mean concentrations of major cations and major anions were similar during various exposure periods within a metal exposure and among four metal exposures in the sturgeon and trout tests, and ranged from 26 to $27 \mathrm{mg} / \mathrm{L}$ for calcium, 8.6 to $9.3 \mathrm{mg} / \mathrm{L}$ for magnesium, 0.8 to $1.0 \mathrm{mg} / \mathrm{L}$ for potassium, 8.6 to $9.9 \mathrm{mg} / \mathrm{L}$ for sodium, 0.11 to $0.14 \mathrm{mg} / \mathrm{L}$ for strontium, 10 to $12 \mathrm{mg} / \mathrm{L}$ for chloride, 0.12 to $0.21 \mathrm{mg} / \mathrm{L}$ for fluoride, and 17 to 19 for sulfate (appendix table 2-2). The concentrations of nitrate or nitrite were less than the reporting limit of $0.1 \mathrm{mg} / \mathrm{L}$ in all water samples. The DOC of test waters for the sturgeon and rainbow trout tests was estimated as $0.4 \mathrm{mg} \mathrm{C} / \mathrm{L}$ (appendix 6). The POC measured in the one water sample obtained from the sturgeon study was $0.21 \mathrm{mg} \mathrm{C/L}$. The POC values for the cadmium, copper, and zinc control waters from rainbow trout study were $0.86,0.93$, and $0.57 \mathrm{mg} \mathrm{C} / \mathrm{L}$, respectively, before mixing the water of test chambers; after mixing, the POC values were $4.2,3.7$, and $3.0 \mathrm{mg} \mathrm{C/L}$, respectively.

\section{White Sturgeon Toxicity Tests}

Immediately after being transferred into the test chambers in the $\mathrm{C} 1 / \mathrm{CC}$ exposures, the newly hatched sturgeon started to hide along the edges of the stones. During the first 2 weeks of the exposures, lack of hiding, immobilization, or elevated mortality of the larval sturgeon were observed at the medium or high exposure concentrations of copper or zinc, whereas the active hiding behavior was observed in the controls and the control survival was 100 percent (fig. B-1). Specifically, the percent mortality, mortality plus immobilization, or mortality plus immobilization and lack of hiding were significantly greater at the medium $(1.7 \mu \mathrm{g} \mathrm{Cu} / \mathrm{L})$ to high $(6.9 \mu \mathrm{g} \mathrm{Cu} / \mathrm{L})$ concentrations of copper, or at the high concentration of zinc $(369 \mu \mathrm{g} \mathrm{Zn} / \mathrm{L})$ than in the controls on test days 4 and 8 (fig. B-2). The 4-d EC50 for copper based on mortality plus immobilization $(5.29 \mu \mathrm{g} \mathrm{Cu} / \mathrm{L})$ or based on mortality plus immobilization and lack of hiding $(4.52 \mu \mathrm{g} \mathrm{Cu} / \mathrm{L})$ was about 40 percent less than the 4-d LC50 based on mortality alone $(8.06 \mu \mathrm{g} \mathrm{Cu} / \mathrm{L}$, appendix table $2-5)$. Similarly, the 8-d EC50 for copper based on mortality plus immobilization $(2.57 \mu \mathrm{g} \mathrm{Cu} / \mathrm{L})$ or based on mortality plus immobilization and lack of hiding $(2.53 \mu \mathrm{g} \mathrm{Cu} / \mathrm{L})$ was 60 percent less than the 8 -d LC50 based on mortality alone $(5.98 \mu \mathrm{g} \mathrm{Cu} / \mathrm{L}$, appendix table 2-5). No mortality or immobilization of newly hatched sturgeon were observed in any cadmium or lead treatments during the 4- or 8-d observation period, and a low percentage of the fish were recorded as lack of hiding, but the treatments were not significantly different from the controls, except at a medium-high concentration of cadmium on test day 4 and a medium concentrations of cadmium on test day 8 (fig. B-2).

The larval sturgeon in the controls ended the hiding phase and started feeding on about test day 12 . Starting on test day 15 , elevated mortality of the control fish (about $17 \mathrm{dph}$ ) was observed in all four metal exposures and lasted for about 1 week (fig. B-3). Because of the low control survival by 
A. Actively hiding

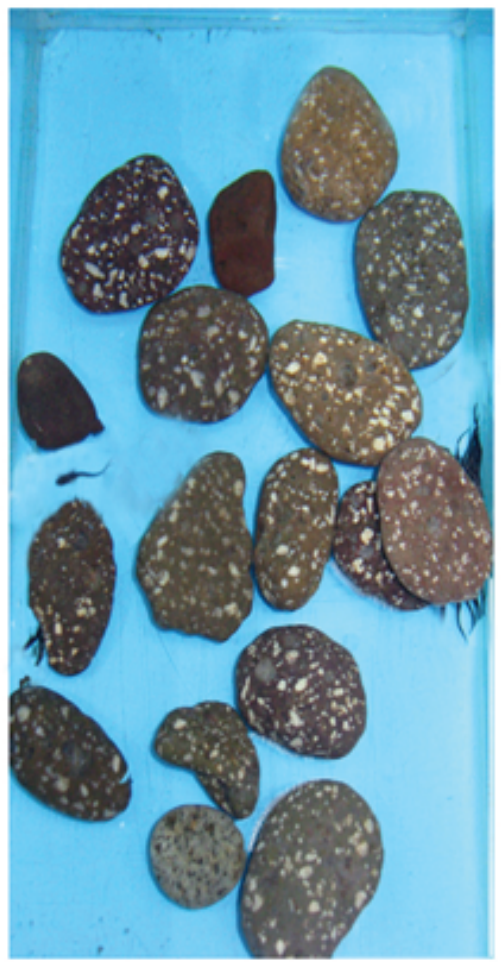

B. Lack of hiding

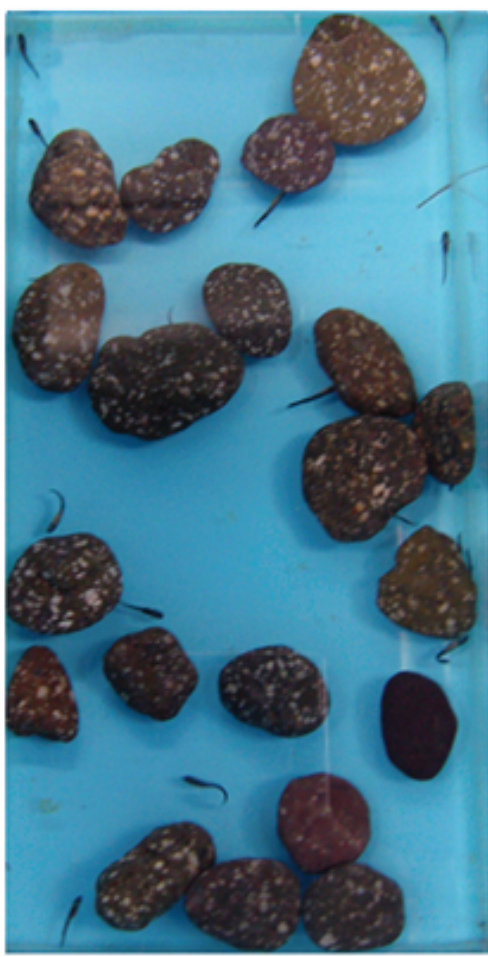

\section{Immobilization}

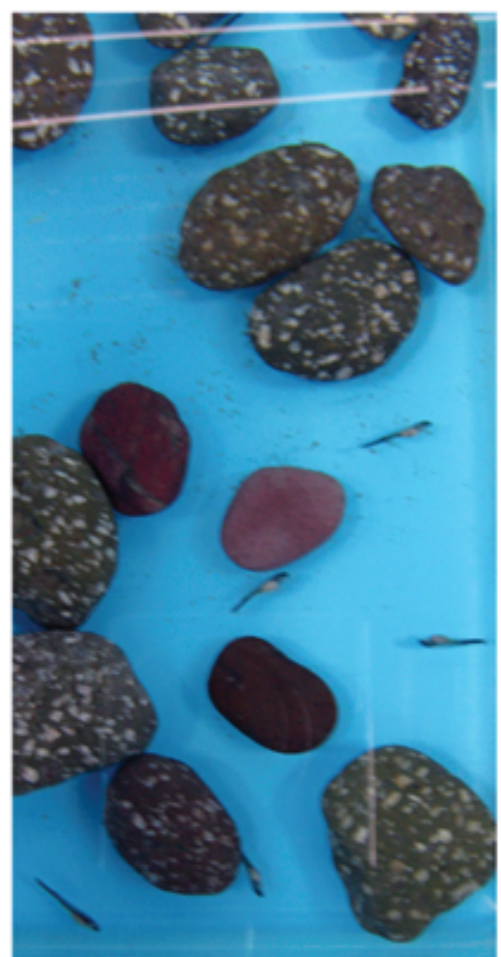

Figure B-1. Examples of hiding behavior and immobilization of white sturgeon (Acipenser transmontanus) on test day 8 in the 53-day exposure starting with 2-days-post-hatch larvae. $A$, fish actively hiding in a control replicate chamber; $B$, lack of hiding in the high concentration of zinc (369 micrograms per liter); and $C$, immobilization in the high concentration of copper (6.91 micrograms per liter). Photos were made using a camera with lens zoom at various magnifications and with or without flash, so sizes of stones or fish and light were different in the three photos.

test day 25, effect concentrations for the $\mathrm{C} 1$ exposures were estimated based on the survival on test day 14 when the mean control survival was high, ranging from 98 to 100 percent (table B-2) and met the test acceptability requirement of $\geq 80$-percent control survival (table B-1).

One or two of the four control replicates in each metal exposure with sturgeon had more than 50-percent mortality by the thinning day (test day 25) during the 53-d CC exposure (appendix table 2-6), that is, $<10$ surviving fish were left in one or two control replicate chambers in a metal exposure before fish thinning. To continue the 53-d CC exposures with each control having 10 fish after thinning for a statistically valid test, a pseudo control replicate was created on the thinning day. The control pseudo replicates for each metal exposure were created by (1) removing all surviving fish in the control chamber that had $<50$-percent survival by test day 25, and (2) transferring the extra surviving fish (after thinning to 10 fish per replicate) from the other control replicates, which had more than 10 fish per replicate and were in the same metal exposure, to a pseudo replicate. The number of the control replicates in the zinc exposure was reduced to three because of limited number of extra surviving fish from the other control replicate chambers in the diluter for the zinc test (appendix table 2-6). From the thinning day to the end of the 53-d exposures, the survival and growth of the sturgeon in the pseudo replicates were not substantially or consistently different from the survival and growth in the true replicates (appendix table 2-6). Therefore, the pseudo replicates were included for the further data analysis in the 53-d CC exposures with sturgeon. However, the data obtained from the 53-d CC exposures were used to calculate nondefinitive effect concentrations for comparisons to other species or for comparisons to applicable national WQC or Washington State WQS.

The mean control survival was 87 to 98 percent from the thinning day 25 to the end of 53-d sturgeon $\mathrm{CC}$ exposures with the four metals (table B-2), which met the test acceptability requirement of $\geq 80$ percent control survival (table $B-1$ ). The overall control survival (percent survival between test days 0 and 25 multiplied by percent survival between test days 25 and 53) ranged from 33 to 68 percent in the four metal 53-d exposures (table B-2). Although the overall control survival of 68 percent in the copper exposure was greater than $(>)$ the test acceptability requirement of 64-percent control survival for a long-term test (table B-1), the low control survival of 71 percent before the thinning on test day 25 did not meet the test acceptability requirement of $\geq 80$ percent (table $\mathrm{B}-1$ ); therefore, all four metal 53-d exposures did not meet the test acceptability requirement for a long-term test. The overall 

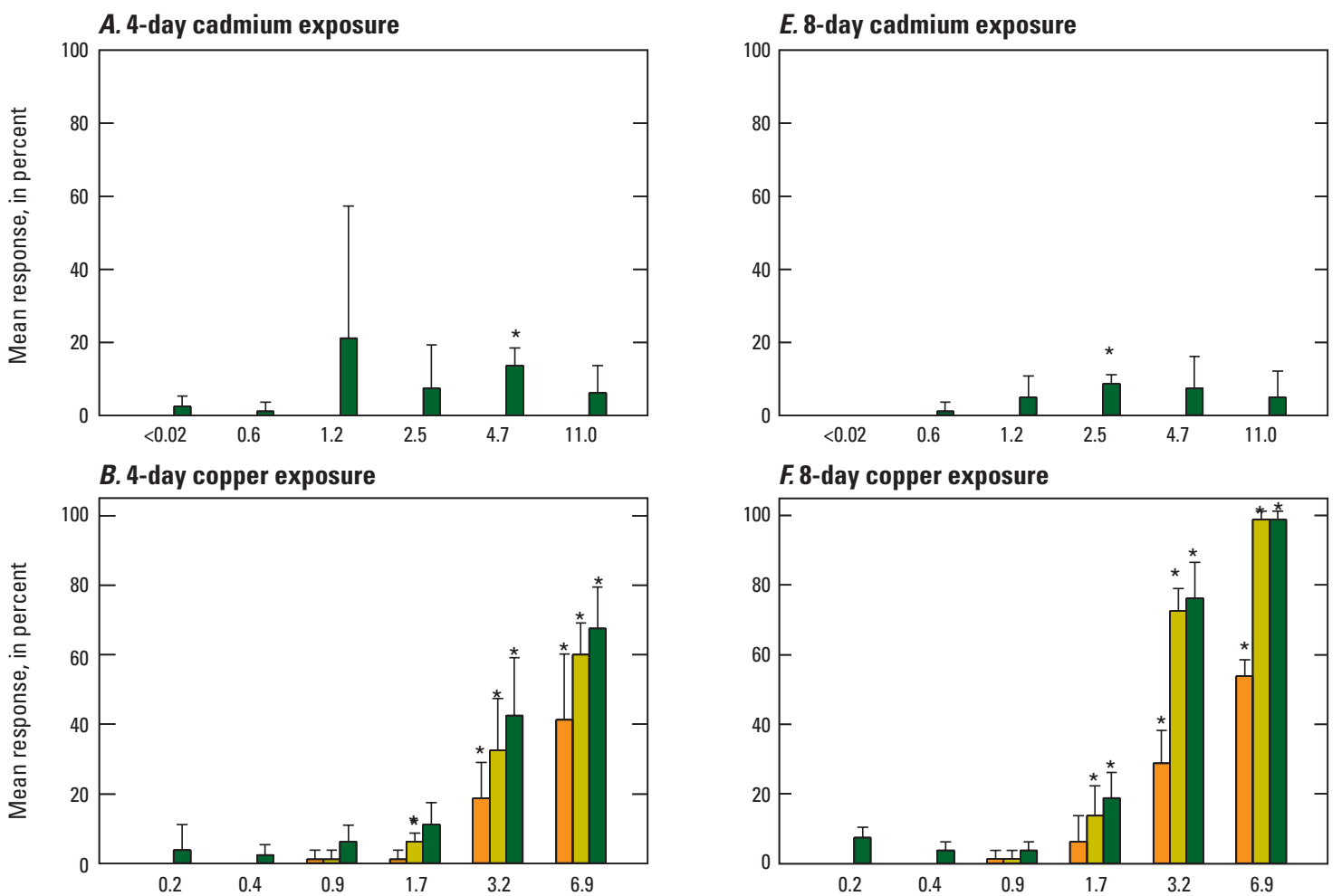

\section{F. 8-day copper exposure}
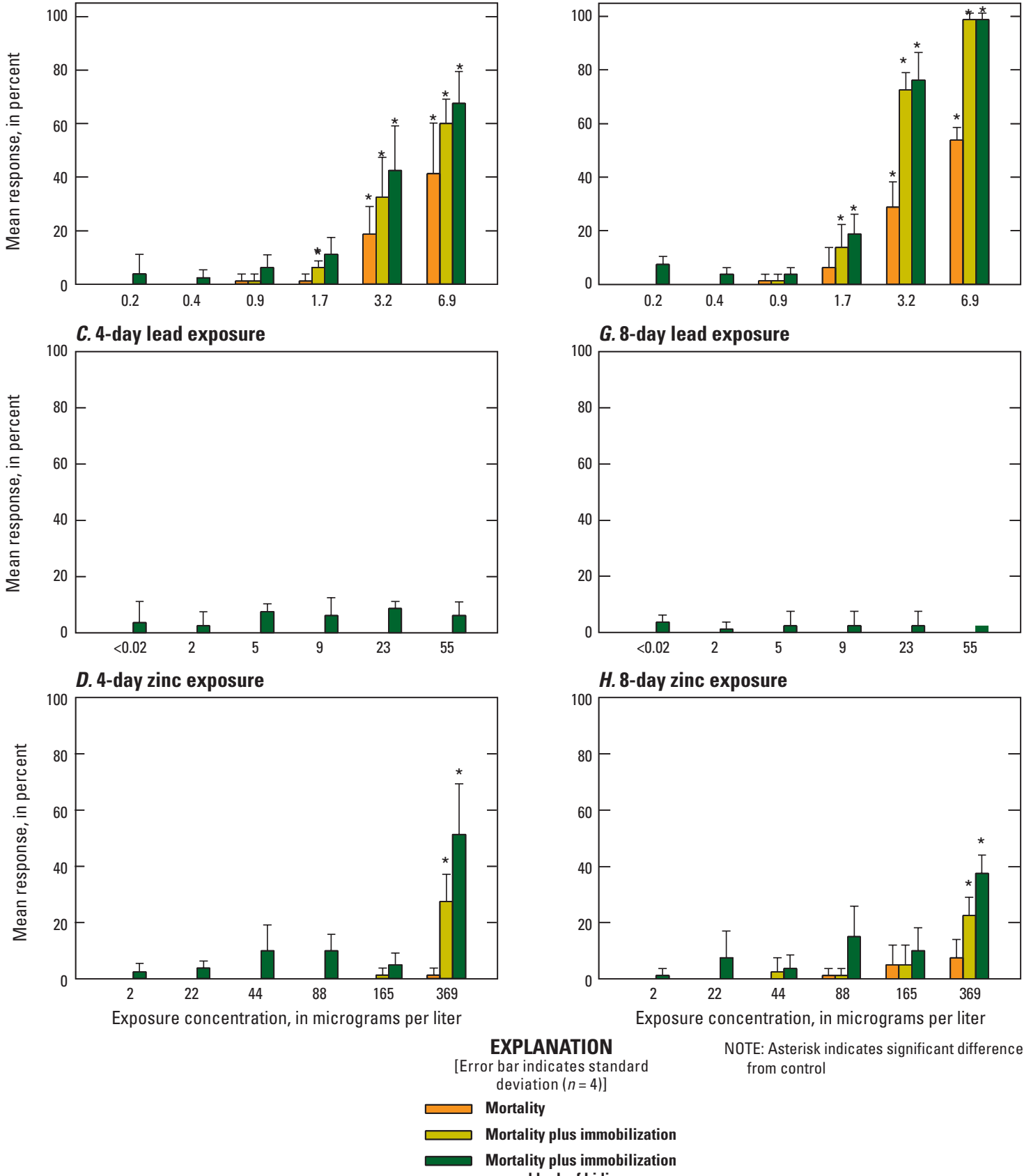
and lack of hiding

Figure B-2. Mean percentage of mortality, mortality plus immobilization, or mortality plus immobilization and lack of hiding of white sturgeon (Acipenser transmontanus) during the first 4 and 8 days of the 53-day exposures starting with 2-days-post-hatch larvae. 


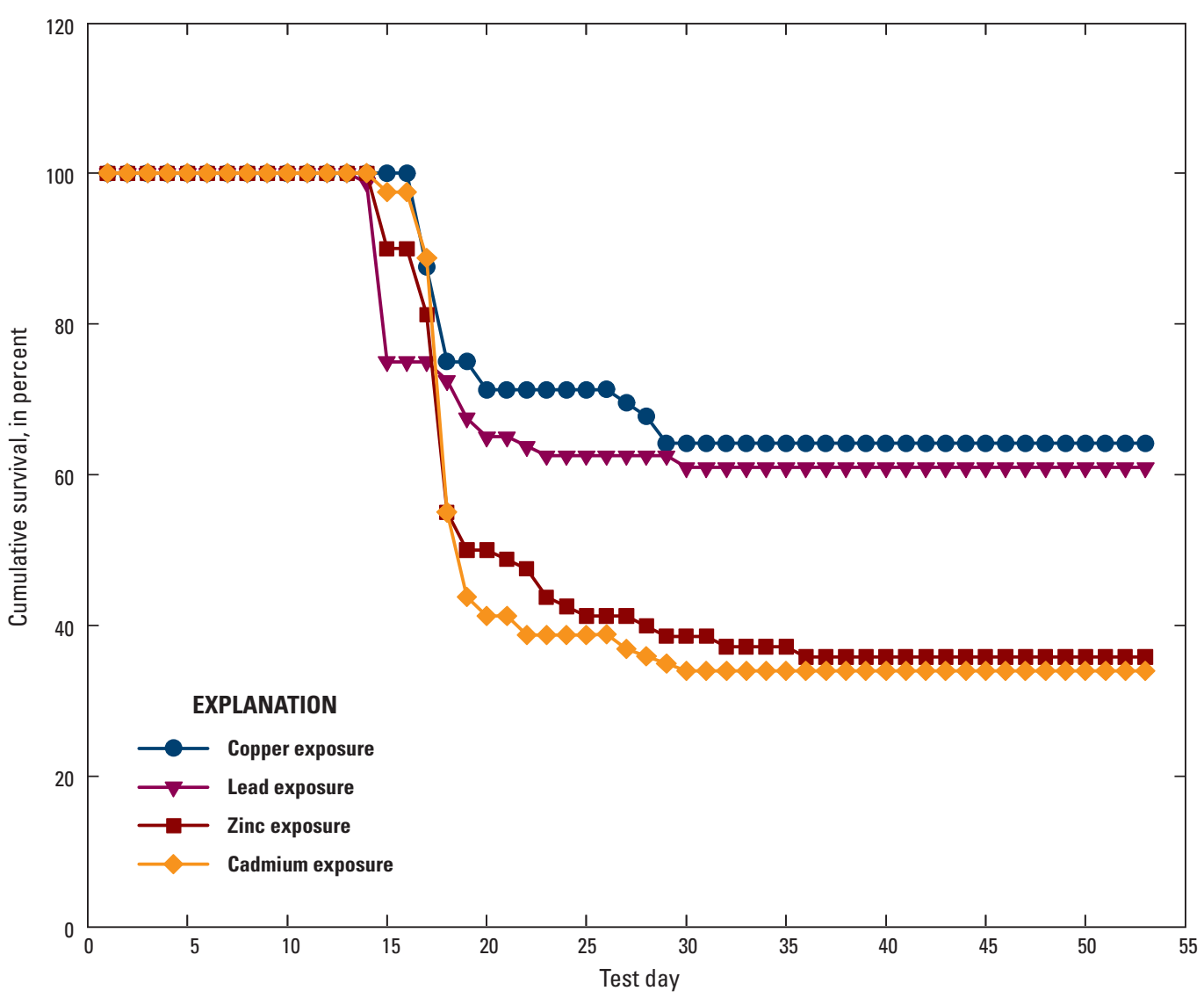

Figure B-3. Cumulative survival of white sturgeon (Acipenser transmontanus) in the controls (percent total number of survivors in the four replicate chambers) during the 53-day test period in the four metal exposures starting with 2-days-posthatch larvae. 53-d effect concentrations based on survival or biomass were not reported (table B-2); however, the effect concentrations generated for survival data from the thinning day to the end of the 53-d exposures and the growth data (length and weight) during the 53-d exposures were considered as nondefinitive effect concentrations for comparisons to other species or to WQC or to the Washington State WQS (table B-2).

The mean control survival ranged from 90 to 98 percent in the four metal, 28-d sturgeon $\mathrm{C} 2$ exposures starting with about 1-month-old juvenile sturgeon (table B-3) and met the test acceptability requirement of $\geq 80$-percent control survival (table B-1). Similar to the larval sturgeon in the $\mathrm{C} 1 / \mathrm{CC}$ exposures, the juvenile sturgeon in the 28-d C2 exposures also had elevated mortality at the high concentration of copper or zinc during the first 4-d exposures. The mean 4-d survival of 48 percent at $7.4 \mu \mathrm{g} \mathrm{Cu} / \mathrm{L}$ or 78 percent at $395 \mu \mathrm{g} \mathrm{Zn} / \mathrm{L}$ was significantly less than the control survival in the copper or zinc exposure (appendix table 2-5).

The acute 4-d effect concentrations for copper or zinc obtained during the first 4 days of the chronic exposures were similar between the two life stages of the sturgeon (appendix table 2-5). For example, the copper LC50 for the newly hatched larval sturgeon was $8.06 \mu \mathrm{g} \mathrm{Cu} / \mathrm{L}$ based on mortality or $5.29 \mu \mathrm{g} \mathrm{Cu} / \mathrm{L}$ based on mortality plus immobilization, which was similar or slightly less than the LC50 of $7.36 \mu \mathrm{g}$ $\mathrm{Cu} / \mathrm{L}$ for the juvenile sturgeon in the $\mathrm{C} 2$ exposure based on mortality (appendix table 2-5). The geometric mean of the
NOEC and LOEC for zinc based on mortality plus immobilization of the larval sturgeon was $247 \mu \mathrm{g} \mathrm{Zn/L} \mathrm{(no} \mathrm{LC50} \mathrm{for}$ zinc was estimated because mortality was $<30$ percent in all exposure concentrations), which was similar to the geometric mean of $264 \mu \mathrm{g} \mathrm{Zn} / \mathrm{L}$ for the juvenile sturgeon in the $\mathrm{C} 2$ exposure based on mortality (appendix table $2-5$ ). The chronic 53-d effect concentrations in the CC exposures starting with the newly hatched larval sturgeon generally were less than the 28-d effect concentrations in the $\mathrm{C} 2$ exposures starting with juvenile sturgeon (tables B-2 and B-3). For example, the EC20s based on dry weight were $5.4 \mu \mathrm{g} \mathrm{Cd} / \mathrm{L}, 1.55 \mu \mathrm{g} \mathrm{Cu} / \mathrm{L}$, $>27 \mu \mathrm{g} \mathrm{Pb} / \mathrm{L}$, and $99 \mu \mathrm{g} \mathrm{Zn} / \mathrm{L}$ in the $\mathrm{CC}$ exposures; and were $6.3 \mu \mathrm{g} \mathrm{Cd} / \mathrm{L}, 2.85 \mu \mathrm{g} \mathrm{Cu} / \mathrm{L},>60 \mu \mathrm{g} \mathrm{Pb} / \mathrm{L}$, and $239 \mu \mathrm{g} \mathrm{Zn} / \mathrm{L}$ in the $\mathrm{C} 2$ exposures (tables $\mathrm{B}-1$ and $\mathrm{B}-2$ ).

\section{Rainbow Trout Toxicity Tests}

The larval trout in the $\mathrm{C} 1$ and $\mathrm{CC}$ exposures started swim up and feeding on test day 12 except for the fish at the high concentration of copper. The overall mean control survival ranged 93 to 100 percent in the 52-d CC exposures (table B-4) and the mean survival in the $21-$ to $28-\mathrm{d} \mathrm{C} 1$ and $\mathrm{C} 2$ exposures ranged from 98 to 100 percent (table B-5), meeting the test acceptability requirement of $\geq 64$-percent overall control survival for a long-term test and meeting the test acceptability of $\geq 80$-percent control survival for a 28 -d test (table B-1). 
Table B-2. Chronic responses of white sturgeon (Acipenser transmontanus) (mean of four replicates unless noted) and effect concentrations in 53-day exposures to four metals starting with 2-days-post-hatch larval sturgeon.

[Yellow shading indicates significant reduction relative to the control. Due to 100-percent mortality in one replicate at a high exposure treatment, replicate number for length and weight calculation was 3 at the $12 \mu \mathrm{g} / \mathrm{L}$ cadmium treatment and at the $4 \mu \mathrm{g} / \mathrm{L}$ copper treatment. C1, chronic life stage 1 exposure; CC, chronic continuous exposure; $\mu \mathrm{g} / \mathrm{L}$, microgram per liter; \%, percent; SD, standard deviation; mm, millimeter; g, gram; <, less than; NOEC, no-observed-effect concentration; LOEC, lowest-observed-effect concentration; Geomean, geometric mean of the NOEC and LOEC; LC/EC10, 10-percent lethal or effect concentration; LC/EC20, 20-percent lethal or effect concentration; CL, 95-percent confidence limits; >, greater than; --, not applicable; NC, not calculated due to low control survival; NE, not estimated because the data do not meet the conditions for any logistic regression or probit analysis]

\begin{tabular}{|c|c|c|c|c|c|c|c|c|c|}
\hline \multirow{3}{*}{$\begin{array}{c}\text { Nominal } \\
\text { concentration } \\
(\mu \mathrm{g} / \mathrm{L})\end{array}$} & \multicolumn{3}{|c|}{ C1/CC over days 0 to 14} & \multicolumn{3}{|c|}{ CC 0-25 day ${ }^{1}$} & \multicolumn{3}{|c|}{ CC over days 25 to 53} \\
\hline & \multirow{2}{*}{$\begin{array}{c}\text { Measured } \\
\text { concentration } \\
(\mu \mathrm{g} / \mathrm{L})\end{array}$} & \multicolumn{2}{|c|}{$\begin{array}{c}\text { Survival } \\
(\%)\end{array}$} & \multirow{2}{*}{$\begin{array}{c}\text { Measured } \\
\text { concentration } \\
(\mu \mathrm{g} / \mathrm{L})\end{array}$} & \multicolumn{2}{|c|}{$\begin{array}{c}\text { Survival } \\
(\%)\end{array}$} & \multirow{2}{*}{$\begin{array}{c}\text { Measured } \\
\text { concentration } \\
(\mu \mathrm{g} / \mathrm{L})\end{array}$} & \multicolumn{2}{|c|}{$\begin{array}{c}\text { Survival } \\
(\%)\end{array}$} \\
\hline & & Mean & SD & & Mean & SD & & Mean & SD \\
\hline 0 & $<0.02$ & 100.0 & 0.0 & $<0.02$ & 38.8 & 40.5 & $<0.05$ & 87.5 & 25.0 \\
\hline 0.75 & 0.55 & 100.0 & 0.0 & 0.58 & 65.0 & 17.8 & 0.67 & 92.5 & 15.0 \\
\hline 1.5 & 1.17 & 100.0 & 0.0 & 1.20 & 63.8 & 15.5 & 1.31 & 97.5 & 5.0 \\
\hline 12 & 10.9 & 100.0 & 0.0 & 11.1 & 87.5 & 9.6 & 11.7 & 7.5 & 5.0 \\
\hline NOEC & & 11 & & & $\mathrm{NC}$ & & & 5.3 & \\
\hline LOEC & & $>11$ & & & $\mathrm{NC}$ & & & 11.7 & \\
\hline Geomean & & $>11$ & & & $\mathrm{NC}$ & & & 7.9 & \\
\hline $\mathrm{LC} / \mathrm{EC} 10(\mathrm{CL})$ & & $>11$ & & & $\mathrm{NC}$ & & & 8.8 (no CL) & \\
\hline $\mathrm{LC} / \mathrm{EC} 20(\mathrm{CL})$ & & $>11$ & & & $\mathrm{NC}$ & & & 9.2 (no CL) & \\
\hline \multicolumn{10}{|c|}{ Copper } \\
\hline 2 & 1.66 & 93.8 & 7.5 & 1.71 & 63.8 & 19.3 & 1.83 & 100.0 & 0.0 \\
\hline 4 & 3.21 & 50.0 & 9.1 & 3.31 & 15.0 & 10.8 & 3.37 & 75.0 & 50.0 \\
\hline 8 & 6.88 & 6.3 & 6.3 & 7.05 & 0.0 & 0.0 & 7.34 & 0.0 & - \\
\hline NOEC & & 1.66 & & & $\mathrm{NC}$ & & & 3.37 & \\
\hline LOEC & & 3.21 & & & $\mathrm{NC}$ & & & 7.34 & \\
\hline Geomean & & 2.31 & & & $\mathrm{NC}$ & & & 4.97 & \\
\hline $\mathrm{LC} / \mathrm{EC} 10(\mathrm{CL})$ & & $1.83(1.71-1.96)$ & & & $\mathrm{NC}$ & & & $3.11(1.71-5.63)$ & \\
\hline $\mathrm{LC} / \mathrm{EC} 20(\mathrm{CL})$ & & $2.24(2.12-2.37)$ & & & $\mathrm{NC}$ & & & $3.32(3.01-3.67)$ & \\
\hline \multicolumn{10}{|c|}{ Lead } \\
\hline 0 & $<0.02$ & 98.8 & 2.5 & $<0.04$ & 62.5 & 46.3 & $<0.03$ & 97.5 & 5.0 \\
\hline 5 & 2.45 & 100.0 & 0.0 & 2.71 & 67.5 & 16.6 & 3.11 & 77.5 & 22.2 \\
\hline LC/EC20 (CL) & & $>56$ & & & $\mathrm{NC}$ & & & $29(28-30)$ & \\
\hline \multicolumn{10}{|c|}{ Zinc } \\
\hline 0 & 1.54 & 100.0 & 0.0 & 1.67 & 40.0 & 38.5 & 1.50 & 86.7 & 11.5 \\
\hline 25 & 21.3 & 98.8 & 2.5 & 21.7 & 53.8 & 32.8 & 23.5 & 100.0 & 0.0 \\
\hline 50 & 43.0 & 98.8 & 2.5 & 44.5 & 58.8 & 30.9 & 47.4 & 97.5 & 5.0 \\
\hline 100 & 87.9 & 98.8 & 2.5 & 89.7 & 60.0 & 27.4 & 94.8 & 100.0 & 0.0 \\
\hline 200 & 166 & 95.0 & 7.1 & 170 & 78.8 & 10.3 & 187 & 97.5 & 5.0 \\
\hline 400 & 369 & 91.3 & 8.5 & 378 & 82.5 & 6.5 & 404 & 70.0 & 11.5 \\
\hline NOEC & & 369 & & & $\mathrm{NC}$ & & & 404 & \\
\hline LOEC & & $>369$ & & & $\mathrm{NC}$ & & & $>404$ & \\
\hline Geomean & & $>369$ & & & $\mathrm{NC}$ & & & $>404$ & \\
\hline LC/EC10 (CL) & & $>369$ & & & $\mathrm{NC}$ & & & $325(181-583)$ & \\
\hline $\mathrm{LC} / \mathrm{EC} 20(\mathrm{CL})$ & & $>369$ & & & $\mathrm{NC}$ & & & $373(304-458)$ & \\
\hline
\end{tabular}


Table B-2. Chronic responses of white sturgeon (Acipenser transmontanus) (mean of 4 replicates unless noted) and effect concentrations in 53-day exposures to four metals starting with 2-days-post-hatch larval sturgeon.-Continued

[Yellow shading indicates significant reduction relative to the control. Due to 100-percent mortality in one replicate at a high exposure treatment, replicate number for length and weight calculation was 3 at the $12 \mu \mathrm{g} / \mathrm{L}$ cadmium treatment and at the $4 \mu \mathrm{g} / \mathrm{L}$ copper treatment. C1, chronic life stage 1 exposure; CC, chronic continuous exposure; $\mu \mathrm{g} / \mathrm{L}$, microgram per liter; \%, percent; SD, standard deviation; mm, millimeter; g, gram; <, less than; NOEC, no-observed-effect concentration; LOEC, lowest observed effect concentration; Geomean, geometric mean of the NOEC and LOEC; LC/EC10, 10-percent lethal or effect concentration; LC/EC20, 20-percent lethal or effect concentration; CL, 95-percent confidence limits; >, greater than; --, not applicable; NC, not calculated due to low control survival; NE, not estimated because the data do not meet the conditions for any logistic regression or probit analysis]

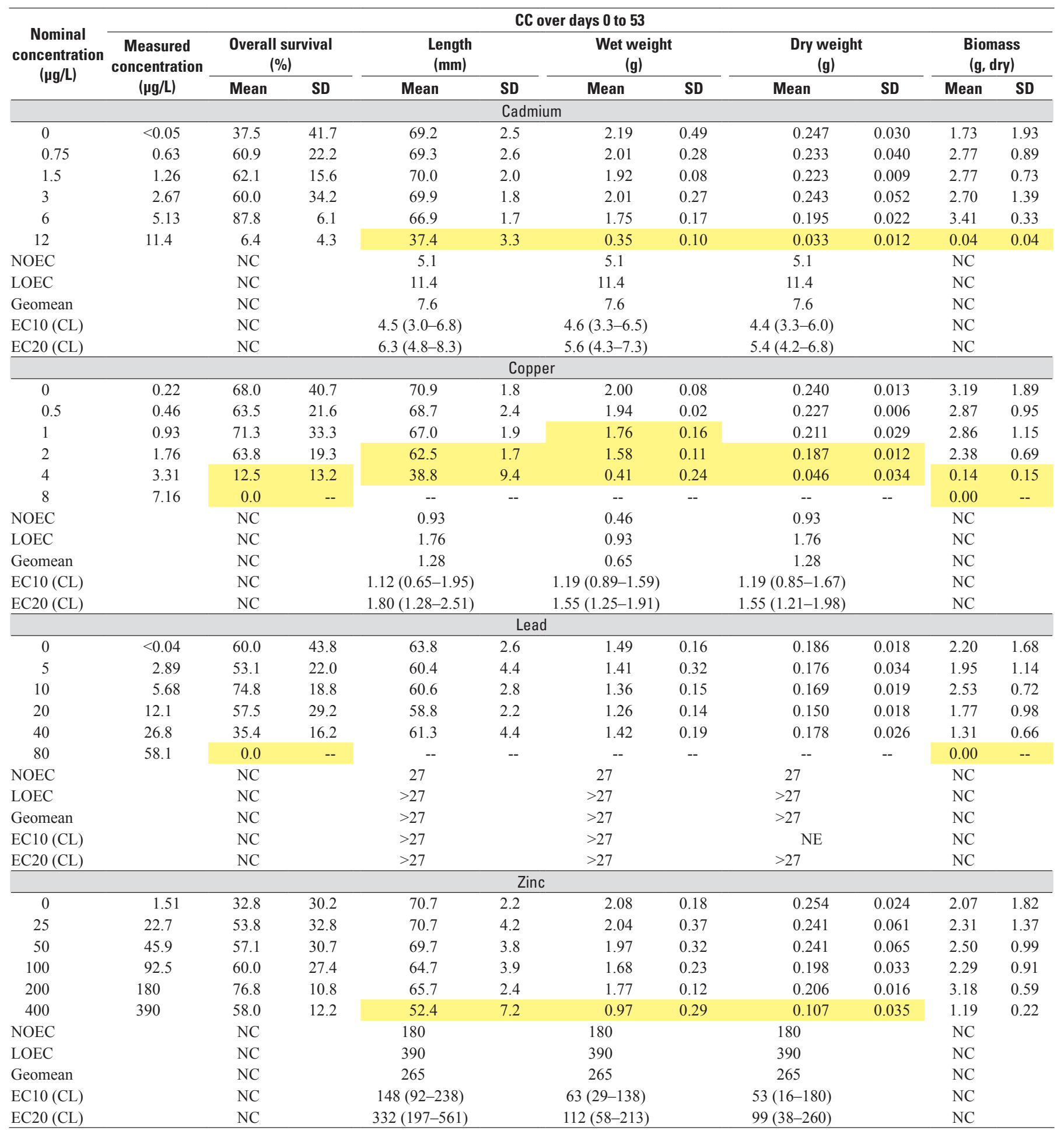

${ }^{1}$ Growth data are not reported due to no or few fish available in each replicate chamber for the growth measurements on fish thinning day (test day 25 ). 
Table B-3. Chronic responses (mean of four replicates unless noted) of white sturgeon (Acipenser transmontanus) and effect concentrations in 28-day exposures starting with 27-days-post-hatch juvenile sturgeon.

[Yellow shading indicates significant reduction relative to the control. Replicate number for length and weight calculation was 3 at the $12 \mu \mathrm{g} / \mathrm{L}$ cadmium treatment due to 100-percent mortality in the replicate at this high exposure treatment. $\mathrm{C} 2$, chronic life stage 2 exposure; $\mu \mathrm{g} / \mathrm{L}$, microgram per liter; \%, percent; SD, standard deviation; mm, millimeter; g, gram; <, less than; NOEC, no-observed-effect concentration; LOEC, lowest-observed-effect concentration; Geomean, geometric mean of the NOEC and LOEC; LC/EC10, 10-percent lethal or effect concentration; LC/EC20, 20-percent lethal or effect concentration; CL, 95-percent confidence limits; >, greater than]

\begin{tabular}{|c|c|c|c|c|c|c|c|c|c|c|c|}
\hline \multicolumn{12}{|c|}{ C2 (starting with 27-days-post-hatch fish) over days 0 to 28} \\
\hline \multirow{2}{*}{$\begin{array}{c}\text { Nominal } \\
\text { concen- } \\
\text { tration } \\
(\mu \mathrm{g} / \mathrm{L})\end{array}$} & \multirow{2}{*}{$\begin{array}{c}\text { Measured } \\
\text { concen- } \\
\text { tration } \\
(\mu \mathrm{g} / \mathrm{L})\end{array}$} & \multicolumn{2}{|l|}{$\begin{array}{c}\text { Survival } \\
(\%)\end{array}$} & \multicolumn{2}{|c|}{$\begin{array}{c}\begin{array}{c}\text { Length } \\
(\mathrm{mm})\end{array} \\
\end{array}$} & \multicolumn{2}{|c|}{$\begin{array}{c}\text { Wet weight } \\
(\mathrm{g})\end{array}$} & \multicolumn{2}{|l|}{$\begin{array}{l}\text { Dry weight } \\
\text { (g) }\end{array}$} & \multicolumn{2}{|l|}{$\begin{array}{c}\text { Biomass } \\
\text { (g, dry) }\end{array}$} \\
\hline & & Mean & SD & Mean & SD & Mean & SD & Mean & SD & Mean & SD \\
\hline \multicolumn{12}{|c|}{ Cadmium } \\
\hline 0 & $<0.05$ & 97.5 & 5.0 & 65.6 & 0.4 & 1.70 & 0.06 & 0.197 & 0.008 & 1.92 & 0.15 \\
\hline 0.75 & 0.67 & 92.5 & 5.0 & 64.9 & 1.9 & 1.63 & 0.14 & 0.192 & 0.016 & 1.77 & 0.10 \\
\hline 6 & 5.29 & 80.0 & 16.3 & 64.4 & 1.8 & 1.58 & 0.11 & 0.182 & 0.016 & 1.44 & 0.19 \\
\hline 12 & 11.7 & 25.0 & 5.8 & 39.6 & 5.6 & 0.41 & 0.17 & 0.037 & 0.019 & 0.09 & 0.03 \\
\hline NOEC & & 5.3 & & 5.3 & & 5.3 & & 5.3 & & 2.7 & \\
\hline LOEC & & 11.7 & & 11.7 & & 11.7 & & 11.7 & & 5.3 & \\
\hline Geomean & & 7.9 & & 7.9 & & 7.9 & & 7.9 & & 3.8 & \\
\hline LC/EC10 (CL) & & $4.8(4.4-5.3)$ & & $6.5(6.0-7.0)$ & & $5.8(5.3-6.4)$ & & $5.7(5.1-6.3)$ & & $2.4(1.5-4.0)$ & \\
\hline 1 & 0.95 & 95.0 & 5.8 & 63.9 & 0.7 & 1.57 & 0.04 & 0.185 & 0.008 & 1.75 & 0.04 \\
\hline 2 & 1.83 & 97.5 & 5.0 & 62.7 & 0.7 & 1.46 & 0.07 & 0.170 & 0.009 & 1.66 & 0.06 \\
\hline 4 & 3.37 & 90.0 & 8.2 & 63.0 & 2.7 & 1.46 & 0.22 & 0.177 & 0.026 & 1.58 & 0.11 \\
\hline 8 & 7.34 & 12.5 & 9.6 & 28.3 & 5.6 & 0.13 & 0.04 & 0.018 & 0.003 & 0.02 & 0.02 \\
\hline NOEC & & 3.37 & & 3.37 & & 0.95 & & 0.95 & & 0.95 & \\
\hline LOEC & & 7.34 & & 7.34 & & 1.83 & & 1.83 & & 1.83 & \\
\hline Geomean & & 4.97 & & 4.97 & & 1.32 & & 1.32 & & 1.32 & \\
\hline LC/EC10 (CL) & & $3.72(3.44-4.02)$ & & $3.85(3.65-4.06)$ & & $1.96(1.21-3.19)$ & & $2.04(1.19-3.48)$ & & $2.03(1.33-3.11)$ & \\
\hline LC/EC20 (CL) & & $4.21(3.95-4.49)$ & & $4.44(4.23-4.65)$ & & $2.65(1.86-3.77)$ & & $2.85(1.94-4.19)$ & & $2.67(1.95-3.66)$ & \\
\hline \multicolumn{12}{|c|}{ Lead } \\
\hline 0 & $<0.03$ & 92.5 & 15.0 & 60.0 & 3.4 & 1.25 & 0.14 & 0.165 & 0.025 & 1.51 & 0.18 \\
\hline 5 & 3.11 & 97.5 & 5.0 & 58.9 & 2.7 & 1.20 & 0.22 & 0.147 & 0.028 & 1.43 & 0.19 \\
\hline LC/EC20 (CL) & & $>60$ & & $>60$ & & $>60$ & & $>60$ & & $>60$ & \\
\hline \multicolumn{12}{|c|}{ Zinc } \\
\hline 0 & 1.50 & 97.5 & 5.0 & 64.1 & 0.8 & 1.54 & 0.10 & 0.180 & 0.013 & 1.76 & 0.13 \\
\hline 25 & 23.5 & 90.0 & 14.1 & 63.3 & 0.6 & 1.56 & 0.04 & 0.188 & 0.009 & 1.68 & 0.20 \\
\hline 50 & 47.4 & 95.0 & 10.0 & 62.6 & 1.8 & 1.50 & 0.13 & 0.176 & 0.018 & 1.67 & 0.23 \\
\hline 100 & 94.8 & 92.5 & 9.6 & 62.6 & 0.6 & 1.57 & 0.13 & 0.183 & 0.018 & 1.69 & 0.06 \\
\hline 200 & 187 & 85.0 & 5.8 & 63.0 & 0.7 & 1.56 & 0.04 & 0.174 & 0.006 & 1.48 & 0.05 \\
\hline 400 & 404 & 50.0 & 11.5 & 48.1 & 5.0 & 0.72 & 0.18 & 0.083 & 0.043 & 0.38 & 0.13 \\
\hline NOEC & & 187 & & 187 & & 187 & & 187 & & 95 & \\
\hline LOEC & & 404 & & 404 & & 404 & & 404 & & 187 & \\
\hline Geomean & & 275 & & 275 & & 275 & & 275 & & 133 & \\
\hline LC/EC10 (CL) & & $187(162-217)$ & & $257(233-283)$ & & 219 (no CL) & & $205(171-245)$ & & $181(161-203)$ & \\
\hline LC/EC20 (CL) & & $248(225-274)$ & & $356(319-397)$ & & 253 (no CL) & & $239(205-278)$ & & $203(184-225)$ & \\
\hline
\end{tabular}


Table B-4. Chronic responses (mean of four replicates unless noted) of rainbow trout (Oncorhynchus mykiss) and effect concentrations in 52-day exposures starting with 1-day-post-hatch larval trout.

[Yellow shading indicates significant reduction relative to the control. Due to 100-percent mortality in one or more replicates at the high exposure treatment, replicate number for length, wet weight, and dry weight was 2 at the $12 \mu \mathrm{g} / \mathrm{L}$ in the 52 -day cadmium exposure, 3 at the $60 \mu \mathrm{g} / \mathrm{L}$ in the 21-day copper exposure, and 1 at the $60 \mu \mathrm{g} / \mathrm{L}$ in the 52 -day copper exposure. CC, chronic continuous exposure; $\mu \mathrm{g} / \mathrm{L}$, microgram per liter; $\%$, percent; SD, standard deviation; mm, millimeter; g, gram; <, less than; NOEC, no-observed-effect concentration; LOEC, lowest-observed-effect concentration; >, greater than; Geomean, geometric mean of the NOEC and LOEC; LC/EC10, 10-percent lethal or effect concentration; CL, 95-percent confidence limits; LC/EC20, 20-percent lethal or effect concentration; NA, not applicable due to only one replicate]

\begin{tabular}{|c|c|c|c|c|c|c|}
\hline \multirow{3}{*}{$\begin{array}{c}\text { Nominal } \\
\text { concentration } \\
(\mu \mathrm{g} / \mathrm{L})\end{array}$} & \multicolumn{3}{|c|}{ CC over days 0 to 21} & \multicolumn{3}{|c|}{ CC over days 21 to 52} \\
\hline & \multirow{2}{*}{$\begin{array}{c}\text { Measured } \\
\text { concentration } \\
(\mu \mathrm{g} / \mathrm{L})\end{array}$} & \multicolumn{2}{|c|}{$\begin{array}{c}\text { Survival } \\
(\%)\end{array}$} & \multirow{2}{*}{$\begin{array}{c}\text { Measured } \\
\text { concentration } \\
(\mu \mathrm{g} / \mathrm{L})\end{array}$} & \multicolumn{2}{|c|}{$\begin{array}{c}\text { Survival } \\
(\%)\end{array}$} \\
\hline & & Mean & SD & & Mean & SD \\
\hline \multicolumn{7}{|c|}{ Cadmium } \\
\hline 0 & $<0.02$ & 96.3 & 7.5 & $<0.02$ & 97.5 & 5.0 \\
\hline 0.75 & 0.70 & 98.8 & 2.5 & 0.63 & 97.5 & 5.0 \\
\hline 1.5 & 1.38 & 97.5 & 2.9 & 1.20 & 100.0 & 0.0 \\
\hline 3 & 2.95 & 98.8 & 2.5 & 2.64 & 100.0 & 0.0 \\
\hline 6 & 5.22 & 97.5 & 5.0 & 4.89 & 85.0 & 5.8 \\
\hline 12 & 11.5 & 85.0 & 4.1 & 11.0 & 5.0 & 5.8 \\
\hline NOEC & & 12 & & & 4.9 & \\
\hline LOEC & & $>12$ & & & 11.0 & \\
\hline Geomean & & $>12$ & & & 7.3 & \\
\hline LC/EC10 (CL) & & $11(9.2-14)$ & & & $4.6(4.4-4.9)$ & \\
\hline $\mathrm{LC} / \mathrm{EC} 20(\mathrm{CL})$ & & $17(11-24)$ & & & $5.3(5.0-5.5)$ & \\
\hline \multicolumn{7}{|c|}{ Copper } \\
\hline 0 & 0.16 & 100.0 & 0.0 & 0.20 & 100.0 & 0.0 \\
\hline 4 & 3.33 & 98.8 & 2.5 & 3.02 & 100.0 & 0.0 \\
\hline 8 & 7.20 & 100.0 & 0.0 & 6.31 & 100.0 & 0.0 \\
\hline 16 & 14.4 & 98.8 & 2.5 & 12.7 & 100.0 & 0.0 \\
\hline 32 & 29.0 & 98.8 & 2.5 & 26.7 & 100.0 & 0.0 \\
\hline 64 & 60.1 & 48.8 & 22.9 & 53.8 & 25.0 & 50.0 \\
\hline NOEC & & 29 & & & 27 & \\
\hline LOEC & & 60 & & & 54 & \\
\hline Geomean & & 42 & & & 38 & \\
\hline LC/EC10 (CL) & & $41(37-46)$ & & & 43 (no CL) & \\
\hline LC/EC20 (CL) & & $47(44-50)$ & & & 45 (no CL) & \\
\hline \multicolumn{7}{|c|}{ Lead } \\
\hline 0 & $<0.03$ & 98.8 & 2.5 & $<0.02$ & 100.0 & 0.0 \\
\hline 10 & 7.29 & 96.3 & 4.8 & 5.69 & 95.0 & 5.8 \\
\hline 20 & 13.4 & 96.3 & 7.5 & 11.0 & 97.5 & 5.0 \\
\hline 40 & 29.3 & 96.3 & 4.8 & 27.9 & 100.0 & 0.0 \\
\hline 80 & 58.7 & 100.0 & 0.0 & 55.4 & 97.5 & 5.0 \\
\hline 160 & 128 & 100.0 & 0.0 & 128 & 100.0 & 0.0 \\
\hline NOEC & & 128 & & & 128 & \\
\hline LOEC & & $>128$ & & & $>128$ & \\
\hline Geomean & & $>128$ & & & $>128$ & \\
\hline LC/EC10 (CL) & & $>128$ & & & $>128$ & \\
\hline LC/EC20 (CL) & & $>128$ & & & $>128$ & \\
\hline \multicolumn{7}{|c|}{ Zinc } \\
\hline 0 & 1.27 & 97.5 & 2.9 & 1.43 & 95.0 & 5.8 \\
\hline 50 & 47.9 & 93.8 & 2.5 & 46.4 & 97.5 & 5.0 \\
\hline 100 & 95.6 & 97.5 & 5.0 & 93.3 & 100.0 & 0.0 \\
\hline 200 & 194 & 100.0 & 0.0 & 185 & 100.0 & 0.0 \\
\hline 400 & 377 & 100.0 & 0.0 & 365 & 97.5 & 5.0 \\
\hline 800 & 753 & 98.8 & 2.5 & 755 & 95.0 & 5.8 \\
\hline NOEC & & 753 & & & 755 & \\
\hline LOEC & & $>753$ & & & $>755$ & \\
\hline Geomean & & $>753$ & & & $>755$ & \\
\hline LC/EC10 (CL) & & $>753$ & & & $>755$ & \\
\hline LC/EC20 (CL) & & $>753$ & & & $>755$ & \\
\hline
\end{tabular}


Table B-4. Chronic responses (mean of four replicates unless noted) of rainbow trout (Oncorhynchus mykiss) and effect concentrations in 52-day exposures starting with 1-day-post-hatch larval trout.-Continued

[Yellow shading indicates significant reduction relative to the control. Due to 100-percent mortality in one or more replicates at the high exposure treatment, replicate number for length, wet weight, and dry weight was 2 at the $12 \mu \mathrm{g} / \mathrm{L}$ in the 52 -day cadmium exposure, 3 at the $60 \mu \mathrm{g} / \mathrm{L}$ in the 21 -day copper exposure, and 1 at the $60 \mu \mathrm{g} / \mathrm{L}$ in the 52-day copper exposure. CC, chronic continuous exposure; $\mu \mathrm{g} / \mathrm{L}$, microgram per liter; \%, percent; SD, standard deviation; mm, millimeter; g, gram; <, less than; NOEC, no-observed-effect concentration; LOEC, lowest-observed-effect concentration; >, greater than; Geomean, geometric mean of the NOEC and LOEC; LC/EC10, 10-percent lethal or effect concentration; CL, 95-percent confidence limits; LC/EC20, 20-percent lethal or effect concentration; NA, not applicable due to only one replicate]

\begin{tabular}{|c|c|c|c|c|c|c|c|c|c|c|c|}
\hline \multirow{3}{*}{$\begin{array}{c}\text { Nominal } \\
\text { concentration } \\
(\mu \mathrm{g} / \mathrm{L})\end{array}$} & \multicolumn{11}{|c|}{ CC over days 0 to 52} \\
\hline & \multirow{2}{*}{$\begin{array}{c}\text { Measured } \\
\text { concentration } \\
(\mu \mathrm{g} / \mathrm{L})\end{array}$} & \multicolumn{2}{|c|}{$\begin{array}{c}\text { Overall survival } \\
(\%)\end{array}$} & \multicolumn{2}{|c|}{$\begin{array}{l}\text { Length } \\
(\mathrm{mm})\end{array}$} & \multicolumn{2}{|c|}{$\begin{array}{c}\text { Wet weight } \\
\text { (g) }\end{array}$} & \multicolumn{2}{|c|}{$\begin{array}{c}\text { Dry Weight } \\
\text { (g) }\end{array}$} & \multicolumn{2}{|c|}{$\begin{array}{c}\text { Biomass } \\
\text { (g, dry) }\end{array}$} \\
\hline & & Mean & SD & Mean & SD & Mean & SD & Mean & SD & Mean & SD \\
\hline \multicolumn{12}{|c|}{ Cadmium } \\
\hline 0 & $<0.02$ & 93.8 & 7.5 & 36.9 & 1.3 & 0.53 & 0.04 & 0.098 & 0.007 & 1.85 & 0.25 \\
\hline 0.75 & 0.65 & 96.4 & 7.3 & 36.7 & 0.8 & 0.54 & 0.04 & 0.098 & 0.009 & 1.87 & 0.03 \\
\hline 1.5 & 1.26 & 97.5 & 2.9 & 36.2 & 0.3 & 0.53 & 0.02 & 0.097 & 0.003 & 1.90 & 0.11 \\
\hline 3 & 2.74 & 98.8 & 2.5 & 36.4 & 0.4 & 0.53 & 0.01 & 0.098 & 0.003 & 1.93 & 0.08 \\
\hline 6 & 4.98 & 83.0 & 8.7 & 36.7 & 0.7 & 0.52 & 0.06 & 0.100 & 0.005 & 1.66 & 0.10 \\
\hline 12 & 11.2 & 4.3 & 4.9 & 42.3 & 1.7 & 0.84 & 0.08 & 0.165 & 0.021 & 0.14 & 0.16 \\
\hline NOEC & & 5.0 & & 12 & & 12 & & 12 & & 5.0 & \\
\hline LOEC & & 11.2 & & $>12$ & & $>12$ & & $>12$ & & 11.2 & \\
\hline Geomean & & 7.5 & & $>12$ & & $>12$ & & $>12$ & & 7.5 & \\
\hline LC/EC10 (CL) & & $4.7(4.5-5.0)$ & & $>12$ & & $>12$ & & $>12$ & & $4.8(4.2-5.5)$ & \\
\hline LC/EC20 (CL) & & $5.3(5.1-5.6)$ & & $>12$ & & $>12$ & & $>12$ & & $5.6(4.9-6.3)$ & \\
\hline \multicolumn{12}{|c|}{ Copper } \\
\hline 0 & 0.18 & 100.0 & 0.0 & 36.9 & 0.4 & 0.56 & 0.02 & 0.105 & 0.006 & 2.11 & 0.12 \\
\hline 4 & 3.12 & 98.8 & 2.5 & 37.0 & 1.3 & 0.57 & 0.04 & 0.107 & 0.006 & 2.11 & 0.13 \\
\hline 8 & 6.59 & 100.0 & 0.0 & 37.0 & 0.9 & 0.56 & 0.04 & 0.105 & 0.008 & 2.10 & 0.15 \\
\hline 16 & 13.3 & 98.8 & 2.5 & 37.0 & 0.8 & 0.58 & 0.02 & 0.106 & 0.003 & 2.09 & 0.08 \\
\hline 32 & 27.7 & 98.8 & 2.5 & 36.6 & 1.0 & 0.57 & 0.03 & 0.106 & 0.005 & 2.10 & 0.07 \\
\hline 64 & 56.5 & 3.8 & 7.5 & 39.6 & NA & 0.73 & NA & 0.143 & NA & 0.11 & 0.22 \\
\hline NOEC & & 28 & & 57 & & 57 & & 57 & & 28 & \\
\hline LOEC & & 57 & & $>57$ & & $>57$ & & $>57$ & & 57 & \\
\hline Geomean & & 40 & & $>57$ & & $>57$ & & $>57$ & & 40 & \\
\hline LC/EC10 (CL) & & $34(31-37)$ & & $>57$ & & $>57$ & & $>57$ & & $30(28-31)$ & \\
\hline LC/EC20 (CL) & & $36(34-39)$ & & $>57$ & & $>57$ & & $>57$ & & $32(31-34)$ & \\
\hline \multicolumn{12}{|c|}{ Lead } \\
\hline 0 & $<0.03$ & 98.8 & 2.5 & 36.3 & 0.8 & 0.54 & 0.04 & 0.097 & 0.009 & 1.91 & 0.14 \\
\hline 10 & 6.19 & 91.3 & 2.5 & 36.7 & 0.6 & 0.54 & 0.00 & 0.098 & 0.001 & 1.80 & 0.06 \\
\hline 20 & 11.7 & 94.1 & 11.8 & 36.9 & 0.5 & 0.56 & 0.01 & 0.102 & 0.003 & 1.92 & 0.27 \\
\hline 40 & 27.9 & 96.3 & 4.8 & 37.0 & 0.4 & 0.57 & 0.03 & 0.101 & 0.005 & 1.95 & 0.09 \\
\hline 80 & 55.7 & 97.5 & 5.0 & 36.5 & 0.6 & 0.57 & 0.05 & 0.106 & 0.007 & 2.06 & 0.09 \\
\hline 160 & 126 & 100.0 & 0.0 & 35.8 & 0.6 & 0.53 & 0.02 & 0.095 & 0.004 & 1.91 & 0.08 \\
\hline NOEC & & 126 & & 126 & & 126 & & 126 & & 126 & \\
\hline LOEC & & $>126$ & & $>126$ & & $>126$ & & $>126$ & & $>126$ & \\
\hline Geomean & & $>126$ & & $>126$ & & $>126$ & & $>126$ & & $>126$ & \\
\hline LC/EC10 (CL) & & $>126$ & & $>126$ & & $>126$ & & $>126$ & & $>126$ & \\
\hline LC/EC20 (CL) & & $>126$ & & $>126$ & & $>126$ & & $>126$ & & $>126$ & \\
\hline \multicolumn{12}{|c|}{ Zinc } \\
\hline 0 & 1.31 & 92.8 & 8.4 & 36.7 & 0.6 & 0.56 & 0.03 & 0.104 & 0.006 & 1.93 & 0.08 \\
\hline 50 & 46.8 & 91.4 & 4.6 & 36.0 & 0.5 & 0.54 & 0.01 & 0.102 & 0.004 & 1.86 & 0.11 \\
\hline 100 & 94.0 & 97.5 & 5.0 & 36.5 & 0.8 & 0.52 & 0.02 & 0.097 & 0.006 & 1.89 & 0.17 \\
\hline 200 & 189 & 100.0 & 0.0 & 36.4 & 0.4 & 0.56 & 0.02 & 0.111 & 0.001 & 2.21 & 0.03 \\
\hline 400 & 370 & 97.5 & 5.0 & 36.6 & 0.3 & 0.57 & 0.01 & 0.110 & 0.005 & 2.14 & 0.10 \\
\hline 800 & 755 & 93.8 & 4.8 & 35.9 & 0.6 & 0.54 & 0.03 & 0.103 & 0.009 & 1.93 & 0.12 \\
\hline NOEC & & 755 & & 755 & & 755 & & 755 & & 755 & \\
\hline LOEC & & $>755$ & & $>755$ & & $>755$ & & $>755$ & & $>755$ & \\
\hline Geomean & & $>755$ & & $>755$ & & $>755$ & & $>755$ & & $>755$ & \\
\hline LC/EC10 (CL) & & $>755$ & & $>755$ & & $>755$ & & $>755$ & & $>755$ & \\
\hline LC/EC20 (CL) & & $>755$ & & $>755$ & & $>755$ & & $>755$ & & $>755$ & \\
\hline
\end{tabular}


Table B-5. Chronic responses (mean of four replicates unless noted) of rainbow trout (Oncorhynchus mykiss) and effect concentrations in 21-day exposures starting with 1-day-post-hatch larvae or in 28-day exposures with 26-days-post-hatch juveniles.

[Yellow shading indicates significant reduction relative to the control. Due to 100-percent mortality in one or more replicates at the high exposure treatment, replicate number for length, wet weight, and dry weight was 3 for the $\mathrm{C} 1$ and $\mathrm{C} 264 \mu \mathrm{g} / \mathrm{L}$ copper treatment and was 1 for the $\mathrm{C} 2800 \mu \mathrm{g} / \mathrm{L}$ zinc treatment. $\mathrm{C} 1$, chronic life stage 1 exposure; $\mu \mathrm{g} / \mathrm{L}$, microgram per liter; \%, percent; SD, standard deviation; mm, millimeter; g, gram; <, less than; NOEC, no-observed-effect concentration; LOEC, lowest-observed-effect concentration; >, greater than; Geomean, geometric mean of the NOEC and LOEC; LC/EC10, 10-percent lethal or effect concentration; CL, 95-percent confidence limits; LC/EC20, 20-percent lethal or effect concentration; C2, chronic life stage 2 exposure; --, no data due to 100-percent mortality in all replicates; NE, not estimated because the data do not meet the conditions for any logistic regression or probit analysis; NA, not applicable due to only one replicate]

\begin{tabular}{|c|c|c|c|c|c|c|c|c|c|c|c|}
\hline \multirow{3}{*}{$\begin{array}{c}\text { Nominal } \\
\text { concentration } \\
(\mu \mathrm{g} / \mathrm{L})\end{array}$} & \multicolumn{11}{|c|}{ C1 (starting with 1-day-post-hatch fish) over days 0 to 21} \\
\hline & \multirow{2}{*}{$\begin{array}{c}\text { Measured } \\
\text { concentration } \\
(\mu \mathrm{g} / \mathrm{L}) \\
\end{array}$} & \multicolumn{2}{|c|}{$\begin{array}{c}\text { Survival } \\
(\%)\end{array}$} & \multicolumn{2}{|c|}{$\begin{array}{c}\text { Length } \\
(\mathrm{mm})\end{array}$} & \multicolumn{2}{|c|}{$\begin{array}{l}\text { Wet weight } \\
\text { (g) }\end{array}$} & \multicolumn{2}{|c|}{$\begin{array}{c}\text { Dry weight } \\
(\mathrm{g})\end{array}$} & \multicolumn{2}{|c|}{$\begin{array}{l}\text { Biomass } \\
\text { (g, dry) }\end{array}$} \\
\hline & & Mean & SD & Mean & SD & Mean & SD & Mean & SD & Mean & SD \\
\hline 0 & $<0.02$ & 97.5 & 2.9 & 22.6 & 0.2 & 0.109 & 0.004 & 0.016 & 0.001 & 0.32 & 0.03 \\
\hline 0.75 & 0.70 & 96.3 & 4.8 & 22.8 & 0.2 & 0.113 & 0.003 & 0.017 & 0.001 & 0.33 & 0.04 \\
\hline 1.5 & 1.38 & 97.5 & 5.0 & 22.9 & 0.2 & 0.115 & 0.004 & 0.018 & 0.001 & 0.34 & 0.03 \\
\hline 12 & 11.5 & 81.3 & 16.5 & 22.3 & 0.5 & 0.115 & 0.007 & 0.018 & 0.001 & 0.29 & 0.05 \\
\hline NOEC & & 5.2 & & 11.5 & & 11.5 & & 11.5 & & 11.5 & \\
\hline LOEC & & 11.5 & & $>11.5$ & & $>11.5$ & & $>11.5$ & & $>11.5$ & \\
\hline Geomean & & 7.8 & & $>11.5$ & & $>11.5$ & & $>11.5$ & & $>11.5$ & \\
\hline LC/EC10 (CL) & & $9.8(8.2-12)$ & & $>11.5$ & & $>11.5$ & & $>11.5$ & & $9.2(4.6-18.7)$ & \\
\hline LC/EC20 (CL) & & $12(11-14)$ & & $>11.5$ & & $>11.5$ & & $>11.5$ & & $>11.5$ & \\
\hline 16 & 14.4 & 100.0 & 0.0 & 23.4 & 0.2 & 0.113 & 0.002 & 0.018 & 0.000 & 0.35 & 0.00 \\
\hline 32 & 29.0 & 97.5 & 5.0 & 22.8 & 0.3 & 0.112 & 0.003 & 0.017 & 0.001 & 0.34 & 0.01 \\
\hline 64 & 60.1 & 40.0 & 32.7 & 22.2 & 0.5 & 0.108 & 0.000 & 0.019 & 0.001 & 0.15 & 0.13 \\
\hline NOEC & & 29 & & 60 & & 60 & & 60 & & 29 & \\
\hline LOEC & & 60 & & $>60$ & & $>60$ & & $>60$ & & 60 & \\
\hline Geomean & & 42 & & $>60$ & & $>60$ & & $>60$ & & 42 & \\
\hline LC/EC10 (CL) & & $37(35-40)$ & & $>60$ & & $>60$ & & $>60$ & & $31(25-38)$ & \\
\hline LC/EC20 (CL) & & $43(40-45)$ & & $>60$ & & $>60$ & & $>60$ & & $36(30-42)$ & \\
\hline \multicolumn{12}{|c|}{ Lead } \\
\hline 0 & $<0.03$ & 97.5 & 2.9 & 22.7 & 0.2 & 0.112 & 0.002 & 0.017 & 0.001 & 0.33 & 0.00 \\
\hline 10 & 7.29 & 98.8 & 2.5 & 22.8 & 0.5 & 0.116 & 0.007 & 0.017 & 0.001 & 0.35 & 0.03 \\
\hline LC/EC20 (CL) & & $>128$ & & $>128$ & & $>128$ & & $>128$ & & $>128$ & \\
\hline \multicolumn{12}{|c|}{ Zinc } \\
\hline 0 & 1.27 & 100.0 & 0.0 & 22.7 & 0.1 & 0.111 & 0.002 & 0.017 & 0.001 & 0.34 & 0.01 \\
\hline 50 & 47.9 & 98.8 & 2.5 & 22.8 & 0.3 & 0.112 & 0.004 & 0.017 & 0.000 & 0.33 & 0.00 \\
\hline 100 & 95.6 & 100.0 & 0.0 & 22.9 & 0.2 & 0.119 & 0.003 & 0.018 & 0.000 & 0.36 & 0.01 \\
\hline 200 & 194 & 100.0 & 0.0 & 23.2 & 0.3 & 0.122 & 0.006 & 0.018 & 0.000 & 0.37 & 0.01 \\
\hline 400 & 377 & 100.0 & 0.0 & 22.9 & 0.3 & 0.114 & 0.001 & 0.018 & 0.000 & 0.36 & 0.01 \\
\hline 800 & 753 & 100.0 & 0.0 & 22.6 & 0.1 & 0.113 & 0.002 & 0.017 & 0.001 & 0.34 & 0.02 \\
\hline NOEC & & 753 & & 753 & & 753 & & 753 & & 753 & \\
\hline LOEC & & $>753$ & & $>753$ & & $>753$ & & $>753$ & & $>753$ & \\
\hline Geomean & & $>753$ & & $>753$ & & $>753$ & & $>753$ & & $>753$ & \\
\hline LC/EC10 (CL) & & $>753$ & & $>753$ & & $>753$ & & $>753$ & & $>753$ & \\
\hline LC/EC20 (CL) & & $>753$ & & $>753$ & & $>753$ & & $>753$ & & $>753$ & \\
\hline
\end{tabular}


Table B-5. Chronic responses (mean of four replicates unless noted) of rainbow trout (Oncorhynchus mykiss) and effect concentrations in 21-day exposures starting with 1-day-post-hatch larvae or in 28-day exposures with 26-days-post-hatch juveniles.Continued

[Yellow shading indicates significant reduction relative to the control. Due to 100-percent mortality in one or more replicates at the high exposure treatment, replicate number for length, wet weight, and dry weight was 3 for the $\mathrm{C} 1$ and $\mathrm{C} 264 \mu \mathrm{g} / \mathrm{L}$ copper treatment and was 1 for the $\mathrm{C} 2800 \mu \mathrm{g} / \mathrm{L}$ zinc treatment. $\mathrm{C} 1$, chronic life stage 1 exposure; $\mu \mathrm{g} / \mathrm{L}$, microgram per liter; \%, percent; SD, standard deviation; mm, millimeter; g, gram; <, less than; NOEC, no-observed-effect concentration; LOEC, lowest-observed-effect concentration; >, greater than; Geomean, geometric mean of the NOEC and LOEC; LC/EC10, 10-percent lethal or effect concentration; CL, 95-percent confidence limits; LC/EC20, 20-percent lethal or effect concentration; C2, chronic life stage 2 exposure; --, no data due to 100-percent mortality in all replicates; NE, not estimated because the data do not meet the conditions for any logistic regression or probit analysis; NA, not applicable due to only one replicate]

\begin{tabular}{|c|c|c|c|c|c|c|c|c|c|c|c|}
\hline \multirow{3}{*}{$\begin{array}{c}\text { Nominal } \\
\text { concentration } \\
(\mu \mathrm{g} / \mathrm{L})\end{array}$} & \multicolumn{11}{|c|}{ C2 (starting with 26-days-post-hatch fish) over days 0 to 28} \\
\hline & \multirow{2}{*}{$\begin{array}{c}\text { Measured } \\
\text { concentration } \\
\text { ( } \mu \mathrm{g} \mathrm{Cd} / \mathrm{L})\end{array}$} & \multicolumn{2}{|c|}{$\begin{array}{c}\text { Survival } \\
(\%)\end{array}$} & \multicolumn{2}{|c|}{$\begin{array}{l}\text { Length } \\
\text { (mm) }\end{array}$} & \multicolumn{2}{|c|}{$\begin{array}{l}\text { Wet weight } \\
\text { (g) }\end{array}$} & \multicolumn{2}{|c|}{$\begin{array}{c}\text { Dry Weight } \\
\text { (g) }\end{array}$} & \multicolumn{2}{|c|}{$\begin{array}{c}\text { Biomass } \\
\text { (g, dry) }\end{array}$} \\
\hline & & Mean & SD & Mean & SD & Mean & SD & Mean & SD & Mean & SD \\
\hline \multicolumn{12}{|c|}{ Cadmium } \\
\hline 0 & $<0.02$ & 100.0 & 0.0 & 36.6 & 0.7 & 0.56 & 0.01 & 0.102 & 0.005 & 1.02 & 0.05 \\
\hline 0.75 & 0.63 & 100.0 & 0.0 & 36.5 & 0.8 & 0.53 & 0.03 & 0.098 & 0.005 & 0.98 & 0.05 \\
\hline 1.5 & 1.20 & 100.0 & 0.0 & 36.1 & 0.9 & 0.51 & 0.02 & 0.095 & 0.006 & 0.95 & 0.06 \\
\hline 3 & 2.64 & 95.0 & 5.8 & 36.3 & 0.5 & 0.52 & 0.02 & 0.099 & 0.005 & 0.94 & 0.04 \\
\hline 6 & 4.89 & 22.5 & 18.9 & 37.3 & 1.8 & 0.70 & 0.15 & 0.139 & 0.037 & 0.28 & 0.17 \\
\hline 12 & 11.0 & 0.0 & 0.0 & -- & -- & -- & -- & -- & -- & 0.00 & 0.00 \\
\hline NOEC & & 2.6 & & 4.9 & & 4.90 & & 4.9 & & 2.6 & \\
\hline LOEC & & 4.9 & & $>4.9$ & & $>4.9$ & & $>4.9$ & & 4.9 & \\
\hline Geomean & & 3.6 & & $>4.9$ & & $>4.9$ & & $>4.9$ & & 3.6 & \\
\hline $\mathrm{LC} / \mathrm{EC} 10(\mathrm{CL})$ & & $2.9(2.8-3.0)$ & & $>4.9$ & & $>4.9$ & & $>4.9$ & & $1.5(1.0-2.1)$ & \\
\hline LC/EC20 (CL) & & $3.2(3.1-3.4)$ & & $>4.9$ & & $>4.9$ & & $>4.9$ & & $1.9(1.3-2.6)$ & \\
\hline \multicolumn{12}{|c|}{ Copper } \\
\hline 0 & 0.20 & 100.0 & 0.0 & 37.2 & 0.4 & 0.55 & 0.03 & 0.102 & 0.005 & 1.02 & 0.05 \\
\hline 4 & 3.02 & 97.5 & 5.0 & 37.5 & 0.2 & 0.56 & 0.02 & 0.103 & 0.006 & 1.00 & 0.04 \\
\hline 8 & 6.31 & 97.5 & 5.0 & 36.9 & 0.6 & 0.53 & 0.01 & 0.095 & 0.002 & 0.93 & 0.06 \\
\hline 16 & 12.7 & 100.0 & 0.0 & 36.9 & 0.2 & 0.53 & 0.01 & 0.097 & 0.001 & 0.96 & 0.01 \\
\hline 32 & 26.7 & 97.5 & 5.0 & 36.3 & 1.1 & 0.49 & 0.05 & 0.088 & 0.006 & 0.86 & 0.03 \\
\hline 64 & 53.8 & 35.0 & 23.8 & 32.9 & 2.1 & 0.42 & 0.08 & 0.076 & 0.016 & 0.27 & 0.19 \\
\hline NOEC & & 27 & & 54 & & 27 & & 13 & & 13 & \\
\hline LOEC & & 54 & & $>54$ & & 54 & & 27 & & 27 & \\
\hline Geomean & & 38 & & $>54$ & & 38 & & 18 & & 18 & \\
\hline $\mathrm{LC} / \mathrm{EC} 10(\mathrm{CL})$ & & $34(32-38)$ & & $\mathrm{NE}$ & & NE & & $13(6.4-27)$ & & $25(20-32)$ & \\
\hline $\mathrm{LC} / \mathrm{EC} 20(\mathrm{CL})$ & & $39(36-41)$ & & $>54$ & & $>54$ & & 43 (19-98) & & $30(25-36)$ & \\
\hline \multicolumn{12}{|c|}{ Lead } \\
\hline 0 & $<0.02$ & 100.0 & 0.0 & 37.1 & 0.7 & 0.54 & 0.02 & 0.097 & 0.007 & 0.97 & 0.07 \\
\hline 10 & 5.69 & 100.0 & 0.0 & 36.1 & 0.6 & 0.49 & 0.03 & 0.088 & 0.006 & 0.88 & 0.06 \\
\hline 20 & 11.0 & 97.5 & 5.0 & 36.3 & 0.3 & 0.50 & 0.03 & 0.090 & 0.006 & 0.87 & 0.04 \\
\hline 40 & 27.9 & 100.0 & 0.0 & 36.4 & 0.7 & 0.52 & 0.03 & 0.094 & 0.007 & 0.94 & 0.07 \\
\hline 80 & 55.4 & 100.0 & 0.0 & 36.0 & 0.4 & 0.50 & 0.02 & 0.091 & 0.005 & 0.91 & 0.05 \\
\hline 160 & 128 & 95.0 & 5.8 & 35.6 & 1.3 & 0.48 & 0.03 & 0.088 & 0.010 & 0.83 & 0.05 \\
\hline NOEC & & 128 & & 55 & & 55 & & 128 & & 55 & \\
\hline LOEC & & $>128$ & & 128 & & 128 & & $>128$ & & 128 & \\
\hline Geomean & & $>128$ & & 84 & & 84 & & $>128$ & & 84 & \\
\hline $\mathrm{LC} / \mathrm{EC} 10(\mathrm{CL})$ & & $>128$ & & $>128$ & & $>128$ & & $>128$ & & $>128$ & \\
\hline LC/EC20 (CL) & & $>128$ & & $>128$ & & $>128$ & & $>128$ & & $>128$ & \\
\hline \multicolumn{12}{|c|}{ Zinc } \\
\hline 0 & 1.43 & 100.0 & 0.0 & 36.6 & 0.7 & 0.52 & 0.04 & 0.096 & 0.007 & 0.96 & 0.07 \\
\hline 50 & 46.4 & 100.0 & 0.0 & 36.3 & 0.1 & 0.51 & 0.02 & 0.094 & 0.004 & 0.94 & 0.04 \\
\hline 100 & 93.3 & 100.0 & 0.0 & 36.8 & 0.4 & 0.54 & 0.03 & 0.101 & 0.006 & 1.01 & 0.06 \\
\hline 200 & 185 & 72.5 & 5.0 & 37.5 & 1.2 & 0.58 & 0.06 & 0.114 & 0.015 & 0.82 & 0.08 \\
\hline 400 & 365 & 20.0 & 8.2 & 39.2 & 2.2 & 0.74 & 0.10 & 0.146 & 0.018 & 0.30 & 0.13 \\
\hline 800 & 755 & 5.0 & 10.0 & 38.1 & NA & 0.78 & NA & 0.125 & NA & 0.06 & 0.13 \\
\hline NOEC & & 93 & & 753 & & 753 & & 753 & & 185 & \\
\hline LOEC & & 185 & & $>753$ & & $>753$ & & $>753$ & & 365 & \\
\hline Geomean & & 131 & & $>753$ & & $>753$ & & $>753$ & & 260 & \\
\hline $\mathrm{LC} / \mathrm{EC} 10(\mathrm{CL})$ & & $135(126-144)$ & & $>755$ & & $>755$ & & $>755$ & & $161(123-210)$ & \\
\hline $\mathrm{LC} / \mathrm{EC} 20$ (CL) & & $169(160-178)$ & & $>755$ & & $>755$ & & $>755$ & & $201(164-245)$ & \\
\hline
\end{tabular}


During the first 4 days of the $\mathrm{C} 1$ and $\mathrm{CC}$ exposures starting with larval trout, significant reduction in survival relative to the controls was observed only in the high concentration of copper and the 4-d LC50 for copper was $60 \mu \mathrm{g} \mathrm{Cu} / \mathrm{L}$; no acute effects were observed during the first 4 days in other three metal exposures (appendix table 2-7). However, during the first 4 days of the $\mathrm{C} 2$ exposures starting with juvenile trout, the survival was significantly reduced relative to the controls at the medium or high concentrations of cadmium, copper, and zinc (appendix table 2-7). The 4-d LC50 for cadmium $(5.14 \mu \mathrm{g} \mathrm{Cd} / \mathrm{L})$ or for zinc $(267 \mu \mathrm{g} \mathrm{Zn} / \mathrm{L})$ based on survival of the juvenile trout were less than the 4-d LC50s for cadmium $(>12 \mu \mathrm{g} \mathrm{Cd} / \mathrm{L})$ or zinc ( $>748 \mu \mathrm{g} \mathrm{Zn/L})$ based on the larval trout (by a factor of more than 2), whereas the 4-d LC50s for copper were similar between the larval $(60 \mu \mathrm{g} \mathrm{Cu} / \mathrm{L})$ and juvenile $(63 \mu \mathrm{g} \mathrm{Cu} / \mathrm{L})$ stages (appendix table 2-7).

In the 21-d $\mathrm{C} 1$ and 52-d CC exposures starting with larval trout, survival or biomass was reduced significantly relative to the controls in the high concentration of cadmium or copper by the end of the exposures, whereas no significant reduction was observed in lead or zinc exposures (tables B-4 and B-5); however, significant reduction in survival, growth, or biomass was observed in the 28-d C2 exposures of all four metals starting with juvenile trout (table B-5). In contrast to those observed in the sturgeon tests, the effect concentrations from the $\mathrm{C} 1$ exposures starting with larval trout generally were greater than the effect concentrations from the $\mathrm{C} 2$ exposures starting with juvenile trout (table B-5). For example, the geometric means of the NOECs and LOECs for biomass of larval trout in the 21-d C1 exposures (>11.5 $\mu \mathrm{g} \mathrm{Cd} / \mathrm{L}, 42 \mu \mathrm{g} \mathrm{Cu} / \mathrm{L}$, $>128 \mu \mathrm{g} \mathrm{Pb} / \mathrm{L}$, and $>753 \mu \mathrm{g} \mathrm{Zn} / \mathrm{L}$ ) were substantially greater than the geometric means of the NOECs and LOECs for biomass of juvenile trout in the $28-\mathrm{d} \mathrm{C} 2$ exposures $(3.6 \mu \mathrm{g} \mathrm{Cd} / \mathrm{L}$, $18 \mu \mathrm{g} \mathrm{Cu} / \mathrm{L}, 84 \mu \mathrm{g} \mathrm{Pb} / \mathrm{L}$, and $260 \mu \mathrm{g} \mathrm{Zn/L;} \mathrm{table} \mathrm{B-5).}$

\section{Species Sensitivity Comparisons}

The acute 4-d LC50s based on survival for cadmium, copper, or zinc from the $\mathrm{C} 2$ juvenile fish tests were used for the comparison of acute sensitivity between white sturgeon and rainbow trout because (1) elevated mortality was observed at the high concentrations of cadmium, copper, or zinc during the first 4 days of the $\mathrm{C} 2$ exposures with juvenile sturgeon or juvenile trout; (2) the 4-d LC50s for larvae of the two species in the $\mathrm{C} 1$ and $\mathrm{CC}$ exposures were similar to or greater than those for juveniles in the $\mathrm{C} 2$ exposures to each of the four metals as described above; and (3) no LC50s could be calculated for the lead exposures with sturgeon or trout (also see appendix tables 2-5 and 2-7). The 4-d LC50 for cadmium or zinc on the sturgeon was about 2-fold (or more) greater than the 4-d LC50 for the trout, whereas the LC50 for copper on the sturgeon was 8.6-fold lower than the LC50 for the trout (fig. B-4).

The 4- or 8-d EC50s or EC20s for copper, estimated based on mortality plus immobilization of the larval sturgeon in the $\mathrm{C} 1 / \mathrm{CC}$ exposures, were substantially less than

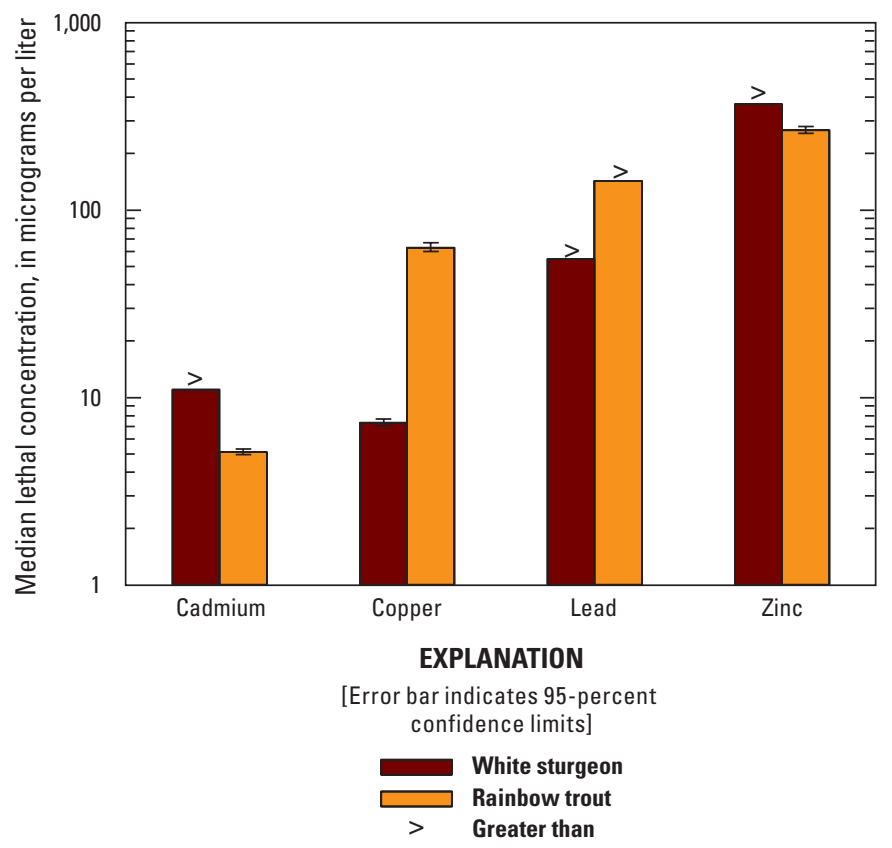

Figure B-4. Acute 4-day 50-percent lethal concentrations for the four metals in the first 4 days of 28-day exposures starting with 27-days-post-hatch white sturgeon (Acipenser transmontanus) and 26-days-post-hatch rainbow trout (Oncorhynchus mykiss).

the LC50s or LC20s based on mortality (fig. B-5). The 4-d EC50s (mortality plus immobilization) for copper were below the FAV in the USEPA BLM-based acute WQC for copper (U.S. Environmental Protection Agency, 2007a), and were more than 3-fold lower than the Washington State acute WQS (fig. B-5A), which was developed based on the USEPA acute WQC. Furthermore, the 4- or 8-d LC20s and EC20s for copper were more than 2-fold lower than the chronic WQS (fig. B-5B). In addition, the 8-d copper EC20s based on mortality plus immobilization or the EC20s based on mortality plus immobilization and lack of hiding were below the chronic WQC for copper (fig. B-5B).

The EC20s for an endpoint in the chronic exposures generally (in more than 80 percent of the cases) were equal to or less than the chronic values based on geometric means of the NOEC and LOEC for the endpoint across all treatments for the sturgeon and trout tests (tables B-2 to B-5). Note that the $\mathrm{EC} 20$ is the preferred chronic value to the geometric mean of the NOEC and LOEC for deriving the chronic WQC for copper (U.S. Environmental Protection Agency, 2007a). Therefore, the EC20 for the most sensitive endpoint among survival, length, weight, and biomass from each exposure was used for the sensitivity comparison between the sturgeon and trout in figure B-6. The EC20s for the sturgeon were similar to or less than the EC20s for the trout for the four metals (fig. B-6). Specifically, the cadmium EC20s between the two species were similar in the CC exposures (fig. B-6A), but the copper, lead, or zinc EC20s for the sturgeon were about 4- to 21-fold lower than that for the trout in the $\mathrm{CC}$ exposures (fig. $\mathrm{B}-6 B, C, D$ ). 

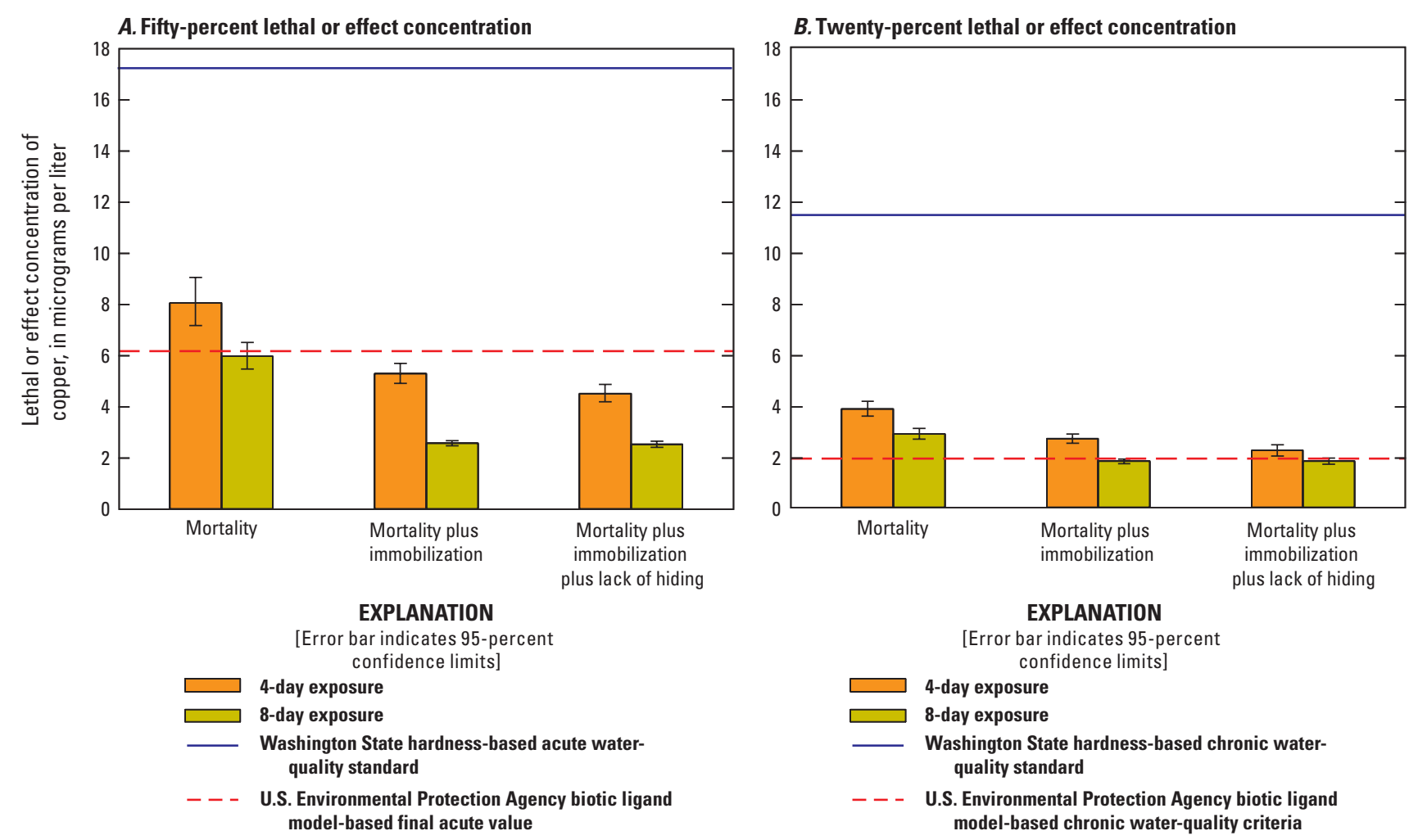

Figure B-5. Acute 4-day and short-term 8-day A, 50-percent lethal concentration or B, 20-percent effect concentration for copper during the first 4 and 8 days of the 53-day exposures starting with 2-days-post-hatch white sturgeon (Acipenser transmontanus), compared to U.S. Environmental Protection Agency water-quality criteria (U.S. Environmental Protection Agency, 2007a) and Washington State water-quality standards for copper (Washington State Department of Ecology, 2006) adjusted to test water-quality characteristics.

Based on definitive effect concentrations from the sturgeon $\mathrm{C} 1$ and $\mathrm{C} 2$ exposures and all trout exposures, the $\mathrm{EC} 20 \mathrm{~s}$ for the four metals in the trout exposures and the EC20s for cadmium, lead, or zinc in the sturgeon exposures with the two life stages of fish were above the chronic WQC and the Washington State chronic WQS, whereas the sturgeon EC20s for copper were $<1 \mu \mathrm{g} \mathrm{Cu} / \mathrm{L}$ above the chronic WQC and more than 4-fold lower than the Washington State WQS for copper (fig. B-6). Furthermore, the nondefinitive EC20 obtained from the 53-d sturgeon CC exposure for copper or zinc was below the WQC and Washington State WQS for copper or zinc (fig. B-6).

Species mean chronic values (SMCVs) for all freshwater species in the compiled toxicity databases were ranked and plotted in cumulative distribution for the four metals with addition of the definitive EC20s based on the most sensitive endpoint for white sturgeon and rainbow trout obtained from the exposures that met test acceptability requirements in the present study (fig. B-7). The EC20s for the sturgeon were in a relatively low percentile of the species sensitivity distribution in the toxicity database for copper (9th percentile) and in the middle percentile for cadmium (55th percentile), zinc (40th percentile), or lead (50th percentile; fig. B-7); however, the EC20s for the trout were in the high percentiles for copper, lead, or zinc (about 68th to 82nd percentile), but in a low percentile for cadmium (23rd percentile; fig. B-7). If the nondefinitive EC20s obtained from the 53-d sturgeon exposures were used for the comparison, the rank of white sturgeon for cadmium, copper, or lead would not change substantially; however, the rank of the sturgeon would be much lower for zinc (26th percentile).

\section{Discussion}

\section{Species Sensitivity in Short-Term Exposures}

Acute toxicity data generated during the first 4 days of the chronic exposures indicate that the white sturgeon was less acutely sensitive to cadmium or zinc compared to the commonly tested rainbow trout; in contrast, the sturgeon was more acutely sensitive to copper than the trout (fig. B-4; appendix tables 2-5 and 2-7). No acute toxicity was observed during the first 4-d lead exposures to the sturgeon or trout. These findings were consistent with those obtained in the companion study on acute sensitivity between the two species when the fish were $<1$ month old (chapter A). The 4-d copper EC50 based on mortality plus immobilization of newly hatched larval sturgeon was 14 percent below the FAV in the 


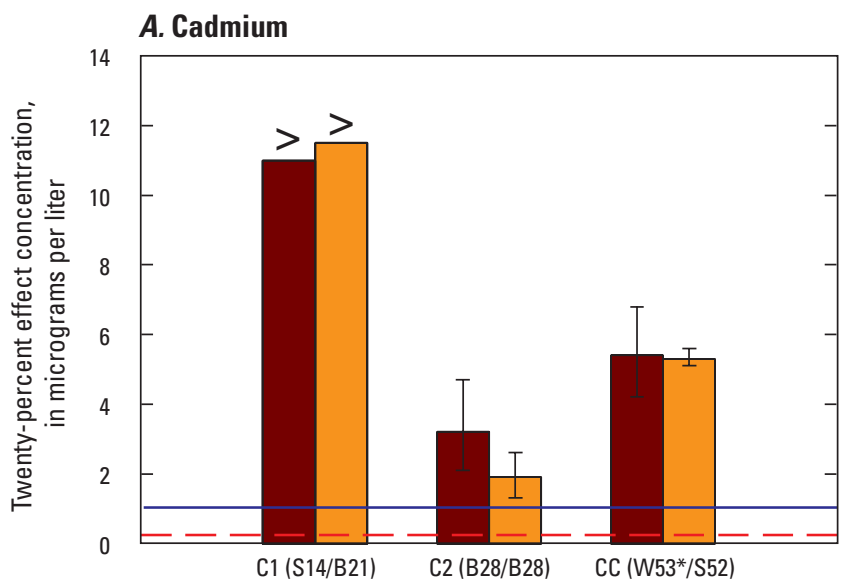

\section{B. Copper}

100

10

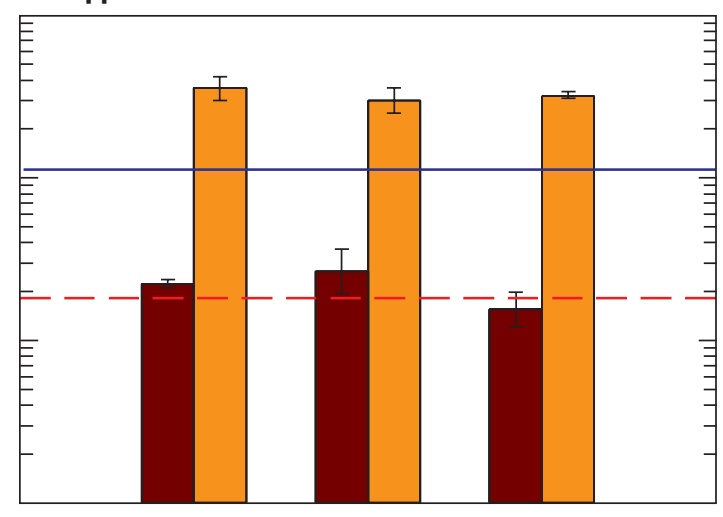

C1 (S14/B21)

C2 (B28/B28)

CC (W53*/S52)

\section{Zinc}

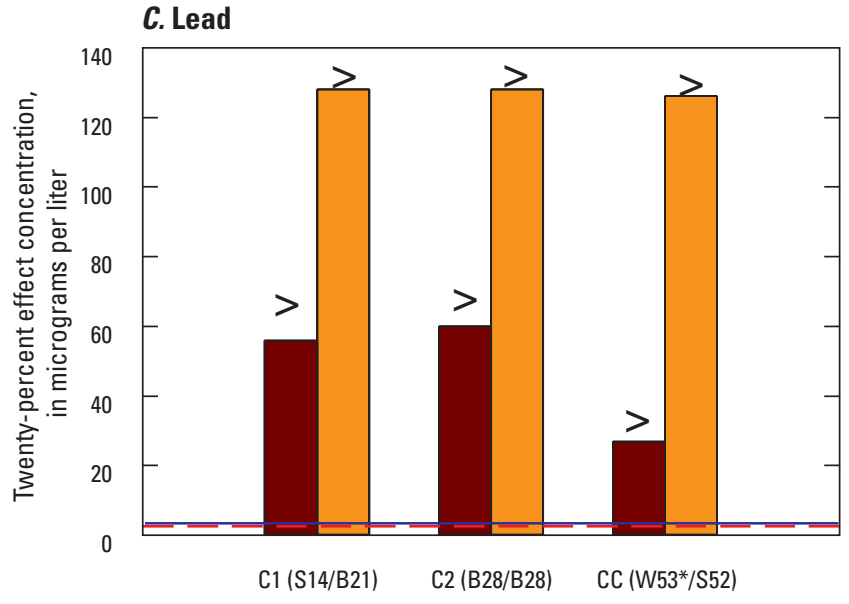

800

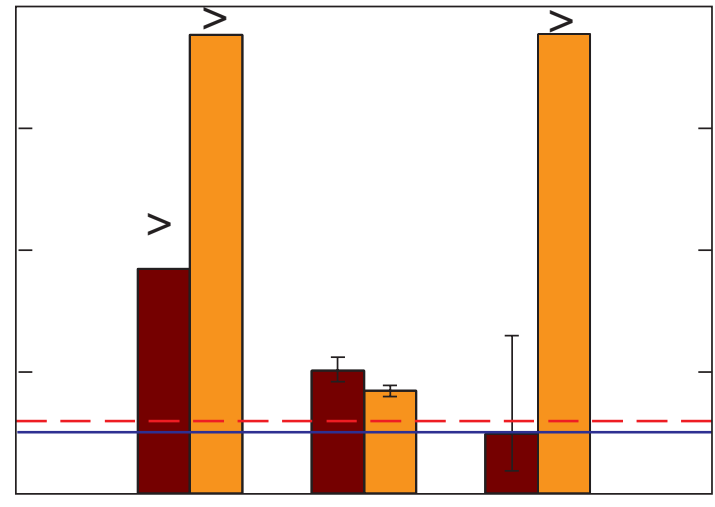

0

C1 (S14/B21)

C2 (B28/B28) CC (W53*/S52)

NOTE: Asterisk indicates a nondefinitive effect concentrations because of low control survival in the 53-day sturgeon test

\section{EXPLANATION}

[Error bar indicates 95 -percent

confidence limits]

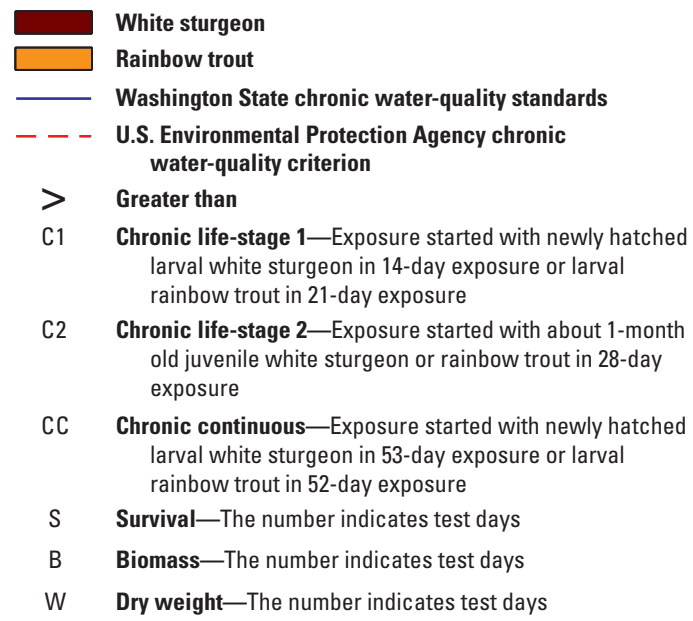

Figure B-6. Twenty-percent effect concentrations for four metals based on the most sensitive endpoint in three chronic exposures with different life stages of white sturgeon (Acipenser transmontanus) and rainbow trout (Oncorhynchus mykiss), compared to the U.S. Environmental Protection Agency chronic water-quality criterion (U.S. Environmental Protection Agency, 2007a, 2012) and the Washington State chronic water-quality standard (Washington State Department of Ecology, 2006) adjusted to test water-quality characteristics. 

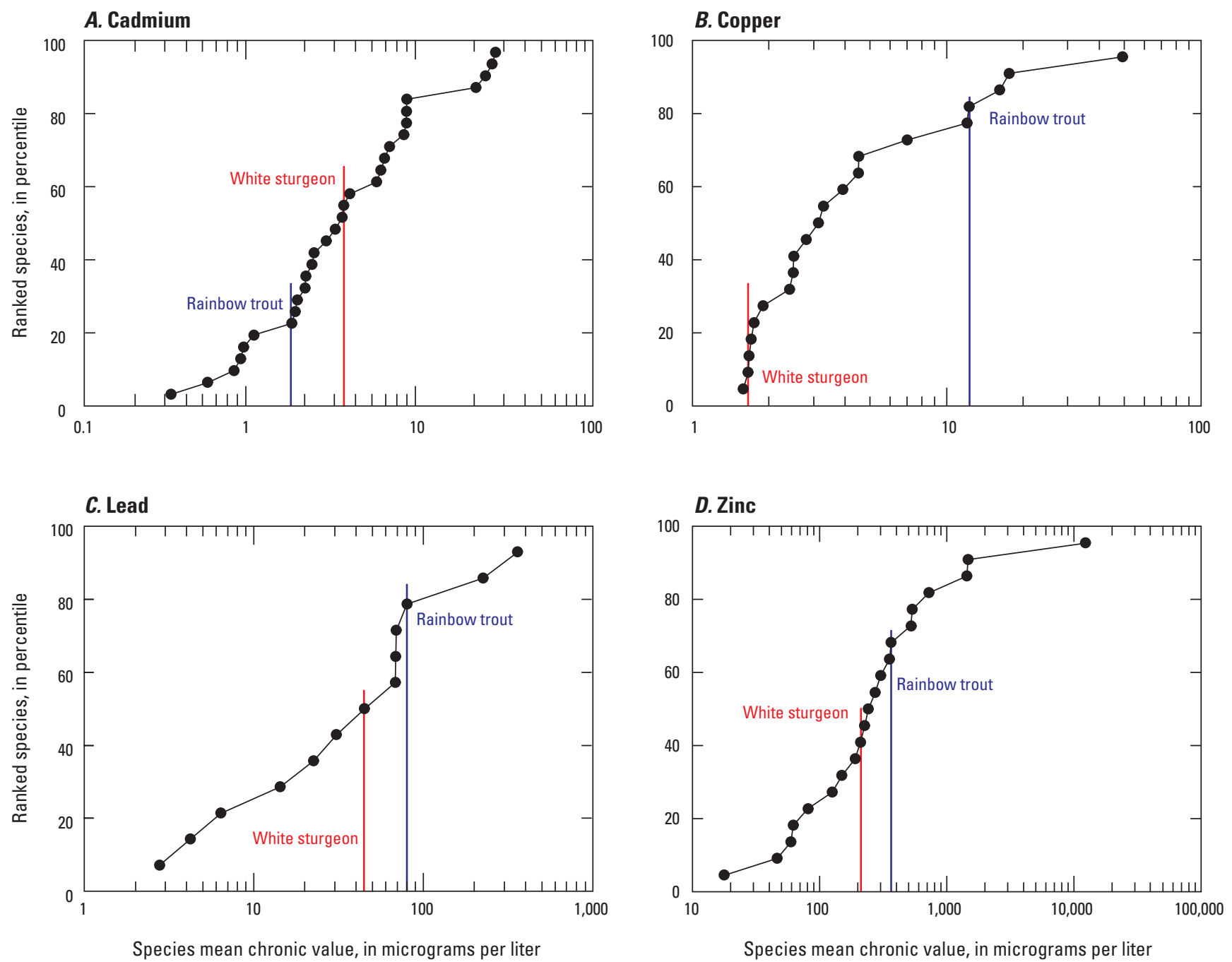

Figure B-7. Ranks of white sturgeon (Acipenser transmontanus) and rainbow trout (Oncorhynchus mykiss) in species sensitivity distribution from compiled databases for cadmium (Mebane, 2006; hardness normalized), copper [Chris Mebane, unpub. data, 2013; biotic ligand model (BLM) normalized], lead (Jasim Chowdhury, unpub. data, 2013; BLM normalized), and zinc (DeForest and Van Genderen, 2012; BLM normalized). The databases are compiled with 20-percent effect concentrations or geometric means of the no-observed-effect concentrations and the lowest-observed-effect concentrations.

USEPA acute WQC for copper (U.S. Environmental Protection Agency, 2007a), and was more than 3-fold lower than the Washington State hardness-dependent acute WQS (Washington State Department of Ecology, 2006; fig. B-5A). In addition, the 8-d copper EC20 based on mortality plus immobilization, or EC20s based on mortality plus immobilization and lack of hiding of larval sturgeon were below the chronic WQC for copper and were 5-fold lower than the Washington State chronic WQS (fig. B-5B), indicating the survival and behavior of the newly hatched sturgeon were rapidly impaired at the concentrations close to the USEPA chronic WQC or below the Washington State chronic WQS for copper.

The 4-d LC50 for copper in the companion acute toxicity test starting with the 2-dph sturgeon (chapter A) was higher ( $>23.6 \mu \mathrm{g} \mathrm{Cu} / \mathrm{L}$; table A-5) than the 4-d LC50 observed during the first 4 days of the chronic copper exposure $(8.06 \mu \mathrm{g} / \mathrm{L}$; appendix table 2-5); however, the 4-d EC50 for copper $(2.67 \mu \mathrm{g} \mathrm{Cu} / \mathrm{L})$ obtained from the companion acute toxicity test was less than the 4-d EC50 (5.29 $\mu \mathrm{g} \mathrm{Cu} / \mathrm{L})$ during the first 4 days of the chronic $\mathrm{C} 1 / \mathrm{CC}$ exposure. The difference in EC50s for the 2-dph larval sturgeon between the two studies might be because two additional endpoints of immobilization and loss of equilibrium were used for EC50 calculations in chapter A acute exposures but only immobilization was recorded and used for EC50 calculations in the chronic exposures. In addition, different types of exposure chambers were used (smaller circular chambers in the acute exposures and larger rectangular chambers in the chronic exposures), and stones were placed in the bottoms of the test chambers in the chronic exposures. Whether the presence of the stones for hiding could have also affected the loss of equilibrium endpoint is unknown. In contrast to studies started with newly hatched sturgeon, the 4-d 
EC50s observed between the two studies started with the about 1-month-old sturgeon were similar: $6.31 \mu \mathrm{g} \mathrm{Cu} / \mathrm{L}$ in chapter A acute exposures and $7.36 \mu \mathrm{g} \mathrm{Cu} / \mathrm{L}$ in the first $4 \mathrm{~d}$ of the chronic exposures (table A-2; appendix table 2-5).

\section{Species Sensitivity in Long-Term Exposures}

The definitive EC20s for the four metals in the trout tests and the definitive EC20s for cadmium, lead, or zinc in the two life stages of the sturgeon tests were above the USEPA chronic WQC and the Washington State WQS, in contrast, the sturgeon definitive EC20s for copper were at or below the chronic WQC and below the Washington State WQS for copper (fig. B-6). Noticeably, the chronic value of $1.32 \mu \mathrm{g} \mathrm{Cu} / \mathrm{L}$ based on geometric mean of NOEC and LOEC for dry weight or biomass in the 28-d C2 copper exposure (table B-3) was about 30 percent below chronic WQC for copper $(1.85 \mu \mathrm{g} \mathrm{Cu} / \mathrm{L}$ after BLM normalization to test water). The results of these comparisons did not change when including the nondefinitive EC20s obtained from the CC 53-d exposure with the sturgeon, where control survival did not meet test acceptability requirements (because of low control survival). An exception was that the nondefinitive 53-d copper or zinc EC20 based on dry weight was below the WQC for copper (fig. B-6B) or zinc (fig. B-6D).

When compared to a proposed revised chronic WQC in the expanded hardness-based cadmium database (Mebane, 2006) or the recently developed BLM-based lead database (Jasim Chowdhury, International Lead Zinc Research Organization, Durham, N.C., unpub. data, 2013), the cadmium or lead EC20s for the two species tested in the present study were still above the revised WQC for cadmium or lead, which was similar to the USEPA WQC for cadmium or for lead. (appendix fig. 2-1A, $B$ ). In contrast, the proposed revised chronic WQC for zinc based on the BLM-based zinc database (DeForest and Van Genderen, 2012) decreased substantially and all zinc EC20s for the two species were above the proposed revised chronic WQC for zinc (appendix fig. 2-1C).

Similar to the acute response observed during the first 4-d exposures, the chronic sensitivity to cadmium was similar between the sturgeon and trout, and the sturgeon chronically was more sensitive to copper than the trout across different life stages and exposure durations (fig. B-6A, $B$; tables B-2 to $\mathrm{B}-5$ ); however, in contrast to the acute exposures of lead or zinc, the sturgeon chronically was more sensitive to lead or zinc than the trout (fig. B-6C, D; tables B-2 to B-5). Hence, rainbow trout could be a good surrogate species for white sturgeon in a chronic exposure to cadmium; however, rainbow trout would not be a good surrogate species protecting white sturgeon from chronic exposure to copper, lead, or zinc. In addition, because only 14-d survival data were available for the sturgeon $\mathrm{C} 1$ exposures and because only dry weight was used for the 53-d sturgeon CC exposure (biomass was not considered as a valid endpoint because of low control survival), the sturgeon sensitivity might be underestimated when comparing to the trout, where a longer (21-d) test duration was used in the
$\mathrm{C} 1$ exposures and the more sensitive biomass endpoint (combined effect of survival and growth) obtained in all $\mathrm{C} 1$ and $\mathrm{CC}$ exposures often was used for the comparisons (fig. B-6).

White sturgeon ranked lower than rainbow trout in the species sensitivity distributions for copper, lead, or zinc, but ranked higher than the trout for cadmium in the toxicity databases (fig. B-7). In addition, the white sturgeon ranked relatively lower than most of other freshwater species in the species sensitivity distributions for copper (fig. B-7). Importantly, white sturgeon is the second most sensitive species ever tested in the species sensitivity distribution for copper (fig. B-7B). Furthermore, when the nondefinitive EC20 for zinc obtained from the 53-d sturgeon exposure was included in the species sensitivity comparison, white sturgeon also would rank lower than the most other species. These results indicate the white sturgeon was highly sensitive to copper or zinc, but was moderately sensitive to lead and relatively insensitive to cadmium in compiled toxicity databases.

\section{Comparison to Other Studies with White Sturgeon}

Vardy and others (2011) reported chronic LC20s for cadmium, copper, or zinc in the 66-d exposures with white sturgeon (length or weight data were not reported in Vardy and others, 2011). The LC20s were estimated by Vardy and others (2011) after adjusting to different starting number of fish in different treatments and were calculated with TOXSTAT ${ }^{\circledR}$ software after the normalization for reference mortality using Abbott's correction (Abbott, 1925). The reported 66-d LC20s were $1.5 \mu \mathrm{g} \mathrm{Cd} / \mathrm{L}, 5.5 \mu \mathrm{g} \mathrm{Cu} / \mathrm{L}$, and $112 \mu \mathrm{g} \mathrm{Zn} / \mathrm{L}$ in test water with hardness of about 65 to $70 \mathrm{mg} / \mathrm{L}$ and with DOC reported to be about 2 to $3 \mathrm{mg} / \mathrm{L}$ (Vardy and others, 2011).

Abbott's correction was an advance in statistical analyses of toxicity data in the hand calculation era, making it possible to estimate LC50s from linear regression with transformed data (for example, Finney, 1944); however, a disadvantage of Abbott's correction is that it requires the analyst to change data, and the advent of computer iteration algorithms makes the use of Abbott's correction unnecessary for accounting for differences in number of organisms tested/treatment and normalization for control mortality. A more unified approach to analyze toxicity data with control survivals $<100$ percent is to use a 3-parameter method that fits responses relative to control response and thus do not require the analyst to manipulate data before generation off effect concentrations. The Toxicity Response Analysis Program (Erickson, 2012) supported nonlinear regression approaches, and a 3-parameter maximum likelihood tolerance distribution analysis model, which for brevity, is called a 3-parameter probit model.

When comparing the chronic toxicity data reported by Vardy and others (2011) to the chronic toxicity generated in the present study, the LC20s in Vardy and others (2011) were recalculated based on percent survival at each of six exposure concentrations reported by Cardno Entrix and University of 
Saskatchewan (2008, table 8 in that report), and the LC20s were recalculated with the Toxicity Response Analysis Program (Erickson, 2012) without Abbott's correction and without adjusting for starting number of organisms per replicate to be consistent with the data analysis process in the present study. These recalculated LC20s were slightly greater than the LC20s reported in Vardy and others (2011; table B-6). After hardness normalization with recalculated cadmium or zinc value based on equations in the USEPA WQC for cadmium or zinc (U.S. Environmental Protection Agency, 2012), and BLM normalization with recalculated copper value (U.S. Environmental Protection Agency, 2007a), the normalized 66-d LC20s for the three metals from Vardy and others (2011) consistently were less than the normalized 53-d LC20s obtained in the present study (table B-6), but were similar to the normalized 53-d EC20s based on the most sensitive endpoints (dry weight) in the present study (table B-6).

A follow-up study indicates that DOC concentrations in blanks for the water samples reported in Vardy and others (2011) could be high (1.6 mg/L; appendix 7). After the blank correction, the concentration of DOC would be about $1.0 \mathrm{mg} / \mathrm{L}$ and the BLM-normalized LC20 for copper would be $2.6 \mu \mathrm{g} \mathrm{Cu} / \mathrm{L}$ (rather than $1.0 \mu \mathrm{g} \mathrm{Cu} / \mathrm{L}$ in table B-6), and an $\mathrm{LC} 20$ of $2.6 \mu \mathrm{g} \mathrm{Cu} / \mathrm{L}$ is above the BLM-normalized LC20 of $1.5 \mu \mathrm{g} \mathrm{Cu} / \mathrm{L}$ obtained in the present 53-d study (table B-6). Vardy and others (2011) primarily reported mortality as the toxicity endpoint, in contrast to the present study in which determined growth (dry weight) and biomass responses usually were the most sensitive endpoints. Growth as a condition factor, or plumpness, of fish was reported by Vardy and others (2011) to be less sensitive or similarly sensitive as the mortality endpoints; however, a higher number of fish tested in the controls and higher mortality in the controls throughout the 66-d exposure may have compromised robust determination of effects on sturgeon growth (for example, dry weight) in the study performed by Vardy and others (2011).
A follow-up 24-d copper exposure with white sturgeon was performed at the CERC laboratory in 2012 (detailed test conditions and results are described in appendix 8). The objective of the 2012 study was to determine if improved control survival of newly hatched sturgeon could be achieved in a chronic copper toxicity test. Methods for culturing the sturgeon and for performing the toxicity tests performed in 2012 were consistent with the methods used to culture and perform toxicity tests with sturgeon in 2010. Newly fertilized eggs from two female and one male white sturgeon were provided by Yakima Fish Hatchery (Toppenish, Wash.), on June 16, 2012. The sturgeon were caught between May 23 and 25, 2012, in the John Day pool at the McNary Dam tailrace on the Columbia River, near Benton County, Wash., and held individually in 4-meter $(\mathrm{m})$ diameter (1.2-m high) fiberglass circular tank at $14{ }^{\circ} \mathrm{C}$. The fish were not fed in the hatchery before spawning on June 14, 2012. The exposures started with 1-dph larval sturgeon under similar test conditions that were used in the 25- $\mathrm{d} \mathrm{C} 1$ exposure of the 2010 study (table B-1). The exceptions were that (1) the light intensity was reduced to about 50 lux during the first 14 days of the 2012 exposure when the larval sturgeon were in the hiding phase (rather than a light intensity of about 900 to 1,300 lux in the 2010 exposures), and (2) the number of fish per replicate was 30 (rather than 20 per replicate in the 2010 exposures). After the hiding phase, the light intensity was increased on test day 15 of the exposure and maintained at about 500 lux when the sturgeon started swimming up and actively feeding. The mean control survival was 93 percent by the end of the 24-d copper exposure, and met the test acceptability of $\geq 80$-percent control survival (table B-1). The LC20 was $3.01 \mu \mathrm{g} \mathrm{Cu} / \mathrm{L}$, and the $\mathrm{EC} 20$ was $1.44 \mu \mathrm{g} \mathrm{Cu} / \mathrm{L}$ based on dry weight and $1.72 \mu \mathrm{g} \mathrm{Cu} / \mathrm{L}$ based on biomass (appendix table 8-1). After the BLM normalization, the 24-d LC20 was $2.0 \mu \mathrm{g} \mathrm{Cu} / \mathrm{L}$, which was similar to the 66-d LC20 reported by Vardy and others (2011) of $1.0 \mu \mathrm{g} \mathrm{Cu} / \mathrm{L}$ (or $2.6 \mu \mathrm{g} \mathrm{Cu} / \mathrm{L}$ after the DOC

Table B-6. Comparison of toxicity data from three studies on chronic cadmium, copper, or zinc toxicity to white sturgeon (Acipenser transmontanus), U.S. Environmental Protection Agency chronic water-quality criterion (U.S. Environmental Protection Agency, 2007a, 2012), and Washington State chronic water-quality standard (Washington State Department of Ecology, 2006).

[Twenty-percent lethal concentrations in 66-day exposures reported by Vardy and others (2011) were recalculated in the present study. Toxicity data, national water-quality criterion or Washington State water-quality standard for cadmium and zinc were normalized to a water hardness of $85 \mathrm{mg} / \mathrm{L}$. Toxicity data and the national water-quality criterion for copper were normalized using biotic ligand model based on moderately hard reconstituted water (hardness $85 \mathrm{mg} / \mathrm{L}$, dissolved organic carbon $0.5 \mathrm{mg} / \mathrm{L}$ ), and the State water-quality standard for copper was normalized to hardness of $85 \mathrm{mg} / \mathrm{L}$. $\mathrm{mg} / \mathrm{L}$, milligram per liter; LC20, 20-percent lethal concentration; $\mu \mathrm{g} / \mathrm{L}$, microgram per liter; CERC, Columbia Environmental Research Center; dph, days-post-hatch; EC20, 20-percent effect concentration based on dry weight; BLM, biotic ligand model; WQC, water-quality criterion; WQS, water-quality standard; >, greater than; values from the 66or 53-day exposures were calculated based on data with low control survival and considered as nondefinitive effect concentrations]

\begin{tabular}{|c|c|c|c|c|c|c|c|c|c|}
\hline \multirow[b]{2}{*}{ Toxicant } & \multicolumn{3}{|c|}{$\begin{array}{l}\text { Vardy and others (2011) 66-day exposure } \\
\text { starting with fertilized eggs }\end{array}$} & \multicolumn{2}{|c|}{$\begin{array}{l}\text { CERC } 2010 \text { 53-day exposure } \\
\text { starting with 2-dph larvae }\end{array}$} & \multicolumn{2}{|c|}{$\begin{array}{l}\text { CERC } 2012 \text { 24-day exposure } \\
\text { with 1-dph larvae }\end{array}$} & \multirow{2}{*}{$\begin{array}{l}\text { Hardness- or } \\
\text { BLM-dependent } \\
\text { national chronic } \\
\text { WOC } \\
(\mu \mathrm{g} / \mathrm{L})\end{array}$} & \multirow{2}{*}{$\begin{array}{l}\text { Hardness-dependent } \\
\text { Washington State } \\
\text { chronic WOS } \\
(\mu \mathrm{g} / \mathrm{L})\end{array}$} \\
\hline & $\begin{array}{l}\text { Reported } \\
\text { LC20 } \\
(\mu \mathrm{g} / \mathrm{L})\end{array}$ & $\begin{array}{c}\text { Recalculated } \\
\text { LC20 } \\
(\mu \mathrm{g} / \mathrm{L})\end{array}$ & $\begin{array}{c}\text { Normalized } \\
\text { LC20 } \\
(\mu \mathrm{g} / \mathrm{L})\end{array}$ & $\begin{array}{c}\text { Normalized } \\
\text { LC20 } \\
(\mu \mathrm{g} / \mathrm{L})\end{array}$ & $\begin{array}{l}\text { Normalized } \\
\text { EC20 } \\
(\mu \mathrm{g} / \mathrm{L})\end{array}$ & $\begin{array}{c}\text { Normalized } \\
\text { LC20 } \\
(\mu \mathrm{g} / \mathrm{L})\end{array}$ & $\begin{array}{l}\text { Normalized } \\
\text { EC20 } \\
(\mu \mathrm{g} / \mathrm{L})\end{array}$ & & \\
\hline Cadmium & 1.5 & 2.5 & 2.9 & 8.3 & 5.4 & Not tested & Not tested & 0.22 & 0.91 \\
\hline Copper & 5.5 & 7.2 & 1.0 & 1.5 & 1.1 & 2.0 & 1.0 & 1.45 & 9.9 \\
\hline
\end{tabular}


blank correction), and also was similar to the 53-d LC20 of $1.5 \mu \mathrm{g} \mathrm{Cu} / \mathrm{L}$ in the study performed in 2010 (table B-6). The EC20 based on dry weight was almost identical between the 2010 53-d exposure $(1.1 \mu \mathrm{g} \mathrm{Cu} / \mathrm{L})$ and the 2012 24-d exposure (1.0 $\mu \mathrm{g} \mathrm{Cu} / \mathrm{L}$; table B-6).

The results of the three studies on white sturgeon indicate that the LC20s or EC20s for copper obtained from the previous 66-d exposure with low control survival (37 percent; Vardy and others, 2011) and in the 2010 53-d exposure with low control survival (68 percent) were similar to the LC20 or EC20 obtained from the 2012 24-d exposure with a high control survival of 93 percent. Hence, the elevated mortality in controls during the transition to exogenous feeding in the 2010 study and in the study reported by Vardy and others (2011) likely did not affect the sensitivity of white sturgeon to copper. Importantly, the normalized LC20s and EC20s for copper from all these studies, including study by Vardy and others (2011), were at or below the USEPA chronic WQC for copper and were far below the Washington State chronic WQS (table B-6). However, Vardy and others (2011) concluded that the chronic WQC for copper was protective of the sturgeon, although the basis for their conclusion was not presented (that is, the BLM-normalized copper final chronic value was missing from table 4 in Vardy and others, 2011).

\section{Acute-to-Chronic Ratios}

Acute-to-chronic ratios (ACRs) are used to extrapolate estimates of chronic effect thresholds from acute exposures. The ACRs are developed from acute and chronic data generated from the same chronic test or different acute and chronic studies with similar test conditions (Stephan and others, 1985). The ACRs provide one means to estimate chronic effects for untested species or even to other substances with similar modes of toxic action. Particularly for species that are difficult to test directly, estimating chronic thresholds is a challenge. For many fish, invertebrates, or amphibians with long life cycles or poorly understood life histories, culturing or collecting suitable organisms for chronic testing can be difficult. In contrast, acute test data can be obtained for many species because of the much simpler methods and shorter exposures. Although the ACR approach has been criticized for application in WQC development or risk assessment, ACRs can be used to estimate chronic effects from acute toxicity data if no chronic toxicity data are available. In such cases, direct analysis of available chronic data may underestimate chronic toxicity, whereas the ACR allows for an extrapolation of chronic effects for sensitive species, even though no chronic data exists (Mount and others, 2003; Raimondo and others, 2007; Mebane and others, 2008).

Acute 4-d EC50s, determined during the first 4 days of the current chronic exposures and chronic EC20s based on the most sensitive endpoint in the chronic exposures with sturgeon and trout, were used to calculate ACRs for the four tested metals (table B-7). The ACRs for copper were similar between the two life stages of both species, and ranged from 2.36 to 3.41 for the sturgeon and 1.67 to 2.10 for the trout (table B-7). Most of ACRs for cadmium, lead, or zinc were greater-than values or were not estimated because of greater-than EC50 or EC20 values.

The ACRs also were calculated based on acute 4-d EC50s determined in chapter A acute exposures and chronic EC20s from the chronic exposures in chapter B (table B-7). The copper ACRs ranged from 1.19 to 2.36 for the sturgeon and 1.75 to 2.00 for the trout, which were similar to the ACRs based on acute EC50 and chronic EC20 from the chronic exposures. An exception was that the copper ACR of 1.19 for newly hatched sturgeon was about 2-fold lower than the ACR of 2.36 from the chronic exposure (table B-7). This difference might have resulted from additional endpoints included in the EC50 estimates in chapter A (that is, mortality, immobilization, and loss of equilibrium) compared to the endpoints included in the EC50 estimates in chapter B (mortality and immobilization). High ACRs for cadmium (32) and zinc (15) were estimated with the chapter A EC50s from acute exposures started with 30 -dph sturgeon, whereas the low ACR for zinc $(<0.4)$ was estimated with the chapter A EC50s from acute exposures started with 2-dph sturgeon (table B-7). No specific explanation can be made for why a paired EC50 and EC20 produced the relative high or low ACRs.

While multiple ACRs could be derived using different chronic endpoints (for example, NOECs, EC10s, EC20s), and the choice of endpoint can affect the resulting ACRs (Mount and others, 2003; Mebane and others, 2008), for brevity, only ACRs based on EC20s are presented in table B-7. Readers can calculate other ACRs from the various acute or chronic effects values reported in chapter $\mathrm{A}$ and in this chronic study.

\section{Effect of the Age of Fish on Sensitivity to Metals}

The age or developmental stage of white sturgeon and rainbow trout affected sensitivity to metals (fig. B-6; tables B-2 to B-5). With the sturgeon tests, the more sensitive life stages to copper, lead, or zinc, but not cadmium, were observed in exposures started with 2-dph fish as compared to the exposures starting with older, 27-dph fish. In contrast, with the trout tests, the most sensitive life stages to cadmium or zinc were observed in exposures that started with 26-dph fish. With copper, similar effect concentrations were observed in the trout exposures started with 1-dph and 26-dph fish.

Body size or developmental stage has been recognized as an important factor influencing the toxicity of chemicals to aquatic organisms; however, the different directions of the apparent responses associated with these metals presently are unexplained. Juvenile organisms are often considered more susceptible to substances than adults of the same species. This has been presumed to be related to the greater ratio of body surface area to volume that in turn affects relative uptake and excretion rates, and to the incomplete development of detoxification mechanisms (Rand and others, 1995; Hendriks 
Table B-7. Acute-to-chronic ratio based on acute (on test day 4) and chronic effect concentrations in four chronic metal exposures with white sturgeon (Acipenser transmontanus) and rainbow trout (Oncorhynchus mykiss). Acute effect concentrations in 4-day exposures (chapter A) with similar ages of fish to those in the chronic exposures also were used for the acute-to-chronic ratio calculation.

[Exposure day for an effect concentration value is included in parentheses. Chronic EC20s from the CC-sturgeon exposure are nondefinitive effect concentrations due to low control survival. dph, dayspost-hatch; $\mu \mathrm{g} / \mathrm{L}$, microgram per liter; EC50, 50-percent effect concentration; EC20, 20-percent effect concentration (based on the most sensitive endpoint in a chronic exposure); ACR, acute-chronic ratio; $\mathrm{C} 1$, chronic life stage 1 exposure; >, greater than; d, day; NE, not estimated because both EC20 and EC50 were greater-than values; CC, chronic continuous exposure; $\mathrm{C} 2$, chronic life stage 2 exposure; A1, acute exposure round 1 (chapter A); <, less than; A3, acute exposure round 3 (chapter A)]

\begin{tabular}{|c|c|c|c|c|c|c|c|c|c|c|c|c|c|}
\hline \multirow[b]{2}{*}{ Exposure } & \multirow{2}{*}{$\begin{array}{c}\text { Age at } \\
\text { test start } \\
\text { (dph) }\end{array}$} & \multicolumn{3}{|c|}{ Cadmium ( $\mu \mathrm{g} / \mathrm{L})$} & \multicolumn{3}{|c|}{ Copper ( $\mu \mathrm{g} / \mathrm{L})$} & \multicolumn{3}{|c|}{ Lead ( $\mu \mathrm{g} / \mathrm{L})$} & \multicolumn{3}{|c|}{ Zinc $(\mu \mathrm{g} / \mathrm{L})$} \\
\hline & & $\begin{array}{l}\text { Acute } \\
\text { EC50 }\end{array}$ & $\begin{array}{c}\text { Chronic } \\
\text { EC20 }\end{array}$ & ACR & $\begin{array}{l}\text { Acute } \\
\text { EC50 }\end{array}$ & $\begin{array}{c}\text { Chronic } \\
\text { EC2O }\end{array}$ & ACR & Acute EC50 & $\begin{array}{c}\text { Chronic } \\
\text { EC20 }\end{array}$ & ACR & Acute EC50 & $\begin{array}{c}\text { Chronic } \\
\text { EC2O }\end{array}$ & ACR \\
\hline \multicolumn{14}{|c|}{ Acute and chronic values from the same chronic exposure } \\
\hline C1-sturgeon & 2 & $>11(4 \mathrm{~d})$ & $>11(14 \mathrm{~d})$ & NE & $5.29(4 \mathrm{~d})$ & $2.24(14 \mathrm{~d})$ & 2.36 & $>55(4 \mathrm{~d})$ & $>56(14 \mathrm{~d})$ & $\mathrm{NE}$ & $>369(4 \mathrm{~d})$ & $>369(14 \mathrm{~d})$ & $\mathrm{NE}$ \\
\hline CC-sturgeon & 2 & $>11(4 \mathrm{~d})$ & $5.4(53 \mathrm{~d})$ & $>2.04$ & $5.29(4 \mathrm{~d})$ & $1.55(53 \mathrm{~d})$ & 3.41 & $>55(4 d)$ & $>27(53 \mathrm{~d})$ & $\mathrm{NE}$ & $>369(4 \mathrm{~d})$ & $99(53 \mathrm{~d})$ & $>3.7$ \\
\hline C2-sturgeon & 27 & $>11(4 d)$ & $3.2(28 \mathrm{~d})$ & $>3.44$ & $7.36(4 d)$ & $2.67(28 \mathrm{~d})$ & 2.76 & $>61(4 d)$ & $>60(28 \mathrm{~d})$ & $\mathrm{NE}$ & $>395$ (4d) & $203(28 d)$ & $>1.95$ \\
\hline C1-trout & 1 & $>12(4 \mathrm{~d})$ & $>12(21 \mathrm{~d})$ & $\mathrm{NE}$ & $60(4 d)$ & $36(21 \mathrm{~d})$ & 1.67 & $>136(4 \mathrm{~d})$ & $>128(21 \mathrm{~d})$ & $\mathrm{NE}$ & $>748(4 \mathrm{~d})$ & $>753(21 \mathrm{~d})$ & $\mathrm{NE}$ \\
\hline CC-trout & 1 & $>12(4 \mathrm{~d})$ & $5.3(52 \mathrm{~d})$ & $>2.26$ & $60(4 d)$ & $32(52 \mathrm{~d})$ & 1.88 & $>136(4 \mathrm{~d})$ & $>126(52 \mathrm{~d})$ & $\mathrm{NE}$ & $>748(4 \mathrm{~d})$ & $>755(52 \mathrm{~d})$ & $\mathrm{NE}$ \\
\hline C2-trout & 26 & $5.1(4 d)$ & $1.9(28 \mathrm{~d})$ & 2.68 & $63(4 d)$ & $30(28 \mathrm{~d})$ & 2.10 & $>143(4 \mathrm{~d})$ & $>128(28 \mathrm{~d})$ & $\mathrm{NE}$ & $267(4 d)$ & $169(28 \mathrm{~d})$ & 1.58 \\
\hline \multicolumn{14}{|c|}{ Acute values from chapter $A$ acute exposures and chronic values from chapter $B$ chronic exposures } \\
\hline A1/C1-sturgeon & $2 / 2$ & $>47(4 \mathrm{~d})$ & $>11(14 \mathrm{~d})$ & NE & $2.67(4 \mathrm{~d})$ & $2.24(14 \mathrm{~d})$ & 1.19 & No test & $>56(14 \mathrm{~d})$ & $\mathrm{NE}$ & $147(4 \mathrm{~d})$ & $>369(14 \mathrm{~d})$ & $<0.4$ \\
\hline A1/CC-sturgeon & $2 / 2$ & $>47(4 \mathrm{~d})$ & $5.4(53 \mathrm{~d})$ & $>8.70$ & $2.67(4 \mathrm{~d})$ & $1.55(53 \mathrm{~d})$ & 1.72 & No test & $>27(53 \mathrm{~d})$ & $\mathrm{NE}$ & 147 (4d) & $99(53 \mathrm{~d})$ & 1.48 \\
\hline $\mathrm{A} 3 / \mathrm{C} 2$-sturgeon & $30 / 27$ & $103(4 d)$ & $3.2(28 \mathrm{~d})$ & 32 & $6.31(4 \mathrm{~d})$ & $2.67(28 \mathrm{~d})$ & 2.36 & No test & $>60(28 \mathrm{~d})$ & $\mathrm{NE}$ & $3,109(4 d)$ & $203(28 d)$ & 15 \\
\hline $\mathrm{A} 1 / \mathrm{C} 1$-trout & $1 / 1$ & $>49(4 \mathrm{~d})$ & $>12(21 \mathrm{~d})$ & $\mathrm{NE}$ & $63(4 d)$ & $36(21 \mathrm{~d})$ & 1.75 & No test & $>128(21 \mathrm{~d})$ & $\mathrm{NE}$ & $>571(4 \mathrm{~d})$ & $>753(21 \mathrm{~d})$ & $\mathrm{NE}$ \\
\hline A1/CC-trout & $1 / 1$ & $>49(4 d)$ & $5.3(52 \mathrm{~d})$ & $>9.2$ & $63(4 d)$ & $32(52 \mathrm{~d})$ & 1.97 & No test & $>126(52 \mathrm{~d})$ & $\mathrm{NE}$ & $>571(4 \mathrm{~d})$ & $>755(52 \mathrm{~d})$ & $\mathrm{NE}$ \\
\hline A3/C2-trout & $32 / 26$ & $4.8(4 \mathrm{~d})$ & $1.9(28 \mathrm{~d})$ & 2.53 & $60(4 d)$ & $30(28 \mathrm{~d})$ & 2.00 & No test & $>128(28 \mathrm{~d})$ & $\mathrm{NE}$ & $449(4 \mathrm{~d})$ & $169(28 \mathrm{~d})$ & 2.66 \\
\hline
\end{tabular}


and Heikens, 2001). With copper, Grosell and others (2002) demonstrated situations where smaller animals may be more sensitive than large animals because smaller animals have higher sodium turnover rates. These principles and patterns suggest that smaller organisms also would have higher calcium turnover rates and in turn, smaller organisms would be more sensitive to calcium antagonists such as cadmium, lead, or zinc.

The results of the sturgeon tests in the present study generally were consistent with this smaller and more sensitive rule of thumb, as have been previous studies with metals, sculpin (Cottus spp.), and fathead minnow (Pimephales promelas; Besser and others, 2007; Klaine and others, 1996; Mebane, 2006); however, the rainbow trout tested in the present study tended to have an opposite pattern than the tests that were initiated with the older and larger fish being more sensitive. For instance, no effects to rainbow trout were observed following 52-d zinc exposures, started with 1-dph fish, to concentrations as high as $755 \mu \mathrm{g} \mathrm{Zn} / \mathrm{L}$; in contrast, a nearly identical zinc concentration killed 95 percent of the trout when the exposures began with 26-dph fish (tables B-4 and B-5). The elevated mortality during the first 4 days of the zinc exposure started with 26-dph fish (appendix table 2-7). Similarly, when the 46-dph rainbow trout were exposed to a similar zinc concentration $(729 \mu \mathrm{g} \mathrm{Zn} / \mathrm{L})$ in the acute 4-d tests reported in chapter A, 88 percent of the trout were killed (table A-3).

This reversal in the general expectation that tests started with older fish would be more resistant previously has been reported in acute and chronic tests with salmonids as well as other species (Brinkman and Hansen, 2007; Hansen and others, 2002; Mebane and others, 2008, 2012). With chronic exposures that began with embryos, the increased resistance has been presumed to result from acclimation secondary to metallothionein induction while still encapsulated in a protective membrane that initially protected larvae (Chapman, 1985).

At present, there are no satisfactory mechanistic explanations for these differing metals sensitivity response patterns with size or early developmental stage of the different fish species. Differences in sensitivity of juvenile fish to ionic metals in water could be related to the intense body changes as the fish metamorphose from larval to juvenile life stages. Two concurrent changes during the early development of sturgeon are the change from relying on the yolk sac for nourishment to external feeding and the switch from passive gas exchange through the body surface to active gill gas exchange (Gisbert, 1999). The transition from passive gas exchange through the body skin to gills during the early development of fish is preceded by a transition from ion regulation through the body skin to the gills (Rombough, 2002; Fu and others, 2010). Because the toxicity of cadmium, copper, lead, and zinc are related to ion regulation disruption, the differing patterns of size and sensitivity to at least copper and zinc suggests possible connections with the timing of changes in ion regulation. These developmental changes in sturgeon seem congruent with the reduced osmoregulatory capacity of juvenile sturgeon compared to adult sturgeon (McEnroe and Cech, 1985). Another intriguing difference in osmoregulation in sturgeon from other fish is that sturgeon may have low concentrations of circulating plasma calcium, requiring unusually tight regulation (Allen and others, 2009). This could make sturgeon vulnerable to disruption of calcium uptake by metals, although the extreme sensitivity of sturgeon to copper but not to other tested metals is puzzling. The comparative biochemistry, physiology, and metals toxicity in sturgeon relative to other species is a topic worthy of study.

\section{Implications of Uncertainty in DOC Measurements on Estimates of the Sensitivity of White Sturgeon to Copper}

The average estimated concentration DOC in the present study was about $0.4 \mathrm{mg} / \mathrm{L} \mathrm{DOC}$ and individual measurements ranged from about 0.1 to $0.6 \mathrm{mg} / \mathrm{L}$; however, measurements obtained from the Huffman Laboratory, which were determined to be the most accurate, ranged from about 0.3 to $0.5 \mathrm{mg} / \mathrm{L}$ (appendix 6). Vardy and others (2011) reported mean DOC concentrations of $2.5 \pm 0.5 \mathrm{mg} / \mathrm{L}$ in test water used to perform white sturgeon toxicity tests; however, following a comparative cross-check analysis of test waters from the CERC and from the University of Saskatchewan, the estimated mean DOC concentration in the study by Vardy and others (2011) was $1.0 \mathrm{mg} / \mathrm{L}$ (appendix 7). Small differences in DOC in test water containing low concentrations of DOC can result in appreciable differences in modeled toxicity of copper in fresh waters (Welsh and others, 2008; Wang and others, 2009). The potential effect of uncertainties in DOC measurement on the BLM-predicted copper toxicity in the present study and in Vardy and others (2011) was evaluated in appendix 7. When the BLM-based FAV or final chronic value were calculated for copper, a low or high bias to DOC values produced a low or high bias, respectively, to the WQC values; however, with the BLM-normalized EC50s or EC20s, the effect of low or high bias in DOC values was reversed. Specifically, the BLM-normalized acute and chronic copper effect concentrations at the estimated DOC concentration of $0.4 \mathrm{mg} / \mathrm{L}$ in the present study would increase about 80 percent if a lower DOC concentration of $0.2 \mathrm{mg} / \mathrm{L}$ was used in the BLM model, or would decrease about 30 percent if a higher DOC concentration of $0.6 \mathrm{mg} / \mathrm{L}$ was used in the BLM model (appendix 6). Historical measurements of DOC in diluted well water to a hardness of about $100 \mathrm{mg} / \mathrm{L}$ at the U.S. Geological Survey CERC laboratory indicate the DOC concentrations ranged from 0.4 to $0.6 \mathrm{mg} / \mathrm{L}$ (for example, Wang and others, 2011; appendix 6).

The most reliable measurements of DOC in test chambers ranged from about 0.3 to $0.5 \mathrm{mg} / \mathrm{L}$, and the best overall estimate of mean DOC in test exposures was determined to be $0.4 \mathrm{mg} / \mathrm{L}$ (appendix 6). This value was used in the extrapolations of measured test values to what those values might have been if tested in standardized moderately hard water with $0.5 \mathrm{mg} / \mathrm{L} \mathrm{DOC} \mathrm{(that}$ is, BLM normalization). Over an uncertainty range of 0.3 to 0.5 $\mathrm{mg} / \mathrm{L} \mathrm{DOC}$, the differences in BLM-predicted copper effects in the standardized moderately hard water were about \pm 30 percent 
in the comparisons (that is, from 1.3 -fold lower to 1.3 -fold higher of the values using $0.4 \mathrm{mg} / \mathrm{L}$ ) (appendix 6).

\section{Developmental Behavior of White Sturgeon Larvae}

The newly hatched white sturgeon were observed hiding along the edge of stones placed on the bottom of test chambers during the first 2 weeks of the exposures, and afterwards, the fish were observed swimming up and starting to feed. These behaviors were consistent with the observations in previous studies on the developmental behavior of the sturgeon. For example, the results of a laboratory study by Kynard and others (2010) indicated that 0 - to 7-dph white sturgeon were photonegative and would hide under cover, 9-dph fish became photopositive, and 13-dph fish foraged in the day and preferred bright habitat.

Lack of hiding of the larval sturgeon was observed at the medium or high exposure concentrations of copper or zinc (fig. B-1B). In the 53-CC exposure, the 4-d EC20 of $2.23 \mu \mathrm{g} \mathrm{Cu} / \mathrm{L}$ and the $8-\mathrm{d} \mathrm{EC} 20$ of $1.81 \mu \mathrm{g} \mathrm{Cu} / \mathrm{L}$ estimated based on mortality, immobilization, plus lack of hiding (fig. B-5; appendix table 2-5) were similar to the 14-d LC20 of $2.24 \mu \mathrm{g} \mathrm{Cu} / \mathrm{L}$ based on mortality and the 53-d EC20s of $1.55 \mu \mathrm{g} \mathrm{Cu} / \mathrm{L}$ based on dry weight (fig. B-6; table B-2).The results indicate that acute effect concentrations on hiding can occur rapidly (within 4 days to within 8 days) after the onset of an exposure and may affect survival and growth of white sturgeon after longer exposures.

\section{Pseudo Control Replicates in 53-day White Sturgeon CC Exposures}

One or two pseudo control replicates were created on the fish thinning day (test day 25) in the 53-d sturgeon exposures. The survival and growth of the sturgeon in the pseudo replicates generally were similar to those in the true replicates from the thinning day to the end of the 53-d exposures (appendix table 2-6); therefore, the data from all replicates were combined and used for analysis of the data from the 53-d exposures in the present study. To evaluate the potential effect of the pseudo replicate data on the results, effect concentrations in the 53-d copper exposure were estimated with or without using the pseudo replicates. The EC20s for copper based on survival, length, or dry weight after the fish thinning were almost identical when estimated with or without using the pseudo replicates (appendix table 2-8).

\section{High Light Intensity during White Sturgeon C1/CC Exposures}

To determine if the high intensity of light (about 1,000 lux) used during the first 3 weeks of the $\mathrm{C} 1 / \mathrm{CC}$ exposures in the study performed in 2010 was stressful to the newly hatched sturgeon, a follow-up study was performed at the CERC in 2012, starting with 3-dph white sturgeon (detailed test conditions and results are described in appendix 8). Newly fertilized eggs from one female and one male were provided on July 11, 2012, from the Sherman Creek Hatchery, the same hatchery that provided eggs for the 2010 study. The sturgeon were caught on July 9, 2012, at Five Mile Creek, Northport, Wash., on the Columbia River, the same location where the sturgeon were caught for the 2010 study. Test conditions were similar to those for the $\mathrm{C} 1 / \mathrm{CC}$ exposures in the 2010 study (table B-1); exceptions were that (1) no toxicant was added in test water, (2) light intensity was about 50 lux in a low-light treatment and about 1,000 lux in a high-light treatment, and (3) there were 10 fish per replicate (rather than 30 fish per replicate tested in 2010). Mortality and behavior were recorded daily at about 9:00 a.m. during the 25-d study.

Most of the fish hid under stones and mean percent hiding was not different between the low- and high-light treatments during the first 11 days of the study. More than 50 percent of the fish ended hiding by test day 11 in the high-light treatment and by test day 14 in the low-light treatment (appendix fig. 8-1). Mean survival (87 percent) and mean dry weight $(14.2 \mathrm{mg} /$ individual) at the end of the low-light treatment were not significantly different from mean survival (96 percent) and mean dry weight (13.5 mg/individual) at the end of the highlight treatment $(t$-test, $p>0.05)$. The result indicates that the high light intensity of 1,000 lux may shorten the hiding phase for about 3 days compared to the low light intensity of 50 lux at $15{ }^{\circ} \mathrm{C}$; however, the light intensity did not affect the 25 -d survival and growth. Thus, the high-light intensity of about 1,000 lux used during the first 3 weeks of the $\mathrm{C} 1 / \mathrm{CC}$ exposures in the 2010 study likely did not contribute to the elevated control mortality during the transition of sturgeon to exogenous feeding. Moreover, similar results between the 2010 sturgeon C1 copper exposure started at the high light intensity of about 1,000 lux and the 2012 copper exposure started at a lower light intensity of about 50 lux also demonstrated that the high light intensity at the start of the copper exposures performed in 2010 did not affect effect concentrations for copper (table B-6).

\section{Variation in Control Survival and Growth among Replicates or Exposure Systems}

The control sturgeon survival varied largely among the replicates in the controls, ranging from 0 to 100 percent during the first 25 days of the 53-d CC exposure to copper or lead, and ranging from 0 to 80 or 85 percent in the exposures to cadmium or zinc (appendix table 2-6). The four replicate chambers for the controls in each metal exposure were placed side-by-side in a diluter and the test conditions were identical. The reason for the large difference in survival among the replicates is unknown. A speculation was that one dead sturgeon in a replicate might have affected the other fish in the same replicate (not likely because of disease, but perhaps because of excess mucus production from that dying fish). 
The growth of the sturgeon in the control treatment in the CC 53-d exposure to lead tended to be slower than the control growth in exposures to the other three metals in three separated diluters. Mean dry weight of the control was $0.186 \mathrm{~g}$ /individual at the end of the 53-d exposure to lead but was 0.240 to 0.254 $\mathrm{g} /$ individual in the $\mathrm{CC}$ exposures to other three metals (table B-2). These differences may have been caused by densitydependent growth (fewer fish in a replicate chamber grow faster). The mean control survival from the thinning day of 25 to the end of the 53-d exposure was higher ( 98 percent) in the lead exposure compared to the control survival in the exposures to other three metals ( 87 to 90 percent; table B-2).

\section{Higher Loading Density at the End of Sturgeon CC 53-day and C2 28-day Exposures}

American Society for Testing and Materials (2012a) provides guidance on loading of fish (grams of organisms; wet weight) in a test chamber. Specifically, the guidance is that the mass of fish should not exceed $0.5 \mathrm{~g} / \mathrm{L}$ of solution passing through the chamber in $24 \mathrm{~h}$ at the end of the test and should not exceed $5 \mathrm{~g} / \mathrm{L}$ in the chamber at any time. In the present study, the loading of the sturgeon or trout never exceeded $5 \mathrm{~g} / \mathrm{L}$ in any chronic exposures and the loading of the trout did not exceed $0.5 \mathrm{~g} / \mathrm{L}$ of solution passing through the chamber in $24 \mathrm{~h}$ at the end of the test, whereas the loading of the sturgeon exceeded $0.5 \mathrm{~g} / \mathrm{L}$ of solution passing through some replicate chambers at the end of the 53-day CC exposure and at the end of the 28-day C2 exposures (tables B-2 and B-3); however, the water quality, including dissolved organic carbon, ammonia, and dissolved oxygen, and measured metal concentrations in chambers with elevated loading still met test acceptability requirements, and did not reflect differences in loading densities across replicates.

\section{Elevated Mortalities at the Onset of Exogenous Feeding}

As observed by Vardy and others (2011), elevated mortality of sturgeon in the controls occurred in the study performed in 2010 when larval sturgeon started exogenous feeding. The sturgeon of the same batch cultured in a flow-through water baths at the USGS CERC laboratory also had a peak of mortality during this same time period. These observations were consistent with previous studies on white sturgeon (for example, Gisbert and Williot, 1997; Bennett and Farrell, 1998; Vardy and others, 2011). Because of the uncertainty of control survival, large numbers of fish (20 per replicate chamber) were used in the present study at the beginning of the 53-d exposures and then were thinned impartially to the desired number of fish (10 per replicate) on test day 25 . Because mean control survival on test day 25 was below the test acceptability requirement of $\geq 80$ percent (table $\mathrm{B}-1$ ), which resulted in low overall control survival ( $<64$ percent) of the sturgeon in the 53- $d$ exposures, effect concentrations for survival or the survival-related endpoint biomass were not reported (table B-2); however, the length and weight of surviving fish throughout the 53-d exposures were considered useful data in the present study because the elevated mortality during exogenous feeding has limited effect on growth. That is, the elevated mortality was observed only for a few days before the thinning day and the number of fish in most of test chambers was adjusted to 10 after thinning or after creating pseudo control replicates on test day 25 for the rest of the 53-day exposures. Nevertheless, the effect concentrations for the growth from the 53-d exposures are classified as nondefinitive effect concentrations in this report.

In contrast to the earlier studies described above, no elevated mortality was observed in the controls at the critical time of exogenous feeding in the two follow-up sturgeon studies performed in 2012: the 24-d copper exposure with a mean of 93-percent control survival (appendix 8), and the 28-d light intensity test with a mean survival of 87 or 96 percent (appendix 8). It is not clear why the control survival of these different batches of sturgeon were different in 2010 and in 2012. Survival of larval sturgeon reportedly varies between different parent fish (Boyd Kynard, BK-Riverfish LLC, Amherst, Mass., written commun., June 14, 2012). Further study is needed to determine the effect of parent sturgeon conditions on the survival of their offspring.

\section{Conclusions}

White sturgeon were more sensitive to copper, lead, or zinc, and were similar in sensitivity to cadmium compared to commonly tested rainbow trout in the chronic exposures. Compared to other test species in the compiled toxicity databases, white sturgeon were highly sensitive to copper and zinc, but were moderately sensitive to lead and relatively insensitive to cadmium. The U.S. Environmental Protection Agency (USEPA) chronic water-quality criteria (WQC) and Washington State chronic water-quality standards (WQS) would be protective of rainbow trout to exposures of all four metals tested in the present study and would be protective of white sturgeon to exposure to cadmium or lead, but may not adequately be protective of white sturgeon to exposure to copper or zinc. In addition, the USEPA acute WQC and Washington State acute WQS for copper may not be protective of white sturgeon to acute exposure to copper. Furthermore, the survival and behavior of the newly hatched sturgeon rapidly were impaired within a 4-day (d) or 8-d exposure period at concentrations close to the chronic WQC and to the Washington State WQS for copper. These conclusions are based on definitive effect concentrations for exposures that met test acceptability requirements. The results based on nondefinitive effect concentrations from the 53-d sturgeon exposures to the four metals performed in 2010 and the definitive effect concentrations from a follow-up 24-d sturgeon exposure to copper performed in 2012 also supported these conclusions. 


\section{References Cited}

Abbott, W.S., 1925, A method of computing the effectiveness of an insecticide: Journal of the American Mosquito Control Association, v. 3, p. 302-303.

Allen, P.J., Webb, M.A.H., Cureton, E., Bruch, R.M., Barth, C.C., Peake, S.J., and Anderson, W.G., 2009, Calcium regulation in wild populations of a freshwater cartilaginous fish, the lake sturgeon Acipenser fulvescens: Comparative Biochemistry and Physiology Part A, Molecular and Integrative Physiology, v. 154, no. 4, p. 437-450.

American Society for Testing and Materials, 2012a, Standard guide for performing early life-sage toxicity tests with fishes, E1241-05, in Annual Book of ASTM Standards, v. 11.06, West Conshohocken, Pa., ASTM International, p. 287-315.

American Society for Testing and Materials, 2012b, Standard guide for measurement of behavior during fish toxicity tests, E1711-95 (2008), in Annual Book of ASTM Standards, v. 11.06, West Conshohocken, Pa., ASTM International, p. $952-963$.

American Society for Testing and Materials, 2012c, Standard guide for performing acute toxicity tests on test materials with fishes, macroinvertebrates, and amphibians, E729-96 (2007), in Annual Book of ASTM Standards, v. 11.06, West Conshohocken, Pa., ASTM International, p. 67-89.

Bennett, W.R., and Farrell, A.P., 1998, Acute toxicity testing with juvenile white sturgeon (Acipenser transmontanus): Water Quality Research Journal of Canada, v. 33, no. 1, p. $95-110$.

Besser, J.M., Mebane, C.A., Mount, D.R., Ivey, C.D., Kunz, J.L., Greer, E.I., May, T.W., and Ingersoll, C.G., 2007, Relative sensitivity of mottled sculpins (Cottus bairdi) and rainbow trout (Oncorhynchus mykiss) to toxicity of metals associated with mining activities: Environmental Toxicology and Chemistry, v. 26, no. 8, p. 1,657-1,665. (Also available at $h t t p: / / d x . d o i . o r g / 10.1897 / 06-571 R .1$.$) .$

Brinkman, S.F., and Hansen, D., 2007, Toxicity of cadmium to early life stage brown trout (Salmo trutta) at multiple hardnesses: Environmental Toxicology and Chemistry, v. 26, no. 8, p. 1,666-1,671. (Also available at $h t t p: / / d x$.doi.org/ DOI: $10.1897 / 06-376$ ).

Brunson, E.L., Canfield, T.J., Dwyer, F.J., Kemble, N.E., and Ingersoll, C.G., 1998, Assessing bioaccumulation of contaminants from sediments from the upper Mississippi River using field-collected oligochaetes and laboratory-exposed Lumbriculus variegatus: Archives of Environmental Contamination and Toxicology, v. 5, p. 191-201.
Cardno Entrix and University of Saskatchewan, 2008, Semichronic water exposures of cadmium, copper, and zinc to early life-stages of white sturgeon (Acipenser transmontanus): Report to Teck American Incorporated, p. 21.

Chapman, G.A., 1985, Acclimation as a factor influencing metal criteria, in Bahner, R.C., and Hansen, D.J., eds., Aquatic toxicology and hazard assessment-Eighth symposium: Philadelphia, Pa., American Society for Testing and Materials, v. STP 891, p. 119-136.

DeForest, D.K., and Van Genderen, E.J., 2012, Application of U.S. EPA guidelines in a bioavailability-based assessment of ambient water-quality criteria for zinc in freshwater: Environmental Toxicology and Chemistry, v. 31, no. 6, p. $1,264-1,272$.

Eaton, A.D., Clesceri, L.S., Rice, E.W., and Greenberg, A.E., 2005, Standard methods for the examination of water and wastewater (21st ed.): Washington, D.C., American Public Health Association, Water Environment Federation, American Water Works Association, 1,368 p.

Environment Canada, 1998, Biological test method-Toxicity tests using early life stages of salmonid fish (rainbow trout), EPS 1/RM/28 (2nd ed.): Ottawa, Ontario, 100 p.

Erickson, R.J., 2012, Toxicity Relationship Analysis Program (TRAP), version 1.21, EPA/600/C-11/002: Washington, D.C., U.S. Environmental Protection Agency.

Finney, M.A., 1944, The application of the probit method to toxicity test data adjusted for mortality in the controls: Annals of Applied Biology, v. 31, no 1, p. 68-74.

Fu, C., Wilson, J.M., Rombough, P.J., and Brauner, C.J., 2010, Ions first- $\mathrm{Na}+$ uptake shifts from the skin to the gills before $\mathrm{O} 2$ uptake in developing rainbow trout, Oncorhynchus mykiss-Proceedings of the Royal Society B: Biological Sciences, v. 277, no. 1687, p. 1,553-1,560.

Gisbert, E., 1999, Early development and allometric growth patterns in Siberian sturgeon and their ecological significance: Journal of Fish Biology, v. 54, no. 4, p. 852-862.

Gisbert, E., and Williot, P., 1997, Larval behavior and effect of the timing of initial feeding on growth and survival of Siberian sturgeon (Acipenser baeri) larvae under small scale hatchery production: Aquaculture, v 156, p. 63-76.

Grosell, M., Nielsen, C., and Bianchini, A., 2002, Sodium turnover rate determines sensitivity to acute copper and silver exposure in freshwater animals: Comparative Biochemistry and Physiology Part C-Toxicology and Pharmacology, v. 133, no. 1-2, p. 287-303. 
Hansen, J.A., Welsh, P.G., Lipton, J., Cacela, D., and Dailey, A.D., 2002, Relative sensitivity of bull trout (Salvelinus confluentus) and rainbow trout (Oncorhynchus mykiss) to acute exposures of cadmium and zinc: Environmental Toxicology and Chemistry, v. 21, no. 1, p. 67-75.

Hendriks, A.J., and Heikens, A., 2001, The power of size. 2. Rate constants and equilibrium ratios for accumulation of inorganic substances related to species weight: Environmental Toxicology and Chemistry, v. 20, no. 7, p. 1,421-1,437.

HydroQual, 2007, The biotic ligand model Windows interface, Version 2.2.3-User's guide and reference manual: Mahwah, New Jersey, HydroQual, 43 p.

Klaine, S.J., Bills, T.L., Wenholz, M.D., Point, T.W.L., Cobb, G.P., and Forsythe, B.L., II, 1996, Influence of age sensitivity on the acute toxicity of silver to fathead minnows at various quality parameters, in The 4th international conference proceedings: transport, fate and effects of silver in the environment: Madison, Wisconsin, University of Wisconsin. (Also available at http://digital.library.wisc. edu/1711.dl/EcoNatRes.Argentumv04).

Kynard, B., Parker, E., and Kynard, B., 2010, Ontogenetic behavior of Kootenai River White Sturgeon, Acipenser transmontanus, with a note on body color-A laboratory study: Environmental Biology of Fishes, v. 88, no. 1, p. 65-77.

Little, E.E., Calfee, R.D., and Linder, G., 2012, Toxicity of copper to early life stages of Kootenai River white sturgeon, Columbia River white sturgeon, and rainbow trout: Archives of Environmental Contamination and Toxicology, v. 63 , no. 3 , p. $400-408$.

McEnroe, M., and Cech, J.J., Jr., 1985, Osmoregulation in juvenile and adult white sturgeon, Acipenser transmontanus: Environmental Biology of Fishes, v. 14, no. 1, p. 23-30.

Mebane, C.A., 2006, Cadmium risks to freshwater life-Derivation and validation of low-effect criteria values using laboratory and field studies, version 1.2: U.S. Geological Survey Scientific Investigations Report 2006-5245, 130 p.

Mebane, C.A., Dillon, F.S., and Hennessey, D.P., 2012, Acute toxicity of cadmium, lead, and zinc and their mixtures to stream resident fish and invertebrates: Environmental Toxicology and Chemistry, v. 31 , no. 6 , p. 1,334-1,338.

Mebane, C.A., Hennessy, D.P., and Dillon, F.S., 2008, Developing acute-to-chronic toxicity ratios for lead, cadmium, and zinc using rainbow trout, a mayfly, and a midge: Water, Air, and Soil Pollution, v. 188, no. 1-4, p. 41-66.
Mount, D.R., Ankley, G.T., Brix, K.V., Clements, W.H., Dixon, D.G., Fairbrother, A., Hickey, C.W., Lanno, R.P., Lee, C.M., Munns, W.R., Ringer, R.K., Staveley, J.P., Wood, C.M., Erickson, R.J., and Hodson, P.V., 2003, Effects assessment, in Reiley, M.C., Stubblefield, W.A., Adams, W.J., Di Toro, D.M., Hodson, P.V., Erickson, R.J., and Keating, F.J., eds., Reevaluation of the State of the Science for Water-Quality Criteria Development, Pensacola, Florida, SETAC Press, p. 53-118.

Parsley, M.J., Anders, P.J., Miller, A.I., Beckman, L.G., and McCabe, G.T., Jr., 2002, Recovery of white sturgeon populations through natural production-Understanding the influence of abiotic and biotic factors on spawning and subsequent recruitment: American Fisheries Society Symposium, v. 28, p. 55-66.

Raimondo, S., Montague, B., and Barron, M.G., 2007, Determinants of variability in acute-to-chronic toxicity ratios in aquatic invertebrates and fish: Environmental Toxicology and Chemistry, v. 26, no. 9, p. 2,019-2,023.

Rand, G.M., Wells, P.G., and McCarty, L.S., 1995, Introduction to aquatic toxicology, in Rand, G.M., ed., Fundamentals of aquatic toxicology-Effects, environmental fate, and risk assessment ( $2 \mathrm{~d}$ ed.): Washington, D.C., Taylor and Francis, p. 3-67.

Rombough, P.J., 2002, Gills are needed for ionoregulation before they are needed for $\mathrm{O} 2$ uptake in developing zebrafish, Danio rerio: Journal of Experimental Biology, v. 205, no. 12 , p. $1,787-1,794$.

Stephan, C.E., Mount, D.I., Hansen, D.J., Gentile, J.H., Chapman, G.A., and Brungs, W.A., 1985, Guidelines for deriving numerical national water-quality criteria for the protection of aquatic organisms and their uses: Duluth, Narragansett, and Corvallis, U.S. Environmental Protection Agency, EPA 822-R-85-100, NTIS PB85 227049, 98 p. (Also available at http://epa.gov/waterscience/criteria/aqlife.html).

U.S. Environmental Protection Agency, 1983, Method 415.2 Total organic carbon, in Methods for chemical analysis of water and wastes, Washington, D.C., U.S. Environmental Protection Agency, EPA/600/4-79-020, 552 p.

U.S. Environmental Protection Agency, 1984, Ambient waterquality criteria for cadmium: Duluth, Minn., U.S. Environmental Protection Agency, EPA 440/5-84-032, 133 pp.

U.S. Environmental Protection Agency, 1985, Ambient waterquality criteria for copper-1984: Duluth, Minn., U.S. Environmental Protection Agency, EPA 440/5-84-031, p. 142.

U.S. Environmental Protection Agency, 1987, Ambient waterquality criteria for zinc: Washington, D.C., U.S. Environmental Protection Agency, EPA 440/5-87-003, 194 p. 
U.S. Environmental Protection Agency, 1994, Method 200.7-Determination of metals and trace metals in water and wastes by inductively coupled plasma-atomic emission spectrometry, revision 4.4.: Cincinnati, Ohio, U.S. Environmental Protection Agency, 58 p.

U.S. Environmental Protection Agency, 1996, Water-quality criteria documents for the protection of aquatic life in ambient water, 1995 updates, EPA-820-B-96-001: Washington, D.C., U.S. Environmental Protection Agency 114 p.

U.S. Environmental Protection Agency, 1999, Data validation standard operating procedures for contract laboratory program routine analytical services: Athens, Ga., U.S. Environmental Protection Agency, Science and ecosystem support division, Office of Quality Assurance, Revision 2.1, 32 p.

U.S. Environmental Protection Agency, 2001, 2001 Update of ambient water quality criteria for cadmium, EPA822-R-01-001: Washington, D.C., U.S. Environmental Protection Agency, 266 p.

U.S. Environmental Protection Agency, 2002, Short-term methods for estimating the chronic toxicity of effluents and receiving water to freshwater organisms, EPA/821/R-02/013 (5th ed.): Washington, D.C., U.S. Environmental Protection Agency, $335 \mathrm{p}$.

U.S. Environmental Protection Agency, 2004, Method 9060A-Total organic carbon, in SW-846 Online-Test methods for evaluating solid waste, physical/chemical methods. (Also available at $h t t p: / / w w w . e p a . g o v / o s w / h a z a r d /$ testmethods/sw846/pdfs/9060a.pdf).

U.S. Environmental Protection Agency, 2007a, Aquatic life ambient freshwater-quality criteria-Copper: Washington, D.C., Office of Water, EPA-822-R-07-001. p. 48.

U.S. Environmental Protection Agency, 2007b, Method 9056 - Determination of inorganic anions by ion chromatography, in SW-846 Online - Test methods for evaluating solid waste, physical/chemical methods. (Also available at http://www.epa.gov/osw/hazard/testmethods/sw846/ pdfs/9056a.pdf).

U.S. Environmental Protection Agency, 2007c, Method $6020 \mathrm{~A}$ - Inductively coupled plasma-mass spectrometry, in SW-846 Online--Test methods for evaluating solid waste, physical/chemical methods. (Also available at $h t t p: / / w w w$. epa.gov/osw/hazard/testmethods/sw846/pdfs/6020a.pdf).

U.S. Environmental Protection Agency, 2010, U.S. Environmental Protection Agency technical team level of effort for investigations on the effects of exposures of White Sturgeon to chemicals of interest in the Upper Columbia River (written commun. from Helen Bottcher, USEPA, Seattle Wash., February 4, 2010).
U.S. Environmental Protection Agency, 2012, National recommended $\backslash$ criteria: Washington, D.C., Office of Water. (Available at http://water.epa.gov/scitech/swguidance/ standards/criteria/current/index.cfm).

U.S. Geological Survey, 2010, USGS-Columbia Quality Assurance Project Plan for an evaluation of the acute or chronic toxicity of individual chemicals of interest to white sturgeon (Acipenser transmontanus) and rainbow trout (Oncorhynchus mykiss) in water-only exposures: Columbia, Missouri, U.S. Geological Survey, Columbia Environmental Research Center $41 \mathrm{p}$.

Upper Columbia White Sturgeon Recovery Initiative, 2002, Upper Columbia White Sturgeon Recovery Plan: accessed December 2012 at http://uppercolumbiasturgeon.org.

Vardy, D.W., Oellers, J., Doering, J.A., Hollert, H., Giesy, J.P., and Hecker, M., 2013, Sensitivity of early life stages of white sturgeon, rainbow trout, and fathead minnow to copper: Ecotoxicology, v. 22, no. 1, p. 139-147.

Vardy, D.W., Tompsett, A.R., Sigurdson, J.L., Doering, J.A., Zhang, X., Giesy, J.P., and Hecker, M., 2011, Effects of subchronic exposure of early life stages of white sturgeon (Acipenser transmontanus) to copper, cadmium, and zinc: Environmental Toxicology and Chemistry, v. 30, p. 2,4972,505 .

Wang N., Mebane C.A., Kunz J.L., Ingersoll C.G., Brumbaugh W.G., Santore R.C., Gorsuch J.W., Arnold W.R., 2011, Influence of dissolved organic carbon on toxicity of copper to a unionid mussel (Villosa iris) and a cladoceran (Ceriodaphnia dubia) in acute and chronic water exposures: Environmental Toxicology and Chemistry, v. 30, no. 9, p. 2,115-2,125.

Wang, N., Mebane, C.A., Kunz, J.L., Ingersoll, C.G., May, T.W., Arnold, W.R., Santore, R.C., Augspurger, T., Dwyer, F.J., and Barnhart, M.C., 2009, Evaluation of acute copper toxicity to juvenile freshwater mussels (fatmucket, Lampsilis siliquoidea) in natural and reconstituted waters: Environmental Toxicology and Chemistry, v. 28, no. 11, p. 2,367-2,377.

Washington State Department of Ecology, 2006, Water-quality standards for surface waters of the State of Washington: Olympia, Washington, Washington State Department of Ecology, Chapter A73-201A WAC, 108 p.

Welsh, P.G., Lipton, J., Mebane, C.A., and Marr, J.C.A., 2008, Influence of flow-through and renewal exposures on the toxicity of copper to rainbow trout: Ecotoxicology and Environmental Safety, v. 69, no. 2, p. 199-208.

Western EcoSystems, 1996, TOXSTAT, version 3.5: Cheyenne, Wyo., 38 p. 
Appendixes 1-8 


\section{Acute and Chronic Sensitivity of White Sturgeon and Rainbow Trout to Cadmium, Copper, Lead, or Zinc}

\section{Appendix 1. Supporting Documentation for Chapter A}

Appendix 1 contains supporting documentation for chapter A in an Excel spreadsheet and two video files. The Excel file and video files are available at $h t t p: / / p u b s . u s g s . g o v /$ sir/2013/5204.

\section{Tables}

Table 1-1. Checklist for daily observations for swimming abnormalites in acute exposures (chapter 1, based on American Society for Testing and Materials 2012b).

Table 1-2. Mean water-quality characteristics $(n=4)$ for each round of the 4-day acute exposures with white sturgeon (Acipenser transmontanus) and rainbow trout (Oncorhynchus mykiss).

Table 1-3. Mean major cations (milligrams per liter, $\mathrm{n}=2$ ) measured during each round of the 4-day acute exposures with white sturgeon (Acipenser transmontanus) and rainbow trout (Oncorhynchus mykiss).

Table 1-4. Mean major anions (milligrams per liter, $\mathrm{n}=2$ ) measured during each round of the 4-day acute exposures with white sturgeon (Acipenser transmontanus) and rainbow trout (Oncorhynchus mykiss).

Table 1-5. Metal concentrations (microgram per liter) measured on day 0 and day 4 during each round of acute exposures with rainbow trout (Oncorhynchus mykiss).

Table 1-6. Metal concentrations (microgram per liter) measured on day 0 and day 4 during each round of acute exposures with white sturgeon (Acipenser transmontanus).

Table 1-7. Summary of water chemistry and response concentrations used in biotic ligand model (BLM) calculations with copper.

\section{Videos}

Video 1-1. Loss of equilibrium toxicity endpoint with some immobilization toxicity endpoint.

Video 1-2. Immobilization toxicity endpoint with some loss of equilibrium.

\section{References}

American Society for Testing and Materials, 2012b, Standard guide for measurement of behavior during fish toxicity tests, E1711-95 (2008), in Annual Book of ASTM Standards, West Conshohocken, Pa., ASTM International, v. 11.06, p. 952-963.

Cardno Entrix and University of Saskatchewan, 2011, Acute water exposures of cadmium, copper, and zinc to early life-stages of white sturgeon (Acipenser transmontanus): Report to Teck American Incorporated, $15 \mathrm{p}$.

U.S. Environmental Protection Agency, 2007a, Aquatic life ambient freshwater-quality criteria—Copper: Washington, D.C., Office of Water, EPA-822-R-07-001. p. 48.

Vardy, D.W., Oellers, J., Doering, J.A., Hollert, H., Giesy, J.P., and Hecker, M., 2013, Sensitivity of early life stages of white sturgeon, rainbow trout, and fathead minnow to copper: Ecotoxicology, v. 22, no. 1, p. 139-147.

Vardy, D.W., Tompsett, A.R., Sigurdson, J.L., Doering, J.A., Zhang, X., Giesy, J.P., and Hecker, M., 2011, Effects of subchronic exposure of early life stages of white sturgeon (Acipenser transmontanus) to copper, cadmium, and zinc: Environmental Toxicology and Chemistry, v. 30, p. 2,497-2,505. 


\section{Appendix 2. Supporting Documentation for Chapter B}

Appendix 2 contains supporting documentation for chapter B in an Excel spreadsheet. The Excel file is available at $h t t p: / /$ pubs.usgs.gov/sir/2013/5204.

\section{Tables}

Table 2-1. Mean water-quality characteristics in four chronic metal exposures with white sturgeon (Acipenser transmontanus) and rainbow trout (Oncorhynchus mykiss).

Table 2-2. Mean concentrations of major cations and major anions (milligram per liter) in four chronic metal exposures with white sturgeon (Acipenser transmontanus) and rainbow trout (Oncorhynchus mykiss).

Table 2-3. Mean metal concentrations (microgram per liter) in four chronic metal exposures with white sturgeon (Acipenser transmontanus).

Table 2-4. Mean metal concentrations (microgram per liter) in four chronic metal exposures with rainbow trout (Oncorhynchus mykiss).

Table 2-5. Short-term (4- or 8-day) responses of white sturgeon (Acipenser transmontanus) and effect concentrations in four metal exposures starting with 2-days-post-hatch larvae or 27-days-post-hatch juveniles .

Table 2-6. Control survival of white sturgeon (Acipenser transmontanus) by day 25 (fish thinning day) in the 53-day exposures, and control survival and individual dry weight in true and pseudo replicates of control treatments from day 25 to the end of the 53-day exposures.

Table 2-7. Acute (4-day) responses of rainbow trout (Oncorhynchus mykiss) and effect concentrations in four metal exposures starting with 1-day-post-hatch larvae or 26-days-post-hatch juveniles.

Table 2-8. Chronic responses of white sturgeon (Acipenser transmontanus) and 20-percent effect concentrations in 53-day copper exposures starting with 2-days-post-hatch sturgeon with or without a pseudo replicate created on day 25 at fish thinning.

\section{Figure}

The pdf file of figure $2-1$ is available at http://pubs.usgs.gov/sir/2013/5204.

Figure 2-1. Hardness- or biotic ligand model-normalized 20-percent effect concentrations for three metals based on the most sensitive endpoint in three exposures with white sturgeon (Acipenser transmontanus) and rainbow trout (Oncorhynchus mykiss) compared to the U.S. Environmental Protection Agency chronic water-quality criterion and proposed revised criterion in the expanded database. [International Lead Zinc Research Organization, ILZRO]

\section{References}

Mebane, C.A., 2006, Cadmium risks to freshwater life-Derivation and validation of low-effect criteria values using laboratory and field studies, version 1.2: U.S. Geological Survey Scientific Investigations Report 2006-5245, 130 p.

DeForest, D.K., and Van Genderen, E.J., 2012, Application of U.S. EPA guidelines in a bioavailability-based assessment of ambient water-quality criteria for zinc in freshwater: Environmental Toxicology and Chemistry, v. 31, no. 6, p. 1,264-1,272. 


\section{Appendix 3. Supporting Chemistry Data for White Sturgeon Toxicity Tests in Chapter A and Chapter B}

Appendix 3 contains supporting chemistry data for white sturgeon toxicity tests in chapter A and chapter B in an Excel spreadsheet. The Excel file is available at $h t t p: / / p u b s . u s g s . g o v / s i r / 2013 / 5204$.

Table 3-1. Concentrations of elements in diluter water from sturgeon chronic exposures.

Table 3-2. Concentrations of elements in diluter water from sturgeon acute exposures.

Table 3-3. Concentrations of elements in filter blanks from sturgeon acute and chronic exposure studies.

Table 3-4. Concentrations of elements in a continuing calibration blank (CCB) and independent calibration verification standard (ICVS) ran every 10 samples during water analyses from sturgeon tests. Results expressed as $\mathrm{ng} / \mathrm{mL}$.

Table 3-5. Recoveries of elements from a reference solution used as a control sample in the ICP-MS quantitative analysis of diluter water from sturgeon exposure studies.

Table 3-6. Recoveries of elements from a low level calibration check in the ICP-MS quantitative analysis of diluter water from sturgeon exposure studies.

Table 3-7. Relative percent difference for duplicate ICP-MS analysis of water samples from sturgeon exposure studies.

Table 3-8. Percent recovery of elements spiked in sturgeon exposure water and analyzed by ICP-MS.

Table 3-9. Interference check using dilution percent difference during ICP-MS analysis of sturgeon exposure water.

Table 3-10. Recovery of elements from an interference check determined during ICP-MS analysis of sturgeon exposure water.

Table 3-11. Mean blank equivalent concentrations (BEC) of $\mathrm{Cu}, \mathrm{Zn}, \mathrm{Cd}$, and $\mathrm{Pb}$ for reagent blanks analyzed with sturgeon exposure water.

Table 3-12. Method detection and quantitation limits for $\mathrm{Cu}, \mathrm{Zn}, \mathrm{Cd}$, and $\mathrm{Pb}$ analyzed with sturgeon exposure water. 


\section{Appendix 4. Supporting Chemistry Data for Rainbow Trout Toxicity Tests in Chapter A and Chapter B}

Appendix 4 contains supporting chemistry data for rainbow trout toxicity tests in chapter A and chapter B in an Excel spreadsheet. The Excel file is available at http://pubs.usgs.gov/sir/2013/5204.

Table 4-1. Concentrations of elements in diluter water from trout chronic exposures.

Table 4-2. Concentrations of elements in diluter water from trout acute exposures.

Table 4-3. Concentrations of elements in filter blanks from trout acute and chronic exposure studies.

Table 4-4. Concentrations of elements in a continuing calibration blank (CCB) and independent calibration verification standard (ICVS) ran every 10 samples during water analyses from trout tests. Results expressed as $\mathrm{ng} / \mathrm{mL}$.

Table 4-5. Recoveries of elements from a reference solution used as a control sample in the ICP-MS quantitative analysis of diluter water from trout exposure studies.

Table 4-6. Recoveries of elements from a low level calibration check in the ICP-MS quantitative analysis of diluter water from trout exposure studies.

Table 4-7. Relative percent difference for duplicate ICP-MS analysis of water samples from trout exposure studies.

Table 4-8. Percent recovery of elements spiked in trout exposure water and analyzed by ICP-MS.

Table 4-9. Interference check of the test water using dilution percent difference during ICP-MS analysis of trout exposure water.

Table 4-10. Recovery of elements from an interference check determined during ICP-MS analysis of trout exposure water.

Table 4-11. Mean blank equivalent concentrations $(\mathrm{BEC})$ of $\mathrm{Cu}, \mathrm{Zn}, \mathrm{Cd}$, and $\mathrm{Pb}$ for reagent blanks analyzed with trout exposure water.

Table 4-12. Method detection and quantitation limits for $\mathrm{Cu}, \mathrm{Zn}, \mathrm{Cd}$, and $\mathrm{Pb}$ for water analysed from trout exposures. 
Appendix 5. Rationale for Applying Corrections to Measured Copper and Zinc Values in Water Samples Collected during the Acute Toxicity Test in Round 6 Performed with 74-days-post-hatch Rainbow Trout (Oncorhynchus mykiss)

Appendix 5 is available at http://pubs.usgs.gov/sir/2013/5204.

Appendix 6. Dissolved Organic Carbon Measurement Variability, Bias, and Implications for Biotic Ligand Model Normalization for Toxicity Data Summarized in Chapter A and Chapter B

Appendix 6 is available at http://pubs.usgs.gov/sir/2013/5204.

\title{
Appendix 7. Results from U.S. Geological Survey Columbia Environmental Research Center and University of Saskatchewan Interlaboratory Comparison of Analyses for Dissolved Organic Carbon in Water Samples
}

Appendix 7 is available at http://pubs.usgs.gov/sir/2013/5204.

\section{Appendix 8. 2012 Chronic Copper Toxicity Test and Light Intensity Test with White Sturgeon (Acipenser transmontanus)}

Appendix 8 is available at http://pubs.usgs.gov/sir/2013/5204.

\author{
Publishing support provided by: \\ Rolla Publishing Service Center \\ For more information concerning this publication, contact: \\ Director, USGS Columbia Environmental Research Center \\ 4200 New Haven Road \\ Columbia, MO 65201 \\ (573) 875-5399
}

Or visit the Columbia Environmental Research Center Web site at: 
Back cover photographs. Example of swimming paths of white sturgeon (Acipenser transmontanus) digitized using Noldus Ethovision ${ }^{\circledR}$ XT. Photographs by Doug Hardesty, U.S. Geological Survey. 

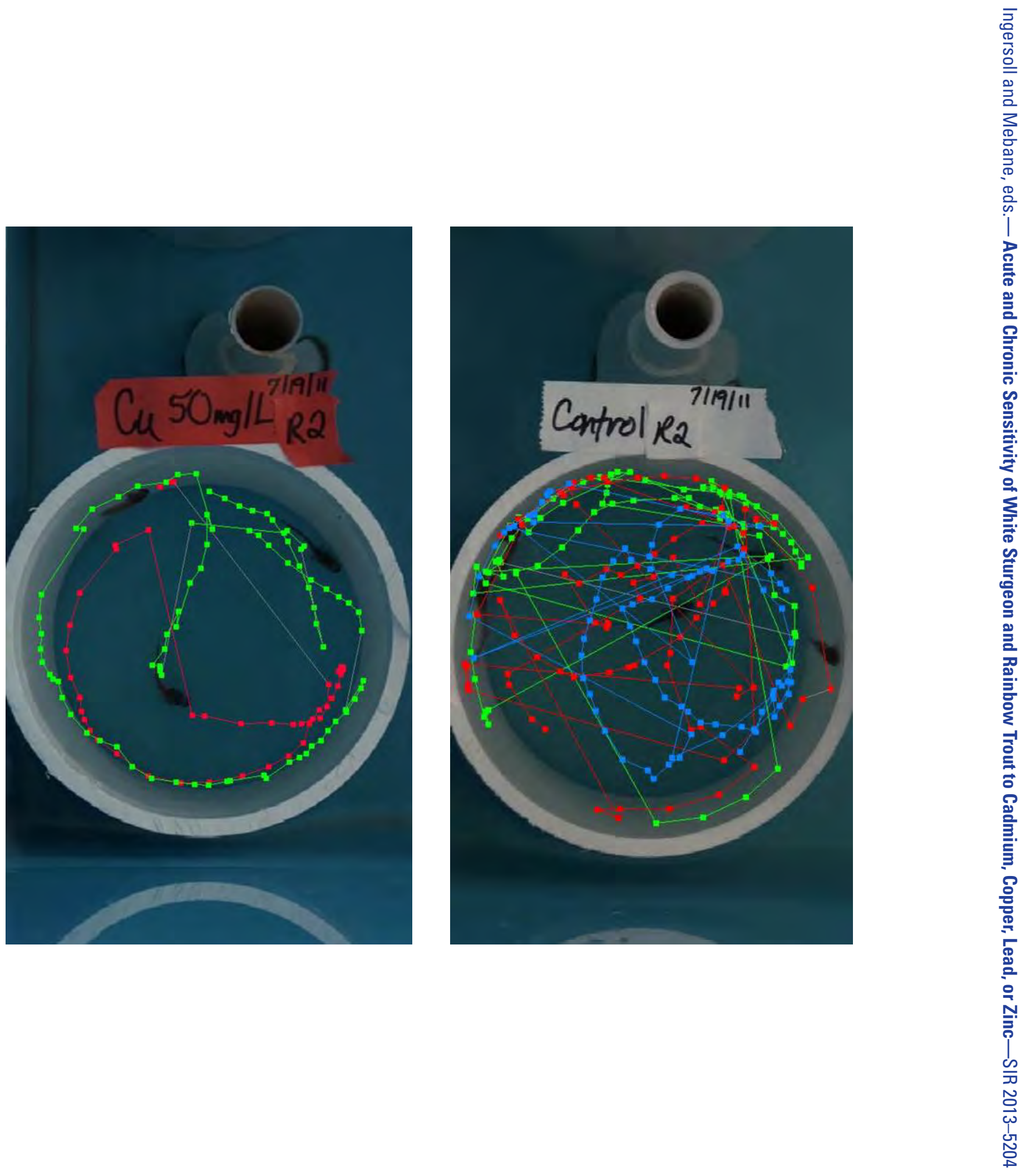